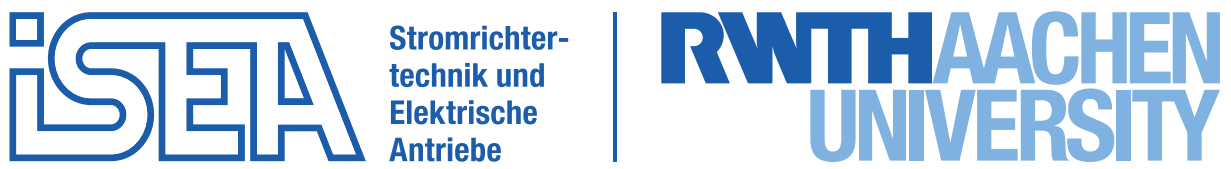

\section{Silvano Taraborrelli}

Bidirectional Dual Active Bridge Converter Using a Tap Changer for Extended Voltage Ranges

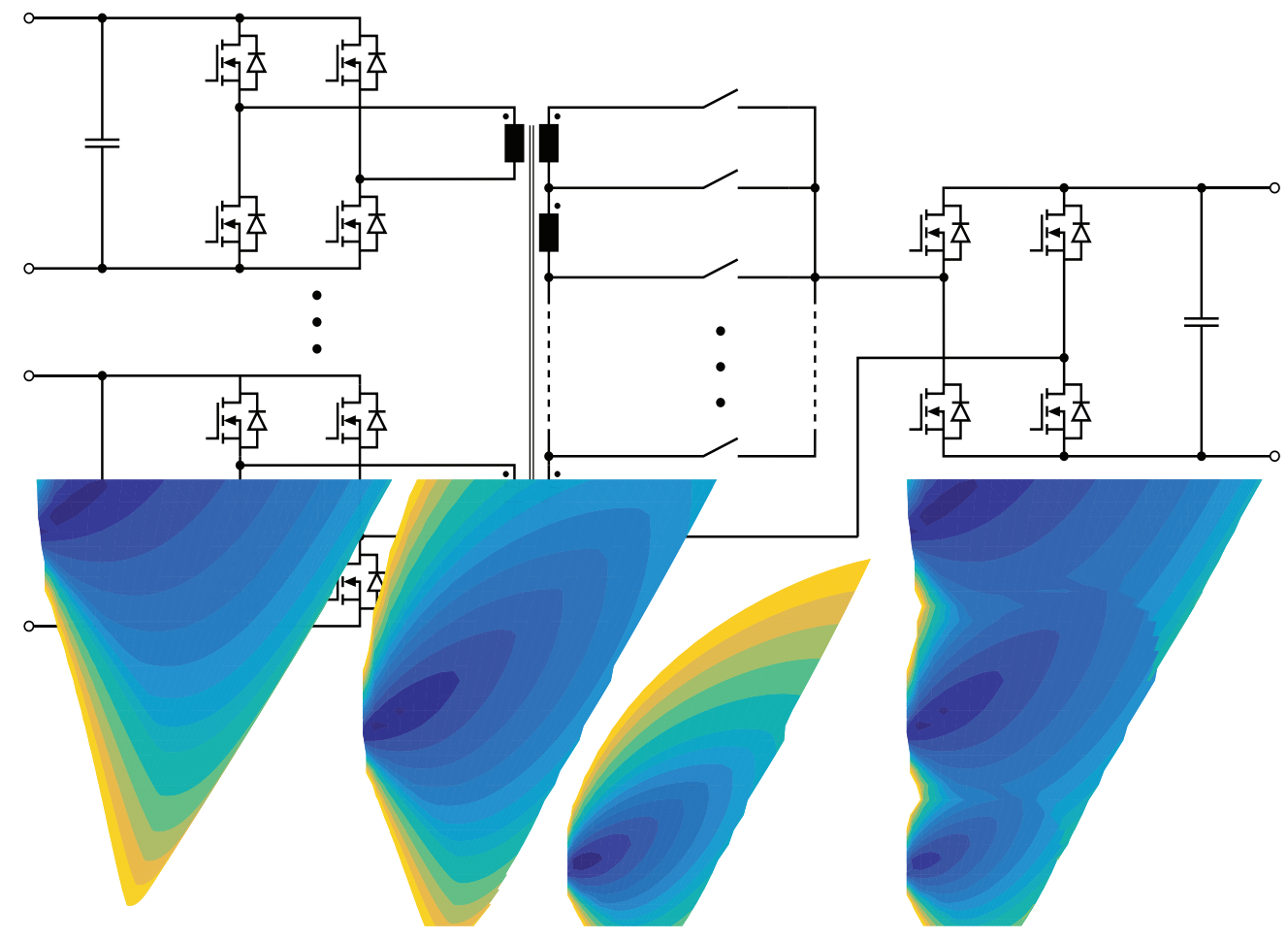

Aachener Beiträge des ISEA Band 106 



\title{
Bidirectional Dual Active Bridge Converter Using a Tap Changer for Extended Voltage Ranges
}

\author{
Von der Fakultät für Elektrotechnik und Informationstechnik der \\ Rheinisch-Westfälischen Technischen Hochschule Aachen \\ zur Erlangung des akademischen Grades eines Doktors der \\ Ingenieurwissenschaften genehmigte Dissertation
}

vorgelegt von

Diplom-Ingenieur

Silvano Taraborrelli

aus Vevey, Schweiz

Berichter:

Universitätsprofessor Dr. ir. Dr. h. c. Rik W. De Doncker

Universitätsprofessorin Ph.D. Ferdinanda Ponci

Tag der mündlichen Prüfung: 26 September 2017

Diese Dissertation ist auf den Internetseiten der Hochschulbibliothek online verfügbar. 

Silvano Taraborrelli

\section{Bidirectional Dual Active Bridge Converter Using a Tap Changer for Extended Voltage Ranges}




\section{Bibliographic information published by the Deutsche Nationalbibliothek}

The Deutsche Nationalbibliothek lists this publication in the Deutsche Nationalbibliographie; detailed bibliographic data are available in the Internet at: http://dnb.d-nb.de.

\section{Electronic version}

The electronic version is available online on the institutional repository of RWTH Aachen University (https://publications.rwth-aachen.de).

\section{AACHENER BEITRÄGE DES ISEA}

Vol. 106

\section{Editor:}

Univ.-Prof. Dr. ir. h. c. Rik W. De Doncker

Director of the Institute for Power Electronics and

Electrical Drives (ISEA), RWTH Aachen University

Copyright ISEA and Silvano Taraborrelli 2017

All rights reserved. No part of this publication may be reproduced, stored in a retrieval system, or transmitted in any form or by any means, electronic, mechanical, photocopying, recording, or otherwise, without prior permission of the publisher.

ISSN 1437-675X

Institut für Stromrichtertechnik und Elektrische Antriebe (ISEA)

Jägerstr. 17/19 • 52066 Aachen • Germany

Tel: $+49(0) 24180-96920$

Fax: $+49(0) 24180-92203$

post@isea.rwth-aachen.de 


\section{Danksagung}

Die vorliegende Arbeit entstand während meiner Tätigkeit als Wissenschaftlicher Mitarbeiter von Januar 2012 bis November 2016 am Institut für Stromrichtertechnik und Elektrische Antriebe (ISEA) der Rheinisch-Westfälischen Technische Hochschule (RWTH) Aachen. Ich danke meinem Doktorvater Herr Professor De Doncker für die Möglichkeit der Promotion am ISEA, für die Betreuung und die großen Freiräume für das eigenständige wissenschaftliche Arbeiten. Frau Professorin Ponci danke ich für die freundliche Übernahme des Korreferats. Ganz herzlich bedanke ich mich bei meinen ehemaligen Kollegen, Studenten und Angestellten des ISEAs für das hervorragende Arbeitsklima. Es war mir immer eine sehr große Freude zum ISEA zu gehen und mich dort in die Arbeit zu stürzen. Bedanken möchte ich mich bei meinen Kollegen der Leistungselektronik für die unzähligen fachlichen Diskussionen und unterstützenden Ratschläge.

Mein besonderer Dank geht an die Studenten, die mich in dieser Zeit am ISEA unterstützt haben, insbesondere danke ich Daniel Prümper, Niklas Fritz, Renè Jörg Spenke, Anna Isabel Ramones, Merlin Marek und an Sascha Rauchholz.

Nicht zuletzt möchte ich mich auch bei meiner Familie bedanken, die akzeptiert hat, dass ich zum Studium und zur Promotion weit weg aus meiner Heimat gegangen bin.

Aachen, September 2017

Silvano Taraborrelli 


\section{Abstract}

In electric vehicles today, typical power train architecture calls for a traction machine and battery pack, with an inverter between them. The inverter adjusts the state-of-chargedependent voltage of the batteries to the speed-dependent voltage of the electric machine. To decouple the inverter and battery voltages, a DC-DC converter between the inverter and the battery pack is added, which, particularly at low speed, can enhance the overall efficiency and reduce its size. The nominal voltages of the batteries currently used in electric vehicles are in the order of hundreds of volts. The use of a DC-DC converter can be used to lower the voltage of the battery packs below the $60 \mathrm{~V}$ safety threshold. In this thesis, DC-DC converters with a low voltage port for the battery storage systems and a high voltage port for the electric machines are designed and implemented. These DC-DC converters base on the dual active bridge DC-DC converter, which has inherent galvanic isolation combined with the capability of high voltage transformation and bidirectional power flow. To obtain a wide voltage operation range at the high voltage port, the use of a transformer with a tap changer is investigated. In the final setup, a dual active bridge converter with tap changer for a rated power of $10 \mathrm{~kW}$ is constructed. The low-voltage port reaches from $30 \mathrm{~V}$ to $60 \mathrm{~V}$, and the high-voltage port spans a range from $100 \mathrm{~V}$ to $400 \mathrm{~V}$. The converter exhibits efficiency above $90 \%$ over the whole voltage and power range. The maximum efficiency is up to $98 \%$. The thesis concludes with an overview and design considerations of a three-phase dual active bridge with tap changer. 


\section{Contents}

1 Introduction $\quad 1$

1.1 Motivation . . . . . . . . . . . . . . . . . . . 1

1.2 DC-DC Converters . . . . . . . . . . . . . . . . 2

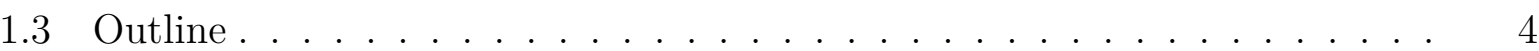

2 Transformer $\mathbf{5}$

2.1 Ideal Transformer . . . . . . . . . . . . . . . . . . . . . . . 5

2.1.1 Physical Model of a Transformer . . . . . . . . . . . . . 5

2.2 Transformer with Multiple Windings in Parallel and in Series . . . . . . . . 8

2.3 Design of the Transformer . . . . . . . . . . . . . . . . . . . . . . 10

2.4 Magnetic Simulations of the Transformer . . . . . . . . . . . . . . . . . 14

2.5 Transformer Prototype with Eight Windings at Primary and Secondary . . 19

2.6 Comparison Between Transformer with Tap Changer and without . . . . . 24

2.7 Leakage Inductance of the Transformer . . . . . . . . . . . . . . . . . . . . 24

3 Dual Active Bridge $\quad 27$

3.1 Phase Shift Modulation . . . . . . . . . . . . . . . . . . . . . . . . . . . . . . . . .

3.1 .1 Zero Voltage Switching . . . . . . . . . . . . . . . 29

3.2 Trapezoidal Current Modulation . . . . . . . . . . . . . . . . . . 33

3.3 Triangular Current Modulation . . . . . . . . . . . . . . . 36

4 Dual Active Bridge with Tap Changer 39

4.1 Characteristics of the Dual Active Bridge with Tap Changer . . . . . . . . 40

4.2 DAB with Tap Changer Simulations . . . . . . . . . . . . . . . 43

5 Implementation and Experimental Results $\quad 51$

5.1 Prototype Specifications . . . . . . . . . . . . . . . . . . . . 51

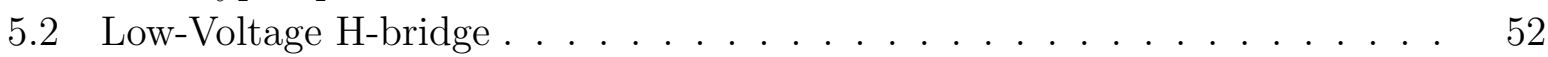

5.3 High-Voltage H-Bridge . . . . . . . . . . . . . . . . . . . . . . . . . . . . . . . . . . . . . . . . . . . .

5.4 Control Board . . . . . . . . . . . . . . . . . . . . . 54

5.5 Tap Changer . . . . . . . . . . . . . . . . . . 54

5.5 .1 Tap Changer with Relays . . . . . . . . . . . . . . . . . 55

5.5 .2 Tap Changer with Brushes . . . . . . . . . . . . . . . . . . 56

5.5.3 Tap Changer with Thyristors . . . . . . . . . . . . . . . 57

5.5.4 Tap Changer with MOSFETs . . . . . . . . . . . . . . . . . . 58

5.5 .5 Tap Changer with IGBTs . . . . . . . . . . . . . . . . . . . . 60

5.5.6 Tap Changer: Conclusion . . . . . . . . . . . . . . . . . 60

5.6 Efficiency Measurement of the Dual Active Bridge with Tap Changer . . . 62 
6 Conclusion and Outlook $\quad 69$

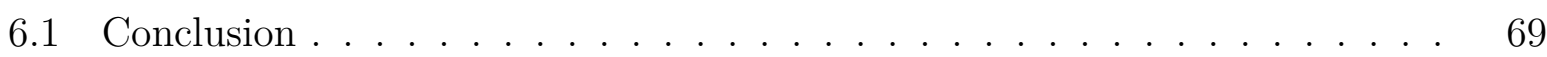

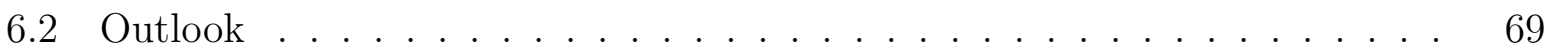

A Transformer with Multiple Windings in Parallel and in Series $\quad 71$

B Measurement results $\quad 75$

$\begin{array}{ll}\text { List of Figures } & 87\end{array}$

List of Tables $\quad 89$

$\begin{array}{lr}\text { Bibliography } & 91\end{array}$ 


\section{Introduction}

It is not yet clear if we are witnessing a new technological revolution in the automotive world today. In recent years, the development of electric cars has grown less than expected, or at least less than hoped for. This is true for Europe and especially Germany, where the plan to have one million electric cars on the roads in 2020 does not at the moment seem achievable. On the other hand, on the other side of the ocean, there is a car factory that cannot produce enough cars to meet demand. In general, we observe that a larger percentage of vehicles sold every year are electric when compared to the previous year, and with exponential growth, even at a low rate. Hence, it is only a matter of time before electric vehicles will overcome those with combustion engines. In Norway last year, more electric vehicles were sold than cars with combustion engines, and this was due to tax advantages and fast charging infrastructure. One thing is certain, however: the number of cars with combustion engines cannot continue to increase, and it is not conceivable that every inhabitant of Earth will be able to operate an internal combustion automobile. We need viable solutions, and the future will tell us if, in addition to better mobility, the electric car can be a worthwhile alternative to vehicles with internal combustion engines. The increasing number of electric vehicles requires the development of more efficient batteries to increase driving distances and to reduce costs. Alongside the development of batteries, the improvement of power electronic converters plays an important role. During charging, accelerating and breaking in electric vehicles, energy flows through one or more power electronic converters. A reduction of their costs and an improvement of their efficiency directly influence the total cost and range of electric vehicles.

\subsection{Motivation}

In electric vehicles, the simplest drive train topology consists of an inverter between the battery stack and the traction machine. In the literature [26, 28, 33, 41], an alternative topology can be found which adds a DC-DC converter to feed the inverter. This DC-DC converter adapts the DC-link voltage $V_{\text {DC-link }}$ depending on the speed of the car and, independently from the voltage level of the battery. In [10] and [30], further considerations

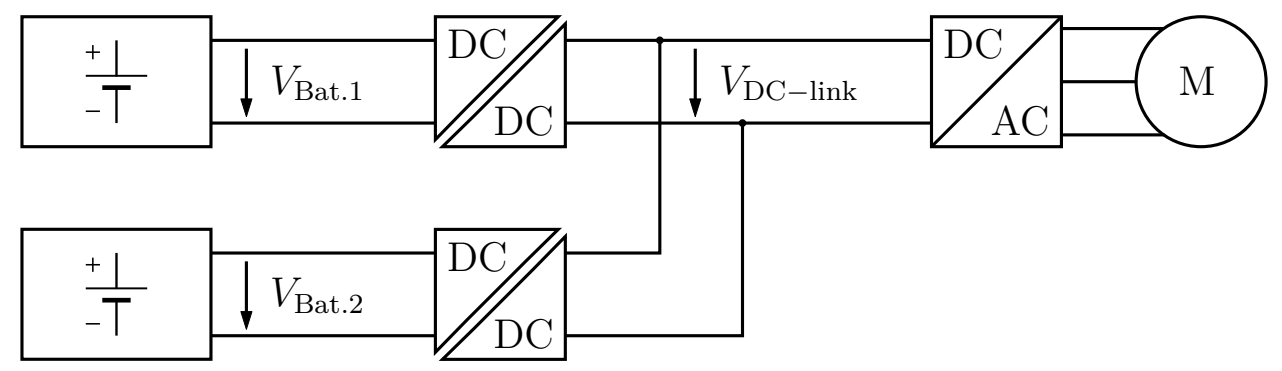

Figure 1.1: Drive train topology 


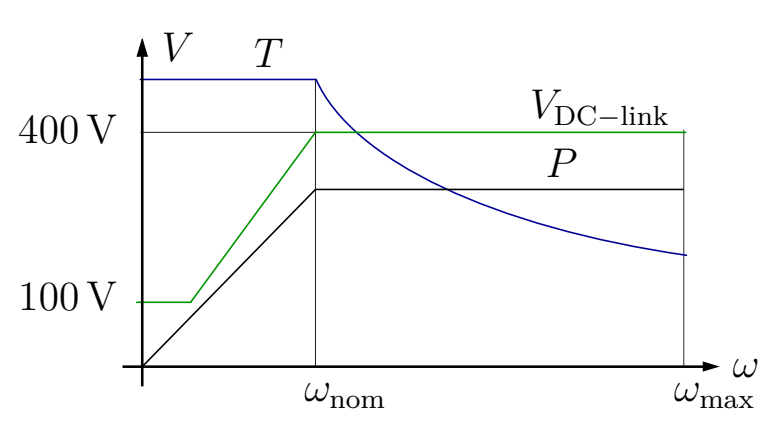

(a) $V_{\text {DC-Link }}$, torque $T$ and power $P$

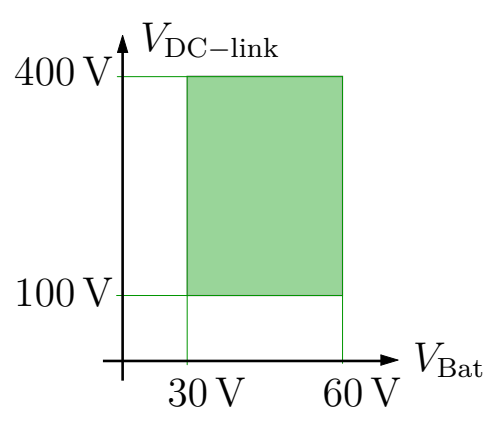

(b) Voltage ranges of the DCDC converter

Figure 1.2: Voltages, torque and power in the drive train topology with DC-DC converter

regarding this topology can be found. In [10], a topology with two battery packs, two DC-DC converters, three traction inverters and a battery charger are connected to the same DC-link. In Fig. 1.1, a drive train topology with two battery packs and two DC-DC converters are depicted. A galvanically isolated DC-DC converter is placed between each battery and the DC-link. The two different battery packs can have different states of charge and different voltage levels. In figure 1.2 is depicted the typical course of torque $T$, DC-link voltage $V_{\text {DC-link }}$, battery voltage $V_{\text {Bat }}$ and traction power $P$ of an electric vehicle with DC-DC converter. It can be seen how for lower speed, i.e. lower $\omega$ values, the $V_{\text {DC-link }}$ is lowered down to $100 \mathrm{~V}$.

In [30], the possibility to using two different battery packs with two different battery types is considered, one with high energy density and one with high power density. Low voltage battery packs can be handled with less stringent safety requirements, and they with considerably decrease the risk of electric hazards in the case of accidents involving electric vehicles. DC-DC converters with high voltage gain are typically galvanically isolated. Galvanic isolation brings an additional level of safety and also reduces parasitic current circulation. Another important aspect, as presented in [30], is the failure probability of a battery pack, which is dependent on the number of cells connected in series. Connecting 96 cells in series gives a failure probability 9.6 times higher than connecting only 12 cells in series. The same authors present the effect of the spread on cell aging in series-connected cells. It is remarkable that the worst cell in a string defines the overall performance and lifetime of the string. This consideration leads to the assumption that having fewer cells connected in series reduces the failure rate. It also reduces the effect of the worst cell on the overall behavior of the pack as a whole.

\subsection{DC-DC Converters}

In power electronics, DC-DC converters are gaining in importance. Before arriving at its final use, electricity is increasingly subject to one or more transformations from AC to DC and from DC to DC with different voltage levels. 


\section{Galvanically non-isolated DC-DC converter}

The galvanically non-isolated DC-DC converter is characterized as having a common potential between the input and output terminals, and typically this common potential is the ground. The electrical connection between the input and output is a bridge for noise, interference and, in case of failure, high voltage discharge. This kind of converter typically does not have a high voltage gain. The most common galvanically non-isolated DC-DC converters are the buck and boost converters, well known from the literature.

\section{Galvanically isolated DC-DC converter}

In this converter, there is no electrical connection between input and output. The input and output potential are totally independent. This kind of converter has a strong blocking capability with regards to interference and noise, and it also increases the general safety of the converter. In the case of accidental contact between electrical conductor and framework, it strongly limits the circulating current. The majority of galvanically isolated DC-DC converters are magnetically coupled by means of transformers.

\section{DC-DC converter with wide voltage range}

DC-DC converters with wide voltage ranges can be created using several different topologies. In [18], four different topologies are compared: a dual active bridge (DAB), or a series resonant converter (SRC), is taken into consideration as a single-stage and in series with a buck converter. Further DC-DC topologies are documented in $[17,35]$. The DAB and SRC provide high efficiency when the voltage ratio of the converter matches the turns ratio of the transformer. The main task of the transformer is to adjust the input and output voltages with a high voltage gain. In the case of a buck or boost converter in series with a DAB or SRC converter, the buck or boost converter provides a relatively variable voltage ratio but has only a modest maximum voltage gain. The total voltage gain is the product of the gains of both stages. The main disadvantage of a topology with two stages as described above is the need of a transformer and inductor. This dissertation will focus on a topology that overcomes these issues. A dual active bridge with tap changer is considered for covering the required voltage range [36]. A simple example with only two taps is described in [34] and with three taps in [38]. Within the scope of this project, a bidirectional DC-DC converter with high voltage gain and wide input and output voltage range is designed, implemented and characterized. The input voltage range is $30 \mathrm{~V}$ to $60 \mathrm{~V}$, and the output voltage range is 100 to $400 \mathrm{~V}$. The nominal power is $10 \mathrm{~kW}$. The converter is based on a dual active bridge in which the voltage range has been extended with a tap changer between the transformer and the high voltage H-bridge. In this work, this converter, is named dual active bridge with tap changer(DAB-TC).

\section{Dual active bridge with tap changer and electric vehicles}

Electric vehicles work with a great variation of speed, and they often, for example when driving through cities, move at low speeds for the majority of the time. In this situation, the use of an efficient DC-DC converter, by lowering the DC-link voltage, contributes to an increase in the efficiency of the car [32]. The DC-DC converter proposed in this thesis is a dual active bridge with tap changer because this topology allows a high efficiency over a wide voltage range and power range. Furthermore, having several LV-H-bridges in parallel at the low voltage side permits the use of different battery technologies. Power can thus flow with a different power rate from each LV-H-bridge and can even, in theory, flow 
from a battery pack connected to an LV-H-bridge to a battery pack connected to another LV-H-bridge.

\subsection{Outline}

\section{Chapter 1 - Introduction}

This chapter introduces the work, illustrates the motivation behind it and gives a short overview of different DC-DC converter topologies.

\section{Chapter 2 - Transformer}

As in all converters that utilize a transformer, it is fundamental to have an accurate model and to know its parameters. In this chapter, the basic theory of transformers is reviewed and extended to consider the transformer of interest for the relevant topologies.

\section{Chapter 3 - Dual Active Bridge}

The converter considered in this work is based on the dual active bridge. This chapter explains the operating principles, the typical features of this topology and the most frequently used modulation strategies for it. In particular, the phase shift modulation, the trapezoidal modulation and the triangular modulation are presented.

\section{Chapter 4 - Dual Active Bridge with Tap Changer}

The aim of this research concerns the extending of the dual active bridge to operate over a wider voltage range. This chapter explains how, by using a transformer with additional taps, this can be achieved. The operating regions and simulation results are presented. Various types of taps are compared.

\section{Chapter 5 - Implementation and Experimental Results}

Here, are listed the specifications of the prototype, the hardware used is described in detail and the measurement results on the prototype are presented.

\section{Chapter 6 - Conclusion and Outlook}

In this final chapter, the results are summarized and potential further improvements and developments of this converter are presented. 


\section{Transformer}

In the dual active bridge, which is introduced in the next chapter, a high-frequency transformer is fundamental. Using a high-frequency transformer means that parasitic effects such as parasitic capacities, inductances and skin effects are no longer negligible, and these are important parameters in the design of the transformer. Here, the fundamental elements of the transformer's theory $[1,20]$ are examined and the most important concepts are described. These concepts will be useful in the description of the operating principle of the converter, which is the subject of this project.

\subsection{Ideal Transformer}

In figure 2.1, an equivalent circuit of the ideal transformer is given. This is a device which simply establishes the relationship between voltages and currents at its terminals according to the equations 2.1 .

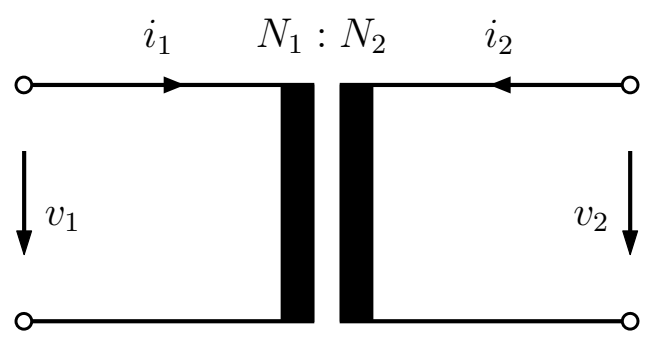

Figure 2.1: Ideal transformer

$$
t=\frac{N_{1}}{N_{2}}=\frac{v_{1}}{v_{2}}=\frac{i_{2}}{i_{1}}
$$

\subsubsection{Physical Model of a Transformer}

Figure 2.2 illustrates the operating principle of a transformer. The simplest transformer consists of a winding $w_{1}$ with $N_{1}$ turns at the primary and a winding $w_{2}$ with $N_{2}$ turns at the secondary. The winding $w_{1}$ produces the total flux $\phi_{1}$ if it conducts the current $i_{1}$ and likewise $w_{2}$ produces the total flux $\phi_{2}$.

$$
\begin{aligned}
& \phi_{1}=\phi_{\mathrm{m}}+\phi_{1 \sigma} \\
& \phi_{2}=\phi_{\mathrm{m}}+\phi_{2 \sigma}
\end{aligned}
$$

The equations 2.3 express the total fluxes $\phi_{1}$ and $\phi_{2}$ as sums of the magnetization flux $\phi_{\mathrm{m}}$ and the leakage fluxes $\phi_{1 \sigma}$ and $\phi_{2 \sigma}$ of each winding. These leakage fluxes are very important 


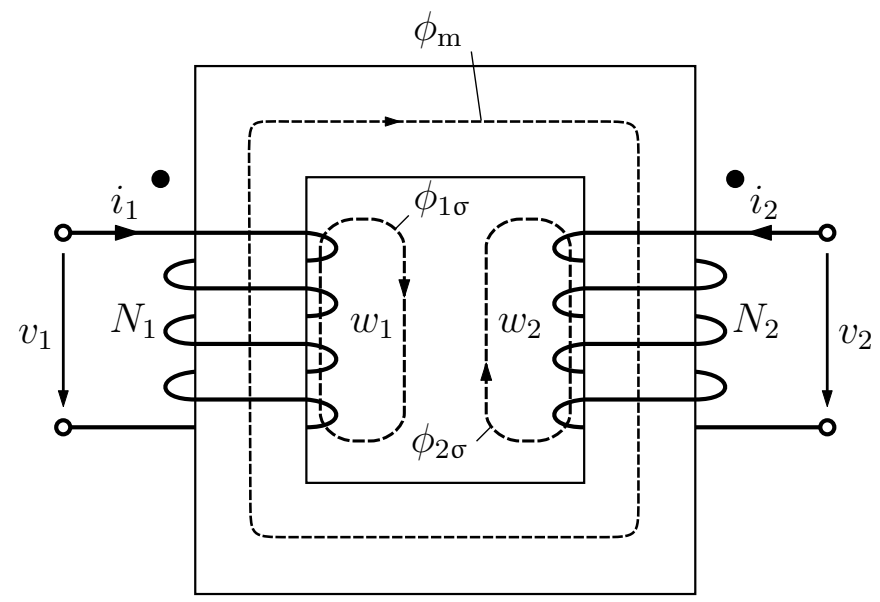

Figure 2.2: Cross section of a transformer

in a dual active bridge because they store the magnetic energy needed to control the energy transfer from one magnetic circuit to the other. The ratio between the flux of a winding and its current is per definition the inductance $L$. The magnetization flux $\phi_{\mathrm{m}}$ can be produced from the primary $\phi_{12}$ or from the secondary $\phi_{21}$ but is $\phi_{\mathrm{m}}=\phi_{12}=\phi_{21}$.

For the inductances in the transformer, we can express the following parameters:

\section{Self inductances}

$$
\begin{aligned}
& L_{1}=\frac{N_{1} \phi_{1}}{i_{1}}=\frac{N_{1} \phi_{1 \sigma}}{i_{1}}+\frac{N_{1} \phi_{12}}{i_{1}} \\
& L_{2}=\frac{N_{2} \phi_{2}}{i_{2}}=\frac{N_{2} \phi_{2 \sigma}}{i_{2}}+\frac{N_{2} \phi_{21}}{i_{2}}
\end{aligned}
$$

\section{Leakage inductances}

$$
\begin{aligned}
& L_{1 \sigma}=\frac{N_{1} \phi_{1 \sigma}}{i_{1}} \\
& L_{2 \sigma}=\frac{N_{2} \phi_{2 \sigma}}{i_{2}}
\end{aligned}
$$

\section{Mutual inductance}

$$
M=M_{12}=M_{21}=\frac{N_{2} \phi_{12}}{i_{1}}=\frac{N_{1} \phi_{21}}{i_{2}}
$$

\section{Magnetizing inductances}

$$
\begin{aligned}
& L_{1 \mathrm{~m}}=L_{1}-L_{1 \sigma}=\frac{N_{1} \phi_{12}}{i_{1}}=\frac{N_{1}}{N_{2}} M \\
& L_{2 \mathrm{~m}}=L_{2}-L_{2 \sigma}=\frac{N_{2} \phi_{21}}{i_{2}}=\frac{N_{2}}{N_{1}} M
\end{aligned}
$$




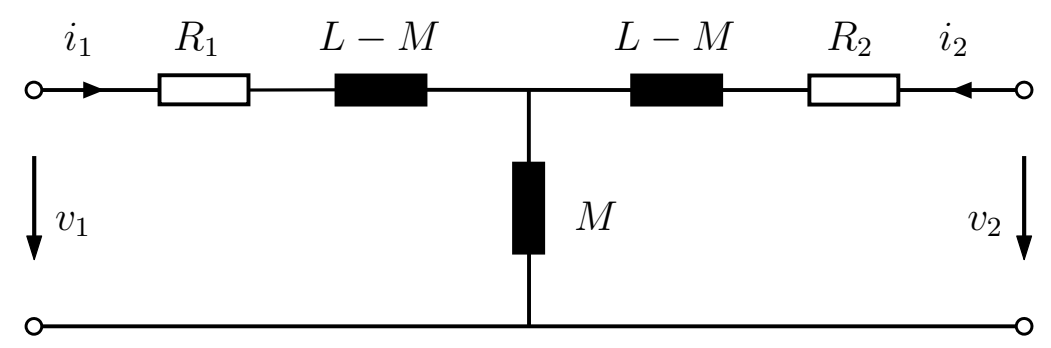

Figure 2.3: Coupling T-model for the transformer

\section{Transformer equations}

$$
\begin{gathered}
v_{1}(t)=L_{1} \frac{\mathrm{d} i_{1}(t)}{\mathrm{d} t}+M \frac{\mathrm{d} i_{2}(t)}{\mathrm{d} t}+R_{1} i_{1}(t) \\
v_{2}(t)=L_{2} \frac{\mathrm{d} i_{2}(t)}{\mathrm{d} t}+M \frac{\mathrm{d} i_{1}(t)}{\mathrm{d} t}+R_{2} i_{2}(t) \\
v_{2}^{\prime}=\frac{1}{t} u_{2} \\
i_{2}^{\prime}=t i_{2} \\
R_{2}^{\prime}=\left(\frac{1}{t}\right)^{2} R_{2} \\
L_{\sigma 2}^{\prime}=\left(\frac{1}{t}\right)^{2} L_{\sigma 2}
\end{gathered}
$$

Where $v_{2}^{\prime}, i_{2}^{\prime}, R_{2}^{\prime}, L_{\sigma 2}^{\prime}$ are the voltage, current, winding resistance and leakage inductance of the secondary referred to the primary of the transformer.

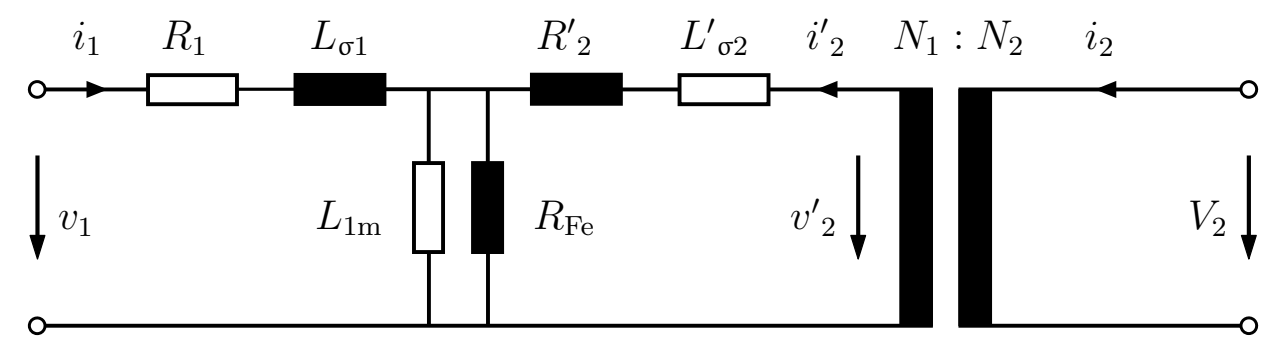

Figure 2.4: Transformer T-model referred to the primary

$$
\begin{gathered}
v_{1}(t)=L_{\sigma 1} \frac{\mathrm{d} i_{1}(t)}{\mathrm{d} t}+L_{1 \mathrm{~m}} \frac{\mathrm{d}\left(i_{1}(t)+i_{2}^{\prime}(t)\right)}{\mathrm{d} t}+R_{1} i_{1}(t) \\
v_{2}^{\prime}(t)=L_{\sigma 2}^{\prime} \frac{\mathrm{d} i_{2}^{\prime}(t)}{\mathrm{d} t}+L_{1 \mathrm{~m}} \frac{\mathrm{d}\left(i_{1}(t)+i_{2}^{\prime}(t)\right)}{\mathrm{d} t}+R_{2}^{\prime} i_{2}^{\prime}(t)
\end{gathered}
$$

The current in $R_{\mathrm{Fe}}$ is supposed to be negligible. 
The equivalent model of the transformer highlights its significant parameters. Particularly important are the total leakage inductance of the transformer since it determine the maximum power that can flow through the converter in relation with the switching frequency, modulation strategy and phase shift angle between the two H-bridges as will be shown later in this work. Other parameters that will be widely referred to below are the self-inductance $\mathrm{L}$ and the mutual inductance $\mathrm{M}$.

\subsection{Transformer with Multiple Windings in Parallel and in Series}

In the previous section 2.1.1, a transformer with only one winding at the primary and only one winding at the secondary has been considered. As will be illustrated below, in this project, it is interesting to consider a transformer with a generic number $m$ of windings connected in parallel at the primary and a generic number $n$ of windings connected in series at the secondary, which make up, in short, an $m+n$-transformer.

In figure 2.5, the schematic of such a transformer is shown. The primary voltage $v_{\mathrm{P}}$ is common to all the windings on the primary side of the transformer, which is also the low voltage side of the transformer. On the secondary side there is a total secondary voltage $v_{\mathrm{S}}$, which is the sum of the voltage of all windings. The secondary current $i_{\mathrm{S}}$ is common to all the windings on the secondary side. Such a transformer has an impedance matrix with dimensions $(m+n)(m+n)$. Obtaining this matrix by means of simulations and determining parameters like leakage inductances, mutual inductances and self-inductances are rather inefficient and impractical.

The previous considerations show that it is necessary to find synthetic parameters that can describe the transformer in a simple and effective way.

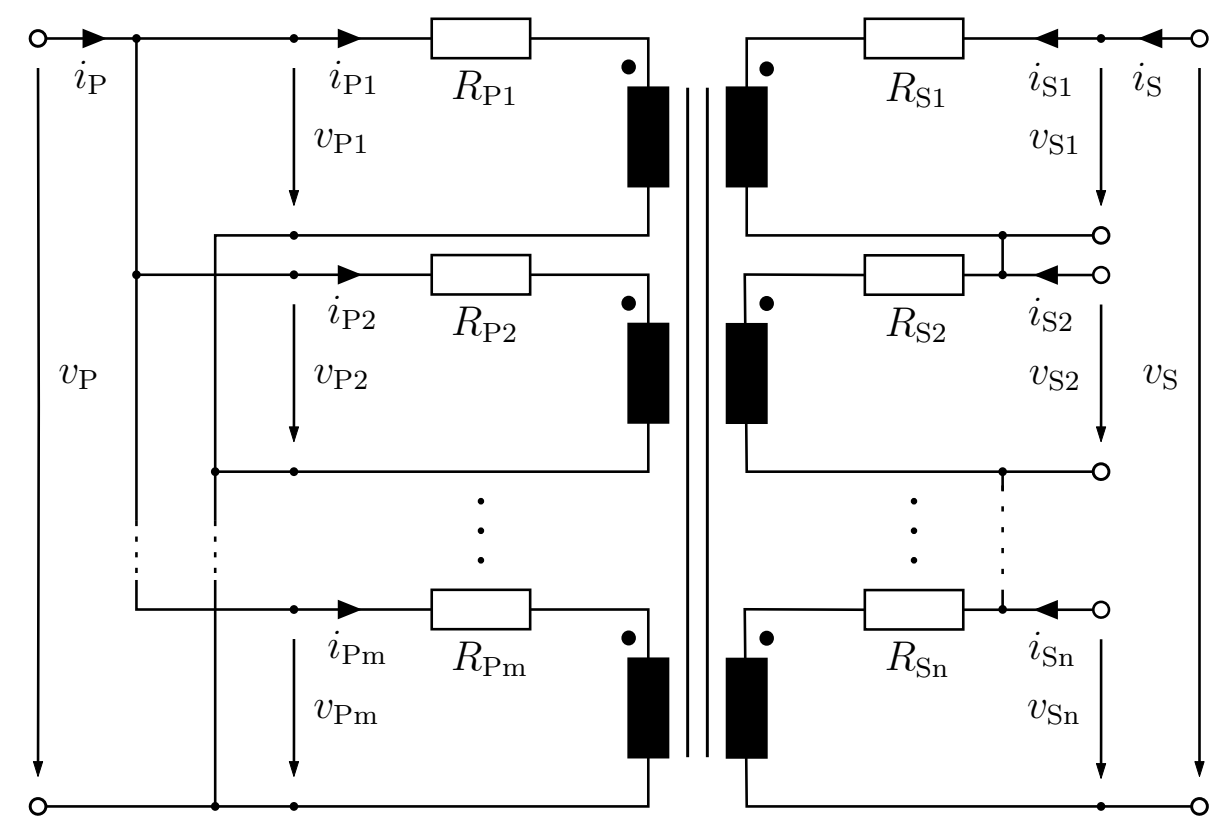

Figure 2.5: Transformer with multiple windings in parallel at the primary side and in series at secondary side 
For this simplification consider the scheme for the $(m+n)$-transformer as depicted in figure 2.5. The following hypotheses are now being made:

- All windings of the transformer have the same number of turns.

- All the mutual inductances $M_{\mathrm{ij}}$ of the transformer are equal and have value $M$.

- All the self-inductances of each winding are equal and with value $L$.

As shown in detail in appendix $\mathrm{A}$, with these hypotheses the equation of the $m+n$-transformer can be written as:

\section{Symmetric transformer}

$$
\begin{aligned}
& v_{\mathrm{P}}=L_{1} \frac{\mathrm{d} i_{\mathrm{P}}}{\mathrm{d} t}+M_{12} \frac{\mathrm{d} i_{\mathrm{S}}}{\mathrm{d} t}+\frac{R_{\mathrm{P}}}{m} \\
& v_{\mathrm{S}}=M_{21} \frac{\mathrm{d} i_{\mathrm{P}}}{\mathrm{d} t}+L_{2} \frac{\mathrm{d} i_{\mathrm{S}}}{\mathrm{d} t}+n R_{\mathrm{S}}
\end{aligned}
$$

where

$$
\begin{aligned}
L_{1} & =\left(\frac{1}{m} L+\frac{m-1}{m} M\right) \\
L_{2} & =n L+n(n-1) M \\
M_{12} & =M_{21}=n M
\end{aligned}
$$

and $m$ number of windings connected in parallel at the primary side of the transformer and $n$ number of windings connected in series at the secondary side of the transformer.

\section{Leakage inductance of the symmetric transformer}

$$
\begin{aligned}
L_{\sigma 1} & =L_{1}-t M, \\
L_{\sigma 2} & =L_{2}-\frac{1}{t} M, \\
L_{\sigma} & =L_{\sigma 1}+t^{2} L_{\sigma 2}
\end{aligned}
$$

Replacing the A.13 in A.14 we obtain for $L_{\sigma}$

$$
\begin{aligned}
L^{\prime}{ }_{\sigma} & =\left(\frac{1}{m}+\frac{1}{n}\right)(L-M) \\
L^{\prime \prime}{ }_{\sigma} & =n^{2}\left(\frac{1}{m}+\frac{1}{n}\right)(L-M)
\end{aligned}
$$

$L_{\sigma}^{\prime}$ is referred to the low voltage side and $L^{\prime \prime}{ }_{\sigma}$ is referred to the high voltage side. 


\section{Coupling capacitance between the primary and the secondary of the transformer}

Generally, the coupling capacitances between the primary and secondary do not cause problems for the operation of a converter working with a transformer. By increasing the working frequency of the transformers and by reducing the leakage inductance by means of interleaved windings between the windings of the primary side and windings of the secondary side, these capacitances will increase and ultimately become critical. The problem of these capacitances is that they resonate with the leakage inductances and produce a spectrum of resonant frequencies. The lowest of these resonant frequencies with the lowest impedance will determine the maximum frequency at which the transformer can function. Typically, this resonant frequency should be at least one decade higher than the switching frequency. Switching frequencies that are too near the resonant frequency of the transformer will increase the losses in the transformer, and if the resonant frequency is too near the switching frequency, the converter can suffer damage.

\subsection{Design of the Transformer}

The aim of this work is to design a prototype for a dual active bridge with tap changer with main specifications including a low voltage range $V_{1, \min }=30 \mathrm{~V}$ to $V_{1, \max }=60 \mathrm{~V}$ and high voltage range $V_{2, \min }=100 \mathrm{~V}$ to $V_{2, \max }=400 \mathrm{~V}$. The nominal power is $10 \mathrm{~kW}$. In the $\mathrm{DAB}$, the RMS currents of the transformer can be significantly increased by increasing the phase shift angle $\phi$ and for voltage ratios of the converter which differs from the voltage ratios of the transformer. The ratio between the RMS current and the DC current can reach $I_{\mathrm{RMS}} / I_{\mathrm{DC}}=1.6$ and more. In the case of this research, we limit this value to 1.4 at the nominal values of the converter at a maximum phase shift $\phi_{\mathrm{N}}=60^{\circ}$.

\begin{tabular}{lclc}
\hline$S_{\operatorname{Tr}}$ & $14 \mathrm{kVA}$ & $n_{\mathrm{T}}$ & $1: 1-1: 8-1: 12$ \\
$V_{1, \min }$ & $30 \mathrm{~V}$ & $V_{1, \max }$ & $60 \mathrm{~V}$ \\
$V_{2, \min }$ & $100 \mathrm{~V}$ & $V_{2, \max }$ & $400 \mathrm{~V}$ \\
$I_{\mathrm{RMS}, 1, \max }$ & $280 \mathrm{~A}$ & $I_{\mathrm{RMS}, 2, \max }$ & $35 \mathrm{~A}$ \\
$L_{\sigma, \mathrm{N}}$ & $220 \mathrm{nH}$ & $f_{\mathrm{N}}$ & $100 \mathrm{kHz}$ \\
$\eta_{\mathrm{MAX}}$ & $>98 \%$ & $S_{\eta, \mathrm{MAX}}$ & $7 \mathrm{kVA}-11 \mathrm{kVA}$ \\
\hline
\end{tabular}

Table 2.1: Transformer specifications

In the design of the transformer, several possible configurations are considered. In the case of the single-phase transformer, a first choice concerns the number of columns and the distribution of the windings. One solution involves primary windings on a column and secondary windings on a second column. This solution generally leads to high leakage inductance and has the advantage that the leakage inductance can be adjusted by varying the air gap. To reduce leakage inductance, the number of turns must be particularly low and the iron area must be considerable. A second solution foresees both windings, the primary and the secondary, on the same column. Furthermore, if the windings are interleaved, a particularly low leakage inductance can be obtained. The drawback of this solution is the increased coupling capacitance between primary and secondary and the increased difficulty to manufacture the transformer. Optimum is a trade-off between these solutions. In this thesis, the second solution is adopted. At this stage, by means of magnetic calculation and simulation, the right core, litz wire and windings configurations were determined. The goal 
was to achieve an efficiency of at least of $98 \%$ over a wide power range, in particular around $75 \%$ of the nominal power. Table 2.1 lists the design specifications of the transformer. The manufactured prototype fulfills all design requirements and specifications except for efficiency. In the transformer prototype, efficiency close to $98 \%$ could be reached only for values for a correspondent power of the converter at around $10 \%$ of the nominal value. The reason for this is explained below in this chapter.

The specifications regarding core size and material are given in figure 2.6 and in table 2.2.

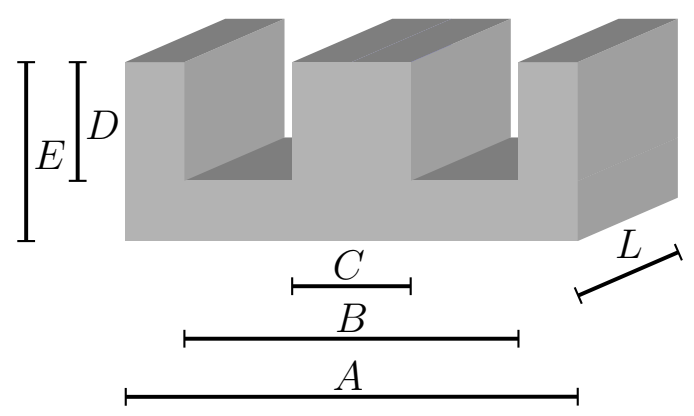

Figure 2.6: Core dimension

\begin{tabular}{ccc}
\hline Core & EE70 & E71/33/32 \\
\hline Material & PC40 & N97 \\
Size A B C in mm & 7050.119 .5 & 70.54822 \\
Size D E L in mm & 35.545 .519 .5 & 21.933 .232 \\
Window height in mm & 71 & 43.8 \\
Window width in mm & 15.3 & 13 \\
Iron eff. area $\mathrm{mm}^{2}$ & 386 & 683 \\
\hline
\end{tabular}

Table 2.2: Used core for the transformers

Further information about relevant cores geometry can be found in [7], about the material PC40 in [39] and about N97 in [40].

\section{Copper losses and iron losses}

To design the transformer several models of it have been simulated with different core and windings configurations. The simulations have been carried out with the program FEMM 4.2 [25]. To evaluate copper losses for the dual active bridge, current waveforms have been calculated using the Fourier series expansion. With the program FEMM 4.2 the resistance $R_{\mathrm{AC}}$ of a frequency spectrum for switching frequency $f_{\mathrm{SW}}=100 \mathrm{kHz}$ to $1 \mathrm{MHz}$ has been determined in consideration of the first relevant harmonic.

$$
P_{\mathrm{Cu}}=R_{\mathrm{DC}} \hat{\mathrm{I}}_{\mathrm{DAB}, \mathrm{DC}}^{2}+\sum_{n=1}^{\infty} R_{\mathrm{AC}, n}\left(\frac{\hat{\mathrm{I}}_{\mathrm{DAB}, n}}{\sqrt{2}}\right)^{2}
$$

For the DAB, $\hat{\mathrm{I}}_{\mathrm{DAB}, \mathrm{DC}}=0$ because the current has only alternate components. The terms of $\hat{\mathrm{I}}_{\mathrm{DAB}, n}$ are the coefficients of the Fourier expansion, which can be calculated for each current waveform by means of a simple program.

With formula 2.23, power loss in the windings can be estimated. This approach is necessary since the waveforms of the dual active bridge are not sinusoidal and because FEMM42 
simulates only with sinusoidal waveforms and only one frequency at a time. The sum in 2.23 is possible because, for copper losses, the superposition principle can be applied [1]. At this stage of the design, the interest was not to determine losses with high accuracy, which would need more effort, but to compare the different transformer windings configurations. For accurate iron loss calculations, many items can be found in the literature [22, 42] . Here, as with copper losses, attention is focused on having a comparison tool between different transformers. By means of the FEMM42 program, the induction strength in the ferrite core has been calculated. From this program, it becomes possible to obtain the induction value of each simulated finite element. By means of a look-up table of the magnetic material in use, the magnetic losses of each of these elements can be calculated. This approach furnishes a good approximation of core losses for the transformer and can be used to compare different transformers.

In the design of the transformer for this topology, particular attention was paid to obtaining the right leakage inductance, symmetry between windings and the feasibility of the transformer itself. The feasibility of the converter strongly depends on these characteristics.

\section{Windings configuration}

As mentioned above, different winding configurations have been simulated, and a selection of these is depicted in figure 2.7. These configurations can be divided into three groups: one with too much leakage inductance, another with too little leakage inductance inductance and a third group with a usable value of leakage inductance.

\begin{tabular}{ccccc}
\hline Transformer name & Core type & Ferrite material & Litz wire & Winding configuration \\
\hline $\mathrm{T}_{1}, \mathrm{~T}_{2}, \mathrm{~T}_{5}$ & EE70 & PC40 & $630 \mathrm{x} 0.1 \mathrm{~mm}$ & $8 \mathrm{x} 4+8 \mathrm{x} 4$ \\
$\mathrm{~T}_{3}, \mathrm{~T}_{6}$ & $\mathrm{EE70}$ & $\mathrm{PC} 40$ & $630 \mathrm{x} 0.1 \mathrm{~mm}$ & $8 \mathrm{x} 3+8 \mathrm{x} 3$ \\
$\mathrm{~T}_{4}$ & $\mathrm{E} 71 / 33 / 32$ & $\mathrm{~N} 97$ & $630 \mathrm{x} 0.1 \mathrm{~mm}$ & $12 \mathrm{x} 3+12 \mathrm{x} 3$ \\
\hline
\end{tabular}

Table 2.3: List of the transformers

Table 2.3 lists the manufactured transformers $\mathrm{T}_{1}, \mathrm{~T}_{2}, \mathrm{~T}_{3}$ and $\mathrm{T}_{4}$, implemented in the dual active bridge converter and the proposed transformer $\mathrm{T}_{5}$ and $\mathrm{T}_{6}$.

- High leakage inductance: configuration as in figures 2.7a, 2.7b, 2.7g, $2.7 \mathrm{~g}$ and 2.7k. These configurations have too high leakage inductance, high proximity effect and high copper losses. In these cases, the magnetic fields obtain high values when compared to the other two cases.

- Low leakage inductance: configuration as in figures $2.7 \mathrm{~d}, 2.7 \mathrm{f}, 2.7 \mathrm{~h}$. These configurations have a coupling capacitance between the primary and secondary that is too high. This is due to the large surface facing between the primary and secondary windings.

- Usable leakage inductance: the configuration in figures $2.7 \mathrm{e}, 2.7 \mathrm{~m}, 2.7 \mathrm{i}, 2.7 \mathrm{n}$ and $2.7 \mathrm{o}$. These windings have a resonance frequency higher than one megahertz. The resonance frequency is due to the leakage inductance and coupling capacitance between primary and secondary which resonates at a certain frequency.

In the configuration with usable leakage inductance, there are some that are more suitable to be wrapped and, others that can be done so only with more difficulty. Here below are listed the windings configurations for the transformers. 


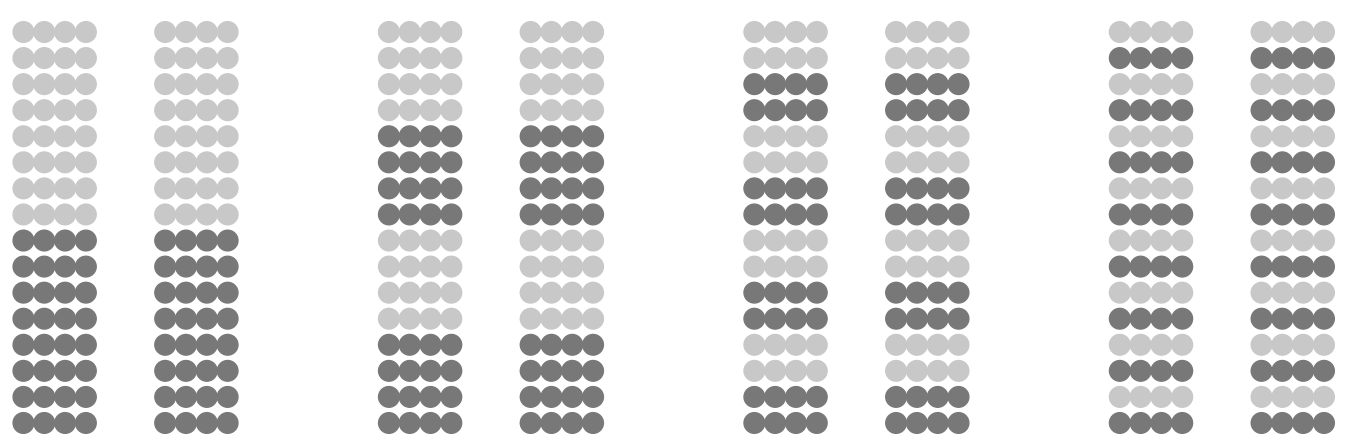

(a)

(b)

(c)

(d)

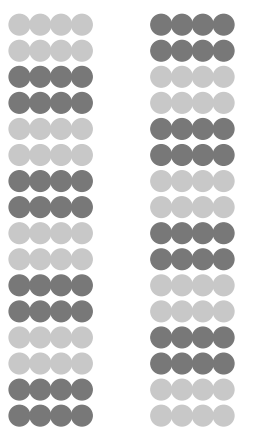

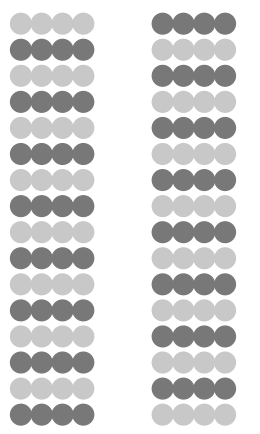

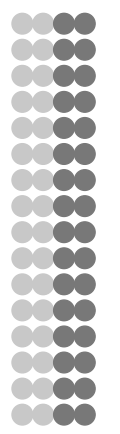
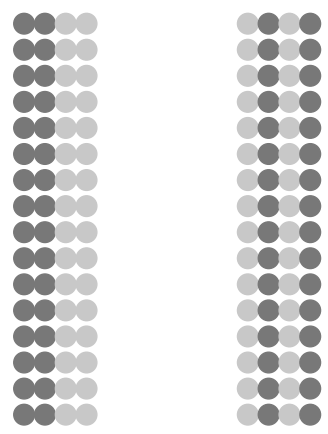

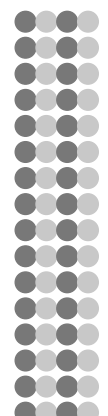

(e)

(f)

(g)

(h)

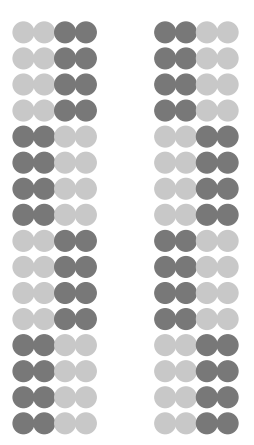

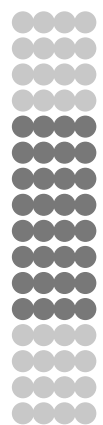

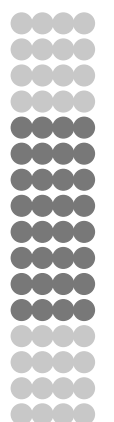
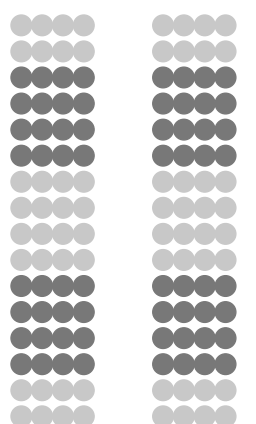

cos $\rightarrow$ cers $\rightarrow \infty$ cose  ๘) $\infty$ coes œ) (-) c) nos eno cos

(i)

(j)

$(\mathrm{k})$

(1)

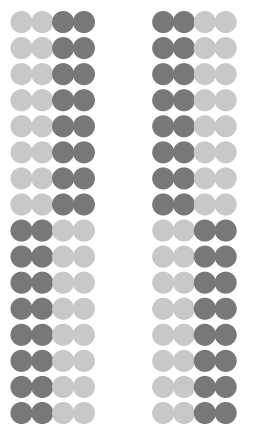

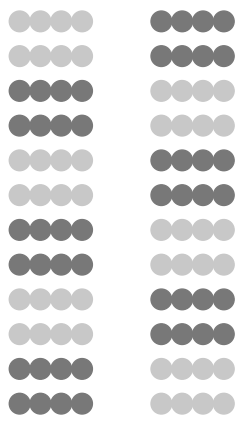

(n)

(o)

Figure 2.7: Transformer winding configurations 
- $\mathrm{T}_{1}, \mathrm{~T}_{2}$ : Configurations as in figure $2.7 \mathrm{e}$.

- $\mathrm{T}_{3}$ : Configuration as in figure $2.7 \mathrm{n}$.

- $\mathrm{T}_{4}$ : Configuration similar as in figure $2.7 \mathrm{n}$ but with twelve windings for the primary and secondary side.

- $\mathrm{T}_{5}$ : Configuration as in figure $2.7 \mathrm{~m}$.

- $\mathrm{T}_{6}$ : Configuration as in figure $2.7 \mathrm{o}$.

The configuration depicted in figures $2.7 \mathrm{~m}, 2.7 \mathrm{i}$ and $2.7 \mathrm{o}$ are supposed to be the best winding configurations, but they were not chosen initially because of the difficulty of wrapping the corresponding windings. As will be explained below, the configurations in figures $2.7 \mathrm{~m}$ and $2.7 \mathrm{o}$ are proposed for the improved version transformers $\mathrm{T}_{5}$ and $\mathrm{T}_{6}$.

\subsection{Magnetic Simulations of the Transformer}

To limit iron losses, a maximum induction for the ferrite has been set to $B_{\max }=200 \mathrm{mT}$. In the figures 2.8, 2.9 and 2.10, the magnetic simulations for a set of configurations already seen in figure 2.7 are depicted. To obtain the proper leakage inductance, different winding configurations have been simulated. Besides the correct value of leakage inductance, it is also necessary to verify that induction in the core does not exceed the maximum allowed value except for a small region near the corner of the transformer window. The windings have a slight current difference due to the magnetization current required to support the voltage of the transformer. If this current is not properly distributed on the transformer, it can bring about a local intensification of the transformer flux.

In figure 2.8a, the effect of non-homogenous distribution of the magnetization current is shown, and the result is a higher induction in the upper part of the transformer. In figure $2.8 \mathrm{~b}$, as compared to the aforementioned figure, only four turns have been moved from the upper section to the bottom section. Now the magnetization current is more evenly distributed across the core, and a considerable reduction in the induction maximum can be observed. In figure $2.8 \mathrm{c}$ and in figure $2.8 \mathrm{~d}$, the effect of winding interleaving can be observed to bring about a reduction of leakage inductance and overall induction in the core. In figure $2.9 \mathrm{a}$, a helicoidal winding is depicted, and with it, the typical antisymmetric distribution of the induction can be recognized. In figures $2.9 \mathrm{~b}$ and $2.9 \mathrm{c}$, a coaxial configuration and an interleaved coaxial configuration, respectively are depicted, and in these cases a very uniform induction distribution is observed. In figure $2.9 \mathrm{~d}$, a coaxial "swap" configuration is simulated. This has similar characteristics to the $2.9 \mathrm{~b}$ but a lower leakage inductance.

In figure 2.10a and 2.10b, there are two winding configurations used: the first has four turns for each winding, and the second has three turns for each winding. In both, the antisymmetric distribution in the induction can be observed. In the second, the maximum induction is higher due to the reduced number of turns. The induction remains beyond the maximum limit of $B_{\max }=200 \mathrm{mT}$ in the entire core. Even if these configurations have the drawback of asymmetry and a region exhibits relatively high induction values, for the relative simplicity with which they can be wrapped they have been chosen for the first prototype. 
The configuration in figure 2.10a compared to 2.10b has more copper losses and fewer iron losses. The configuration in figures $2.10 \mathrm{c}$ and $2.10 \mathrm{~d}$ are the improved version of $2.10 \mathrm{a}$ and $2.10 \mathrm{~b}$ and were planned for the improved transformer which unfortunately could not be wrapped due to limitations of time. These two windings configurations will have fewer iron losses than the two previously mentioned and a slightly bigger leakage inductance. 


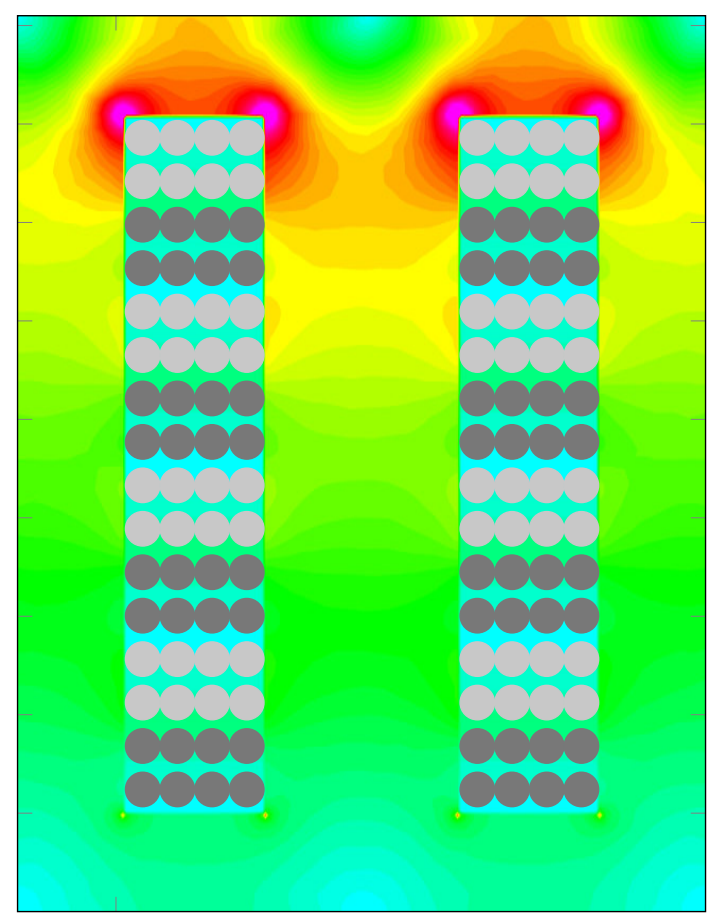

Induction in $\mathrm{mT}$

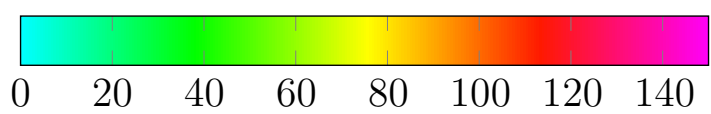

(a)

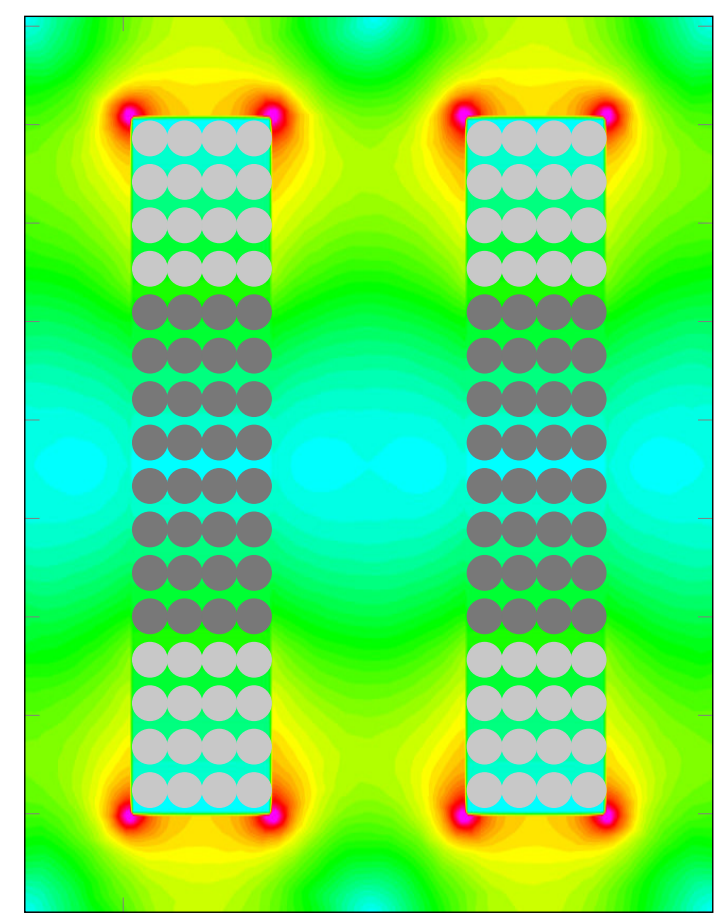

Induction in $\mathrm{mT}$

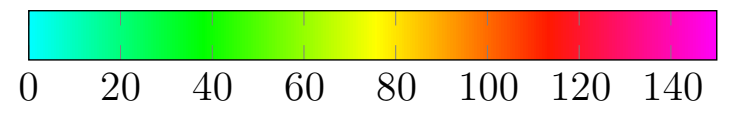

(c)

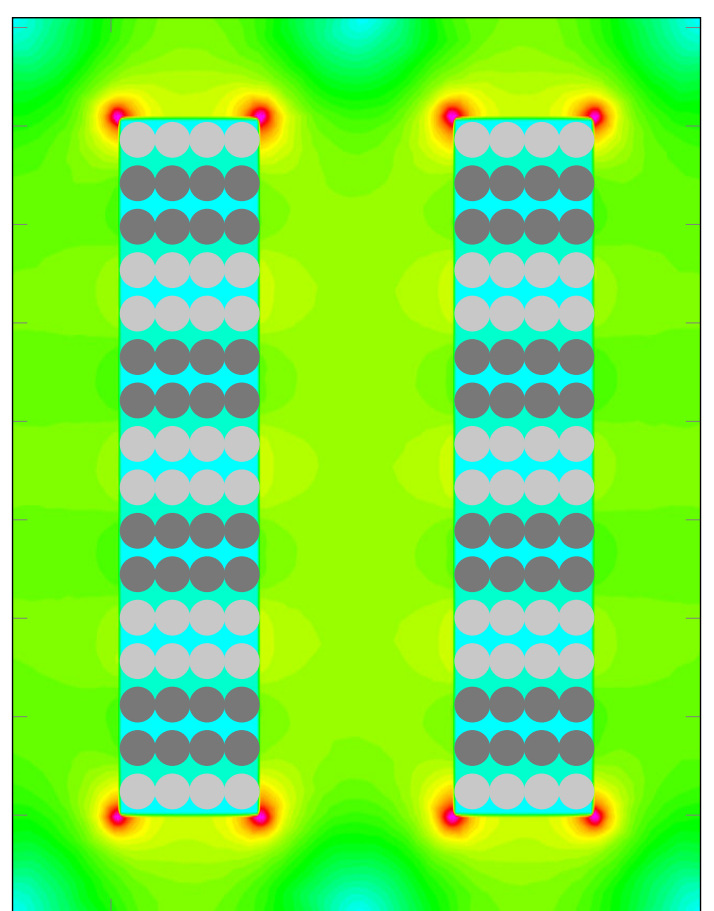

Induction in $\mathrm{mT}$

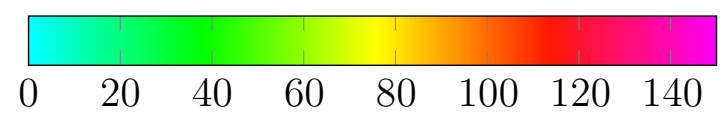

(b)

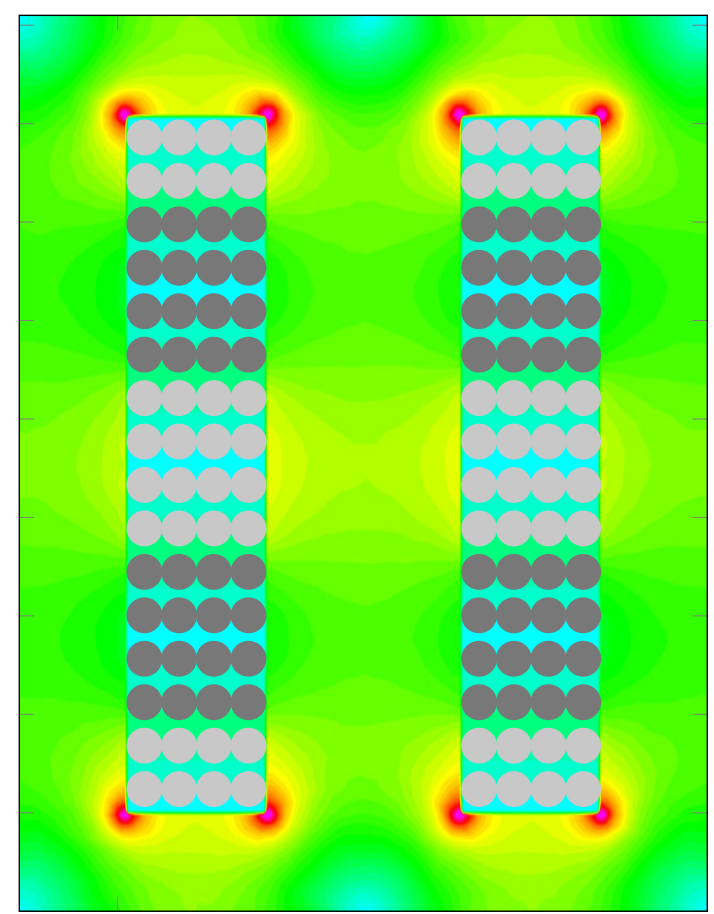

Induction in $\mathrm{mT}$

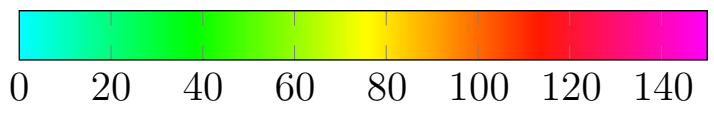

(d)

Figure 2.8: 1 - Magnetic simulations for transformers with EE70 core, $i_{\mathrm{pk}, \mathrm{w}}=30 \mathrm{~A}$ with windings as reported in figure 2.7 


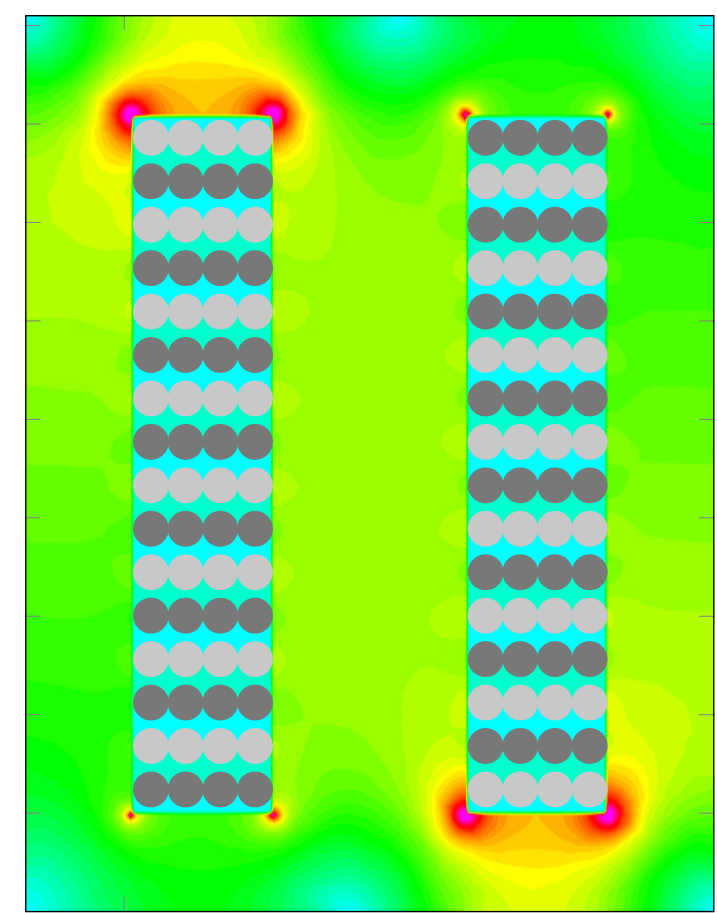

Induction in $\mathrm{mT}$

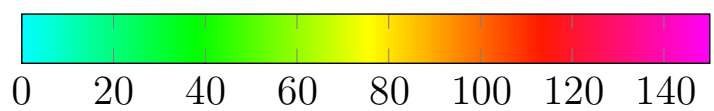

(a)

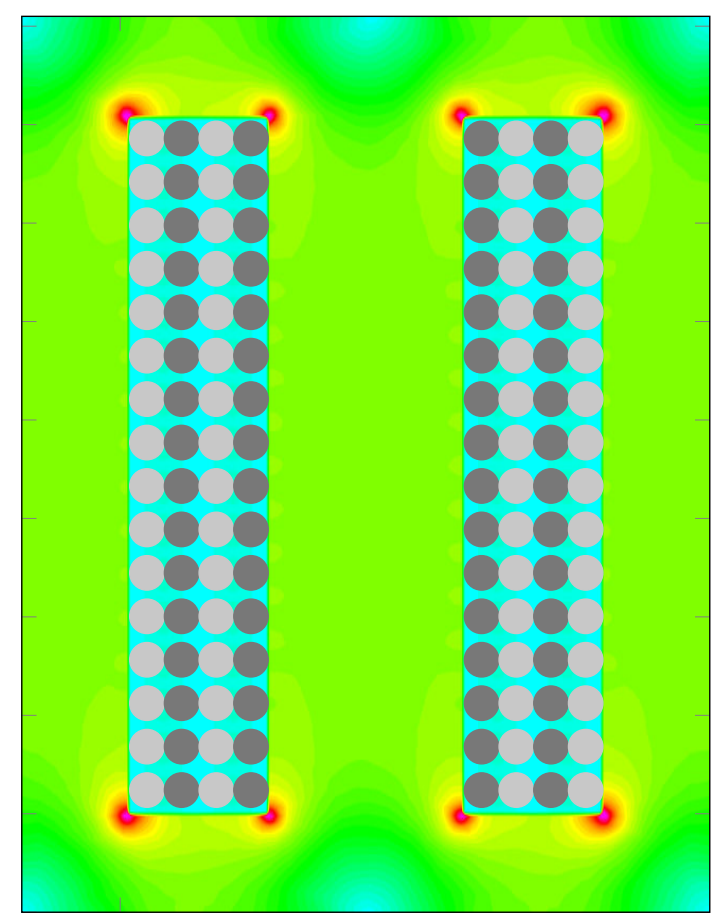

Induction in $\mathrm{mT}$

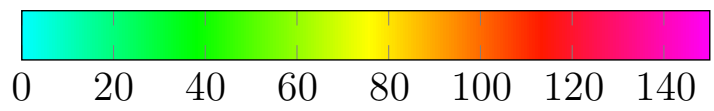

(c)

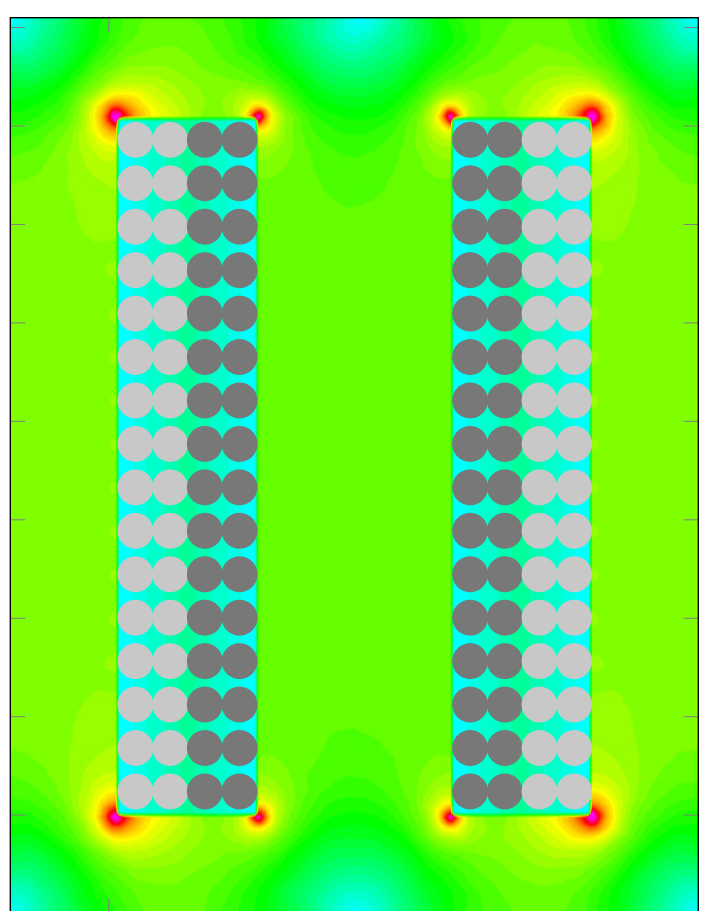

Induction in $\mathrm{mT}$

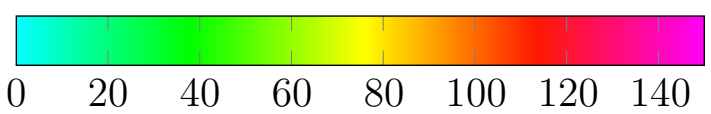

(b)

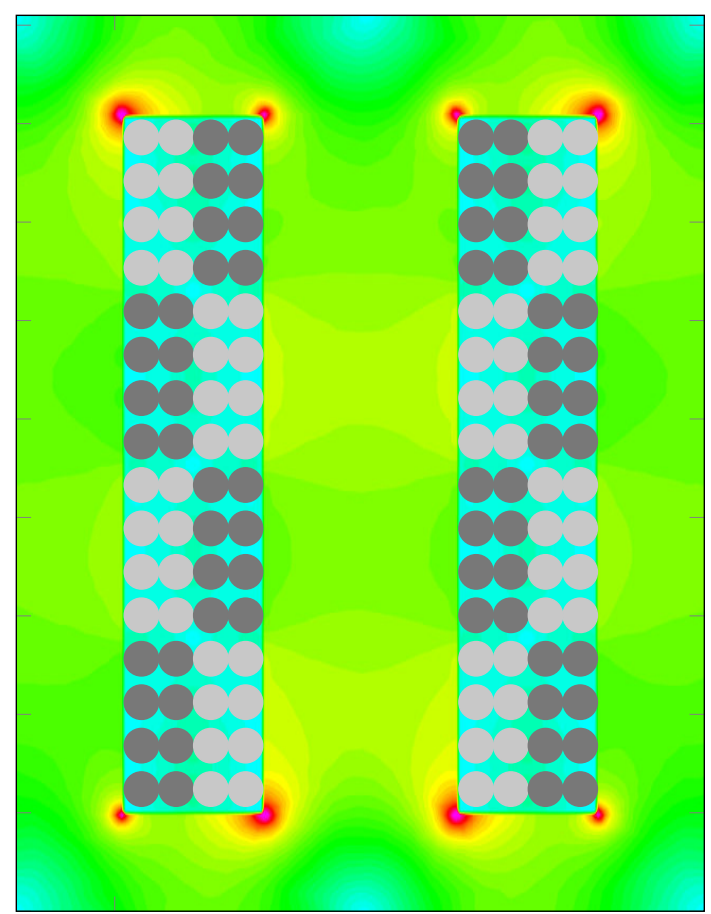

Induction in $\mathrm{mT}$

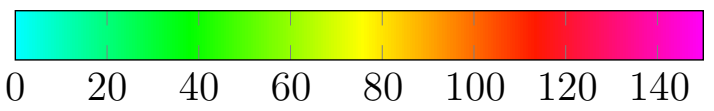

(d)

Figure 2.9: 2 - Magnetic simulations for transformers with EE70 core, $i_{\mathrm{pk}, \mathrm{w}}=30 \mathrm{~A}$ with windings as reported in figure 2.7 


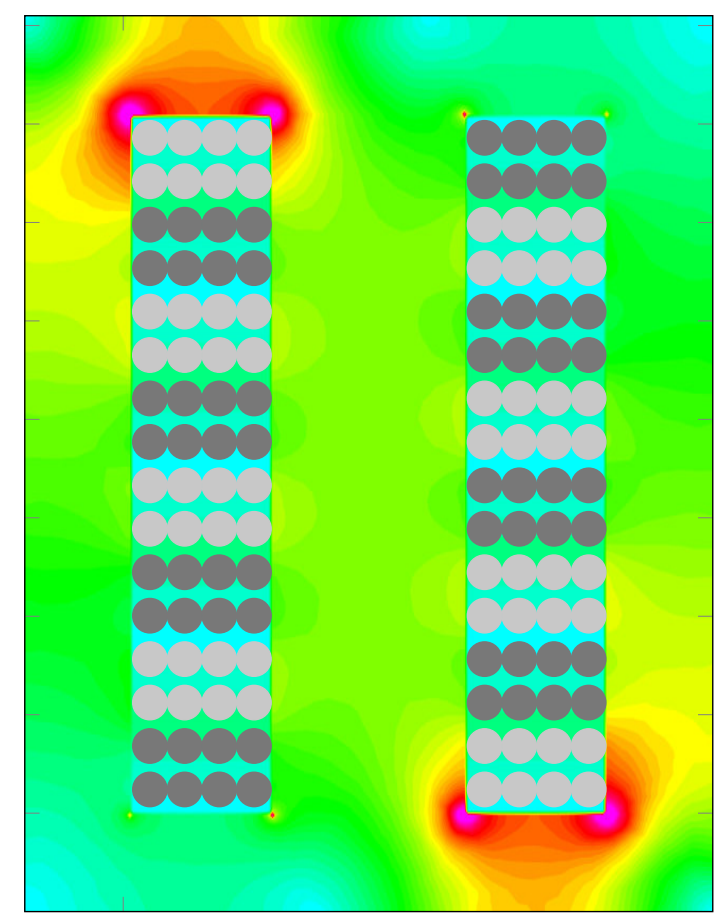

Induction in $\mathrm{mT}$

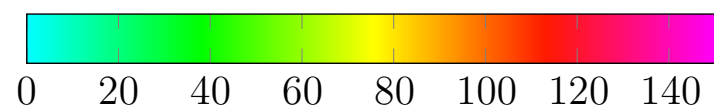

(a)

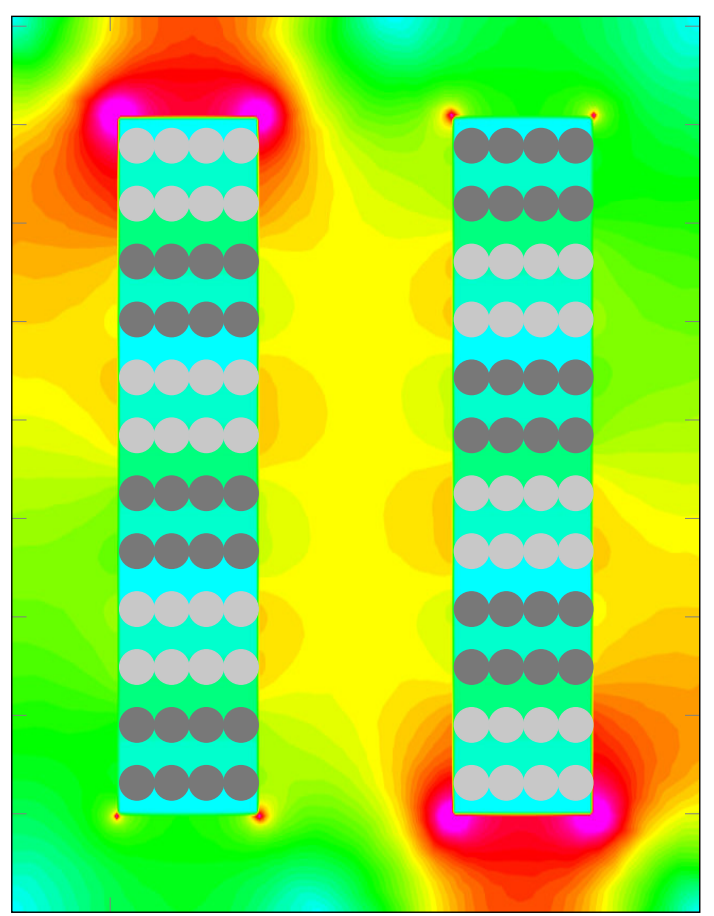

Induction in $\mathrm{mT}$

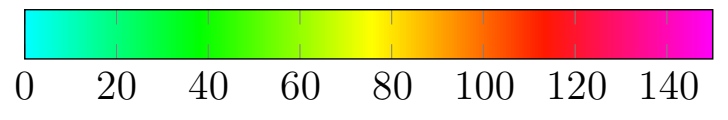

(c)

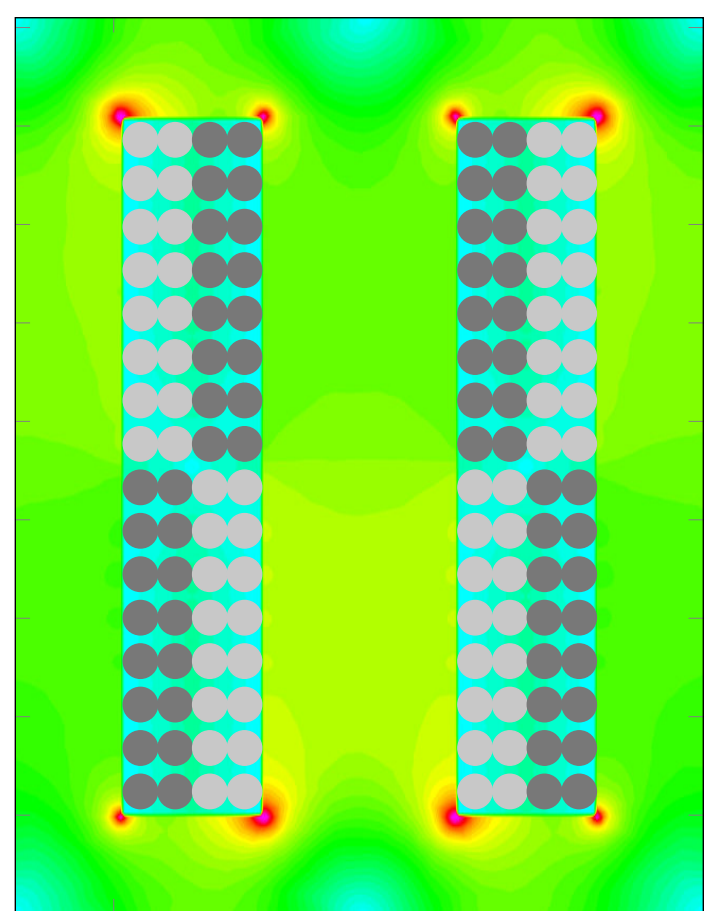

Induction in $\mathrm{mT}$

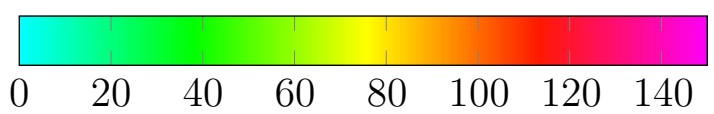

(b)

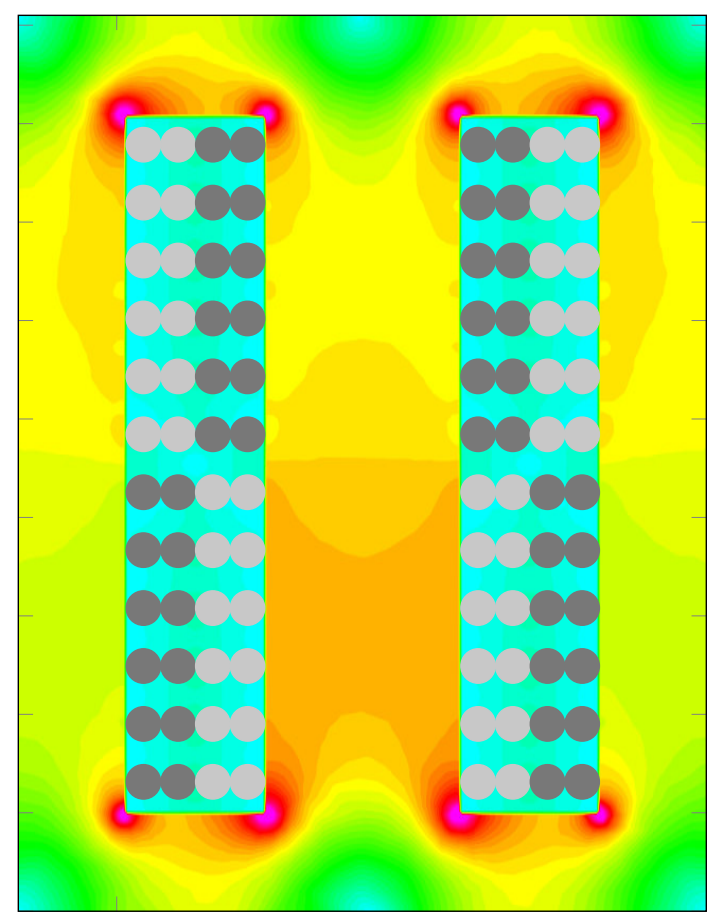

Induction in $\mathrm{mT}$

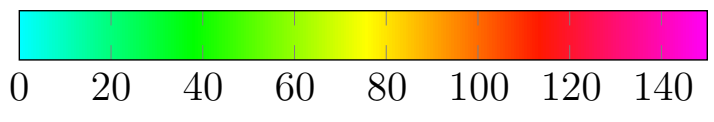

(d)

Figure 2.10: 3 - Magnetic simulations for transformers with EE70 core, $i_{\mathrm{pk}, \mathrm{w}}=30 \mathrm{~A}$ with windings as reported in figure 2.7 


\subsection{Transformer Prototype with Eight Windings at Primary and Secondary}

In this section, the afore mentioned transformers $T_{1}$ and $T_{2}$ with four turns for each winding and $\mathrm{T}_{3}$, with three turns for each winding are considered. In all these transformers, there are eight windings at the primary and eight windings at the secondary, as depicted in figure 2.11. These transformers, fulfill the requirements of the proposed problem, but unfortunately also exhibit some drawbacks that were detected after commissioning.

In the early stages of the design, emphasis was placed on obtaining the right leakage inductance, having a symmetric transformer, and, most importantly, the transformer being actually feasible.

Having the right leakage inductance means transferring the right power for which the transformer is dimensioned. Symmetry is important since, for example, copper losses are proportional to the square of the currents, and, hence, non-symmetry in the transformer would be strongly accentuated in the loss distribution, which can lead to hot spots and, consequently a reduction of efficiency and even local damage to the insulation.

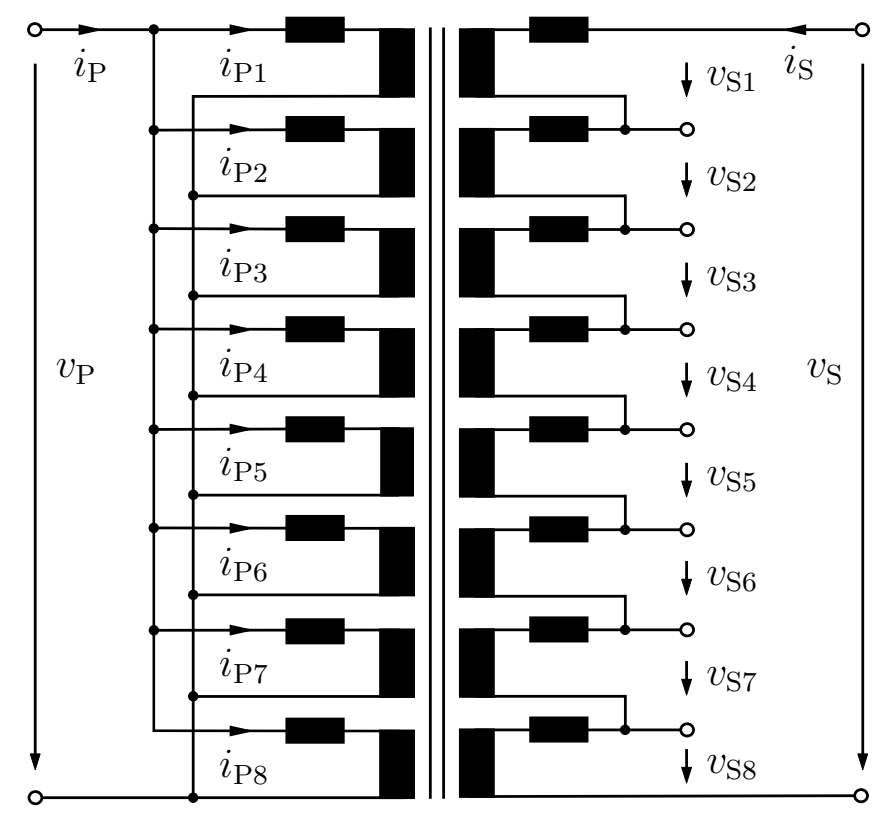

Figure 2.11: Schematic for the transformers $T_{1}, T_{2}$ and $T_{3}$ with eight primary and eight secondary windings

A picture of the transformer $\mathrm{T}_{1}$ can be seen in figure 2.12a, and in figure $2.12 \mathrm{~b}$ the windings configuration for $T_{1}$ and $T_{2}$ is depicted. In particular, the position of the conductors for each winding is given. To obtain a homogeneous distribution of the leakage inductance, the conductors have to change position at each turn. The transformers $T_{1}$ and $T_{2}$ are theoretically identic, the difference are due only to the manufacturing process.

\section{Current distribution in the primary side windings}

To verify the current distribution in the transformer a simulation of the converter has been carried out, and the results are depicted in figure 2.14a. The impedance matrix of the transformer $\mathrm{T}_{1}$ has been simulated with FEMM 4.2. The simulation of the converter 


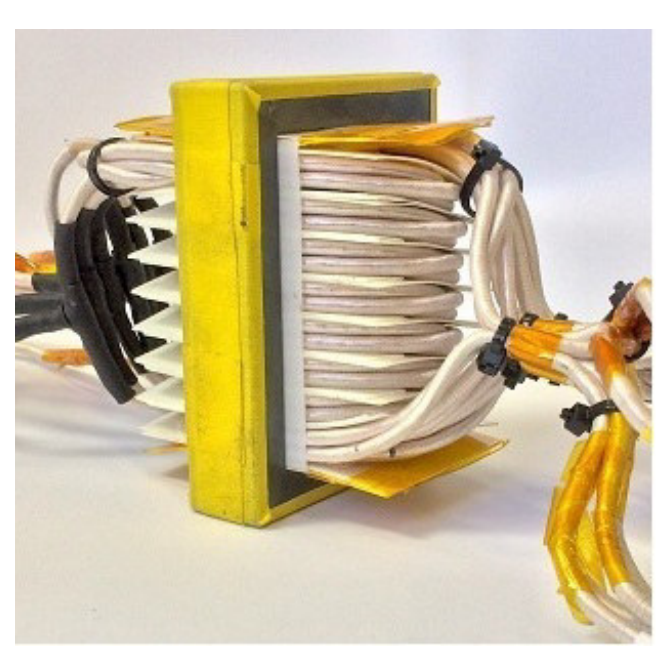

(a) Photography of $\mathrm{T}_{1}$

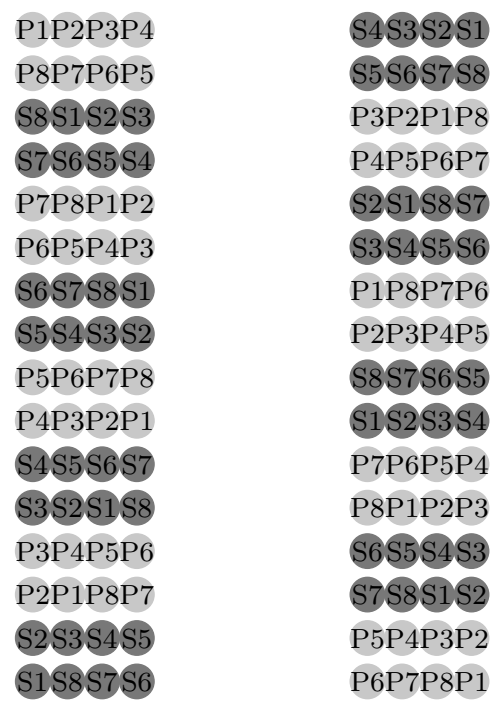

(b) Winding positions in $\mathrm{T}_{1}$

Figure 2.12: Picture of transformer $\mathrm{T}_{1}$ and windings configuration

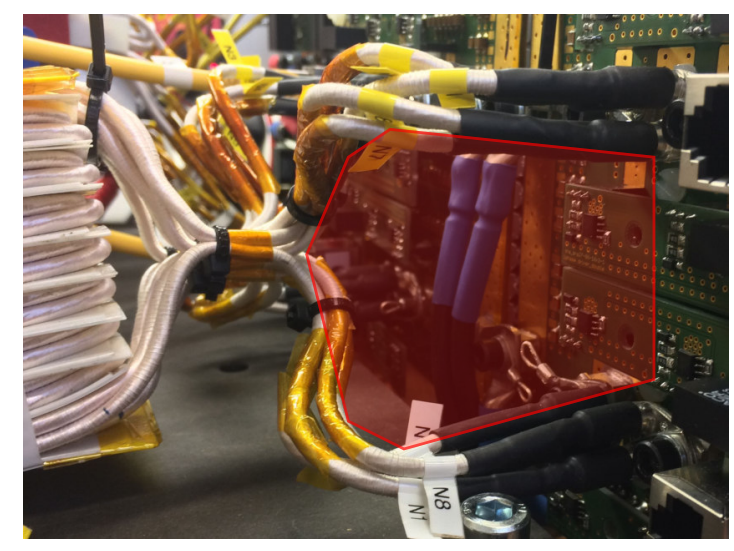

Figure 2.13: Leakage inductance between the transformer and the low voltage H-bridges

indicates that the transformer has a high degree of symmetry. Additionally the measurements showed a completely different situation depicted in figure $2.14 \mathrm{~b}$. This difference could be explained by the different value of the external leakage inductance of the wire that connects the transformer to the low voltage H-bridges.

The area that generates this leakage inductance is highlighted in red in figure 2.13. Each connection exhibits a slightly different area, and it is enough that these areas differ by $10 \mathrm{~cm}^{2}$, which itself corresponds to a difference in leakage inductance $\Delta L_{\sigma}=20 \mathrm{nH}$. The results of this simulation using this external variation of the leakage inductance is depicted in figure 2.14c. Knowing this, attention was paid to arranging the external connections as symmetrically as possible, and the result is shown in figure $2.14 \mathrm{~d}$.

\section{Effect of windings configurations on core losses}

In figure 2.15a, the magnetization of the core of transformer $\mathrm{T}_{1}$ for a current of $10 \mathrm{~A}$ on each winding is showed. The primary side windings also include the magnetization currents. In 


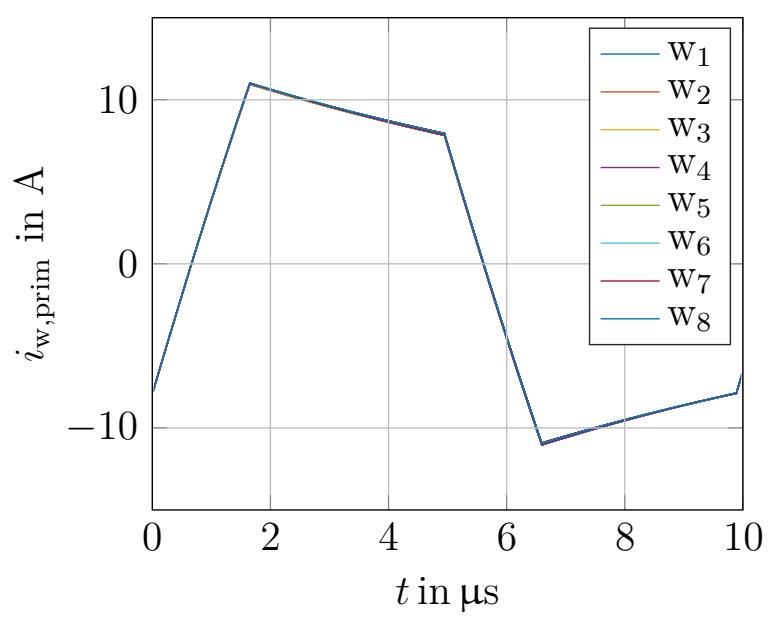

(a) Simulated symmetric current distribution

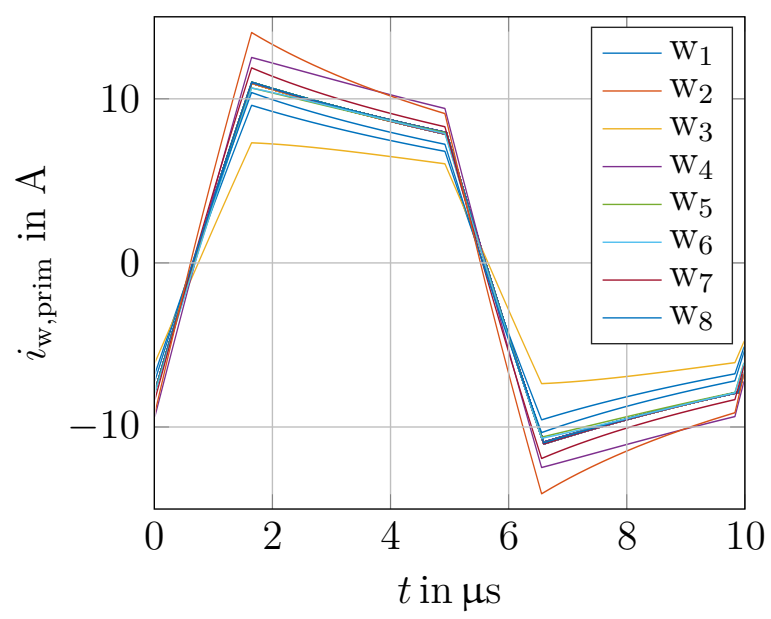

(c) Simulated not symmetric current distribution

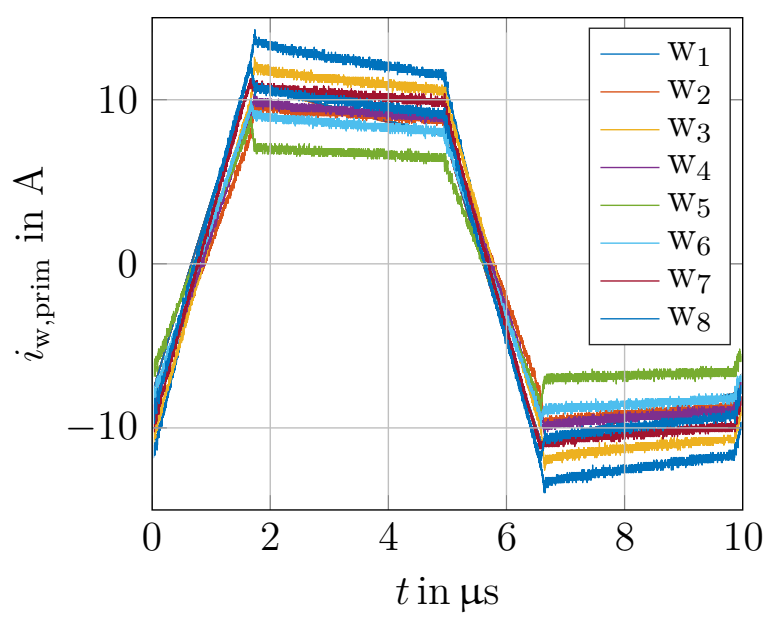

(b) Measured not symmetric current distribution

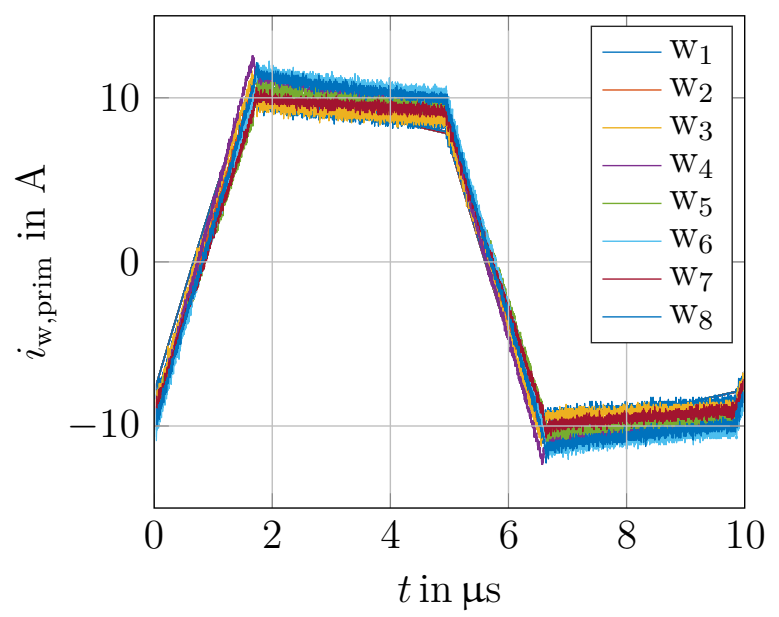

(d) Measured symmetric current distribution

Figure 2.14: Measured and simulated current distribution in the transformer with the effect of the external connectors

figure 2.15b, the same transformer with a $40 \mathrm{~A}$ current in each winding is depicted. In figures $2.15 \mathrm{c}$ and $2.15 \mathrm{~d}$, using the same core, the same amount of windings and turns are wrapped in a coaxial-swap configuration (improved version $\mathrm{T}_{5}$ ) with $10 \mathrm{~A}$ and $40 \mathrm{~A}$, respectively, in each winding. The windings of transformer $\mathrm{T}_{1}$ produce a region with higher induction when the current in the windings increase. The second configuration is much better because the induction remains practically constant when the currents change. The same comparison is made for transformer $T_{3}$ in figure 2.16. The windings configuration presented in figures $2.16 \mathrm{c}$ and $2.16 \mathrm{~d}$ are those for the new proposed and improved transformer $\mathrm{T}_{6}$, which is meant to permit the converter to have a higher efficiency than transformer $\mathrm{T}_{3}$ does. 


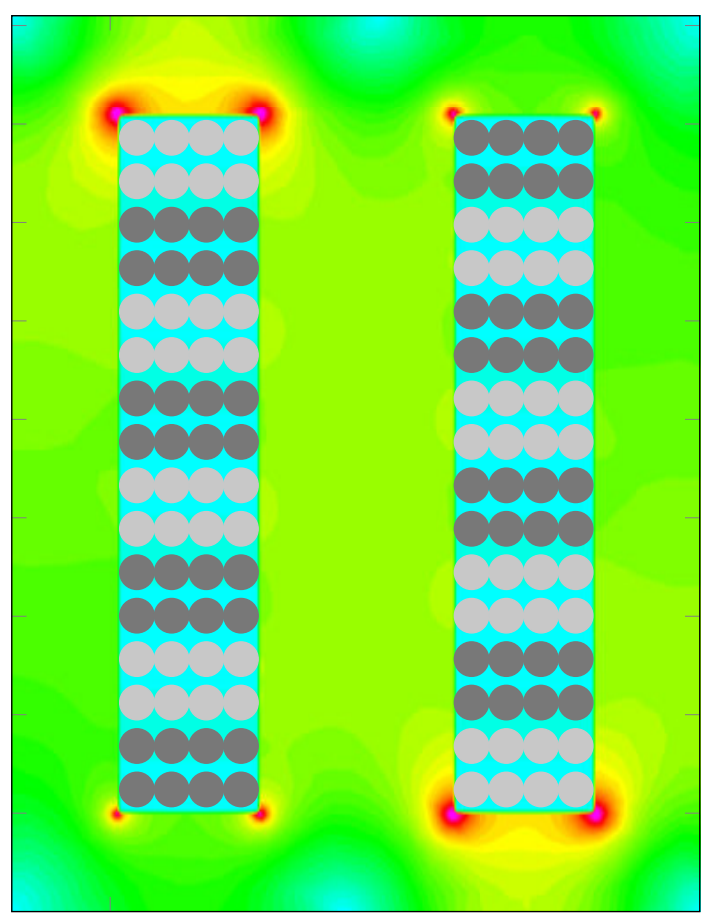

Induction in $\mathrm{mT}$

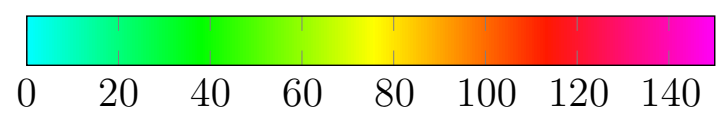

(a) $i_{\mathrm{pk}, \mathrm{w}}=10 \mathrm{~A}$

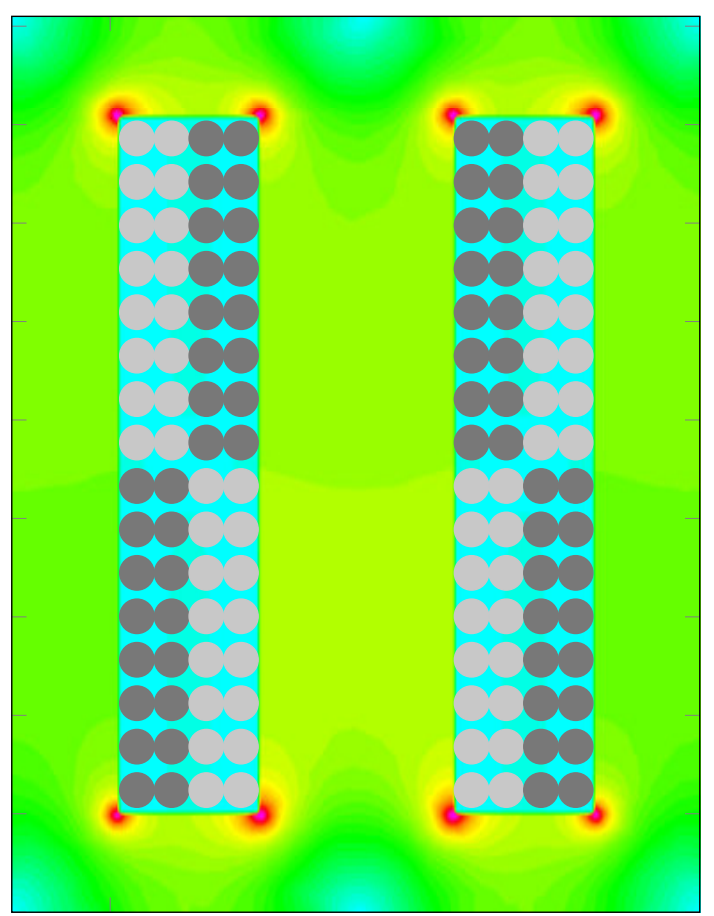

Induction in $\mathrm{mT}$

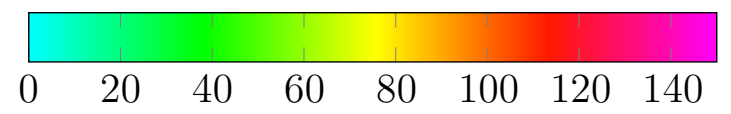

(c) $i_{\mathrm{pk}, \mathrm{w}}=10 \mathrm{~A}$

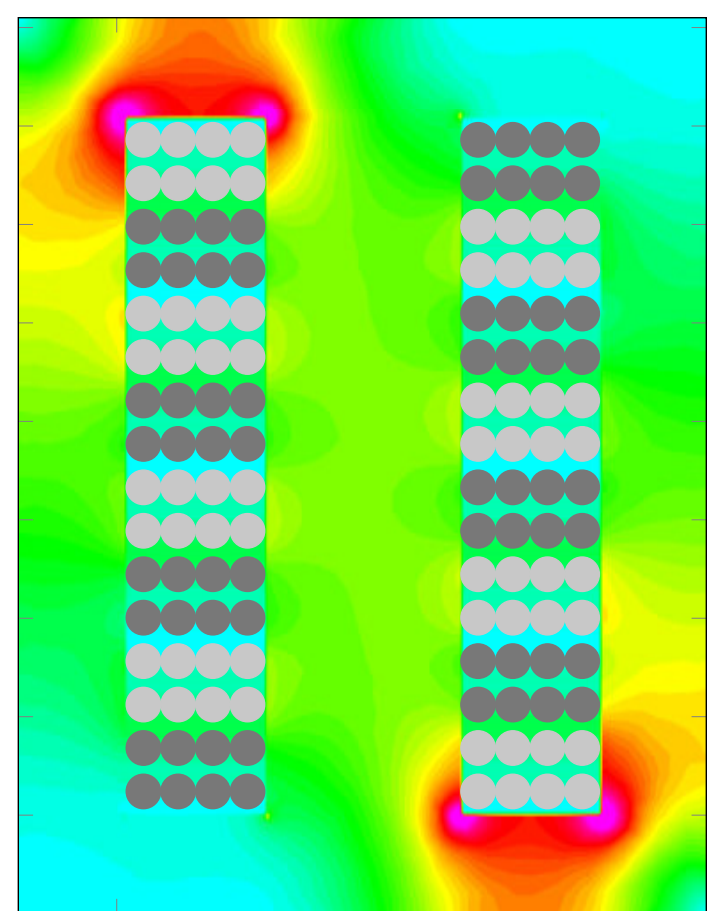

Induction in $\mathrm{mT}$

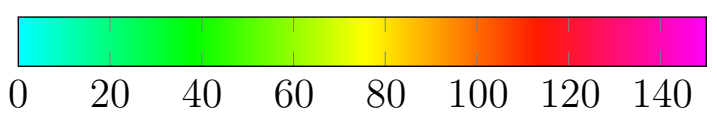

(b) $i_{\mathrm{pk}, \mathrm{w}}=40 \mathrm{~A}$

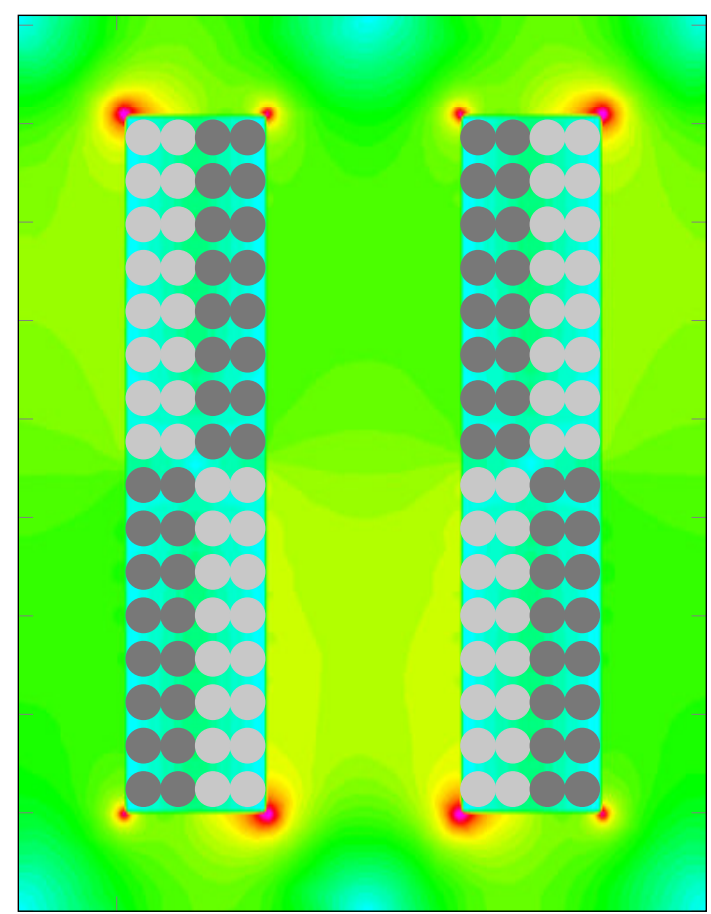

Induction in $\mathrm{mT}$

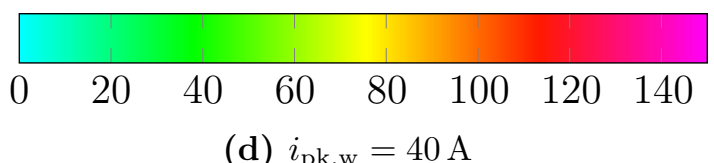

(d) $i_{\mathrm{pk}, \mathrm{w}}=40 \mathrm{~A}$

Figure 2.15: Comparison between transformer $T_{1}$ and the improved version $T_{5}$ 


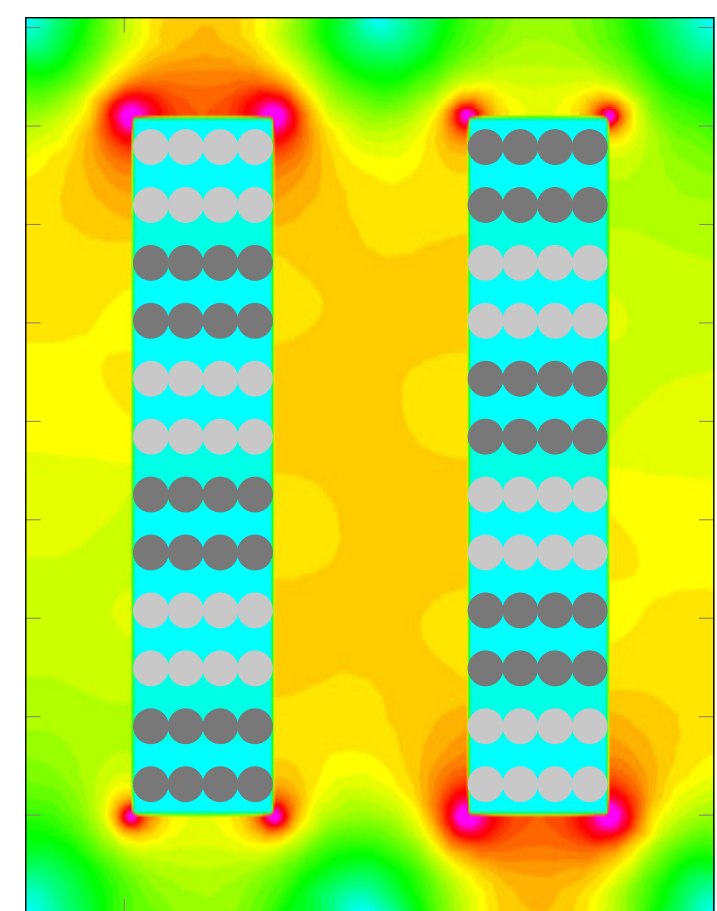

Induction in $\mathrm{mT}$

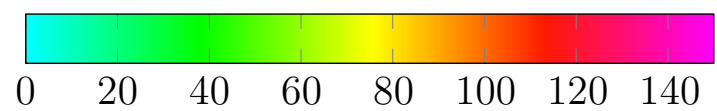

(a) $i_{\mathrm{pk}, \mathrm{w}}=10 \mathrm{~A}$

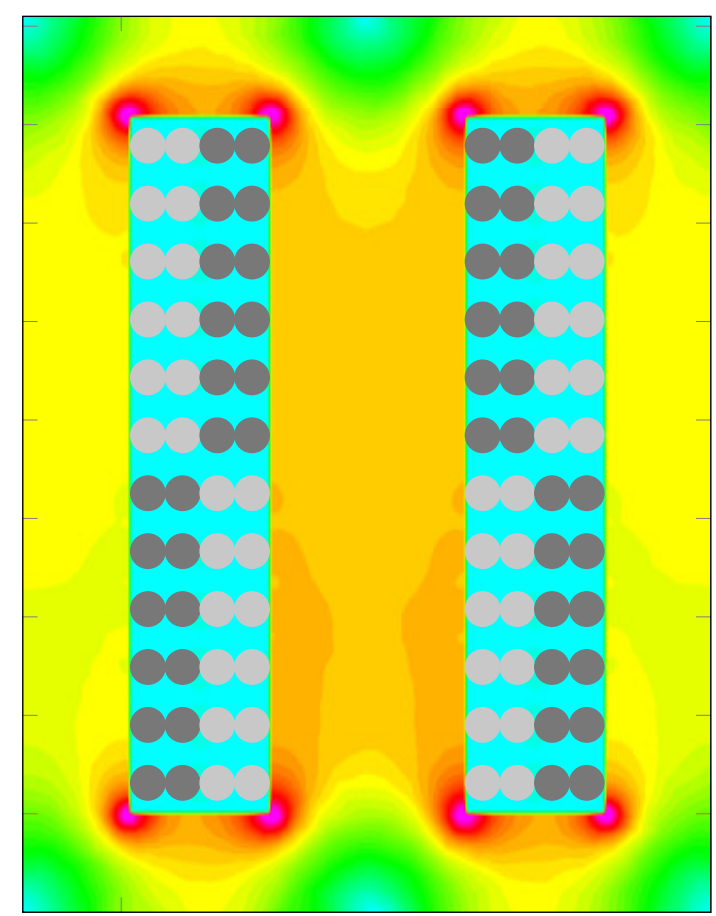

Induction in $\mathrm{mT}$

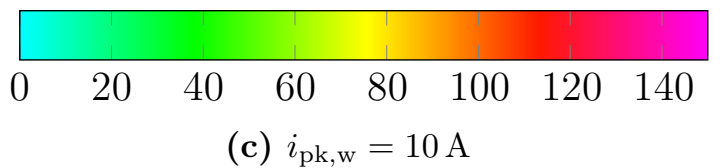

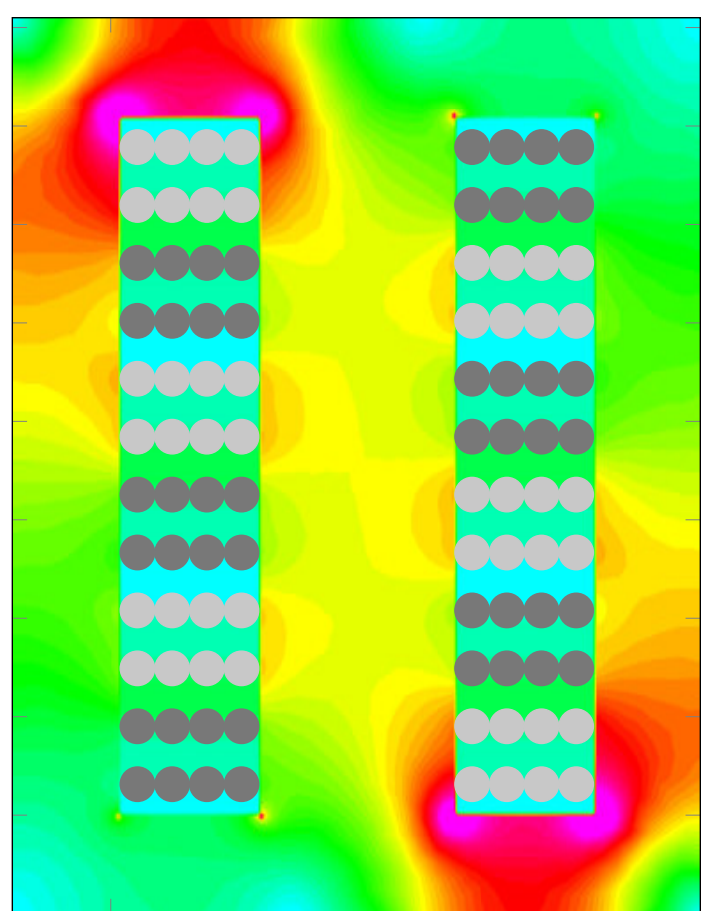

Induction in $\mathrm{mT}$

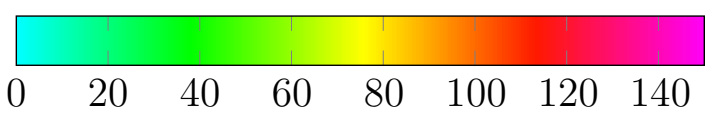

(b) $i_{\mathrm{pk}, \mathrm{w}}=40 \mathrm{~A}$

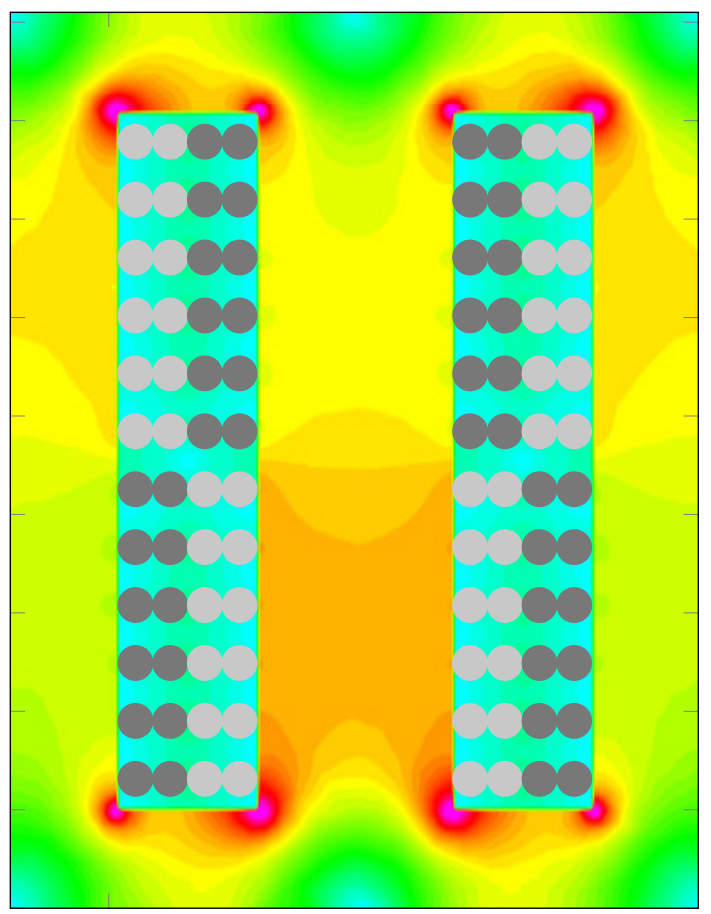

Induction in $\mathrm{mT}$

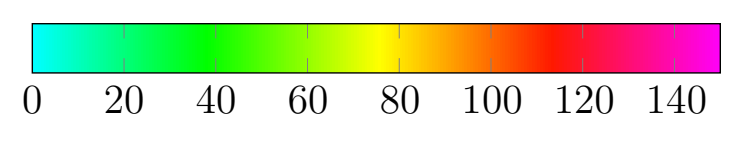

(d) $i_{\mathrm{pk}, \mathrm{w}}=40 \mathrm{~A}$

Figure 2.16: Comparison between transformer $T_{3}$ and the improved version $T_{6}$ 


\subsection{Comparison Between Transformer with Tap Changer and without}

The conventional transformer differs from the transformer with taps by its additional electrical connections. The transformer with taps is designed in a way to allow electrical connections to the correct points of the windings. This means that there are fewer possible ways to spin a transformer and, at the same time, the amount of copper required increases because it is necessary to reach the tap changer switch from the point of the additional connection. The additional copper necessary can be estimated to be about $25 \%$, and copper losses increase by the same amount. In addition, it has to be considered that every tap has a connector which increases weight and generates further conduction losses. On the other hand, the iron losses are not influenced by the presence of the taps since they do not influence the distribution of the windings and therefore do not change the distribution of the magnetic flux in the core. In general, a transformer with tap changer, compared to a transformer without, produces between $10 \%$ and $15 \%$ more losses, or, in other words, in order to keep losses unchanged, the transformer has to be oversized by about $10 \%$ to $15 \%$. In this case the increased copper and the additional connectors increases the total weight of the transformer by about $20 \%$.

\subsection{Leakage Inductance of the Transformer}

In the graph of figure 2.17, we can see that the leakage inductance seen from the primary side decreases with the increase of the number of windings connected in the series at the secondary side. This is because, while the leakage inductance is linearly increasing as the number of the windings in series increase, the impedance transformation increases with the square of the transformation ratio. In figure 2.17a are depicted the calculated leakage inductances and in figure $2.17 \mathrm{~b}$ the measured leakage inductances are depicted for the four realized transformer $\mathrm{T}_{1}, \mathrm{~T}_{2}, \mathrm{~T}_{3}$ and $\mathrm{T}_{4}$.

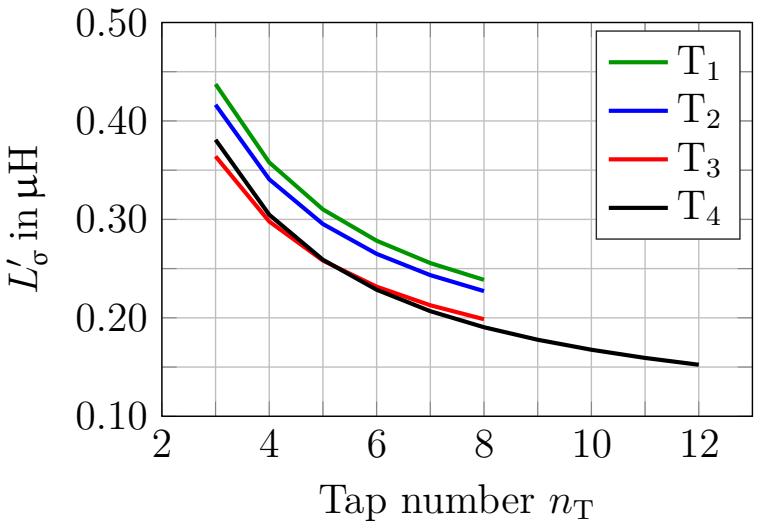

(a) Calculated values

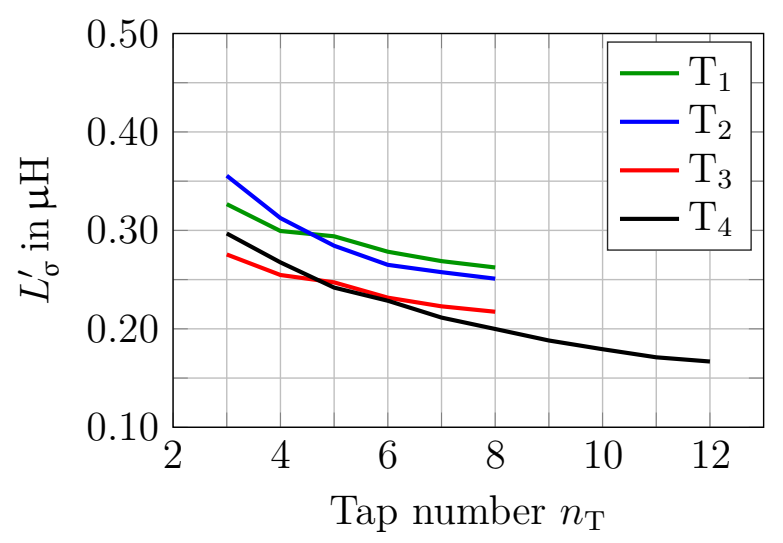

(b) Measured values

Figure 2.17: Primary side referred leakage inductances for the manufactured transformers 


\section{Accuracy of the symmetric transformer model}

The accuracy of the symmetric transformer model clearly depends on how symmetrical the transformer is and how much the leakage inductances are equal to each other. Here, not only do the lengths of the external connections matter but also the variations of the linked flux, as well as the variations due to the different positioning of the conductors in the transformer windings. The formulas $2.22 \mathrm{a}$ and $2.22 \mathrm{~b}$ are accurate for high values of $m$ and $n$, with the decrease of $m$ and $n$, the variability of the inductances of the external conductors and even small variation of the linked flux leading to a high error in the estimation of the total leakage inductance. This is apparent in figure 2.17, where it is noted that for low values of $n$, and in particular for $n=3$, the deviation between the theoretical value and the measured value is about $30 \%$. This error decreases rapidly, and for $n=5$, it reduces to around $10 \%$. It should be kept in mind that we are talking about inductance values of around $200 \mathrm{nH}$ to $300 \mathrm{nH}$. These are very small values, and it is therefore very easy to have measurement errors greater than $50 \mathrm{nH}$ with the common measurement equipment. For higher values of $m$ and, in particular, $n$, it is possible to carry out measurements on the secondary and, therefore, to obtain larger amounts of inductance on which, conversely, there are smaller measurement errors. The value of $(M-L)$ is preferable to calculate it from measurements on the secondary windings for high values of $m$ and $n$. 


\section{Dual Active Bridge}

To implement a galvanically isolated DC-DC converter with wide voltage range several topologies have been considered. In particular, resonant topologies like the series resonant converter (SRC), the parallel resonant converter (PRC) and the LLC resonant converter (LLC), which allows a relatively large voltage range beyond the resonant converter when compared to the first two, were examined.

As will be explained in more detail in chapter 4, the transformer is provided with taps and at these taps high voltage $\mathrm{H}$-bridge is connected by means of a tap changer. Which tap is connected to the H-bridge depends on the high voltage level. When the tap changer changes the connection from a tap to another tap, the leakage inductance, which the transformer passes on the remaining part of the topology, also changes. In resonant topologies having many taps means having many resonant frequencies at which the converter has to be tuned, as at each resonant frequency the converter has to work properly and with high efficiency. If it is supposed to operate at a constant frequency, other reactive components have to be added, removed or varied to maintain this consistency. Although characterized by high efficiency, these solutions are set aside in favor of a topology which is also galvanically isolated and which does not have tuning problem, though even this topology is sensitive to variations of the leakage inductance, the dual active bridge.

\section{Dual Active Bridge}

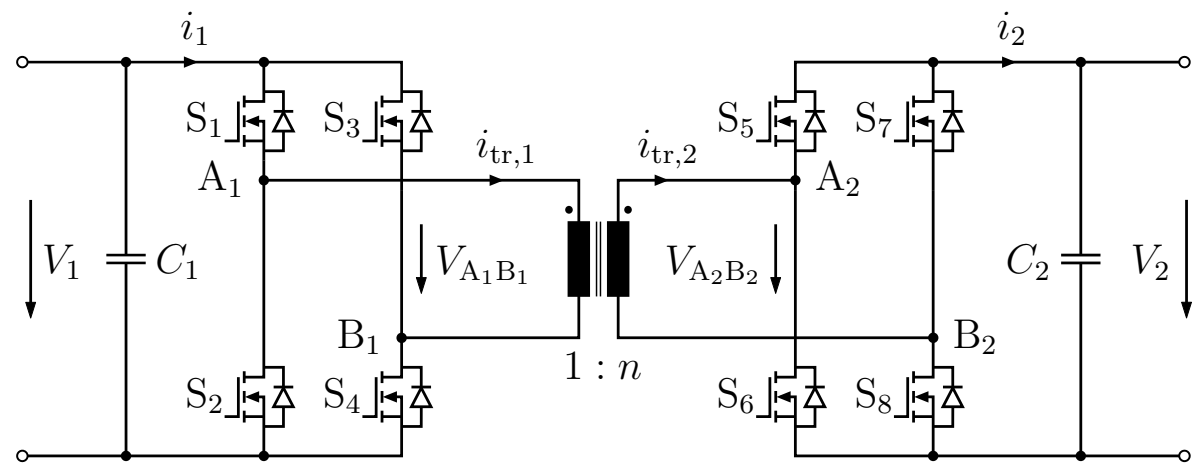

Figure 3.1: Dual active bridge

The dual active bridge (DAB) consists mainly of two H-bridges with one transformer in between, as depicted in 3.1. Each switch $\mathrm{S}_{1}$ to $\mathrm{S}_{8}$ is constituted by a power electronic switch like MOSFET or IGBT, and by a diode $[5,6]$. The transformer is a fundamental component of the $\mathrm{DAB}$, as it allows energy transfer from one side to the other of the two magnetically coupled circuits, and, with its characteristics, shapes the properties of the converter.

In particular, the leakage inductance of the transformer determines power transfer capability and gives the DAB the characteristics of a voltage-driven current source, which allows it to work even in boost mode. This current source behavior leads to an important feature of the DAB because by itself, it is not able to set a voltage like a normal boost or buck 
converter, which, by setting voltage at one end of the converter, allows the voltage at the other end to be principally set by the duty cycle. For the analysis of the DAB, it is useful to consider a simplified model of the converter. In this model, the transformer is replaced with its leakage inductance. The model is depicted in figure 3.2.

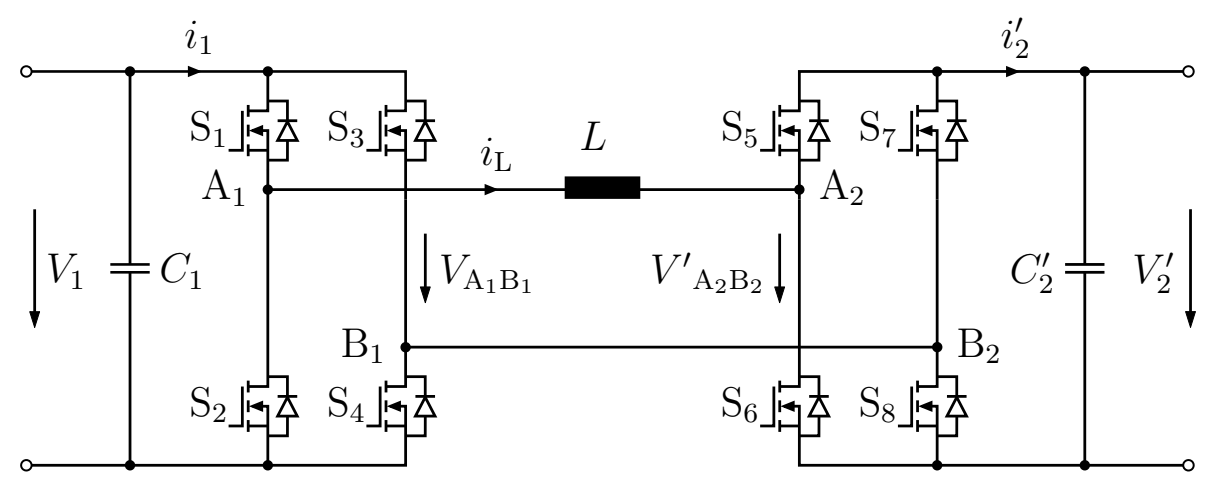

Figure 3.2: Simplified L-model of the DAB

\section{Modulation strategies for the dual active bridge}

There are several modulation strategies which can be applied to the DAB. The most utilized, which will be described in details below, are phase shift (PS) modulation [5, 6], triangular modulation (TRI) and trapezoidal modulation (TRAP) $[9,19,31]$. Beyond these three modulation types, additional improved modulation strategies for a dual active bridge are described in $[9,16,17,19,27,29]$.

\subsection{Phase Shift Modulation}

In phase shift modulation (PS), the two H-bridges in the DAB are driven to produce two rectangular waveforms each with an amplitude corresponding to the DC voltage at the back end and front ends of the converter. These rectangular waveforms are shifted by the phase shift angle $\phi$. Parameter $d$ is defined in equation 3.1 and defines the primary-referred DC voltage gain of the converter. In figure 3.3 a phase shift modulation with $\phi=60^{\circ}$ and $d=1$ is depicted with the two rectangular waveforms with amplitude $V_{1}$ and $V_{2}^{\prime} . V^{\prime}{ }_{2}$ is the primary-referred voltage $V_{2}, i_{\mathrm{L}}$ is the transformer current referred to the primary, $i_{1}$ and $i_{2}$ are the DC side currents, and the magnetization current is neglected.

$$
d=\frac{V_{2}^{\prime}}{V_{1}}
$$

In the same figure, the transferred power from the primary to the secondary of the transformer is represented with $p_{1}$. It can be observed that there is a greater time interval in which power flows in the positive direction, and a smaller time interval in which power flows in the negative direction. This is a reactive power, which flows through the converter without an external contribution to the power transfer of the converter. The ratio between the reactive power and the net power transfer increases with the phase shift $\phi$ and causes additional conduction losses in the transformer as well as switching and conduction losses in the semiconductors. In figure 3.4 the same waveforms as those found in the previous 

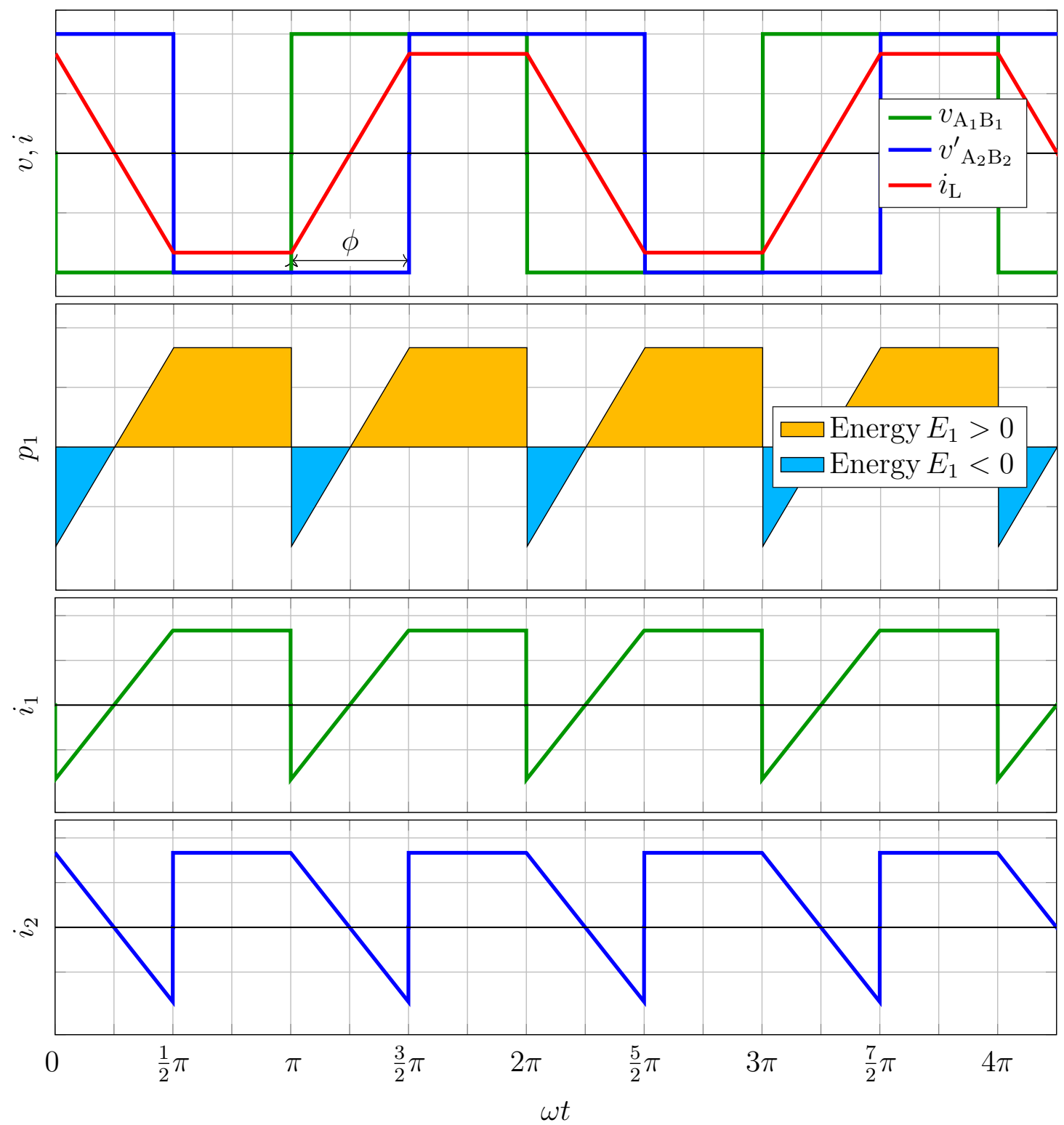

Figure 3.3: Phase shift $d=1, \phi=60^{\circ}$

picture are reported with a phase shift $\phi=45^{\circ}$ and $d>1$. In this case it can be observed that the reactive power is slightly reduced compared to that of the previous case.

\subsubsection{Zero Voltage Switching}

The DAB is a soft switching topology in which the turn-on commutation of the switches can be operated under zero voltage switching (ZVS) conditions. Zero voltage switching means that the switches can be turned on under zero voltage, i.e. with a voltage across the switches equal to the voltage drop across the antiparallel diode of the switch, when this diode is conducting negative current $i_{\mathrm{L}}$. Considering figure 3.5, to have ZVS, it is necessary that current $i_{\mathrm{L}}$ in interval $\mathbf{b}$ and interval $\mathbf{d}$ does not change direction; otherwise, instead of soft turn-on, the switches will turn-on under hard switching condition. To illustrate zero 

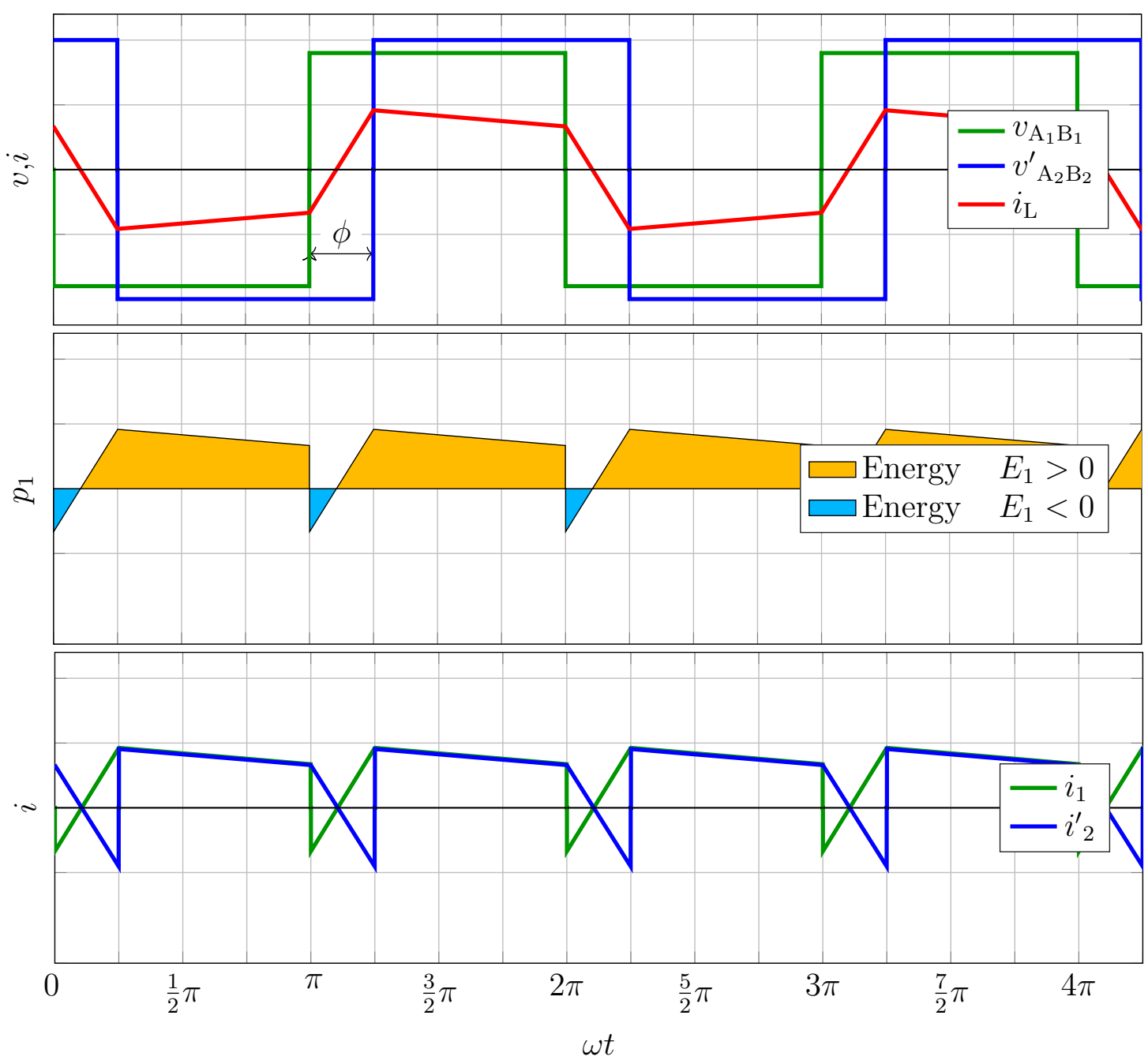

Figure 3.4: Phase shift $\phi=45^{\circ}, d>1$

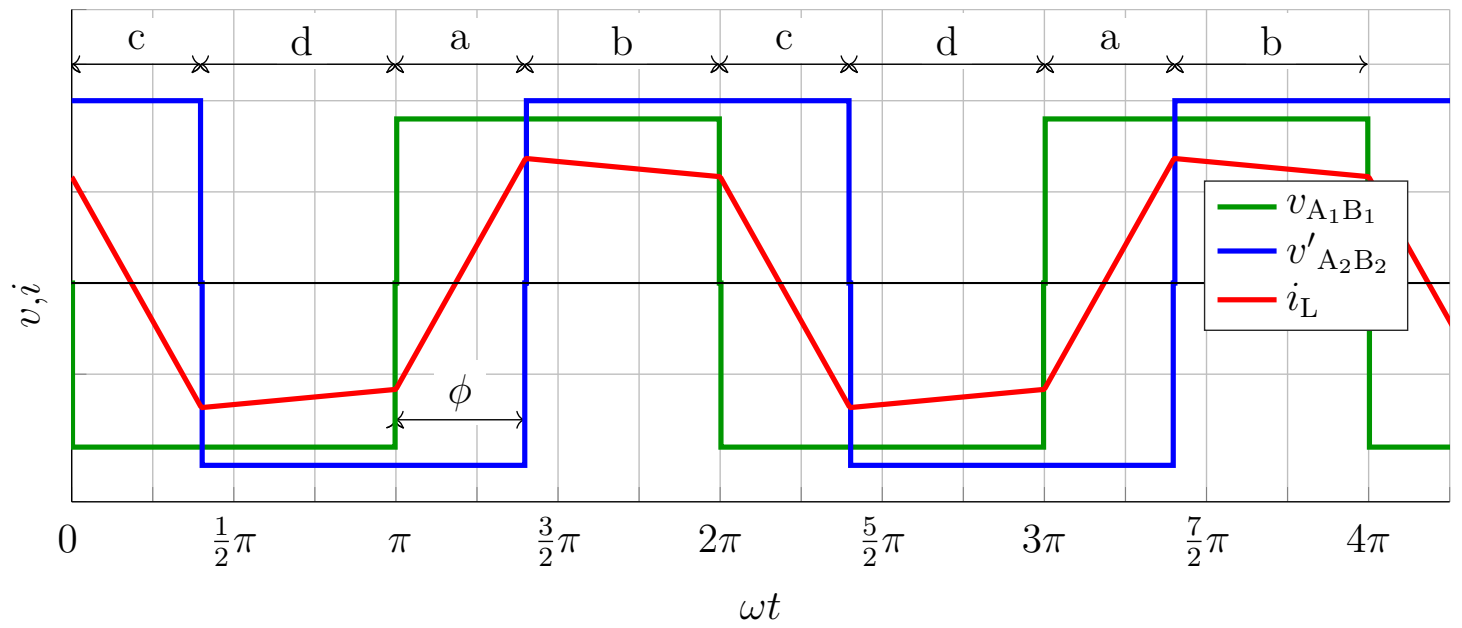

Figure 3.5: Soft turn-on switching in phase shift modulation 
voltage switching, consider the time interval $\mathbf{d}$. In this interval, the switch is conducting in $\mathrm{S}_{2}$ and $\mathrm{S}_{3}$ and the diode in $\mathrm{S}_{6}$ and $\mathrm{S}_{7}$. At the end of $\mathbf{d}$, the switch in $\mathrm{S}_{2}$ and $\mathrm{S}_{3}$ are turned off. The current $i_{\mathrm{L}}$ is negative, the switches in $\mathrm{S}_{1}$ and $\mathrm{S}_{4}$ are still open, and the negative current at this point charges the output capacitance of the MOSFETs in $\mathrm{S}_{2}$ and $\mathrm{S}_{3}$ and discharge the capacitance in $\mathrm{S}_{1}$ and $\mathrm{S}_{4}$ (the output capacitances of the MOSFETs are not depicted). When the voltage across the switches $\mathrm{S}_{2}$ and $\mathrm{S}_{3}$ reaches the voltage $V_{1}$ and the voltage across the switches $\mathrm{S}_{1}$ and $\mathrm{S}_{4}$ reaches zero, the diodes turn on and begin to conduct the negative current $i_{\mathrm{L}}$. At this point, across the switches in $\mathrm{S}_{1}$ and $\mathrm{S}_{4}$, only the forward voltage drop of the diodes is applied. The switches in $\mathrm{S}_{1}$ and $\mathrm{S}_{4}$ can then be turned on under zero voltage condition. It should be noted that to have ZVS, the current at the end of $\mathbf{d}$ has to be negative, and big enough to charge and discharge the output capacitance of the switches. The smaller the output capacitances of the devices are, the smaller the negative current $i_{\mathrm{L}}$ needed to charge the capacitances can be.

In the ideal case in which the switches do not have output capacitances, the limit for the ZVS is obtained for $i_{\mathrm{L}}=0$. This condition can be used to determinate the ideal ZVS areas as shown below. In [15], the manner in which devices with higher output capacitances reduce the ZVS area and how the magnetization current of the transformer extends the ZVS area is analyzed. It should be noted that the capacitors used as turn-off snubbers reduce the ZVS area, and, increasing the magnetization current, for example by increasing the air gap in the transformer, increases the ZVS area. In table 3.1, the switch state in the phase shift modulation are reported.

\begin{tabular}{c|cccc|cccc|cc} 
& 1 & 2 & 3 & 4 & 5 & 6 & 7 & 8 & $v_{\mathrm{A}_{1} \mathrm{~B}_{1}}$ & $v_{\mathrm{A}_{2} \mathrm{~B}_{2}}^{\prime}$ \\
\hline $\mathrm{a}$ & 1 & 0 & 0 & 1 & 0 & 1 & 1 & 0 & $+V_{1}$ & $-V_{2}^{\prime}$ \\
$\mathrm{b}$ & 1 & 0 & 0 & 1 & 1 & 0 & 0 & 1 & $+V_{1}$ & $+V_{2}^{\prime}$ \\
$\mathrm{c}$ & 0 & 1 & 1 & 0 & 1 & 0 & 0 & 1 & $-V_{1}$ & $+V_{2}^{\prime}$ \\
$\mathrm{d}$ & 0 & 1 & 1 & 0 & 0 & 1 & 1 & 0 & $-V_{1}$ & $-V_{2}^{\prime}$ \\
\hline
\end{tabular}

Table 3.1: Switch state in the phase shift mode

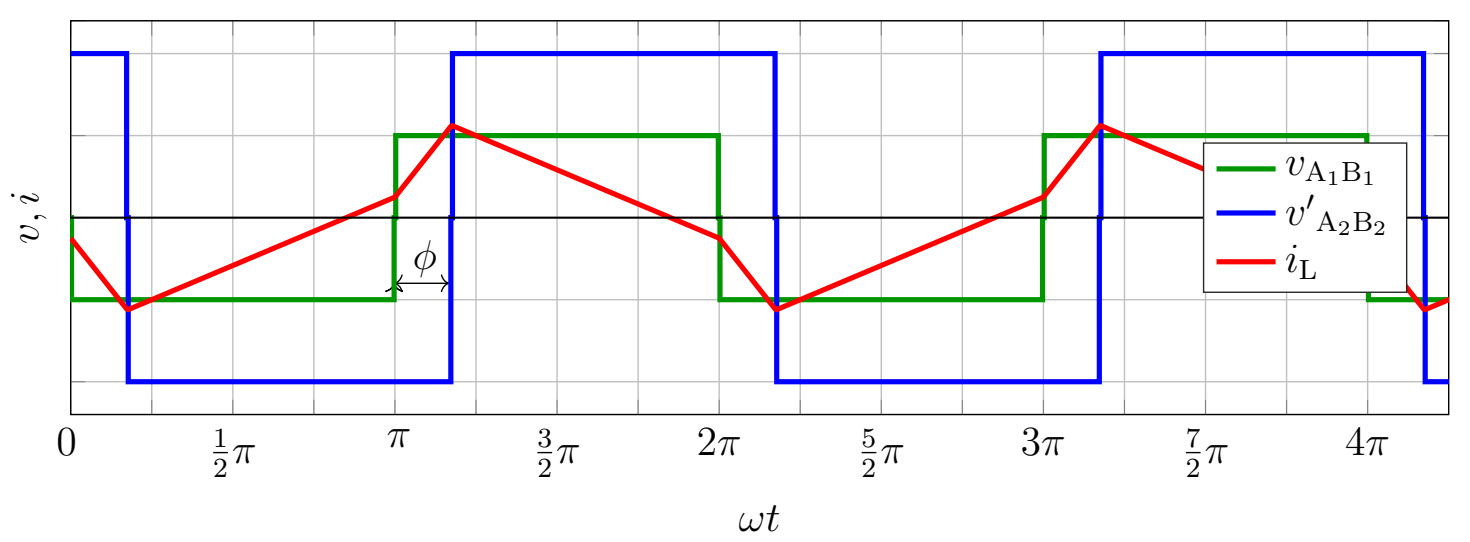

Figure 3.6: Hard turn-on switching in phase shift modulation

In figure 3.6 a case showing hard turn-off is presented. This is the typical case for small 
values of $\phi$ and for $d$ values that differ substantially from one.

\section{Zero voltage switching limit for phase shift modulation}

As introduced before, $i_{\mathrm{L}}=0$ can be used to write 3.2 and 3.2 to obtain the limit of the ZVS area given in equations 3.3 and 3.5 .

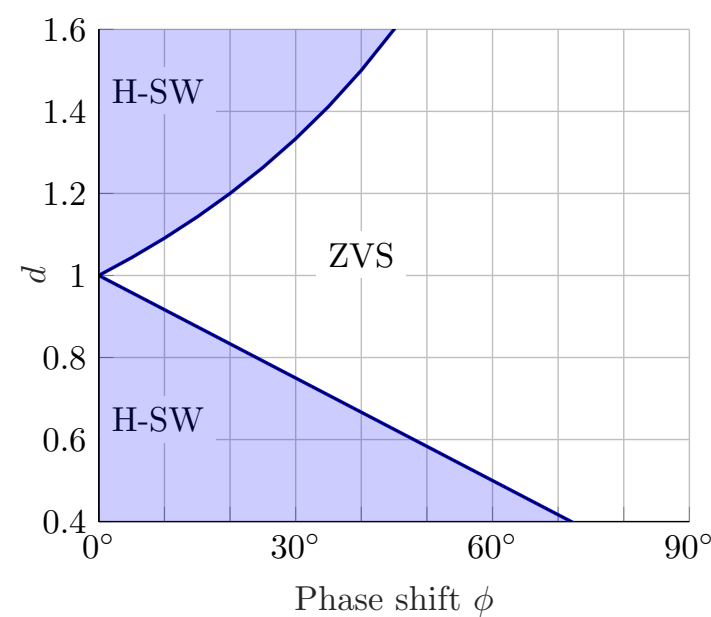

(a) ZVS for phase shift modulation

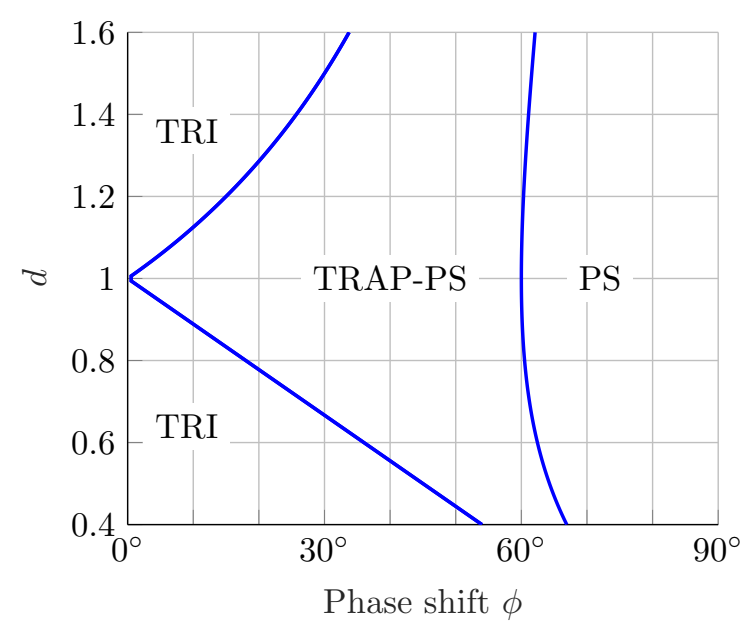

(b) TRI, TRAP and PS areas

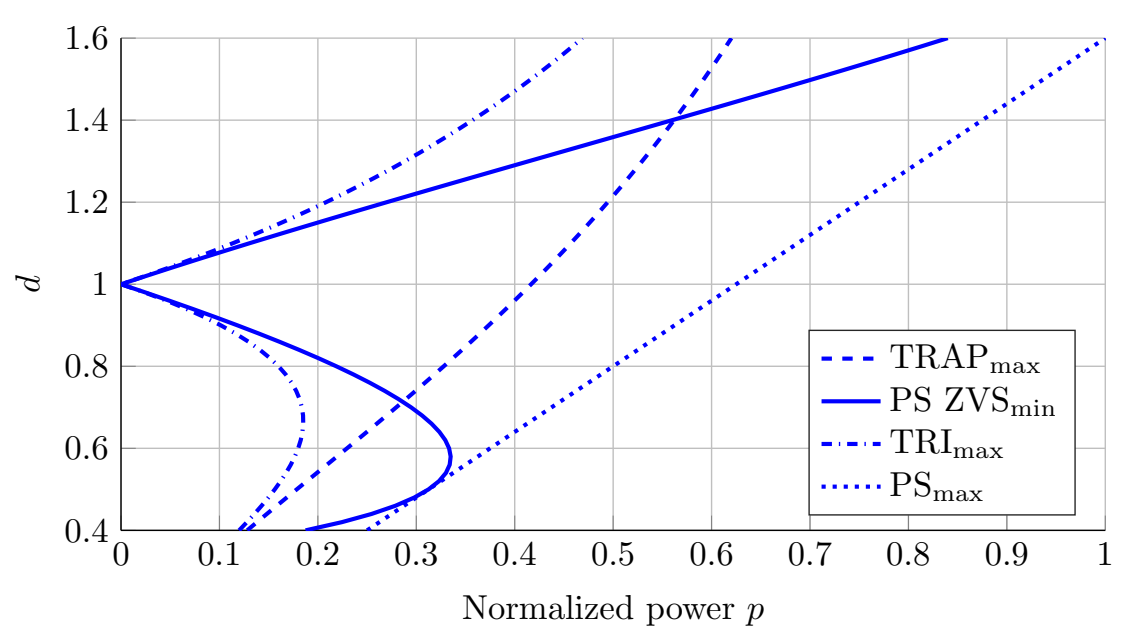

(c) Power limits for the TRI, TRAP and PS modulations

Figure 3.7: Power limits for the modulation strategies

- For $V_{1}<V_{2}^{\prime}$ :

$$
\left(V_{1}+V_{2}^{\prime}\right) \phi=\left(V_{2}^{\prime}-V_{1}\right)(\pi-\phi)
$$




$$
\begin{array}{r}
\phi=\frac{\pi}{2}\left(1-\frac{1}{d}\right) \\
d=\frac{1}{1-\frac{2 \phi}{\pi}}
\end{array}
$$

- For $V_{1} \geq V_{2}^{\prime}$ :

$$
\begin{gathered}
\left(V_{1}+V_{2}^{\prime}\right) \phi=\left(V_{1}-V_{2}^{\prime}\right)(\pi-\phi) \\
\phi=\frac{\pi}{2}(1-d) \\
d=1-\frac{2 \phi}{\pi}
\end{gathered}
$$

\section{Power in phase shift modulations}

With simple geometric considerations of the afore mentioned figures, the formula that gives power as a function of phase shift $\phi$ and DC voltages can be derived. The formula can also be found in $[6]$.

$$
P_{\mathrm{ps}}=\frac{V_{1} V_{2}^{\prime}}{\omega L} \phi\left(1-\frac{\phi}{\pi}\right)
$$

In figure 3.7a the limits of zero voltage switching are depicted for the ideal case in which the output capacitances of the MOSFETs and the magnetization current of the transformer can be neglected. If compared to the other modulation strategies presented below, the phase shift modulation allows for high power transfer, and the output current does not depend on the output voltage. Even at zero voltage at the output, a current will flow. The limit of PS modulation is that at low phase shift angle $\phi$ and for $d$ values that differ from one, the converter produces high commutation losses and high circulating currents. The best performance for PS modulation is for voltage ranges with a variation for $d$ below $20 \%$. The power transfer capability of PS modulation is shown in figure 3.7, in which the curve $\mathrm{PS}_{\max }$ shows the maximum transfer capability of the PS modulation. PS modulation of the dual active bridge is extensively documented in the literature $[8,15,17,31]$.

\subsection{Trapezoidal Current Modulation}

Trapezoidal current modulation (TRAP) is an efficient modulation strategy for the dual active bridge. Typical voltages and current waveforms are depicted in figure 3.8. The most important characteristic of TRAP modulation is the presence in each half modulation period of a time interval in which the current is zero, i.e. the current blanking time, here 
represented by the blanking angle $\psi_{\text {blk }}$. This blanking time allows zero current switching in which switches are turned on under zero current conditions. Compared to PS modulation, TRAP modulation considerably reduces commutation losses and can be used even if voltage ratio $d$ considerably differs from one. TRAP cannot be utilized if one of the two voltages is zero, but in this case, an alternative modulation strategy can be used in which the H-bridge at the zero voltage side is deactivated and instead works as a rectifier, and the other H-bridge will be modulated with short pulses so that the current is held within the allowed limit [31]. In table 3.2, the state of the switch in trapezoidal mode is reported. The minimum and maximum phase shift angle $\phi$ with which TRAP modulation can be used is shown in figure $3.7 \mathrm{~b}$, and the power limit in figure $3.7 \mathrm{c}$.

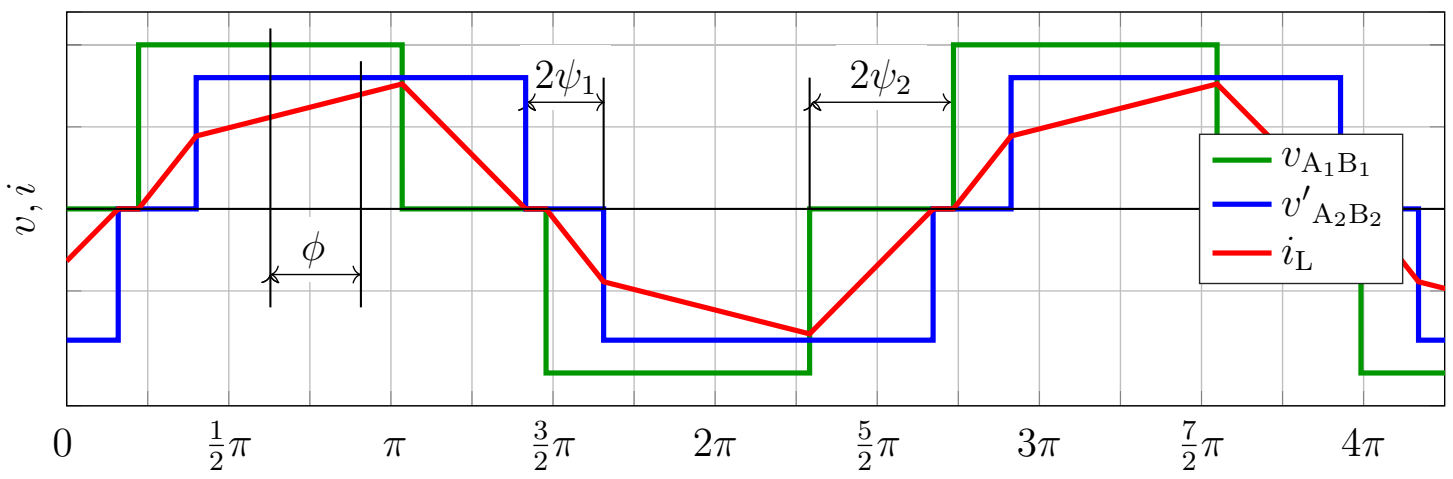

Figure 3.8: Trapezoidal current modulation

\begin{tabular}{c|cccc|cccc|cc} 
& 1 & 2 & 3 & 4 & 5 & 6 & 7 & 8 & $v_{\mathrm{A}_{1} \mathrm{~B}_{1}}$ & $v_{\mathrm{A}_{2} \mathrm{~B}_{2}}^{\prime}$ \\
\hline $\mathrm{a}$ & 1 & 0 & 0 & 1 & 0 & 1 & 0 & 1 & $+V_{1}$ & 0 \\
$\mathrm{~b}$ & 1 & 0 & 0 & 1 & 1 & 0 & 0 & 1 & $+V_{1}$ & $+V_{2}^{\prime}$ \\
$\mathrm{c}$ & 1 & 0 & 1 & 0 & 1 & 0 & 0 & 1 & 0 & $+V_{2}^{\prime}$ \\
$\mathrm{d}$ & 1 & 0 & 1 & 0 & 1 & 0 & 1 & 0 & 0 & 0 \\
$\mathrm{e}$ & 0 & 1 & 1 & 0 & 1 & 0 & 1 & 0 & $-V_{1}$ & 0 \\
$\mathrm{f}$ & 0 & 1 & 1 & 0 & 0 & 1 & 1 & 0 & $-V_{1}$ & $-V_{2}^{\prime}$ \\
$\mathrm{g}$ & 0 & 1 & 0 & 1 & 0 & 1 & 1 & 0 & 0 & $-V_{2}^{\prime}$ \\
$\mathrm{h}$ & 0 & 1 & 0 & 1 & 0 & 1 & 0 & 1 & 0 & 0 \\
\hline
\end{tabular}

Table 3.2: Switch state in trapezoidal mode

Below, the most relevant equations of TRAP modulation are given: the TRAP modulation is only possible between certain phase shift angles. The minimum phase shift angle is given by equations 3.8 or 3.11 , depending on the voltages, and the maximum is given by equation 3.7 .

$$
\phi_{\max }= \pm \frac{\pi-\psi_{\mathrm{blk}}}{2}\left(\frac{V_{1}^{2}+V_{2}^{\prime 2}}{V_{1}^{2}+V_{1} V_{2}^{\prime}+V_{2}^{\prime 2}}\right)
$$

$V_{1}>V_{2}^{\prime}$

$$
\phi_{\min }= \pm \frac{\pi-\psi_{\mathrm{blk}}}{2}\left(1-\frac{V_{2}^{\prime}}{V_{1}}\right)
$$




$$
\begin{gathered}
\psi_{2}=\frac{\pi\left(V_{2}^{\prime}-V_{1}\right)+2 V_{1}\left(\phi+\psi_{\mathrm{blk}}\right)}{2\left(V_{1}+V_{2}^{\prime}\right)} \\
\psi_{1}=|\phi|-\psi_{2}+\psi_{\mathrm{blk}}
\end{gathered}
$$

$V_{1} \leq V_{2}^{\prime}$

$$
\begin{gathered}
\phi_{\min }= \pm \frac{\pi-\psi_{\mathrm{blk}}}{2}\left(1-\frac{V_{1}}{V_{2}^{\prime}}\right) \\
\psi_{1}=\frac{\pi\left(V_{1}-V_{2}^{\prime}\right)+2 V_{2}^{\prime}\left(|\phi|+\psi_{\mathrm{blk}}\right)}{2\left(V_{1}+V_{2}^{\prime}\right)} \\
\psi_{2}=|\phi|-\psi_{1}+\psi_{\mathrm{blk}}
\end{gathered}
$$

The transferred power in TRAP modulation is a function of phase shift $\phi$, DC voltages, and blank angle $\psi_{\text {blk }}$, and is calculated by equation 3.14 , with the power limit calculated by equation 3.15 .

$$
\begin{gathered}
P_{\text {trap }}=\operatorname{sgn}(\phi) \frac{V_{2}^{\prime}\left(\pi-|\phi|-\psi_{1}-\psi_{2}\right)\left[V_{2}^{\prime}\left(|\phi|+\psi_{1}-\psi_{2}\right)+V_{1}\left(|\phi|-\psi_{1}+\psi_{2}\right)\right]}{4 L \pi^{2} f}+ \\
+\operatorname{sgn}(\phi) \frac{V_{2}^{\prime 2}\left(|\phi|+\psi_{1}-\psi_{2}\right)^{2}}{4 L \pi^{2} f} \\
P_{\text {trap } \text { max }}=\frac{\left(\pi-\psi_{\text {blk }}\right)^{2} V_{1}^{2} V_{2}^{\prime 2}}{4 f L\left(V_{1}^{2}+V_{1} V_{2}^{\prime}+V_{2}^{\prime 2}\right)}
\end{gathered}
$$

The two turn off currents can be calculated analytically by the formulas 3.16 and 3.17.

$$
\begin{aligned}
& I_{\text {trap }, \text { max }, 1}=\frac{V_{2}^{\prime}\left(|\phi|-\psi_{2}+\psi_{1}\right)}{2 \pi f L} \\
& I_{\text {trap }, \max , 2}=\frac{V_{1}\left(|\phi|-\psi_{1}+\psi_{2}\right)}{2 \pi f L}
\end{aligned}
$$

By choosing a proper zero state, each switch can be turned on and off only once in a period. In Table 3.3 the turn-on angles of the switches are reported. In this way, the trapezoidal modulation can also be reduced to a phase shift modulation but as a phase shift between switches instead of between H-bridges.

Sw. Turn-on angle $\mid$ Sw. Turn-on angle $\mid$ Sw. Turn-on angle $\mid$ Sw. Turn-on angle

\begin{tabular}{cc|cc|cc|cc}
\hline 1 & $\psi_{1}$ & 2 & $\pi+\psi_{1}$ & 3 & $\pi-\psi_{1}$ & 4 & $-\psi_{1}$ \\
5 & $\phi+\psi_{2}$ & 6 & $\pi+\phi+\psi_{2}$ & 7 & $\pi+\phi-\psi_{2}$ & 8 & $\phi-\psi_{2}$ \\
\hline
\end{tabular}

Table 3.3: Switch turn-on angle for trapezoidal modulation 


\subsection{Triangular Current Modulation}

Triangular current modulation (TRI) is a particular case of trapezoidal modulation in which the time interval of state $\mathbf{c}$ and $\mathbf{g}$ are reduced to zero. Like TRAP modulation, TRI modulation also has a high efficiency and low commutation losses, and it allows for operating at low phase shift angle $\phi$ up to zero, even with a value of $d$ that differs significantly from one. The waveforms of TRI modulations are depicted in 3.9. The phase shift angle limit $\phi$ and the power limit of TRI modulation are reported in figure 3.7. The switch states are reported in table 3.4. As for the other two modulation strategies, as for TRI modulation, by choosing a proper zero state, the switches can be turned on and off only once in a period. The turn-on angle for such modulations with TRI modulation are the same as for the trapezoidal mode reported in table3.3.

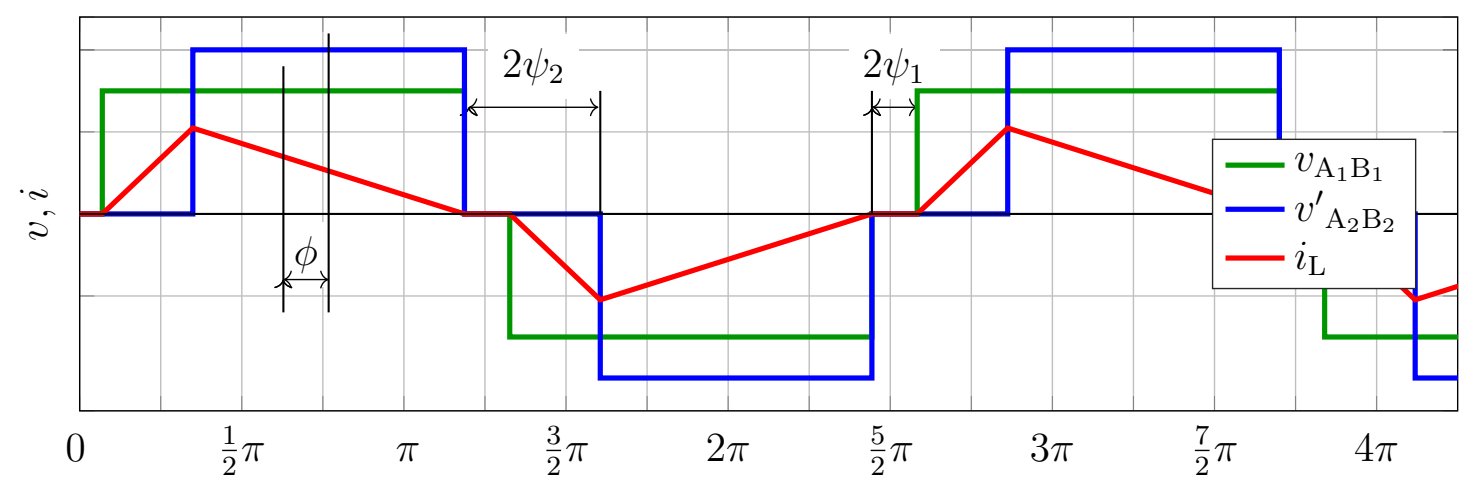

Figure 3.9: Triangular current modulation

\begin{tabular}{c|cccc|cccc|cc} 
& 1 & 2 & 3 & 4 & 5 & 6 & 7 & 8 & $v_{\mathrm{A}_{1} \mathrm{~B}_{1}}$ & $v_{\mathrm{A}_{2} \mathrm{~B}_{2}}$ \\
\hline $\mathrm{a}$ & 1 & 0 & 0 & 1 & 1 & 0 & 1 & 0 & $+V_{1}$ & 0 \\
$\mathrm{~b}$ & 1 & 0 & 0 & 1 & 1 & 0 & 0 & 1 & $+V_{1}$ & $+V_{2}^{\prime}$ \\
$\mathrm{d}$ & 1 & 0 & 1 & 0 & 0 & 1 & 0 & 1 & 0 & 0 \\
$\mathrm{e}$ & 0 & 1 & 1 & 0 & 0 & 1 & 0 & 1 & $-V_{1}$ & 0 \\
$\mathrm{f}$ & 0 & 1 & 1 & 0 & 0 & 1 & 1 & 0 & $-V_{1}$ & $-V_{2}^{\prime}$ \\
$\mathrm{h}$ & 0 & 1 & 0 & 1 & 1 & 0 & 1 & 0 & 0 & 0 \\
\hline
\end{tabular}

Table 3.4: Switch state in triangular mode

The minimum phase shift angle and the minimum power transfer in triangular modulation are both zero, with $\phi_{\text {tri,min }}=0$ and $P_{\text {tri,min }}=0$. For maximum power transfer, two cases must be distinguished between:

$V_{1}>V_{2}^{\prime}$

$$
\begin{gathered}
\phi_{\mathrm{tri}, \max }= \pm \frac{\pi-\psi_{\mathrm{blk}}}{2}\left(1-\frac{V_{2}^{\prime}}{V_{1}}\right) \\
\psi_{2}=\frac{\pi}{2}+\frac{|\phi| V_{1}}{V_{2}^{\prime}-V_{1}}
\end{gathered}
$$




$$
\begin{gathered}
\psi_{1}=|\phi|+\psi_{2} \\
P_{\text {tri }}=\frac{V_{1} V_{2}^{\prime} \phi\left(\pi-2 \psi_{1}\right)}{2 \pi^{2} L f}
\end{gathered}
$$

The maximum transferred power is given by 3.22 :

$$
P_{\text {tri,max }}=\frac{V_{2}^{\prime 2}\left(\pi-\psi_{\mathrm{blk}}\right)^{2}\left(V_{1}-V_{2}^{\prime}\right)}{4 \pi^{2} L f V_{1}}
$$

$V_{1} \leq V_{2}$

$$
\begin{gathered}
\phi_{\text {tri,max }}= \pm \frac{\pi-\psi_{\mathrm{blk}}}{2}\left(1-\frac{V_{1}}{V_{2}^{\prime}}\right) \\
\psi_{1}=\frac{\pi}{2}-\frac{|\phi| V_{2}^{\prime}}{V_{2}^{\prime}-V_{1}} \\
\psi_{2}=|\phi|+\psi_{1} \\
P_{\mathrm{tri}}=\frac{V_{1} V_{2}^{\prime} \phi\left(\pi-2 \psi_{2}\right)}{2 \pi^{2} L f}
\end{gathered}
$$

The maximum transferred power is given by the equation 3.27 :

$$
P_{\text {tri,max }}=\frac{V_{1}^{2}\left(\pi-\psi_{\mathrm{blk}}\right)^{2}\left(V_{2}^{\prime}-V_{1}\right)}{4 \pi^{2} L f V_{2}^{\prime}}
$$

The peak current in the transformer can be calculated analytically by 3.28 :

$$
I_{\text {tri,max }}=\frac{V_{1}|\phi|}{\pi f L}
$$

\section{Conclusion}

In the dual active bridge, with the three modulation strategies presented above, soft switching can be obtained over a wide voltage range and power range. These three modulations strategies are complementary, since when one strategy produces overly large losses or are out of range, another strategy is able to operate with high efficiency and complementary power transfer capability so that in a relatively large $d$ ratio, $0.6<d<1$. , with $d$ defined in equation 3.1, it becomes possible to transfer power from zero to the maximum power transfer allowed by phase shift modulation without power gaps. In the next chapter, is shown what can be done if a wider voltage range is necessary. The limits of the three modulation strategies are provided in figure 3.7. 


\section{Dual Active Bridge with Tap Changer}

The dual active bridge with tap changer (DAB-TC), is an extended version of the dual active bridge. The extension is obtained by means of a transformer with additional connections, here called taps, which allow access at a discrete turn ratio of the transformer. The resulting topology is depicted in figure 4.1. In the literature, this topology can be found in $[34,36$, 38]. The transformer has been described in chapter 2, and it has eight windings in parallel at the primary side and up to eight windings at the secondary side in the $8+8$ version. Beyond this version, a prototype with $12+12$ windings has also been implemented. Each pair of primary windings, or group of three in the $12+12$ configuration, has been connected to one of the four low voltage H-bridges. The windings at the secondary side are connected in series and, at the end of each winding or group of windings, a tap is introduced to allow a connection between this group of windings and the high-voltage H-bridge.

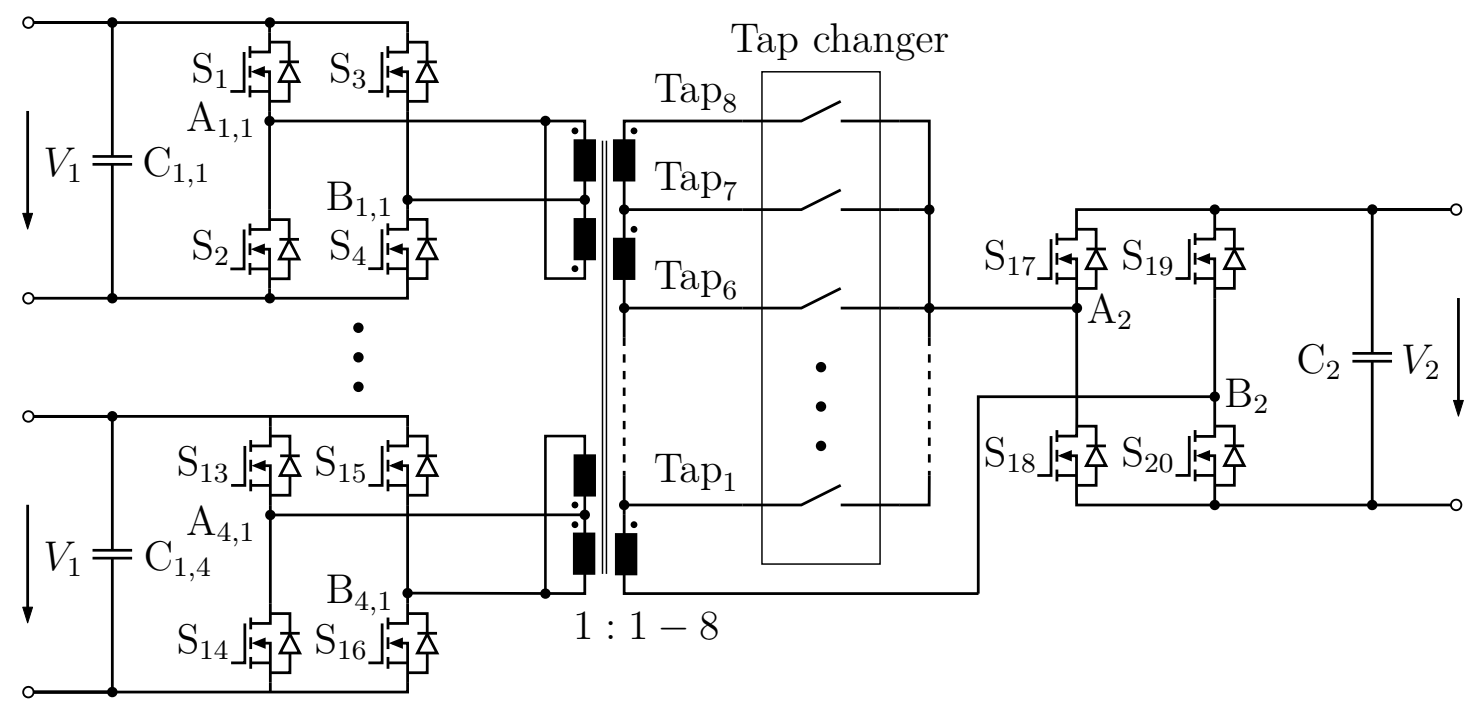

Figure 4.1: Dual active bridge with tap changer

Theoretically, the $8+8$ transformer can be provided for by eight taps, but due to the voltage range with which the DAB can operate, fewer taps are necessary. In this project, three taps are used for the transformer with $8+8$ windings and four taps for the transformer with $12+12$ windings. The transformer, by means of the taps, has a variable turns ratio. In this project, the taps are named with numbers corresponding to is the turn ratio of the taps and, specially, tap $n$ means a turn ratio $\frac{N_{2}}{N_{1}}=n_{\mathrm{T}}=n$. The taps are connected to the high-voltage H-bridge by means of a tap changer. In the tap changer, different device types can be used as switches depending on the efficiency and dynamic specifications. In figure 4.2 , tap changers with different switch types are depicted. 


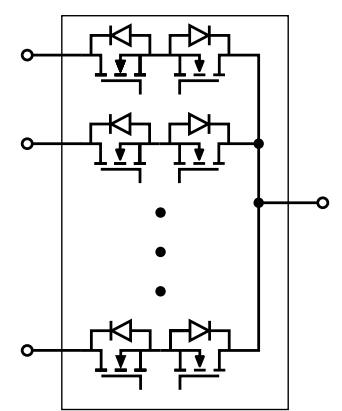

(a) MOSFET

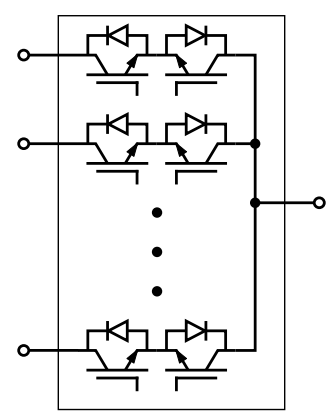

(b) IGBT

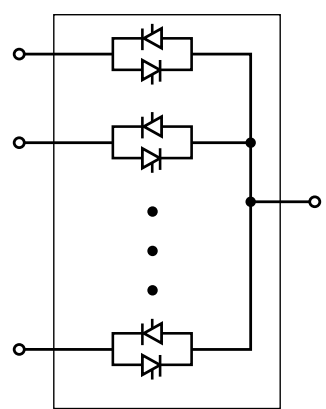

(c) Thyristor

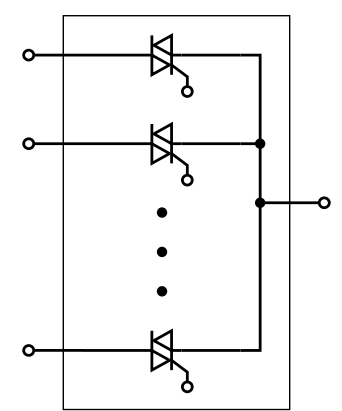

(d) Triac

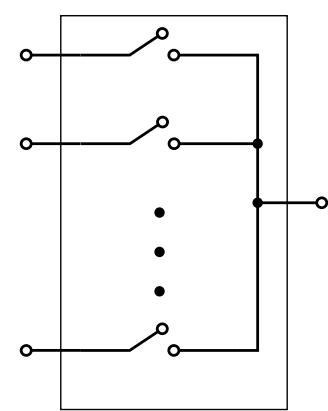

(e) Relay

Figure 4.2: Tap changer structure with different devices

\subsection{Characteristics of the Dual Active Bridge with Tap Changer}

The use of a tap changer in the DAB brings many advantages, as will be explained in this section and examined by means of simulations in the next chapter. In the case of phase shift modulation, the use of the taps increases the ZVS area considerably. In figure 4.3a, a transformer without taps is depicted, and figures $4.3 \mathrm{~b}$ and $4.3 \mathrm{c}$ depict transformers with three taps and all possible taps, respectively. As can be observed, the ZVS area increases considerably by increasing the number of the taps of the tap changer.

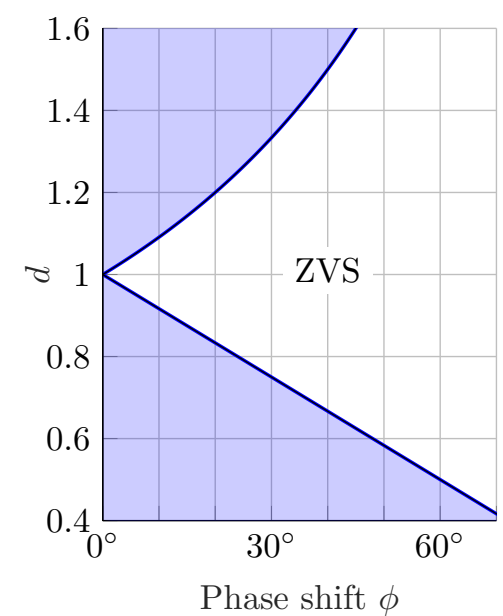

(a) Tap 5

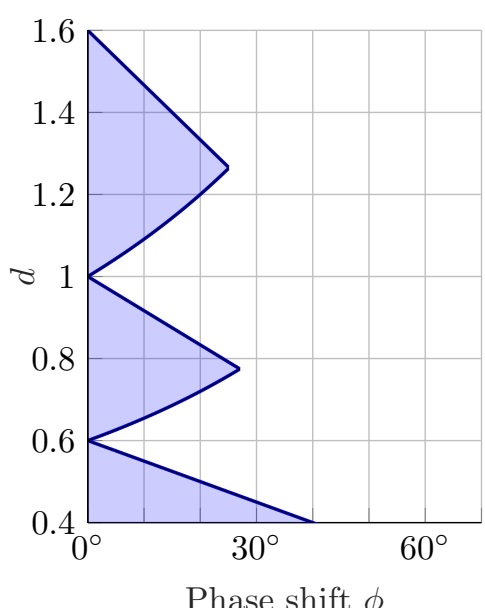

(b) Taps $3,5,8$

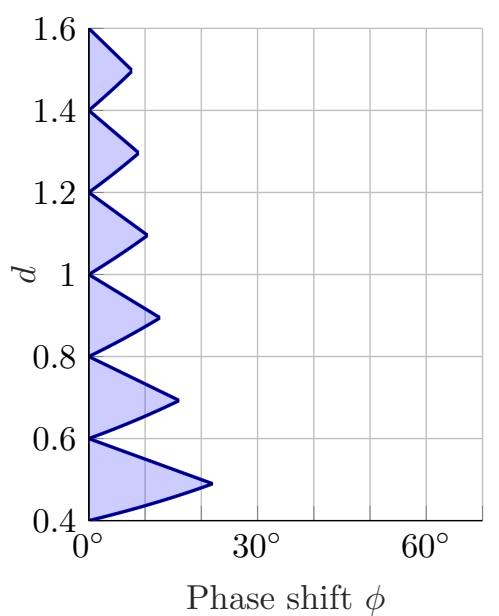

(c) Taps $2-8$

Figure 4.3: Zero voltage switching limits for phase shift modulation

Now the effect of the tap changer on the afore mentioned modulation strategies will be considered. The data for leakage inductance for different taps are calculated with equations 2.22. The value of $(L-M)=1.02 \mu \mathrm{H}$ has been obtained by means of measurement on transformer $\mathrm{T}_{2}$ using the tap $n_{\mathrm{T}}=8$. Transformer $\mathrm{T}_{2}$ has eight windings in parallel at the low-voltage side and up to eight windings in series at the high-voltage side. From this transformer taps with $n_{\mathrm{T}}=3, n_{\mathrm{T}}=5$ and $n_{\mathrm{T}}=8$ were taken. As will be explained below, 
it will be useful to examine a further tap with $n_{\mathrm{T}}=12$. For Tap ${ }_{12}$, to obtain a plausible value of leakage inductance that can be used to calculate the limits of different modulation strategies in figure 4.3, equation 2.22 has been used to obtain a homogeneous and plausible value with the others. In figure $4.4 \mathrm{a}$ the power limits of the three modulation strategies with $V_{1}=30 \mathrm{~V}$ are depicted. For Tap 3 , the bottom edge is located at $50 \mathrm{~V}$ and the upper edge is the point at which the ZVS limit crosses the trapezoidal limit. For Tap 5 , the bottom edge and the upper edge correspond to the bottom cross and upper cross of the ZVS limit with the trapezoidal limit. The same criteria have been chosen for the bottom edge of Tap . $\mathrm{Tap}_{8}$, in the absence of $\mathrm{Tap}_{12}$, has to cover a point with $V_{2}$ even higher than the cross point between the ZVS limit and the TRAP max limit and between the ZVS limit and the TRAP limit, as that is the point at which the converter will work in hard-switching mode. To avoid this problem, a further tap with $n_{\mathrm{T}}=12$ will be useful. Synthesizing, with $V_{1}=30 \mathrm{~V}$, even with the three modulation strategies combined, there are points with a transferred power of about $5 \mathrm{~kW}$ and near the upper border with $V_{2}=400 \mathrm{~V}$ that will turn-on in hard-switching mode. To avoid this situation, the transferred power limit can be reduced or a transformer with a further tap of $n_{\mathrm{T}}=12$ can be implemented. The power limits for this additional $\operatorname{Tap}_{12}$ are also depicted. In figure $4.4 \mathrm{~b}$, it can be observed that the three modulation strategies are enough to cover the entire area only at a point that operates in soft-switching mode. Even if the upper border is at $V_{2}=450 \mathrm{~V}$, $\operatorname{Tap}_{12}$ is not needed anymore. A similar problem is found at the bottom corner, at $V_{2}=100 \mathrm{~V}$, when the low voltage is $V_{1}=50 \mathrm{~V}$ and $V_{1}=60 \mathrm{~V}$, as shown in figures $4.4 \mathrm{c}$ and $4.4 \mathrm{~d}$.

In conclusion, at extreme values for the low voltage range, there are some points at which the switches will commutate under hard-switching conditions. These regions are very small and even in hard-switching mode, they will not produce a relevant increase of losses. To eliminate these areas completely, the nominal power can be reduced or a transformer with more taps can be used. For addition of another tap with lower turns ratio, in theory, it is not necessary to change the transformer but just add one tap. For addition of another upper tap, a different transformer is needed. 


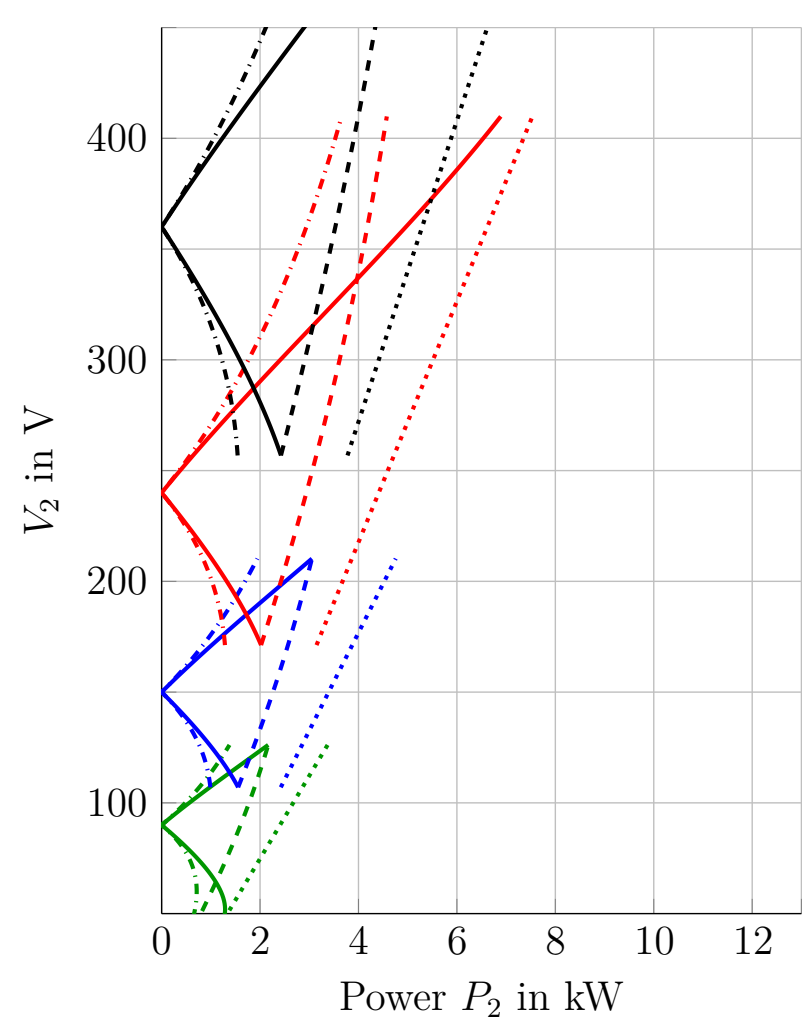

(a) $V_{1}=30 \mathrm{~V}$

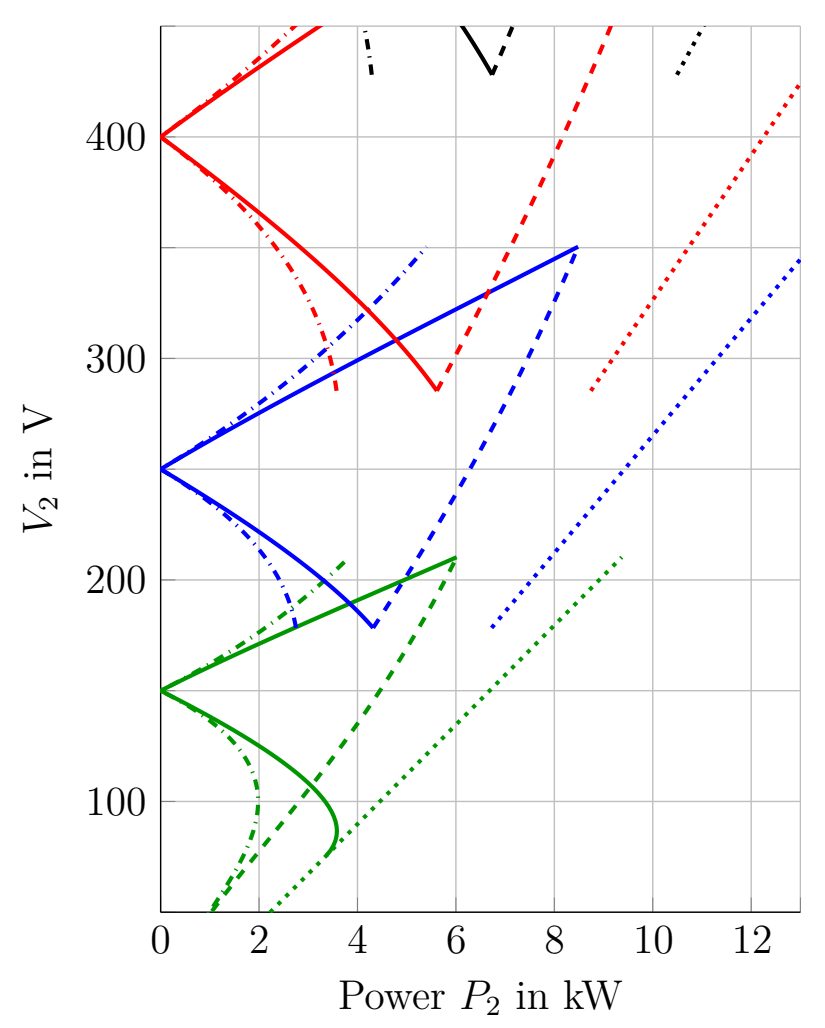

(c) $V_{1}=50 \mathrm{~V}$

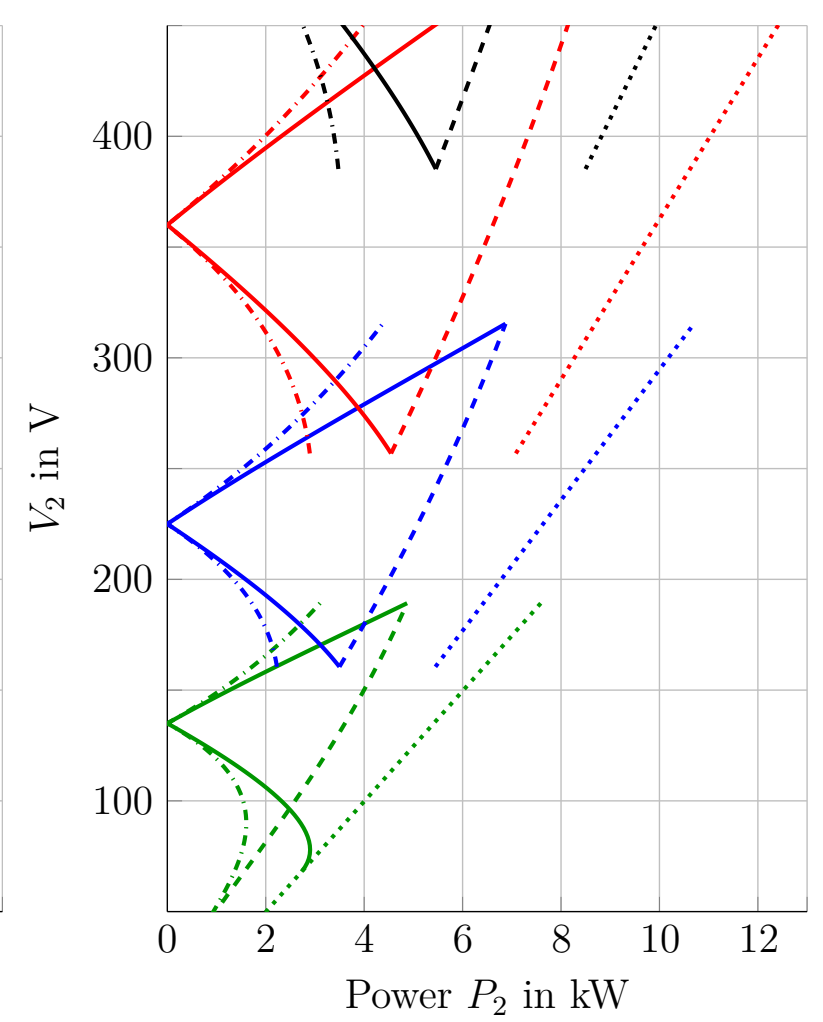

(b) $V_{1}=45 \mathrm{~V}$

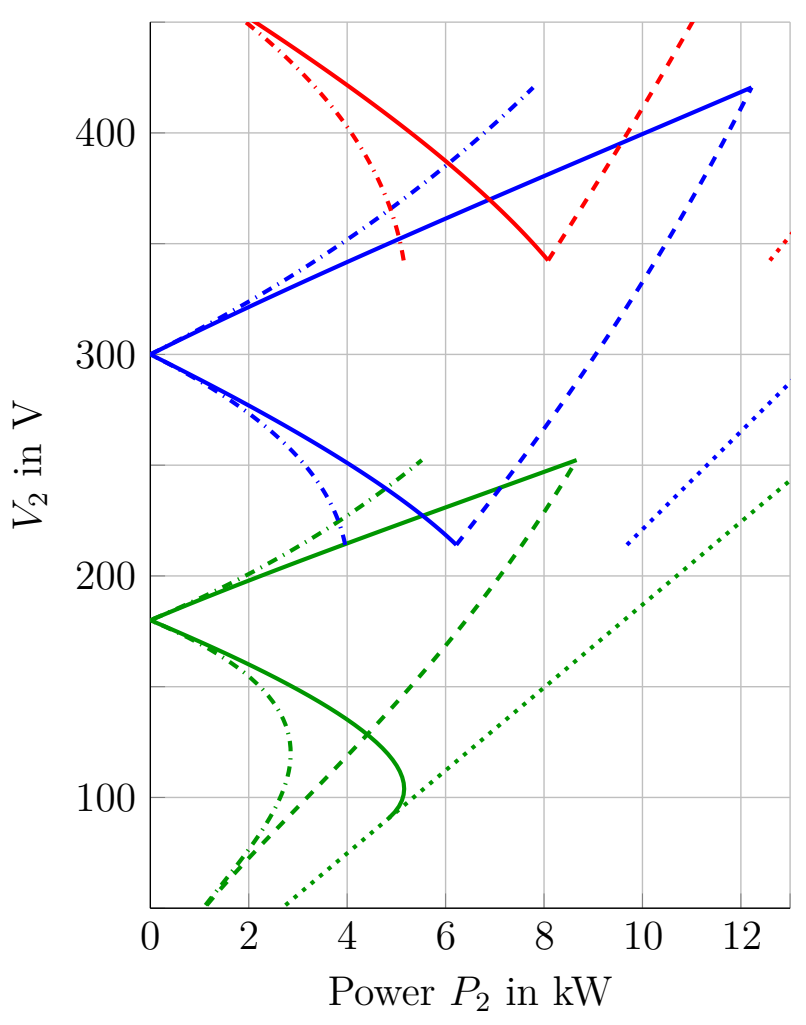

(d) $V_{1}=60 \mathrm{~V}$

$$
\begin{aligned}
& \text {-.. Tri max. — PS ZVS lim. - - Trap max. .... PS max. } \\
& \text { Tap } 3=\text { Tap } 5=\text { Tap } 8 \simeq \text { Tap } 12
\end{aligned}
$$

Figure 4.4: Power limit for the modulation strategies at different taps 


\subsection{DAB with Tap Changer Simulations}

This section explains the simulations of the semiconductor losses for the dual active bridge with tap changer. These simulations were made with the program PLECS from PLEXIM, which uses look-up tables for the electronic devices to calculate the switching losses and conduction losses of the power electronic devices. In this case, the look-up tables have been obtained from data provided by the datasheets of the semiconductors.

The devices used for the switches in the high-voltage H-bridges are silicon carbide MOSFETs type C3M0065090D from CREE [4], and for the low-voltage side H-bridges, the DirectFET IRF4469 MOSFETs from International Rectifier [13]. For the tap changer the MOSFETs IXFX120N65X2 [14] from IXYS are used.

Using these data naturally provides results without a great degree of accuracy. To make more accurate simulations, it would be necessary, for each device, to have a full characterization for different temperatures, currents, voltages, gate resistances and so on. This all goes beyond the scope of this work however.

Here it is interesting to have a relatively simple model for semiconductor losses to evaluate how the converter behaves in different working points and to estimate the use of the right tap of the transformer and the right modulation strategy at specific working points. The same can be said for accurate simulations of copper losses and iron losses, i.e. ferrite losses. The simulation losses with greater accuracy require a concerted effort in terms of characterization of material and can be done in further design iterations to evaluate different version of prototypes with different types of semiconductors, different types of ferrites, and litz wires. In the simulation model, the leakage inductance corresponding to each tap has been calculated with the formula given in 2.22 .

In the previous section 4.1 , the analytical limitations of the various taps and the various modulation strategies were presented. Here, these limitation are underscored by the simulations of semiconductor losses, as well as simulations of the currents in the semiconductors.

Simulation with phase shift modulation and $V_{1}=45 \mathrm{~V}$

In figure 4.5, semiconductor losses with $V_{1}=45 \mathrm{~V}$ and by using the phase shift modulation are depicted.

In particular, in $4.5 \mathrm{a}$ shows the case in which the tap with transformer ratio $n_{\mathrm{T}}$ is used. It can be observed that for voltage $V_{2}$ higher than $135 \mathrm{~V}$, the semiconductor losses increase rapidly in particular for low power level $P_{2}$. In figure $4.5 \mathrm{~b}$, a case using transformer ratio $n_{\mathrm{T}}=5$ is considered.

Here the region with higher efficiency is more extended than the in the previous picture, in case of single tap, the central tap is to prefer. Here the efficiency decreases rapidly for low power levels and the more voltage $V_{2}$ differs from $135 \mathrm{~V}$.

Similarly in figure 4.5c, the region with low efficiency is in the lower voltage level of $V_{2}$. Figure $4.5 \mathrm{~d}$, shows what can be obtained if three taps are used together, with the example are being taps with transformations ratio $n_{\mathrm{T}}=3, n_{\mathrm{T}}=5$ and $n_{\mathrm{T}}=8$. For a point with a certain value of $P_{2}$ and $V_{2}$, the tap with which the highest efficiency is obtained is chosen. For each point of this picture, the same procedure is followed. Finally, the area with high semiconductor losses is considerably reduced even by using only the phase shift modulation. The power limit in the direction of the abscissa in each picture is given by the current, specifically at low voltage $V_{2}$. 


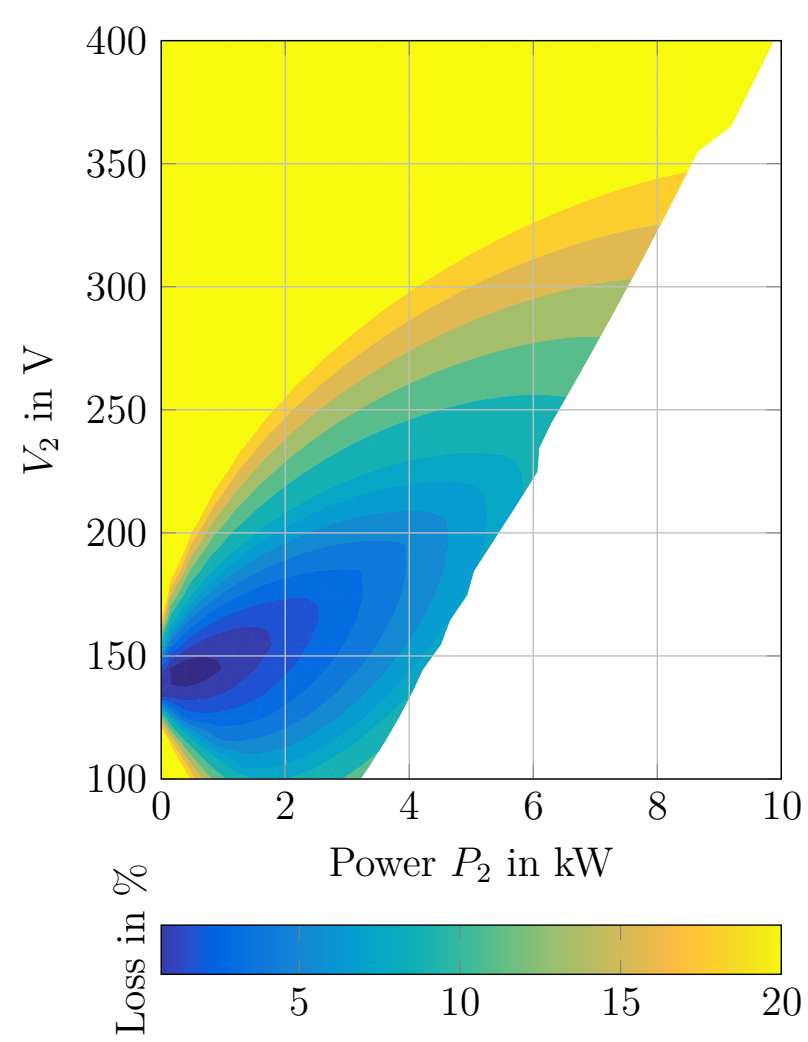

(a) $\mathrm{Tap}_{3}$
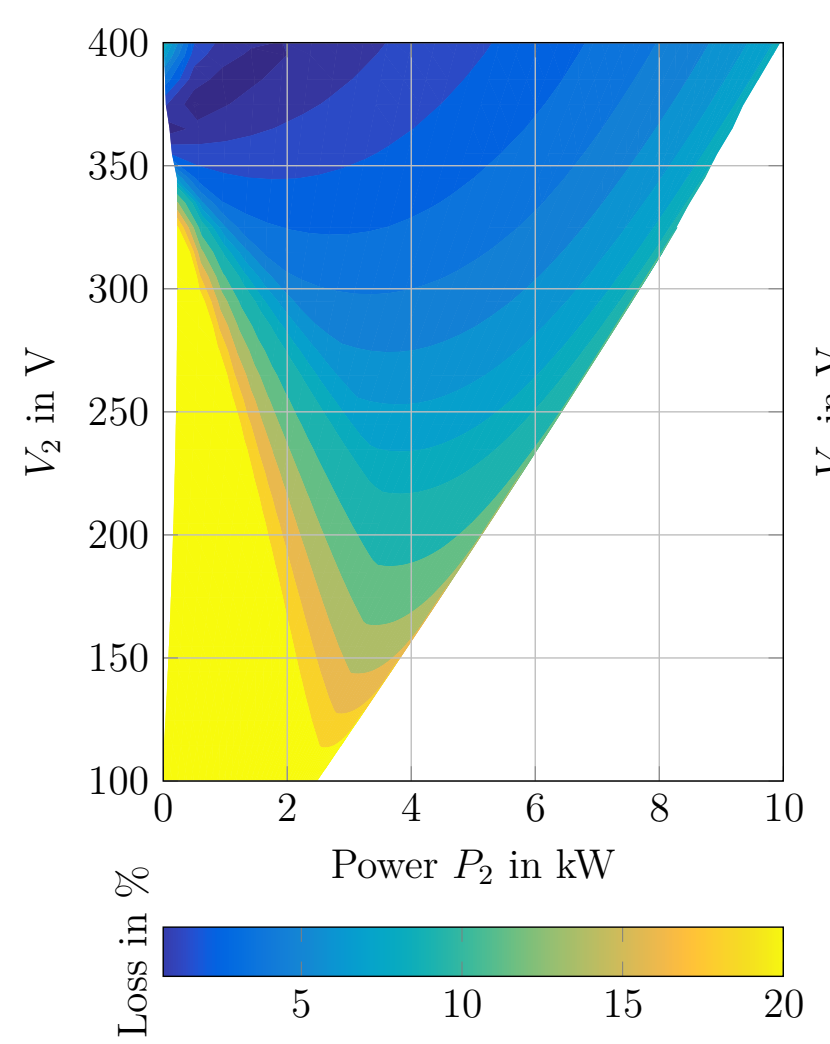

(c) $\mathrm{Tap}_{8}$

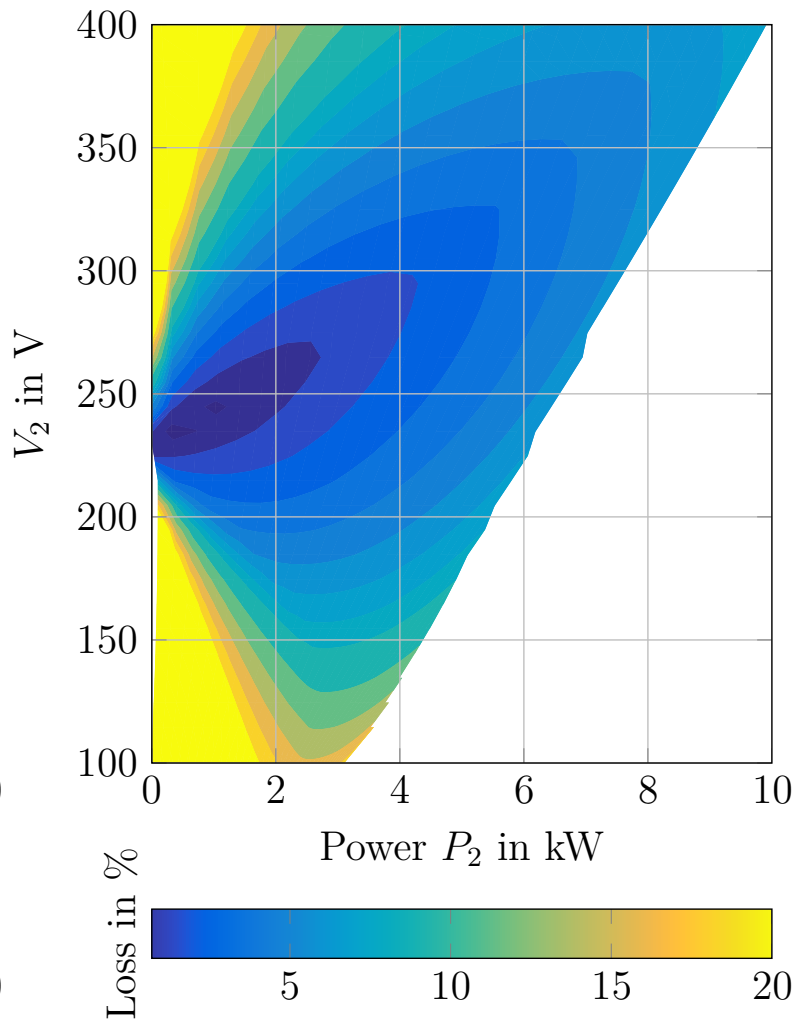

(b) $\mathrm{Tap}_{5}$

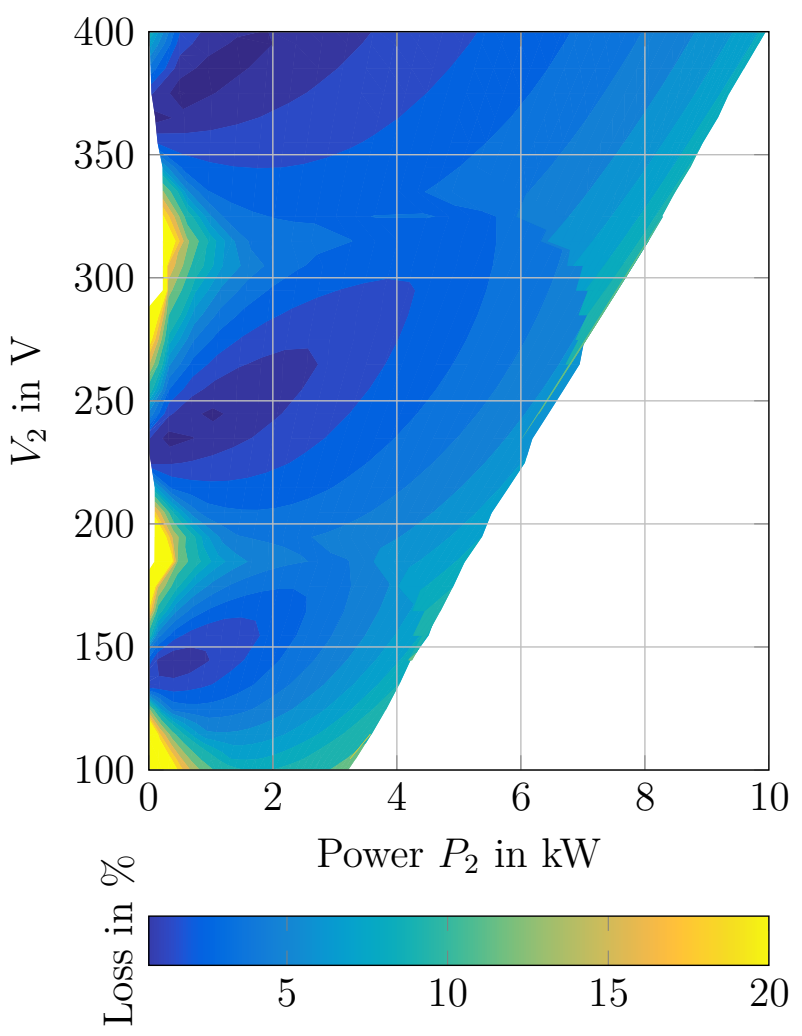

(d) $\mathrm{Tap}_{3}, \mathrm{Tap}_{5}$ and $\mathrm{Tap}_{8}$

Figure 4.5: SMC-losses with $V_{1}=45 \mathrm{~V}$ with phase shift modulation 


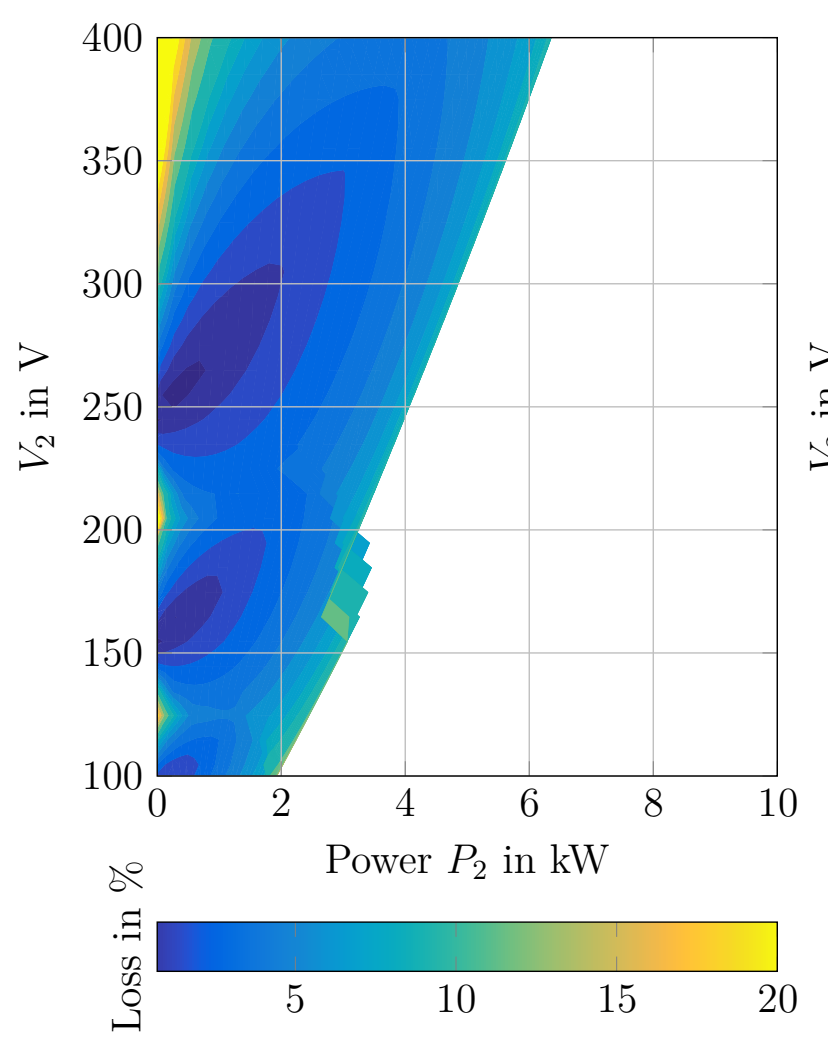

(a) $V_{1}=30 \mathrm{~V}, \mathrm{Tap}_{3}, \mathrm{Tap}_{5}$ and $\mathrm{Tap}_{8}$

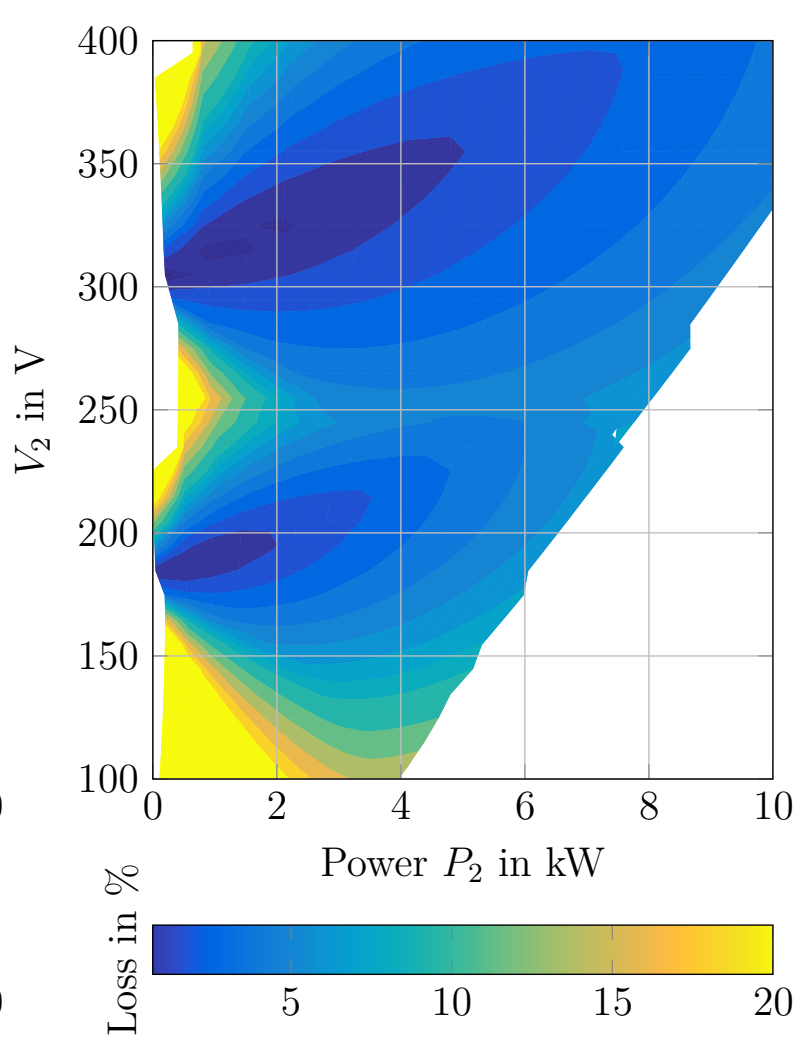

(b) $V_{1}=60 \mathrm{~V}, \mathrm{Tap}_{3}, \mathrm{Tap}_{5}$ and $\mathrm{Tap}_{8}$

Figure 4.6: SMC-losses with phase shift modulation with $V_{1}=30 \mathrm{~V}$ and with $V_{1}=60 \mathrm{~V}$

In preparing the graphs the, semiconductor losses with values higher than twenty per-cent have been saturated to twenty per cent in order to facilitate the representation and on the assumption that no one will work with devices, which have losses over twenty per-cent of the transferred power.

\section{Simulation with phase shift modulation at the range limits of the low voltage side}

The voltage range of the low voltage side goes from $V_{1, \min }=30 \mathrm{~V}$ to $V_{1, \max }=60 \mathrm{~V}$. In figure $4.6 \mathrm{a}$ and in figure $4.6 \mathrm{~b}$, semiconductor losses with $V_{1}=30 \mathrm{~V}$ and $V_{1}=60 \mathrm{~V}$ respectively are given. As before, the taps with voltage ratio $n_{\mathrm{T}}=3, n_{\mathrm{T}}=5$ and $n_{\mathrm{T}}=8$ are used, and for each point, the tap that allows for maximum efficiency has been chosen.

In the first figure, it can be observed how the plotted region has a smaller area, which is because leakage inductance limits the maximum power that can be transferred. The hard switching turn-on region nearly disappears, and more than half is covered by the tap with $n_{\mathrm{T}}=8$. The points from the tap with $n_{\mathrm{T}}=3$ practically disappear. In the second figure, much more power is transferred, and here the points from the tap with $n_{\mathrm{T}}=8$ completely disappear.

\section{Simulation with triangular modulation, trapezoidal modulation and phase shift modulation combined with $V_{1}=45 \mathrm{~V}$}

The complete removal of the turn-on losses of the switches is possible by combining the aforementioned modulations strategies. In figure $4.7 \mathrm{a}$, the triangular mode, the trapezoidal 

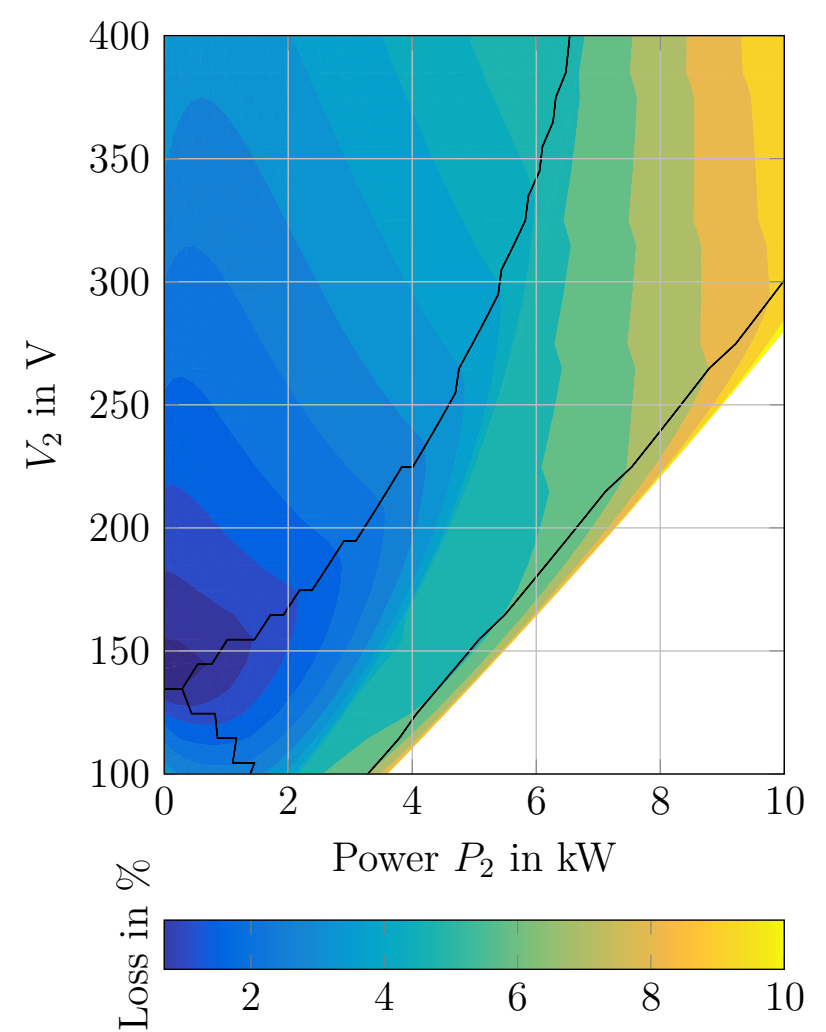

(a) $\mathrm{Tap}_{3}$
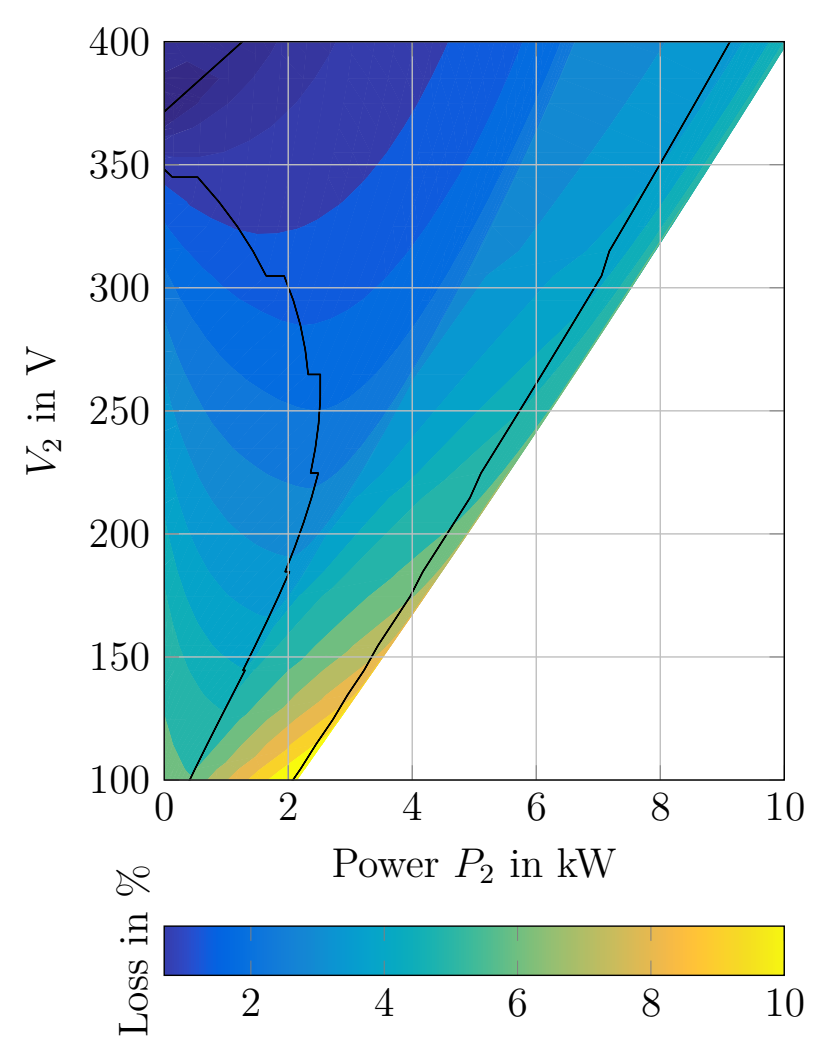

(c) $\operatorname{Tap}_{8}$
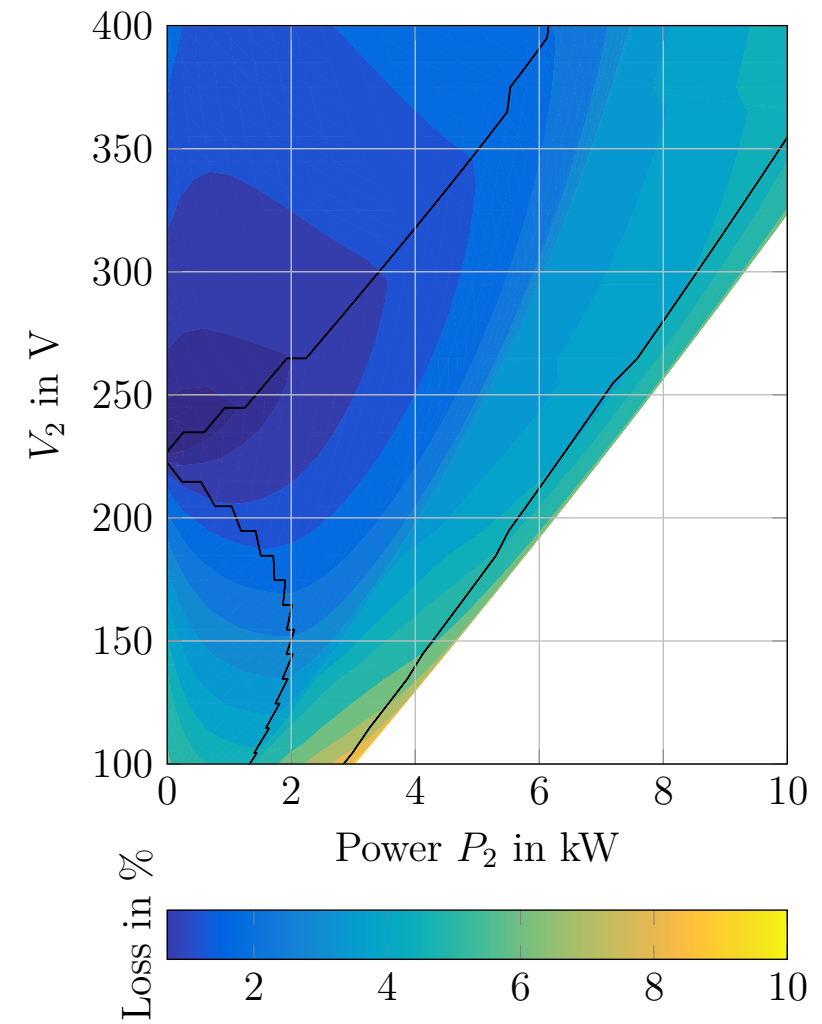

(b) $\operatorname{Tap}_{5}$
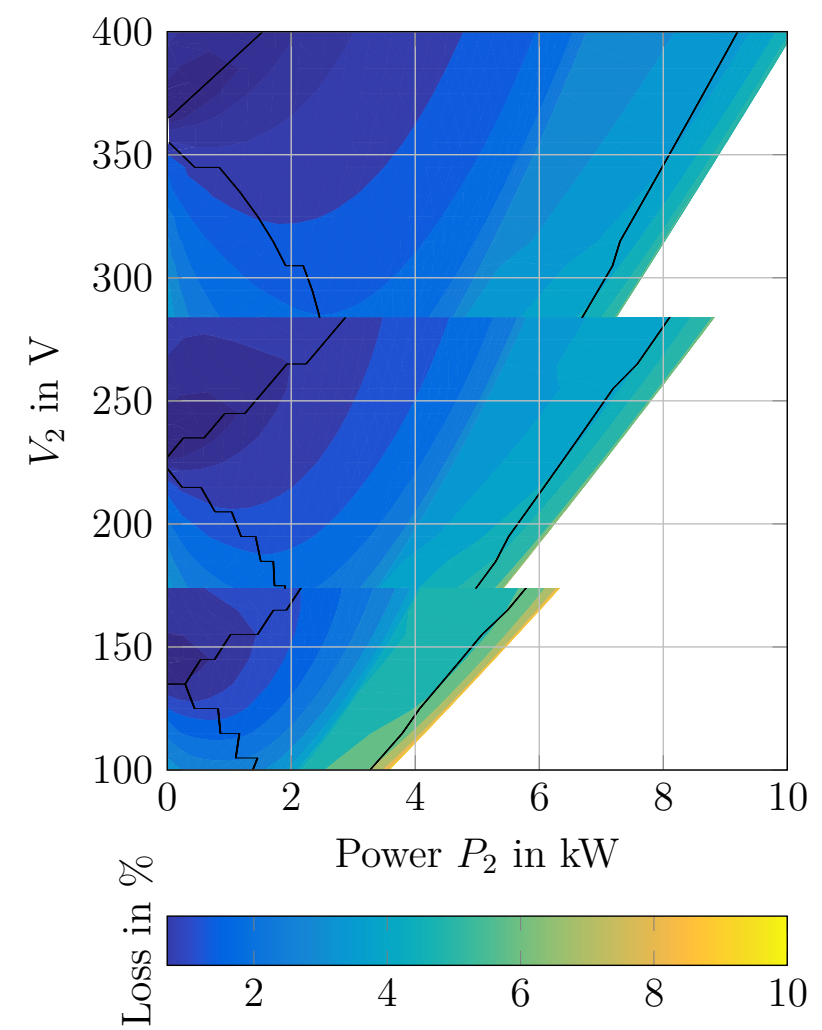

(d) $\mathrm{Tap}_{3}, \mathrm{Tap}_{5}$ and $\mathrm{Tap}_{8}$

Figure 4.7: SMC-losses with $V_{1}=45 \mathrm{~V}$ with PS, TRI and TRAP modulation strategies combined 


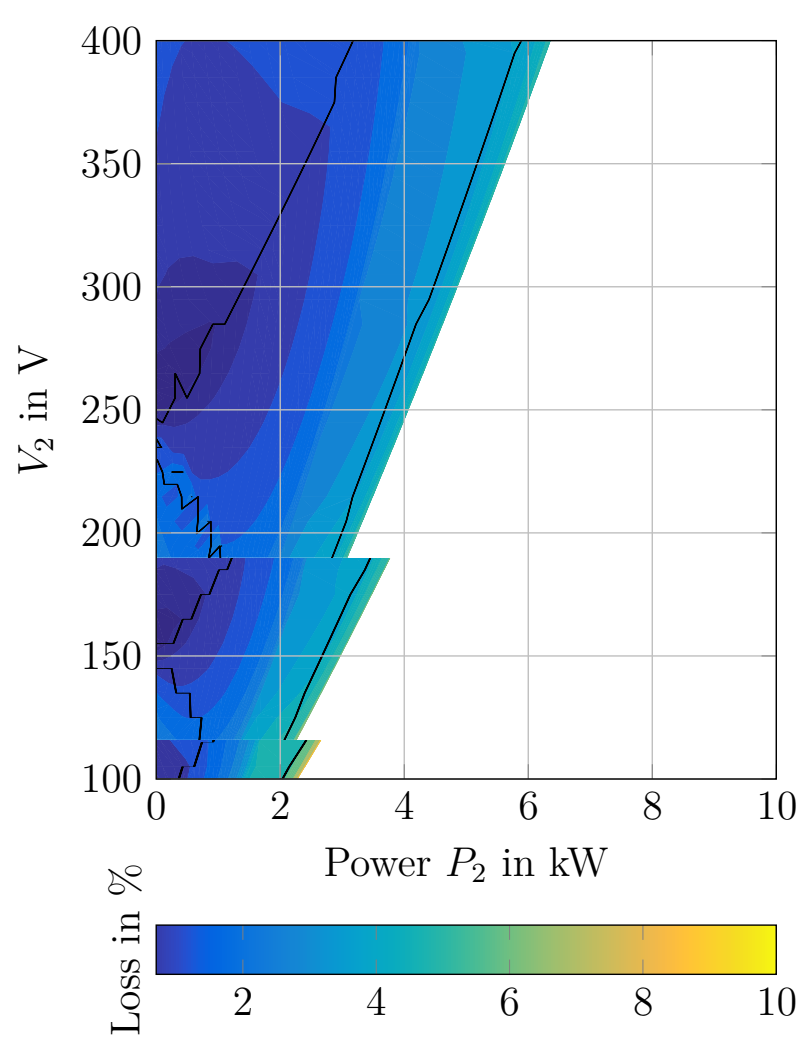

(a) $V_{1}=30 \mathrm{~V}$

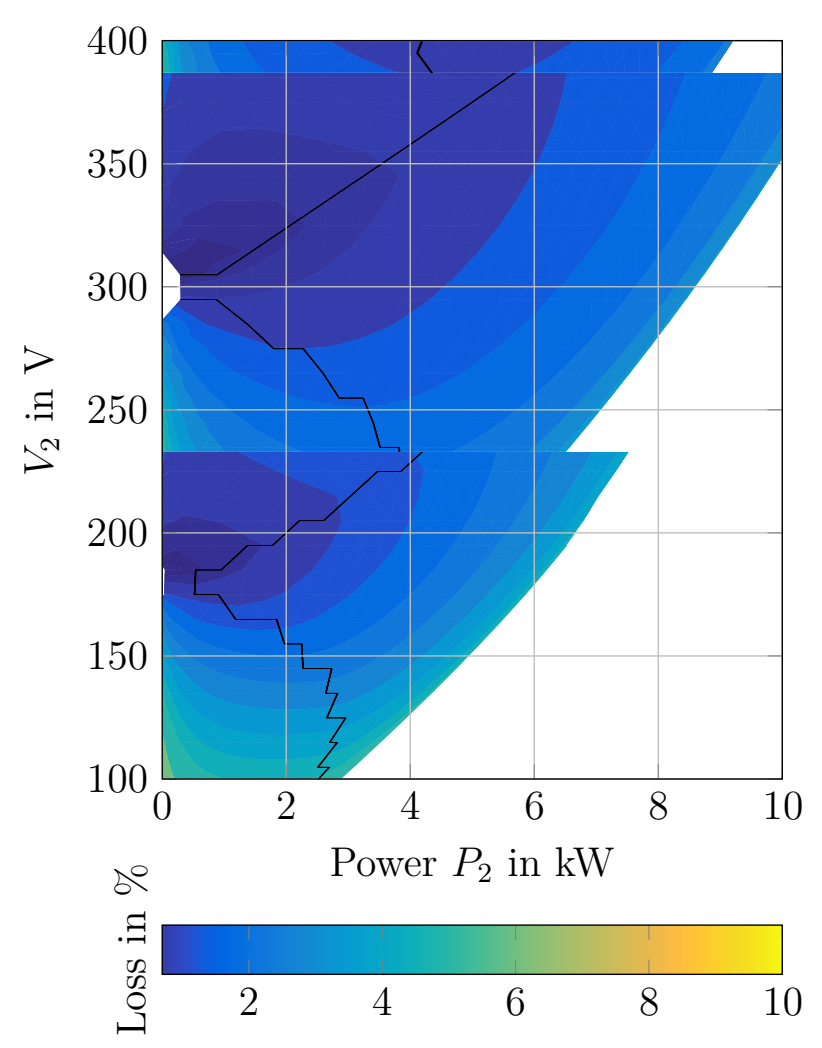

(b) $V_{1}=60 \mathrm{~V}$

Figure 4.8: SMC-losses with PS, TRI and TRAP modulation strategies combined and using $\mathrm{Tap}_{3}, \mathrm{Tap}_{5}$ and $\mathrm{Tap}_{8}$

mode and phase shift have been implemented for the tap with $n_{\mathrm{T}}=3$. Although the large variation in voltage, by combining the three modulation strategies it si possible to hold low the semiconductor losses across the whole working area. The same as the above figure has been done for taps with $n_{\mathrm{T}}=5$ and $n_{\mathrm{T}}=8$ in figure $4.7 \mathrm{~b}$ and $4.7 \mathrm{c}$.

In figure $4.7 \mathrm{~d}$, the effect of combining the taps with $n_{\mathrm{T}}=3, n_{\mathrm{T}}=5$ and $n_{\mathrm{T}}=8$ with the three modulations strategies (triangular, trapezoidal and phase shift) can be seen.

\section{Simulation at the range limits of the low voltage side with triangular modulation, trapezoidal modulation and phase shift modulation combined}

In figures $4.8 \mathrm{a}$ and $4.8 \mathrm{~b}$, the three modulation strategies have been applied at $V_{1}=30 \mathrm{~V}$ and $V_{1}=60 \mathrm{~V}$, respectively. It also becomes apparent here that using the three taps with the three modulations strategies brings a great advantage in terms of reducing semiconductor losses.

\section{Simulation of the current in the transformer}

The use of the tap changer also reduces current in the transformer. As has been shown in chapter 3, the dual active bridge under phase shift modulation produces an alternative power flux across the transformer even if the power flux at the DC terminals flows in a constant direction. In figures $4.9 \mathrm{a}, 4.9 \mathrm{~b}$ and $4.9 \mathrm{c}, \mathrm{RMS}$ currents in the transformer for $V_{1}=45 \mathrm{~V}$, taps with $n_{\mathrm{T}}=3, n_{\mathrm{T}}=5$ and $n_{\mathrm{T}}=8$, and using phase shift modulation are 
shown. In each figure, the manner in which the currents increase with phase shift and when the voltage ratio $d$ differ from one is to observe.

In figure $4.9 d$, currents of the combined effects of all three taps with the same turns ratios that have been used up to now, under phase shift modulation, are shown.

In figures $4.10 \mathrm{~d}$, the combined effects of all three modulation strategies on each tap is depicted as well as the effect of all three strategies with the three taps of the tap changer.

\section{Conclusion}

The simulation of semiconductor losses and the currents in the transformer shows that the tap changer combined with triangular, trapezoidal and phase shift modulation significantly reduces the semiconductor losses and the current in the transformer. Reducing the currents reduces losses in the transformer, but indeed also in the semiconductor. All the simulations here have been carried out by considering MOSFETs in the taps of the tap changer as well. The additional losses introduced by the MOSFETs of the tap changer are largely compensated for by loss reduction in the semiconductors and in the transformer windings. 

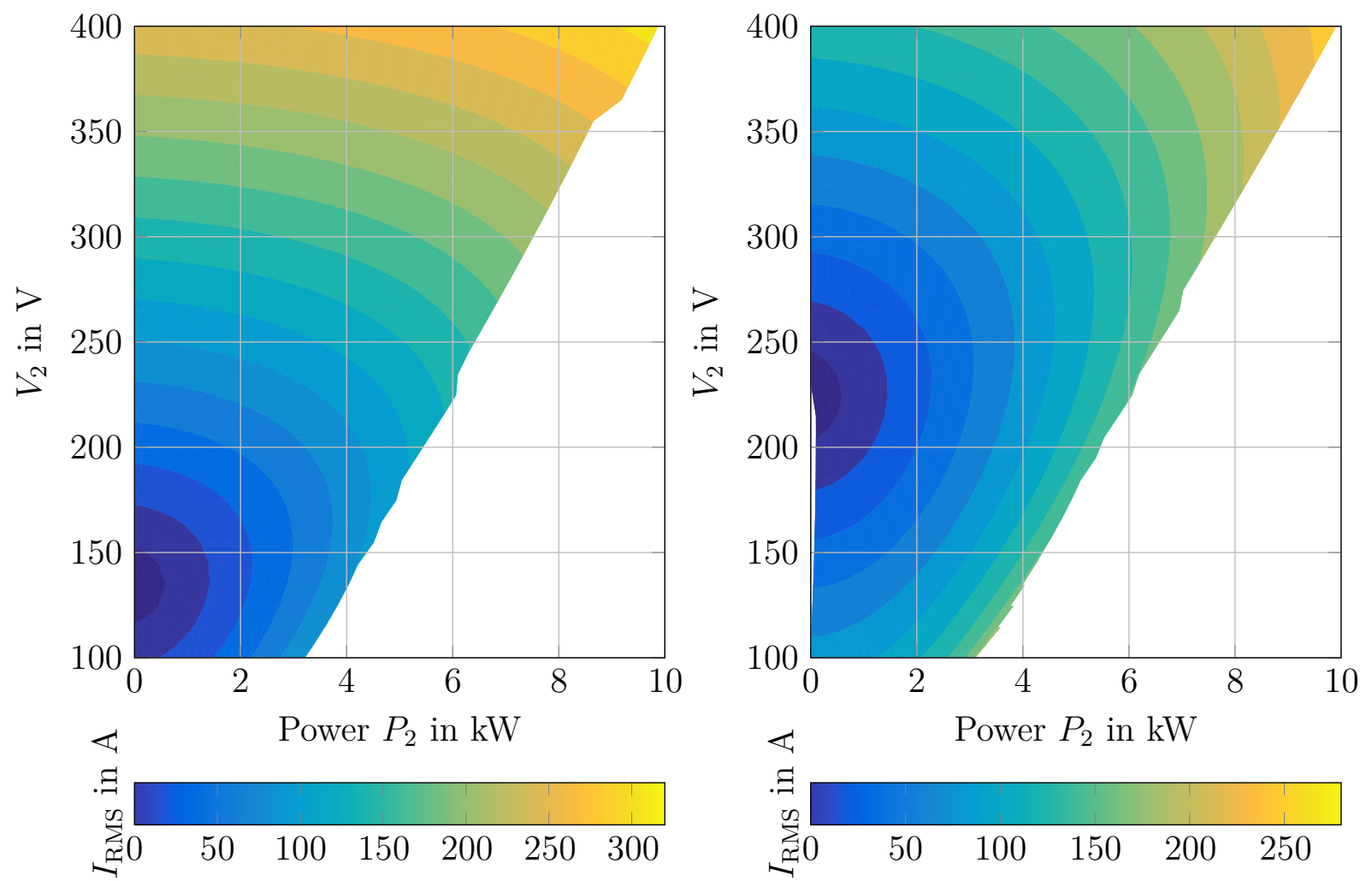

(a) $\mathrm{Tap}_{3}$
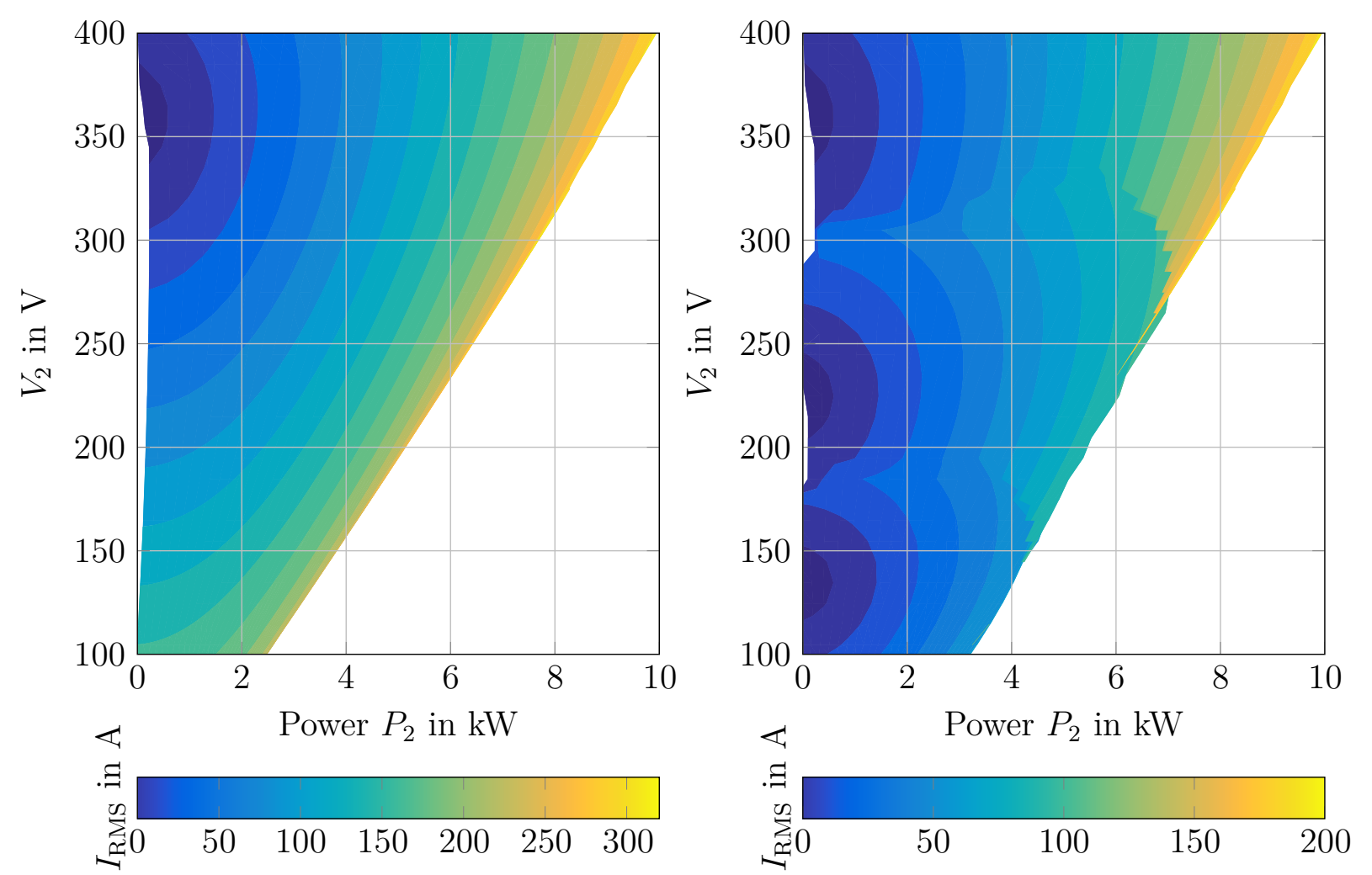

(c) $\mathrm{Tap}_{8}$

(d) $\mathrm{Tap}_{3}, \mathrm{Tap}_{5}$ and $\mathrm{Tap}_{8}$

Figure 4.9: Transformer RMS primary current with $V_{1}=45 \mathrm{~V}$ and PS modulation 


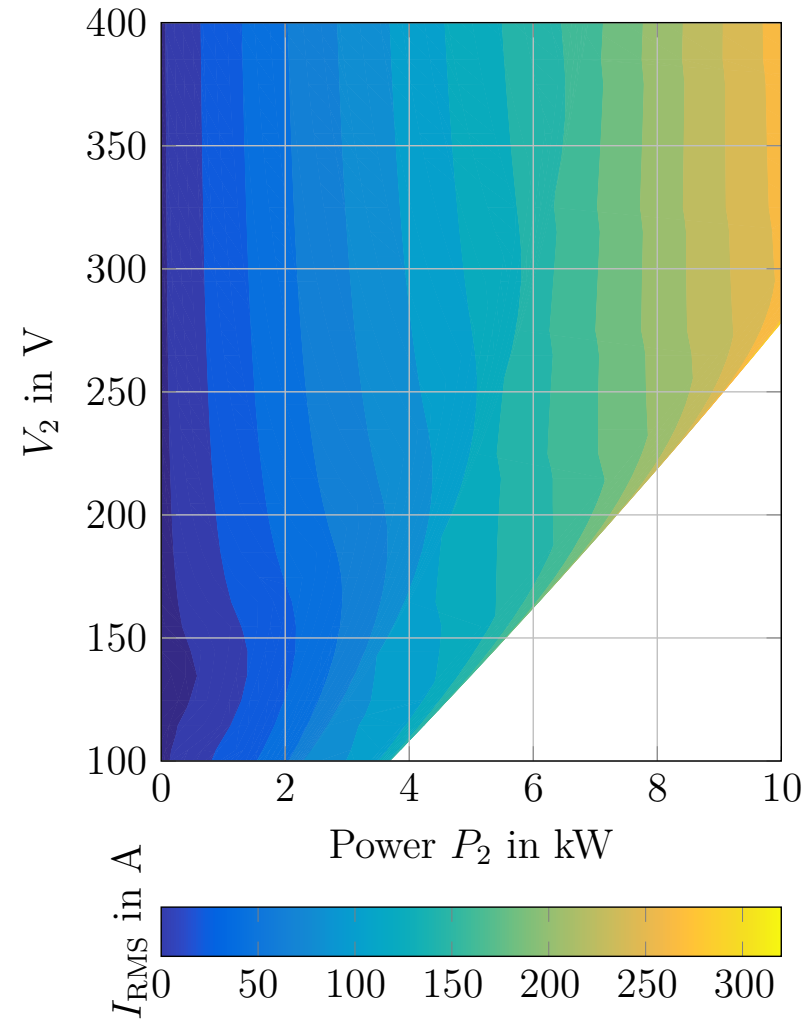

(a) $\mathrm{Tap}_{3}$

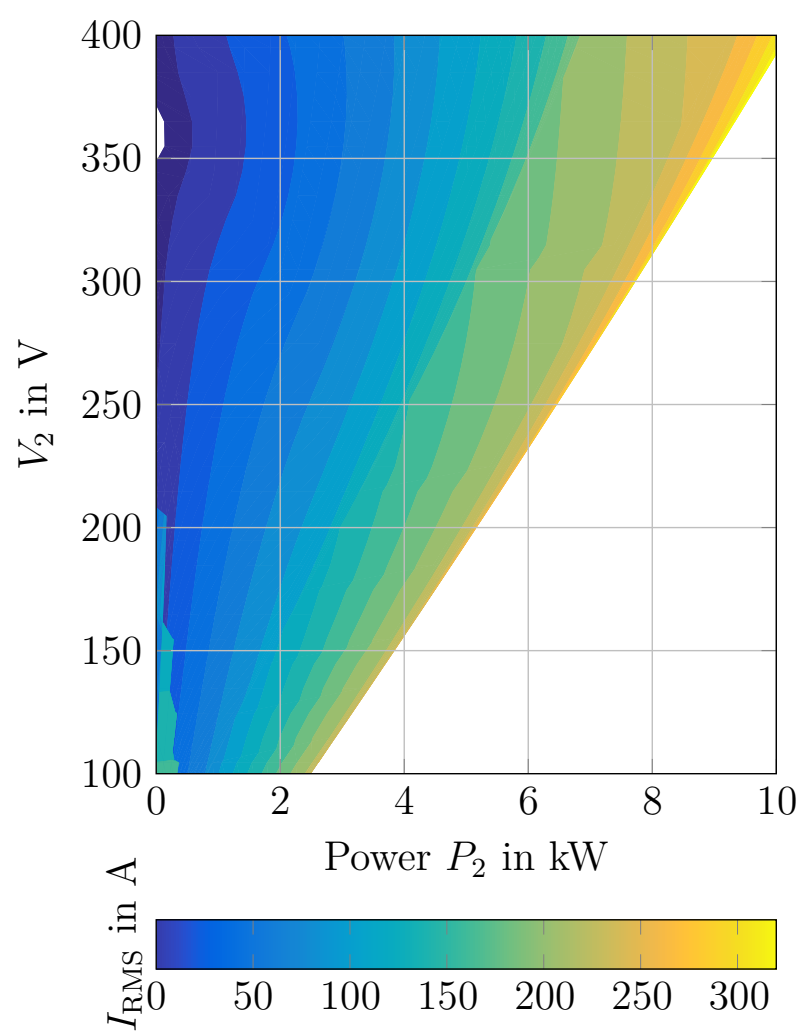

(c) $\mathrm{Tap}_{8}$

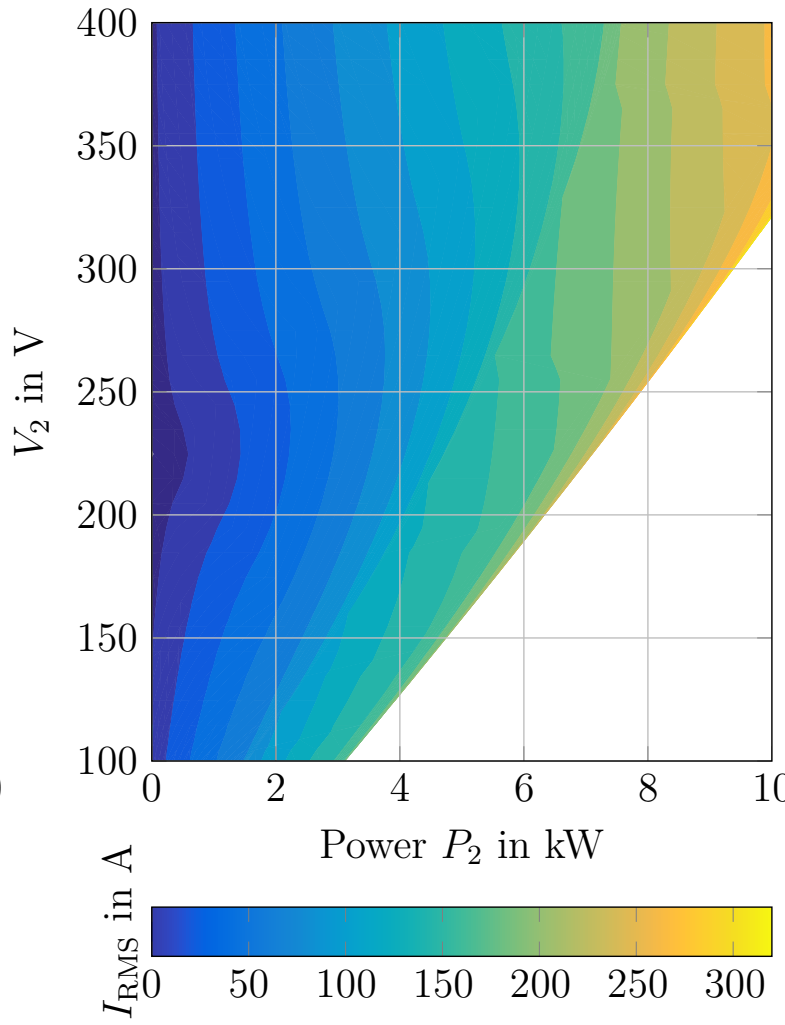

(b) $\operatorname{Tap}_{5}$

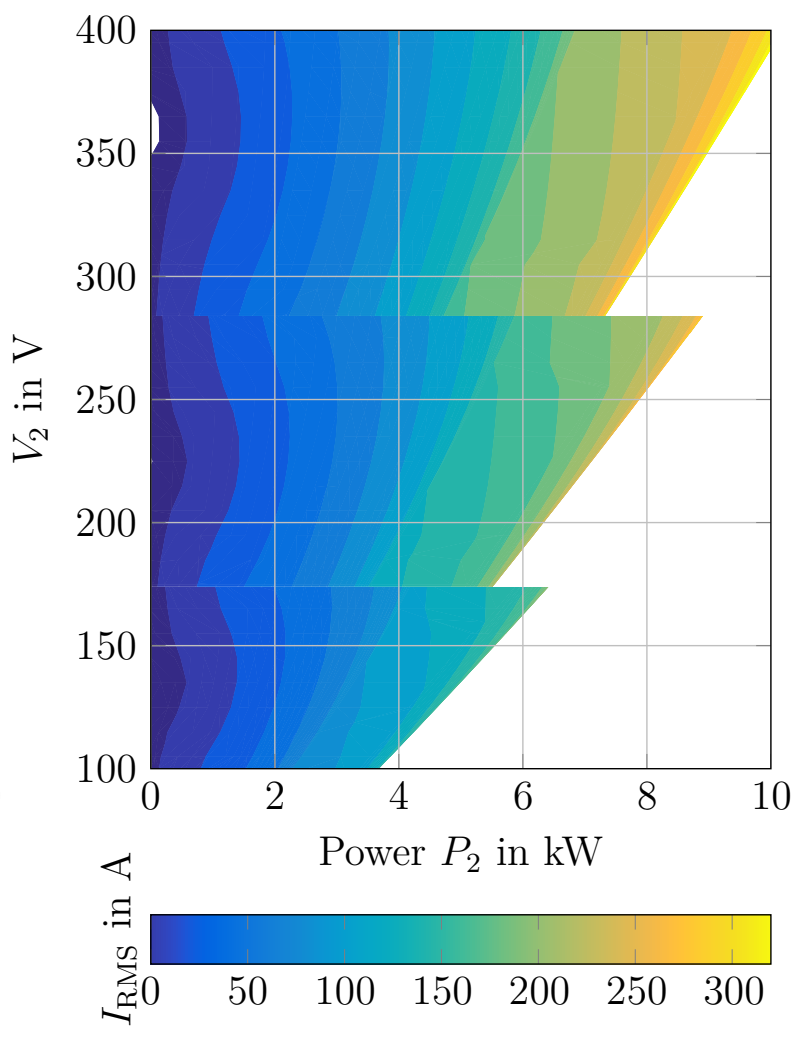

(d) $\mathrm{Tap}_{3}, \mathrm{Tap}_{5}$ and $\mathrm{Tap}_{8}$

Figure 4.10: Transformer RMS primary current with $V_{1}=45 \mathrm{~V}$ and PS, TRI and TRAP modulation strategies combined 


\section{Implementation and Experimental Results}

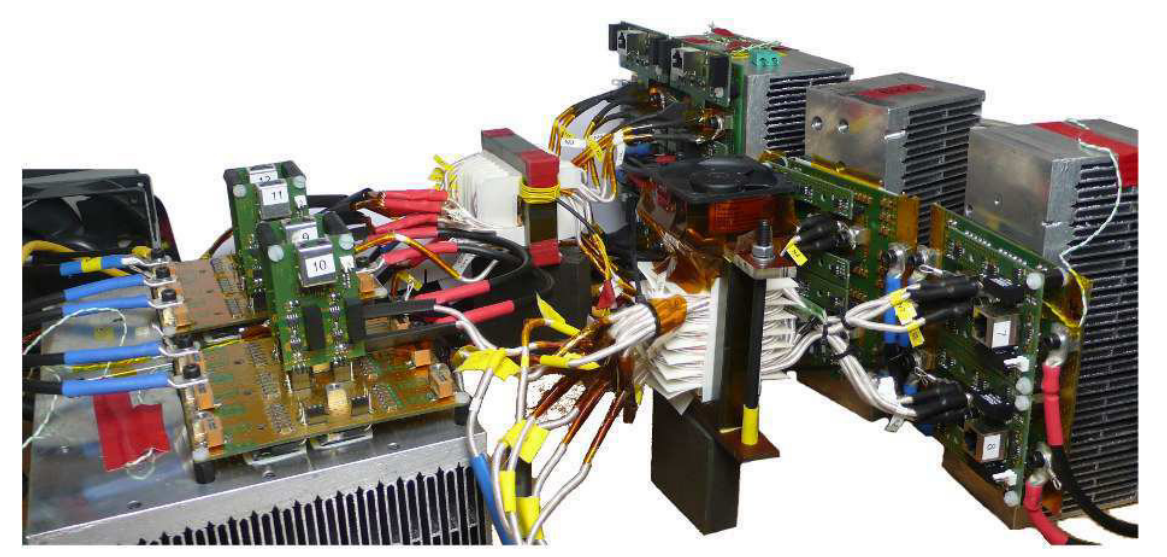

Figure 5.1: Two DABs with tap changer in back-to-back configuration

This chapter describes the various parts of the prototype, the measurement set-up, and the measurement results. The main elements of the prototype are the tap changer, the transformer, four low-voltage H-bridges, and one high voltage $\mathrm{H}$-bridge. At the primary of the transformer, i.e. at the low-voltage side, a pair of parallel windings are connected to each H-bridge. At the secondary of the transformer, depending on the configuration, either the windings of the transformer are directly connected to the high-voltage H-bridge, or a tap changer is interposed between the windings of the transformer and the H-bridge. All of these devices are connected to a control board which furnishes the command signals for each. The prototype is depicted in figure 5.1, where a back-to-back configuration can be seen, as schematized in figure 5.14.

\subsection{Prototype Specifications}

The prototype is designed to transfer a power $P_{\mathrm{N}}=10 \mathrm{~kW}$ with the low voltage $V_{1, \mathrm{~N}}=50 \mathrm{~V}$ and $V_{2, \mathrm{~N}}=400 \mathrm{~V}$. These values lead to a transformer leakage inductance of $L_{\sigma, \mathrm{N}}=220 \mathrm{nH}$ with a phase shift angle $\phi_{\mathrm{N}, \max }=60^{\circ}$. The other specifications data of the converter are listed in table 5.1. The maximum values of the current are given by the thermal limit. Even if, with the nominal voltages the transformer limits the current at the rated values, with different voltage values, or, with a lower voltage ratio than the maximum, it is possible to have much more current in the prototype than the nominal current values. Hence, the thermal limit defines maximum values for the current. For this prototype, two transformer have been used, one with taps one to eight, and a second with taps from one to twelve. 


\begin{tabular}{lclc}
\hline$P_{\mathrm{N}}$ & $10 \mathrm{~kW}$ & $\phi_{\mathrm{N}, \max }$ & $60^{\circ}$ \\
$S_{\operatorname{Tr}}$ & $15 \mathrm{kVA}$ & $n_{\mathrm{T}}$ & $1: 1-1: 8-1: 12$ \\
$V_{1, \mathrm{~N}}$ & $50 \mathrm{~V}$ & $V_{2, \mathrm{~N}}$ & $400 \mathrm{~V}$ \\
$V_{1, \min }$ & $30 \mathrm{~V}$ & $V_{1, \max }$ & $60 \mathrm{~V}$ \\
$V_{2, \min }$ & $100 \mathrm{~V}$ & $V_{2, \max }$ & $400 \mathrm{~V}$ \\
$I_{1, \mathrm{~N}}$ & $200 \mathrm{~A}$ & $I_{1, \max }$ & $280 \mathrm{~A}$ \\
$I_{2, \mathrm{~N}}$ & $25 \mathrm{~A}$ & $I_{2, \max }$ & $35 \mathrm{~A}$ \\
$C_{1}$ & $360 \mu \mathrm{F}$ & $C_{2}$ & $45 \mu \mathrm{F}$ \\
$L_{\mathrm{\sigma}, \mathrm{N}}$ & $220 \mathrm{nH}$ & $f_{\mathrm{N}}$ & $100 \mathrm{kHz}$ \\
\hline
\end{tabular}

Table 5.1: Prototype specifications

\subsection{Low-Voltage H-bridge}

A two layer FR4 power circuit board (PCB) with $70 \mu \mathrm{m}$ copper on both sides is used. The power electronic switches used are the IRF7769 DirectFETs [13] with the characteristics reported in table 5.2. The DirectFETs are very small devices that allow for the creation of a commutation cell with low parasitic inductances. Ceramic capacitors have been placed as close as possible to the MOSFETs to reduce the maximum switching overvoltage. Further capacitors have been placed on the board to reduce the voltage ripple due to the $\mathrm{AC}$ current from the dual active bridge at the transformer side.

\begin{tabular}{ll}
\hline Denomination IRF7769L2PBF & Manufacturer INFINEON \\
Break down voltage $V_{\mathrm{DS}, \mathrm{br}}=100 \mathrm{~V}$ & Resistance $R_{\mathrm{DS}, \text { on }}=2.8 \mathrm{~m} \Omega$ \\
Max. drain current $@ T_{\mathrm{C}}=25{ }^{\circ} \mathrm{C}, I_{\mathrm{D}}=124 \mathrm{~A}$ & Max. drain current $@ T_{\mathrm{C}}=100{ }^{\circ} \mathrm{C}, I_{\mathrm{D}}=88 \mathrm{~A}$ \\
Output capacitance $@ V_{\mathrm{DS}}=60 \mathrm{~V}, C_{\mathrm{oss}}=800 \mathrm{pF}$ & \\
\hline
\end{tabular}

Table 5.2: Specifications of the device in the low voltage H-bridge

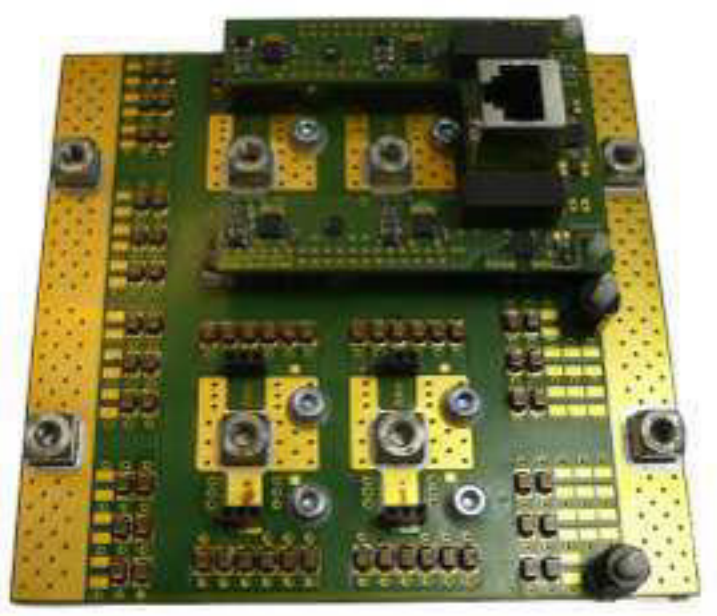

Figure 5.2: Low voltage H-bridge 


\subsection{High-Voltage H-Bridge}

The high-voltage H-bridge is depicted in figure 5.3. The PCB is the same type as on the low-voltage side and is provided for the TO-247 housing. Even here, attention has been paid to keep parasitic inductance of the commutation cell low [11]. Several types of switches were used during the tests, among which the most used are the CoolMOS from INFINEON IPW65R045C7 [12] and a SiC MOSFET, the C3M0065090D from CREE [4].

The measurement results reported later in this dissertation use the $\mathrm{SiC}$ MOSFET. As described before, the aim of this work is to extend both the voltage range of a DAB as well as the soft turn-on region. When the converter works as planned, devices like CoolMOS can be utilized without destroying it with hard turn-on switching. In the measurement phases, because we wanted to do measurements in the border region between the hard-switching and soft-switching regions in the phase shift modulation, the SiC-MOSFET was used, as it allows hard turn-on switching.

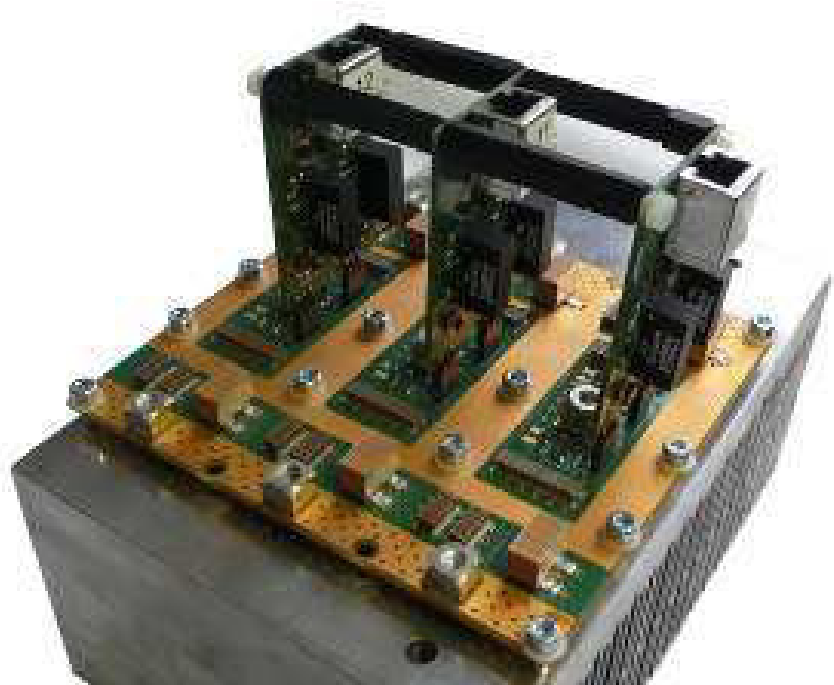

(a) Top

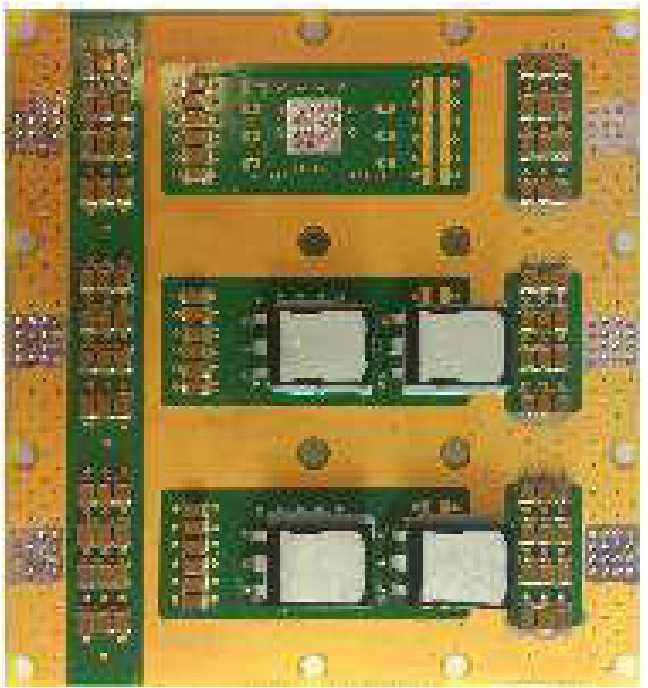

(b) Bottom

Figure 5.3: High voltage H-bridge

\begin{tabular}{llccc}
\hline $\begin{array}{l}\text { Denomination } \\
\text { Manufacturer }\end{array}$ & $\begin{array}{c}\text { C3M0065090D } \\
\text { CREE }\end{array}$ & $\begin{array}{c}\text { IPW65R045C7 } \\
\text { INFINEON }\end{array}$ & $\begin{array}{c}\text { IXFX120N65X2 } \\
\text { IXYS }\end{array}$ \\
\hline Break down voltage & $V_{\mathrm{DS}, \mathrm{br}}$ & $900 \mathrm{~V}$ & $650 \mathrm{~V}$ & $650 \mathrm{~V}$ \\
Max. drain current & $I_{\mathrm{D}} @ T_{\mathrm{C}}=25^{\circ} \mathrm{C}$ & $36 \mathrm{~A}$ & $46 \mathrm{~A}$ & $120 \mathrm{~A}$ \\
& $I_{\mathrm{D}} @ T_{\mathrm{C}}=100^{\circ} \mathrm{C}$ & $23 \mathrm{~A}$ & $29 \mathrm{~A}$ & - \\
Resistance & $R_{\mathrm{DS}, \mathrm{on}} @ T_{\mathrm{C}}=25^{\circ} \mathrm{C}$ & $65 \mathrm{~m} \Omega$ & $40 \mathrm{~m} \Omega$ & $24 \mathrm{~m} \Omega$ \\
& $R_{\mathrm{DS}, \text { on }} @ T_{\mathrm{C}}=150^{\circ} \mathrm{C}$ & $90 \mathrm{~m} \Omega$ & $96 \mathrm{~m} \Omega$ & - \\
\hline
\end{tabular}

Table 5.3: MOSFETs for the high voltage H-bridge 


\subsection{Control Board}

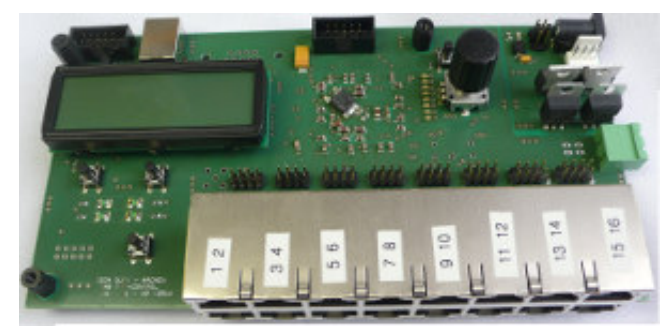

(a) Control board top side

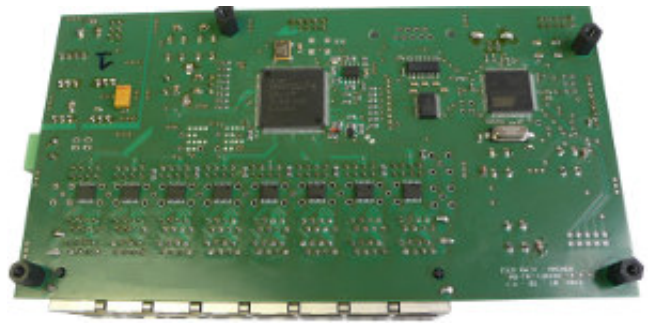

(b) Control board bottom side

Figure 5.4: Control board

The control board in figure 5.4 is designed to produce all the switching signals for the H-bridges and tap changer. By means of differential signals (LVDS) with RJ45 cables, the control board can drive the H-bridges and tap changers within converters. With the proper control firmware, this control board can control two converters with tap changers in back-to-back configuration. For the process of taking measurements, this control board set the right phase shift angle $\phi$ and produced the corresponding signal for each MOSFETs on the converter. The smallest incremental step time that can be set for the switching signal is $t_{\text {step,min }}=10 \mathrm{~ns}$. The main components on the control board are the 32-bit Atmel microcontroller [2], which performs all floating point operations and the FPGA SPARTAN6 from Xilinx [43], which sets all the blank time in the MOSFETs and all the phase shift between the H-bridges after receiving the setting values from the microcontroller. Further features are input, output interfaces and user interface.

\subsection{Tap Changer}

As introduced in Chapter 4, this converter uses a tap changer to connect the high-voltage $\mathrm{H}$-bridge to the proper tap of the transformer and allows for higher efficiency. In this section, different types of tap changers are considered.

Regarding the tap changer, there are two fundamental aspects to keep in mind: the conduction losses and the commutation speed. Commutation speed means the ability to commutate from one tap to another in a very short period of time, and in our case, it is to be considered high commutation speed if the commutation time is smaller than one modulation period of the H-bridges.

Further aspects are the size and the cost. Small and cheap tap changers do not seem to be difficult to obtain, but the challenge is to find such that has low conduction losses and short commutation times. An example with good conduction properties is a relay-based tap changer. This will conduct very well, but it will have a relatively long commutation time. On the other hand, a MOSFET-based tap changer will have high conduction losses but a commutation time, in certain situations, smaller than $100 \mathrm{~ns}$.

In figure 5.5 is depicted the test circuit with which the various devices have been measured to determine their losses in condition as near as possible to the real case is depicted. In this circuit, it is necessary to find a Dual Active Bridge with current recirculation so that 
the power supply has to feed only the losses of the circuit. Under these conditions, DAB produces the classic current wave-form in phase shift modulation, as seen in figure 3.4, and this wave form is also chosen as a reference current for the tests.

The conduction measurements were made by means of an oscilloscope with current and voltage probes. Currents in $\mathrm{SW}_{1}$ and $\mathrm{SW}_{2}$ were measured with current probes, as was the voltage across the switches using low-voltage differential probes, so as to obtain a high degree of accuracy. This kind of probe measures a maximum differential voltage of $25 \mathrm{~V}$ at a maximum voltage versus ground of $60 \mathrm{~V}$. This too is why we made a separate test set. The data were elaborated upon to obtain the conduction losses related to the root mean square of the currents.

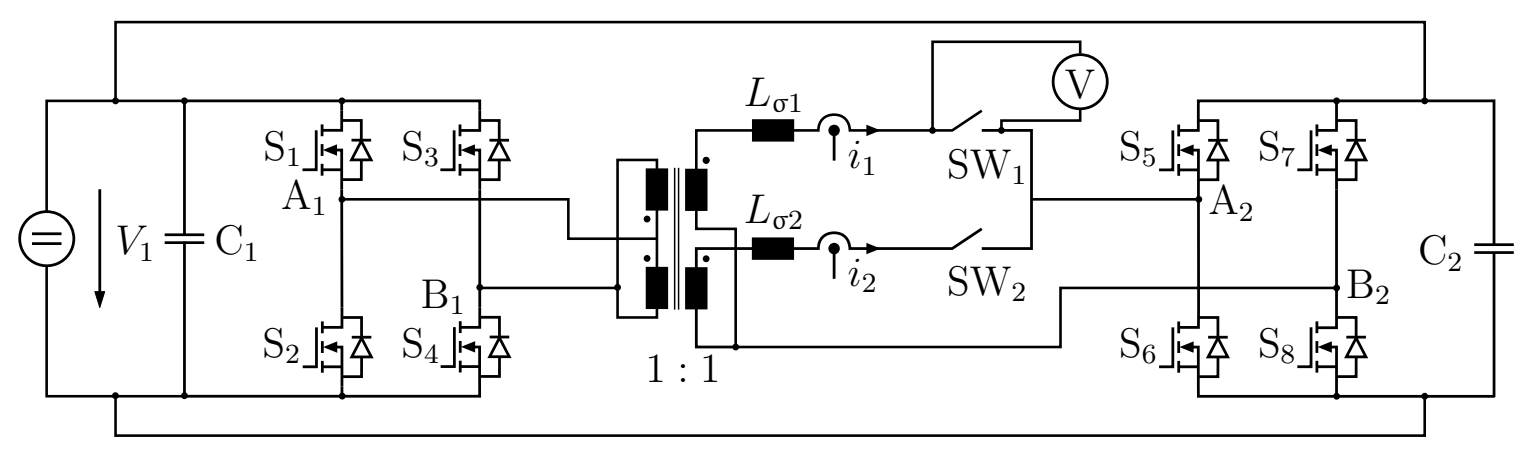

Figure 5.5: Test circuit for the tap changer

\subsubsection{Tap Changer with Relays}

The first type of tap changer considered is one based on relays which have two main characteristics: they have very low conduction losses and a low switching dynamic. The schematic of the tap changer with relays is depicted in figure 5.6, and the test circuit is represented in figure 5.5. During the commutation of the current from one tap to the other, if the switching signal is sent at the same time for the relay that has to be turned on and for the relay that has to be turned off, a current blank time $t_{\mathrm{i}, \text { blank }}=4 \mathrm{~ms}$ will be obtained. This is due to the fact that the turn-on delay of the considered relay is $t_{\text {delay,on }}=8 \mathrm{~ms}$ and the turn-off delay is $t_{\text {delay,off }}=4 \mathrm{~ms}$ ( measured values). In this test, the relay was turning on with the rated current and turning the same current off, but although they still have the capability to turn on and turn off a current, this is not necessary for the tap changer since

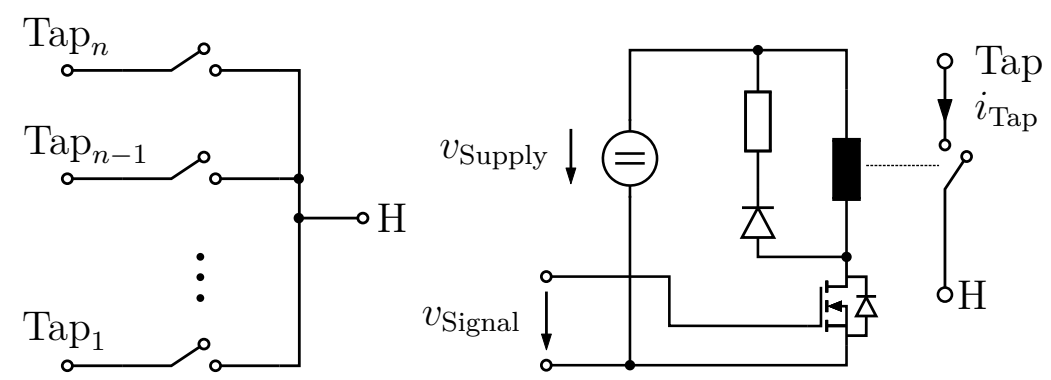

Figure 5.6: Tap changer with relays 
there are the H-bridges that can be turned off during the commutation of the relays and reduce contact wear and heat caused by the electric arc. In the case in which the H-bridges will be turned off at the same time the relays get the commutation signal, and the H-bridges will be turned on after the relay in $\mathrm{SW}_{2}$ has taken its current, the current blank time will be $t_{\mathrm{i}, \mathrm{blank}}=8 \mathrm{~ms}$.

In conclusion, the examined tap changer with relays is capable of commutating the current from one tap to the other in, at least, $t_{\text {comm }}=8 \mathrm{~ms}$. With optimization and a deeper understanding of the features of the relay, it is possible to reduce this time to below $t_{\mathrm{comm}}=4 \mathrm{~ms}$.

\subsubsection{Tap Changer with Brushes}

The idea of a tap changer with brushes comes from the on-load tap changer used in highpower and high-voltage systems and from DC machines. The collector in a DC machine rubs against brushes with high speed and low wear. The idea is to combine the experience of the on-load tap changer with the technique used in the collectors of DC machines. In figure 5.7 a, a tap changer with stepper motor is depicted. In this case, the rotor behaves like the collector of a DC machine and brings the right copper surface in front of the corresponding brush to establish the connection between the chosen tap and the high-voltage H-bridge. One solution is to connect the rotor copper ring to the high-voltage H-bridge and connect each tap of the transformer to a brush. In this way, a single rotor can redirect eight taps, as the example in the figure shows. In the linear configuration depicted in figure 5.7b, the central copper cylinder is connected to the high-voltage $\mathrm{H}$-bridge and each couple of brushes to a tap of the transformer.

For a tap changer in a three-phase system, the rotor ring will not be connected to the high-voltage H-bridge, but instead simply connects the three winding terminal together to form the desired star center. In the case of a linear stepper, like in figure 5.7b, instead of two brushes per level, three brushes per level are used, and each brush is connected to the winding terminal to obtain the star center at the desired position. The tap changer with brushes should be able to connect many circuits together with durability, reduced costs and low conduction losses. One disadvantage is the non-modern use of brushes, which require maintenance and create graphite powder which must be cleaned from time to time. To make a comprehensive comparison between relays and brushes was not possible, as it would necessitate comparing durability costs and maintenance efforts required for both technologies.

\section{Experimental results on the tap changer with brushes}

A tap changer with brushes has been built, and several tests have been carried out using it. To evaluate the resistance of the tap changer with brushes, some measurements have been taken with a setup that reproduces the material configuration in the tap changer. For a brush surface of $1.53 \mathrm{~cm}^{2}$, a resistance between $10 \mathrm{~m} \Omega$ and $40 \mathrm{~m} \Omega$ was determined.

As to be expected, brush resistance strongly depends on pressure, brush material and brush configuration within the tap changer. Soft brushes with high levels of graphite have a lower resistance, whereas hard brushes have a higher resistance. With a piece of pure graphite, the resistance will drop down to a few $\mathrm{m} \Omega$. 


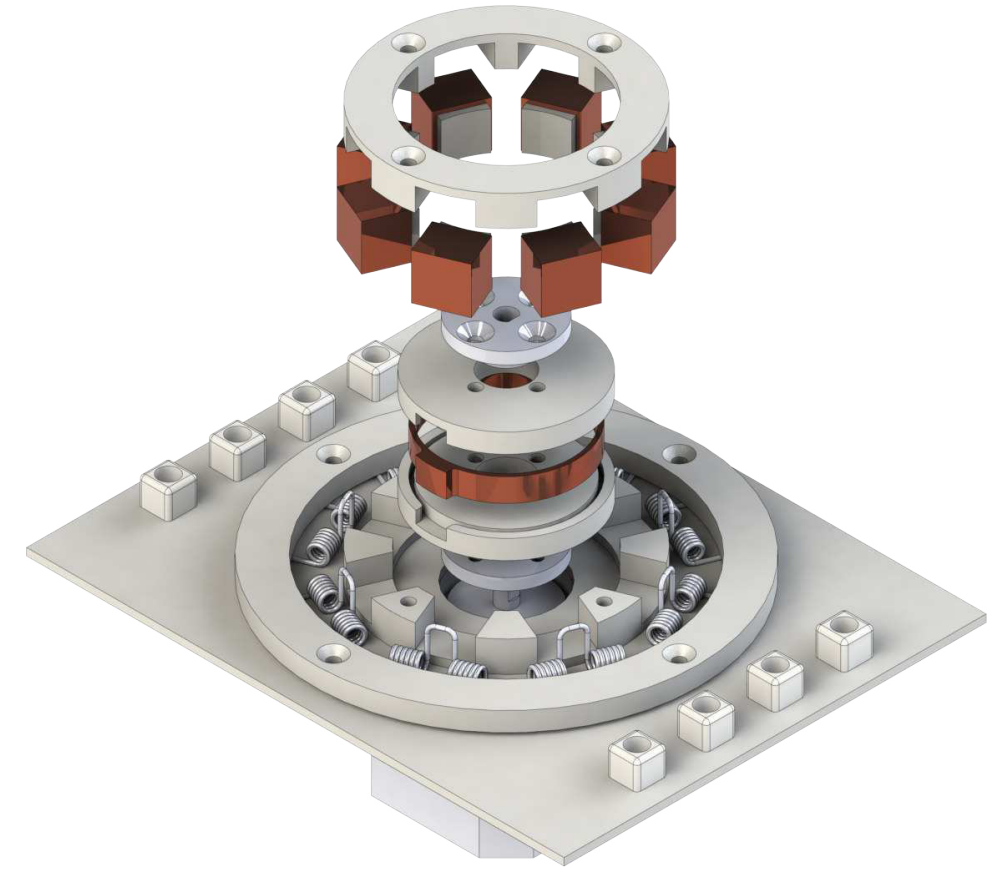

(a) Eight-channel tap changer with stepper motor and brushes

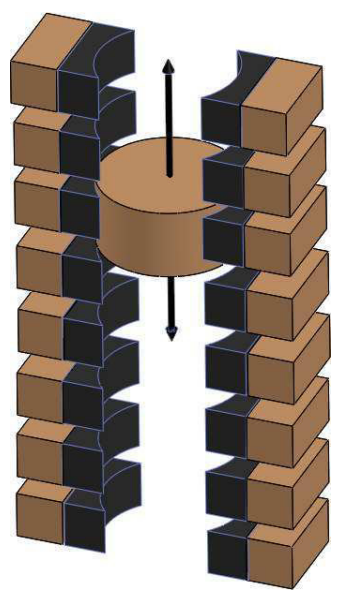

(b) Sketch of a linear tap changer with brushes

Figure 5.7: Brush based tap changers

\subsubsection{Tap Changer with Thyristors}

The good conducting properties of devices from the thyristors family [3, 23, 24] make these interesting for tap changers. Thyristors are very high-voltage and high-power devices that work typically with many $\mathrm{kV}$ and many $\mathrm{kA}$ and at frequencies below $1 \mathrm{kHz}$. For application to this research, we look to the smaller components of the family, especially small thyristors with rated voltage below $1 \mathrm{kV}$ and rated current below $100 \mathrm{~A}$. The SCRs, silicon-controlled rectifiers, also belong to the thyristors family, and, as an example, triacs [37] behave like two thyristor connected in inverse-parallel, and for low-power and low-voltage applications, they have the advantage of being compact and inexpensive. Tap changers with thyristors and triacs are represented in figure 5.8. For these reasons, these devices have been taken into account beyond the possible tap changer. Thyristors are unable to break a current in a circuit, so the current is broken by means of an external circuit, similar to AC circuits. In our case, we will deactivate the high voltage H-bridge, turn-on the thyristor of the tap that has to receive the current, and turn-off the thyristor corresponding to the tap that has to be open. Here the first problem with thyristors arises. After conducting a current of $30 \mathrm{~A}$ at $100 \mathrm{kHz}$, it was discovered that 80 ms must pass before a voltage can be reapplied a cross a thyristor. Tests have been performed at different currents and frequencies, and it was found out that the circuit-commutated turn-off time $t_{\mathrm{q}}$ increases rapidly as the current and frequency increase.

The second limitation of the thyristors come from the static $\frac{\mathrm{d} v}{\mathrm{~d} t}$ turn-on. When the thyristor is in an off state and it is blocking a certain voltage, a small capacitor appears across each internal pn-junctions that is inversely polarized. If the $\frac{\mathrm{d} v}{\mathrm{~d} t}$ applied between the anode and the 

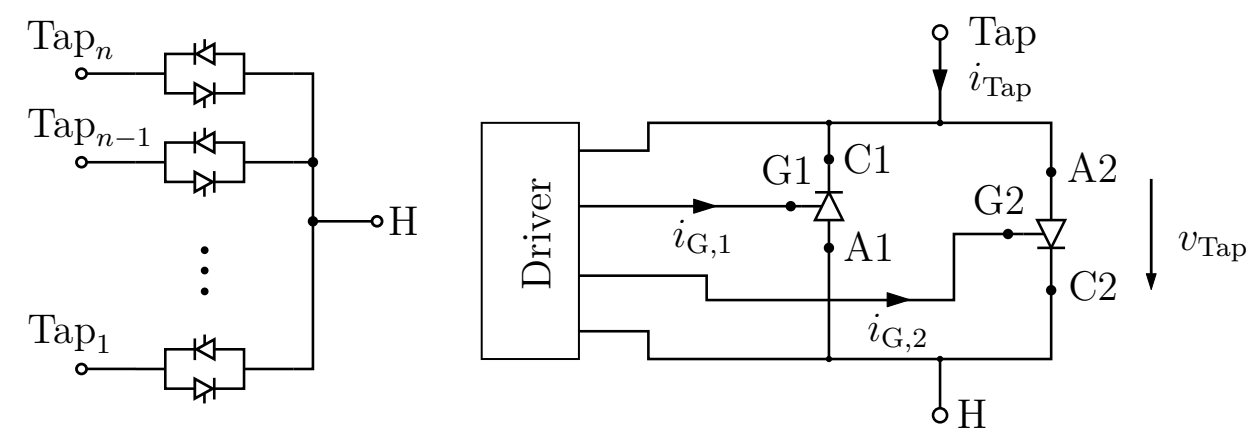

(a) Tap changer with thyristors
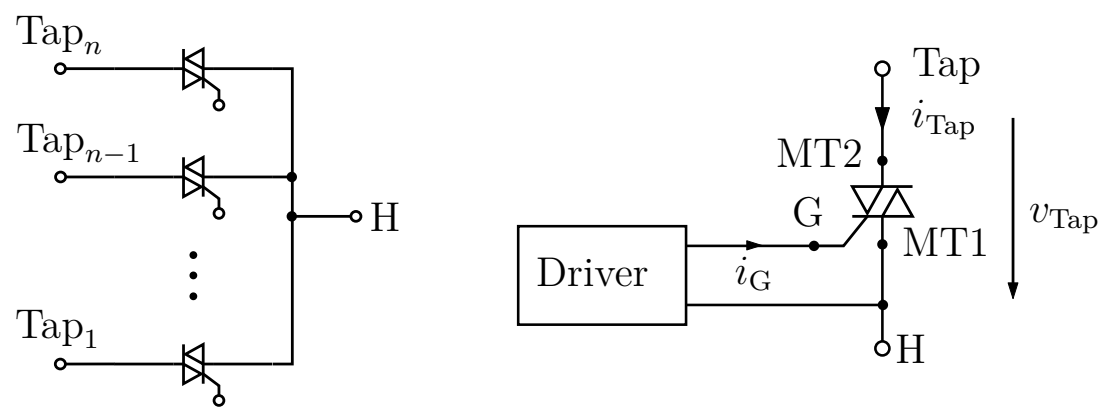

(b) Tap changer with triacs

Figure 5.8: Thyristor based tap changers

cathode is large enough, these capacitors can conduct a current that reaches the thyristor gate trigger current $I_{\mathrm{GT}}$ and turns on the thyristor [44]. This is the biggest limitation for the use of thyristors as switches in tap changers. In our case we found that with $100 \mathrm{kHz}$, the thyristor will spontaneously turn-on with a voltage of about $360 \mathrm{~V}$.

In conclusion, the use of the thyristor for a tap changer applied to a dual active bridge with a switching frequency of $f_{\mathrm{sw}}=100 \mathrm{kHz}$ and $V_{2}=400 \mathrm{~V}$ is not possible. It has been reported here both for completeness and as a consideration for why it might be interesting for topologies that exhibits a lower $\frac{\mathrm{d} v}{\mathrm{~d} t}$ at the tap switches, such as, for example, a resonant topology.

\subsubsection{Tap Changer with MOSFETs}

A tap changer with MOSFETs is schematized in figure 5.10, and the prototype is shown in figure 5.9. This tap changer exhibits the fastest commutation speed and, relatively low losses with low current values, but it has relevant losses at high current values. An important feature of the DAB is that once the two input and output voltages, the phase shift angle, and the leakage inductance are known, it is possible to predict with great precision by means of analytical formulas the instant $t_{\mathrm{i} 0}$ in which the current will cross the zero line and thus obtain a zero current tap changer commutation. This allows for the commutating of the tap exactly at this point and the obtaining a zero current tap changer commutation (ZCC). In figure 5.11, a ZCC between two taps is represented. The characteristics of the implemented MOSFET [14] for the tap changer are reported in table 5.4. ZCC is also 


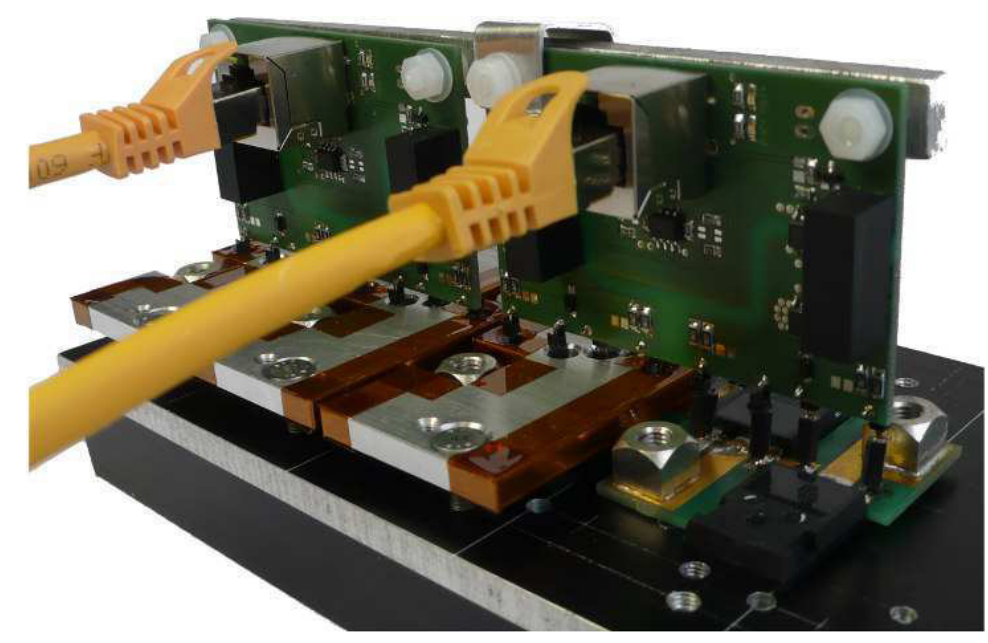

Figure 5.9: Four channel tap changer set-up for MOSFETs and IGBTs

possible with TRAP modulation and TRI modulation in which the commutation can be obtained in the blanking time.
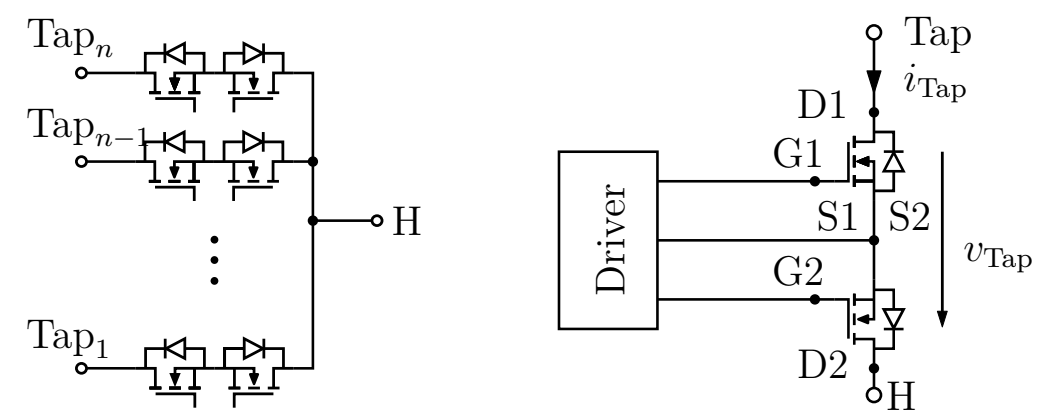

Figure 5.10: Tap changer with MOSFETs

\section{Output capacitance $C_{\text {oss }}$}

In the MOSFTETs as well as in other semiconductors, there is always an output capacitance $C_{\text {oss }}$. These output capacitances lead to swinging as can be seen in figure 5.11. If this capacitance is large, it can lead to swinging. By increasing the number of taps with MOSFETs and by using MOSFETs with large output capacitances, this swinging will increase and negatively impact the efficiency of the converter.

\begin{tabular}{lclc}
\hline Denomination & IXFX120N65X2 & Manufacturer & INFINEON \\
Break down voltage & $V_{\mathrm{DS}, \mathrm{br}}=650 \mathrm{~V}$ & Max. drain curr. @ $T_{\mathrm{C}}=25^{\circ} \mathrm{C}$ & $I_{\mathrm{D}}=124 \mathrm{~A}$ \\
Resistance & $R_{\mathrm{DS}, \mathrm{on}}=2.8 \mathrm{~m} \Omega$ & Max. drain curr. @ $T_{\mathrm{C}}=100{ }^{\circ} \mathrm{C}$ & $I_{\mathrm{D}}=88 \mathrm{~A}$ \\
& & Output capacitance @ $V_{\mathrm{DS}}=60 \mathrm{~V}$ & $C_{\mathrm{oss}}=800 \mathrm{pF}$ \\
\hline
\end{tabular}

Table 5.4: Specifications of the device used in the tap changer 


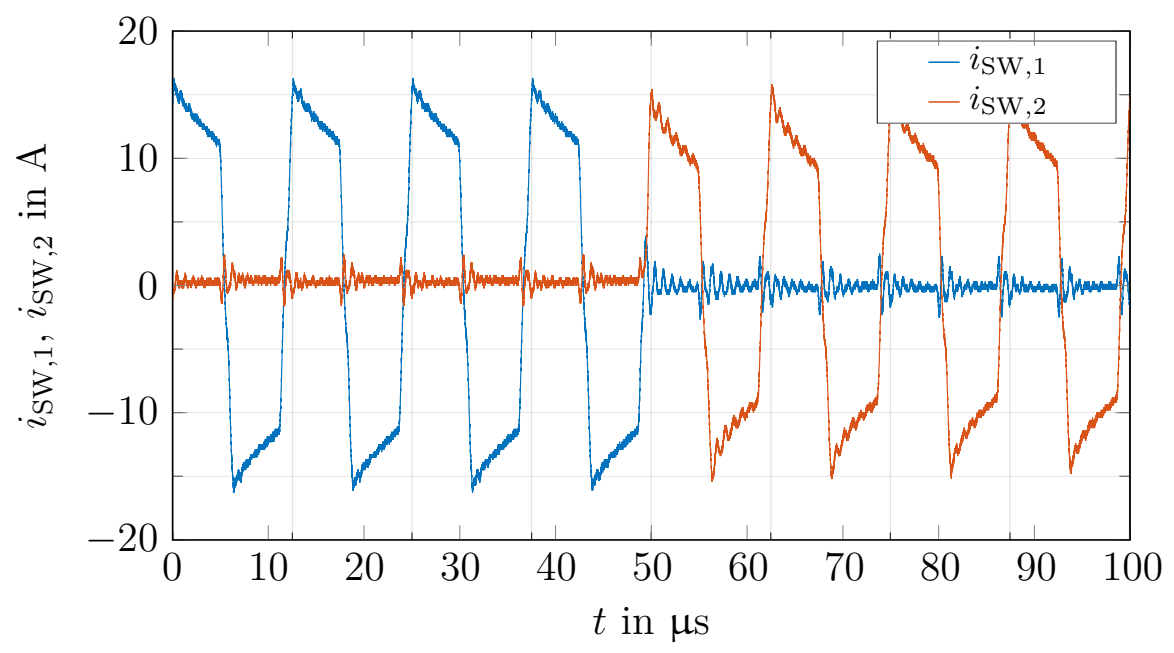

Figure 5.11: Commutation of the tap changer with MOSFETs

\subsubsection{Tap Changer with IGBTs}

The tap changer with IGBTS is similar to the tap changer with MOSFETs, as both use the same tap changer set-up as seen in figure 5.9. The switching speed of the IGBTs is typically lower than the switching speed of MOSFETs, but this is irrelevant in the case of the tap changer because, as with the MOSFETs, it is the leakage inductance that limits the commutation speed of the current between two taps. Due to IGBTs being bipolar devices, they have higher losses at low current values and lower losses at high current values when compared to MOSFETs. In tap changers with high current values, placing MOSFETs in parallel with IGBTs might be considered in order to combine the suitable properties of both. For the IGBTs, only conduction tests were made. The commutation test is assumed to be similar to the commutation of the MOSFETs.
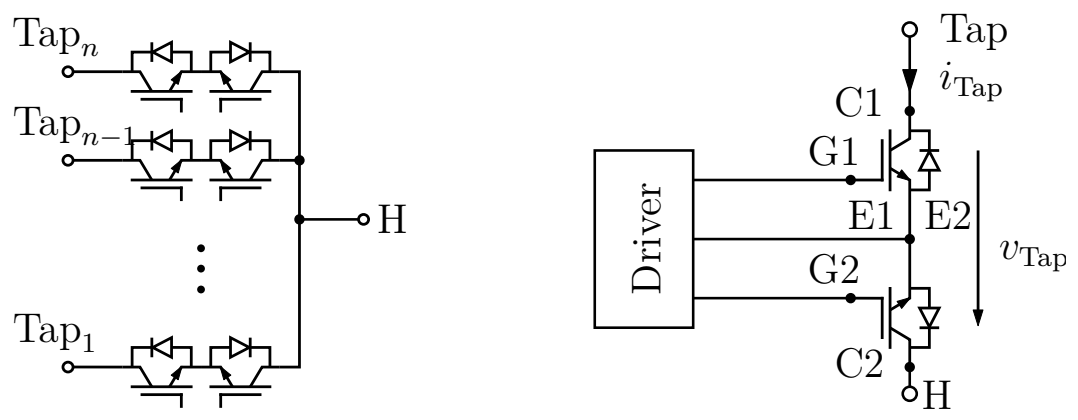

Figure 5.12: Tap changer with IGBTs

\subsubsection{Tap Changer: Conclusion}

Here the main features of the different types of tap changers are summarized:

- Relay: $t_{\mathrm{on}}=8 \mathrm{~ms}, t_{\mathrm{off}}=5 \mathrm{~ms}$ 


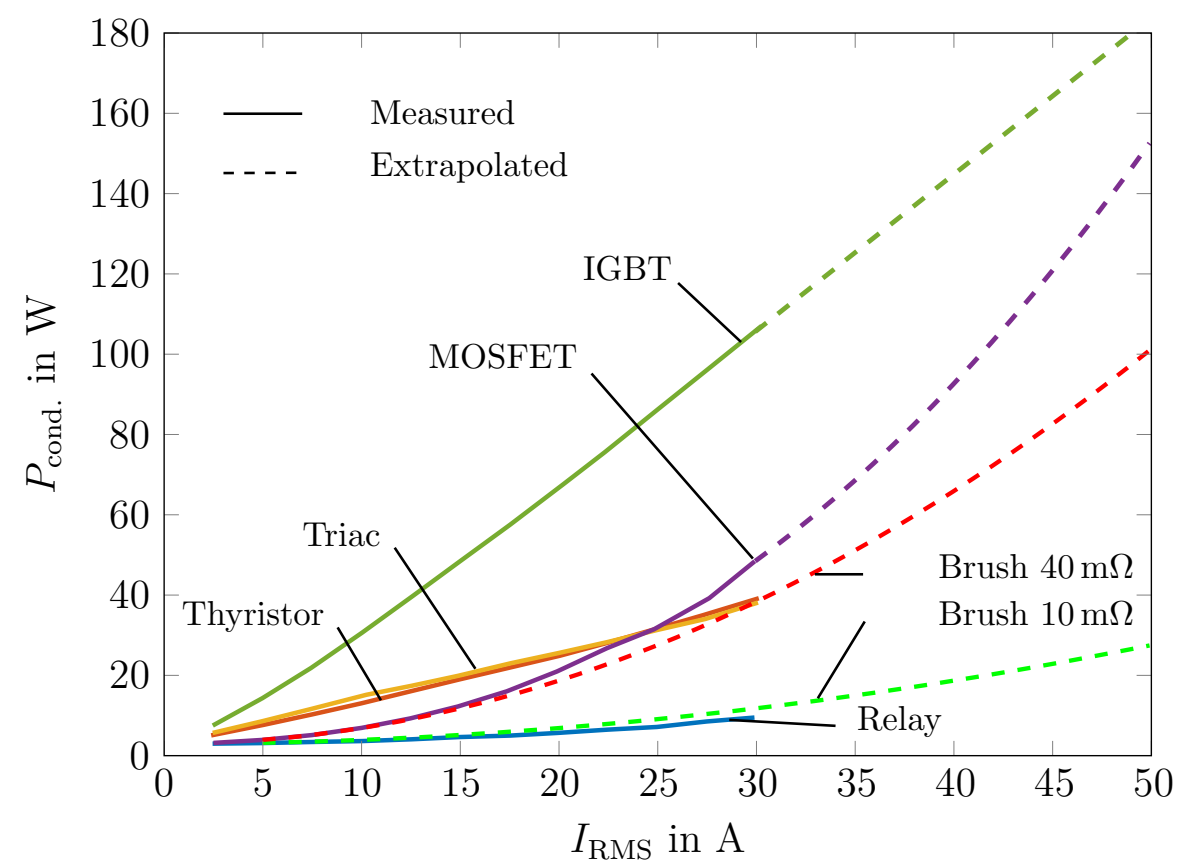

Figure 5.13: Conduction Losses

- Stepper with brushes: $t_{\mathrm{on}}=42 \mathrm{~ms}, t_{\mathrm{off}}=42 \mathrm{~ms}$

- Triac and Thyristor: $t_{\text {off }}=80 \mathrm{~ms}$. These devices have the longest turn-off time and cannot remain in the off-state when a high-frequency alternate voltage is applied to their terminals. These devices are useless for tap changers that work at $100 \mathrm{kHz}$ and $400 \mathrm{~V}$.

- MOSFET: $t_{\mathrm{on}}<1 \mu \mathrm{s}, t_{\mathrm{off}}<1 \mu \mathrm{s}$. Both $t_{\mathrm{on}}$ and $t_{\text {off }}$ depend on the leakage inductance of the commutation mesh. For turn-on, the derivative of the current will be limited by leakage inductance, which operates as a current snubber. For turn-off, with current on the commutation mesh, the $\frac{\mathrm{d} i}{\mathrm{~d} t}$ current derivative has to be limited by the MOSFET with proper gate resistance. The limit of $\frac{\mathrm{d} i}{\mathrm{~d} t}$ is given by the voltage allowed across the tap changer MOSFETs and the voltage limit of the insulating material.

- IGBT: $t_{\text {on }}<1 \mu \mathrm{s}, t_{\text {off }}<1 \mu \mathrm{s}$. Generally, the IGBTs commutates more slowly than the MOSFETs, but likewise for the IGBTs, the limits are determined by the leakage inductance of the commutation mesh, as it is for the MOSFETs. At low current, the IGBTs produce relevant losses compared to the MOSFETs, and they will be convenient only at higher current values.

In conclusion, changers with Triacs or Thyristors are useless for this application. Tap changer can, however, still be implemented using relays, MOSFETs and IGBTs. The results of the conduction measurements are depicted in figure 5.13. 


\subsection{Efficiency Measurement of the Dual Active Bridge with Tap Changer}

To measure the efficiency of the converter, a measurement set-up has been prepared. A picture of the set-up is shown in figure 5.1, and its scheme is depicted in 5.14. In this set-up, there are two converters: one is the device under test (D.U.T.) and the other is used to close the power loop in a back-to-back configuration. In this way, the power supply has only to compensate for the losses of the two converters along with a little extra power to let it flow into the sink, and this produces a stable voltage at the low-voltage side of the converter. The transformers used in these measurements are the $\mathrm{T}_{1}$ and $\mathrm{T}_{1}$, which configuration are reported in 2.3, and $\mathrm{T}_{3}$, which was described in section 2.3. The transformer $\mathrm{T}_{3}$ has less turns than the transformer $\mathrm{T}_{1}$ and exhibits a lower leakage inductance. This leads to reduced copper losses due to the shorter windings length and due to the smaller circulations current in the transformer. The drawback of this transformer $\mathrm{T}_{3}$ is that it has higher core losses. In total, the converter built with $\mathrm{T}_{3}$ has fewer losses than the one made with $\mathrm{T}_{1}$. The measurement results presented here are these made with the transformer $T_{3}$ and $T_{4}$.

\section{Measurement equipment}

At both pair of terminals of the D.U.T. the voltages and currents were measured by means of a precision power meter (ZIMMER LMG500), with an error in the measurement of the power given by equation 5.1 .

$$
P_{\text {error }}=1.5 \cdot 10^{-4} \cdot P_{\text {measure }}+10^{-4} \cdot P_{\text {Range }}
$$

Where $P_{\text {measure }}$ is the measured value and $P_{\text {Range }}$ is the power range.

The voltages have been measured with the internal sensors of the LMG500, and the current with an external current sensor [21]. The traces of the voltages and current of the H-bridges were recorded, and the RMS values of the currents were obtained, all by means of an oscilloscope. The accuracy of the RMS values measured in this way is around $1 \%$ and have not been used to calculate efficiencies or magnetization current.

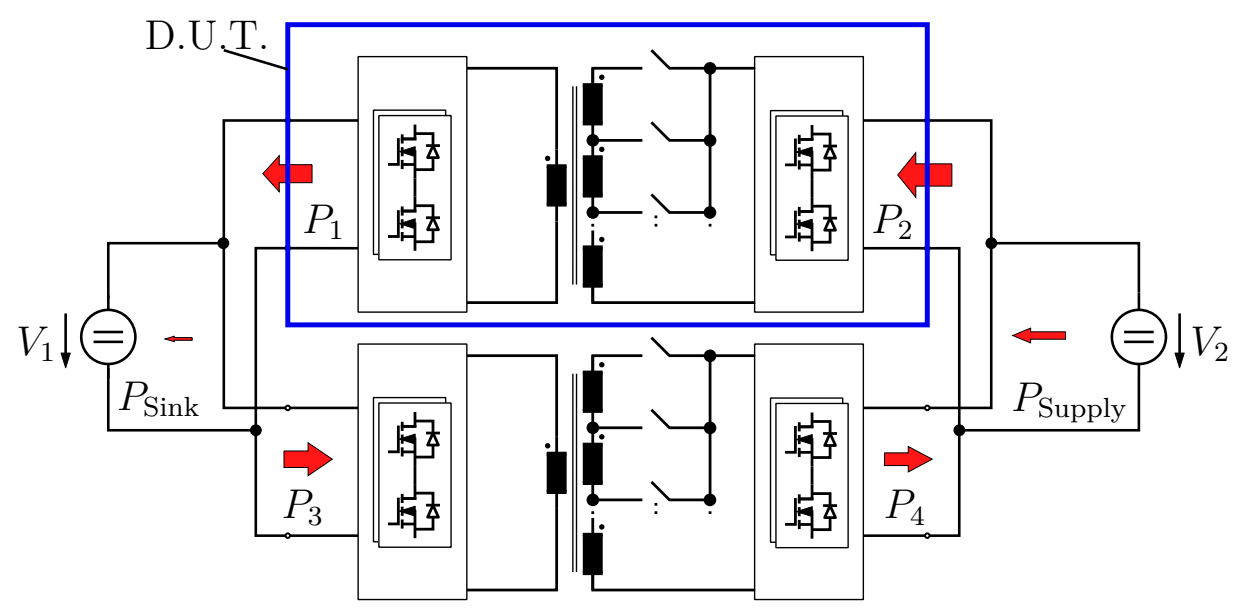

Figure 5.14: Back-to-back configuration in the measurement set-up 


\section{Implementation of the measurements}

To characterize the D.U.T., various working points of the converter have been measured. Voltages $V_{1}$, of the low-voltage side and $V_{2}$, of the high-voltage side, have been set, and, by means of the control board 5.4, the phase shift angle between the two bridges has been varied. For each point, the values of the voltages, the currents, powers and efficiency have been measured with the aforementioned LMG500. The RMS values of the current have been measured with the oscilloscope.

In order to observe the maximum performance obtainable by this topology, the intermediate tap changer was omitted. The obtained results are comparable with what would have been obtained if a relay was used as a tap changer. Measurements were performed at each tap to acquire the transformer limits by providing power at the various taps.

A summary of the measured values is reported in table 5.5. Further measured values are listed in appendix B.

\section{Measurement with $V_{1}=30 \mathrm{~V}$}

Figure 5.15a shows the efficiency values as a function of the phase shift angle $\phi$, as well as the high voltage $V_{2}$, for a fixed low voltage $V_{1}=30 \mathrm{~V}$, using the tap with $n_{\mathrm{T}}=8$. In this figure, it can be seen that the efficiency is high at low $\phi$ values, and for voltage values $V_{2}$ near the transformer ratio, i.e. in situations the $d=1$ with $d=\frac{V_{2}}{n_{\mathrm{T}} V_{1}}$. It can be recognized the ZVS-limits of the phase shift modulation and that in phase shift modulation only at higher phase shift angle i.e. only with higher power the voltage value $V_{2}=400 \mathrm{~V}$ can be reached. As shown in the simulations, these voltage values are easily reached if the triangular modulation of the trapezoidal modulation is implemented. Unfortunately, this modulation strategy could not yet be implemented for these measurements.

In figure $5.15 \mathrm{~b}$, the power lie on the abscissa axis and the voltage $V_{2}$ lie on the ordinates. This figure gives an idea of the transferred power that can be reached.

Here the ZVS limits are visible in a more pronounced way. The bottom limit with low voltage and high power values is given by the current that reaches the maximum allowed current for the converter.

In figure 5.16, in addition to the tap corresponding to $n_{\mathrm{T}}=8$, two other taps with $n_{\mathrm{T}}=4$ and $n_{\mathrm{T}}=6$ have been added. Beyond the points in common between two neighboring taps, the points with the highest efficiency have been taken and plotted.

In the figure, it becomes clear that as the number of taps increases, the ZVS area expands and tends to cover all the space of the $V_{2}-\phi$ i.e. $V_{2}-P_{2}$ domain, and this is the purpose of using tap changers. Moreover, here the use of the triangular and trapezoidal modulations will cover the remaining part of the $V_{2}-P_{2}$ area quite efficiently. Obviously, the region with low voltage and high power cannot be reached because the current limit is exceeded in this area.

With figure 5.16b, is clear that with regard to the phase shift modulation, it would be useful to have an additional tap when the primary side voltage is low, with $V_{1}=30 \mathrm{~V}$.

Figure 5.17 shows the results gotten when adding a transformer with additional tap $n_{\mathrm{T}}=12$. This transformer is different from the previous that instead had taps up to $n_{\mathrm{T}}=8$. That this is a different transformer, can be seen from the different opening angle of the ZVS region, which does not match the increasing opening angle of the ZVS region of the taps with a lower transformation ratio. The opening angle of a ZVS region for a certain tap is strictly connected to the leakage inductance of the tap in question. 


\begin{tabular}{|c|c|c|c|c|c|c|c|c|c|c|c|}
\hline Tap. & $\phi^{\circ}$ & $\begin{array}{c}V_{1} \\
\text { in } \mathrm{V}\end{array}$ & $\begin{array}{c}I_{1} \\
\text { in } \mathrm{A}\end{array}$ & $\begin{array}{c}P_{1} \\
\text { in } \mathrm{W}\end{array}$ & $\begin{array}{l}V_{2} \\
\text { in } \mathrm{V}\end{array}$ & $\begin{array}{c}I_{2} \\
\text { in A }\end{array}$ & $\begin{array}{c}P_{2} \\
\text { in } \mathrm{W}\end{array}$ & $\begin{array}{l}P_{\text {loss }} \\
\text { in } \mathrm{W}\end{array}$ & $\begin{array}{c}\eta \\
\text { in } \%\end{array}$ & $\begin{array}{c}I_{\mathrm{rms}, 1} \\
\text { in A }\end{array}$ & $\begin{array}{c}I_{\mathrm{rms}, 2} \\
\text { in A }\end{array}$ \\
\hline 2 & 5 & 50.12 & 15.99 & 801.2 & 100.5 & 8.295 & 833.4 & 32.25 & 96.13 & 16.8 & 8.31 \\
\hline 2 & 20 & 50.29 & 63.73 & 3205 & 100.2 & 35.51 & 3559 & 353.8 & 90.06 & & \\
\hline 3 & 5 & 50.56 & 14.73 & 744.7 & 150.5 & 5.133 & 744.7 & 28.08 & 96.37 & 15.6 & 5.18 \\
\hline 3 & 25 & 50.81 & 93.50 & 4751 & 150.2 & 34.45 & 4751 & 424.2 & 91.80 & 113 & 36.6 \\
\hline 4 & 5 & 50.20 & 20.13 & 1011 & 201.1 & 5.182 & 1042 & 31.39 & 96.99 & 20.9 & 5.1 \\
\hline 4 & 25 & 50.40 & 104.8 & 5284 & 200.9 & 28.18 & 5662 & 378.2 & 93.32 & 124 & 30.2 \\
\hline 5 & 5 & 50.09 & 16.76 & 839.3 & 250.2 & 3.47 & 867.3 & 28.00 & 96.77 & 17.40 & 3.41 \\
\hline 5 & 30 & 50.36 & 121.4 & 6113 & 249.9 & 26.25 & 6559 & 446.2 & 93.20 & 146 & 28.4 \\
\hline 6 & 5 & 50.03 & 18.74 & 937.5 & 300.7 & 3.21 & 964.4 & 26.89 & 97.21 & & \\
\hline 6 & 50 & 50.31 & 175.7 & 8837 & 300.5 & 32.35 & 9719 & 881.5 & 90.93 & & \\
\hline 7 & 10 & 50.27 & 46.07 & 2316 & 350.7 & 6.850 & 2402 & 86.42 & 96.40 & 49.7 & 7.56 \\
\hline 7 & 40 & 50.52 & 162.8 & 8225 & 350.4 & 25.47 & 8923 & 698.1 & 92.18 & 212 & 31.8 \\
\hline 8 & 10 & 50.09 & 46.86 & 2347 & 401.2 & 6.02 & 2417 & 69.65 & 97.12 & 48.7 & 6.11 \\
\hline 8 & 55 & 49.97 & 203.9 & 10188 & 401.1 & 28.11 & 11275 & 1087 & 90.36 & 271 & 34.0 \\
\hline 4 & 5 & 29.97 & 12.99 & 389.2 & 120.8 & 3.31 & 400.1 & 10.90 & 97.27 & 13.4 & 3.32 \\
\hline 4 & 50 & 30.45 & 103.51 & 3152 & 120.6 & 29.28 & 3530 & 377.8 & 89.30 & 140 & 34.4 \\
\hline 6 & 5 & 29.77 & 13.16 & 391.8 & 180.2 & 2.24 & 403 & 11.41 & 97.17 & 13.6 & 2.2 \\
\hline 6 & 50 & 30.37 & 111.6 & 3390 & 169.4 & 21.90 & 3710 & 320.7 & 91.36 & 149 & 24.5 \\
\hline 8 & 10 & 30.12 & 28.39 & 855.1 & 240.7 & 3.64 & 877 & 22.03 & 97.49 & 29.6 & 3.69 \\
\hline 8 & 70 & 30.09 & 138.4 & 4166 & 240.6 & 19.19 & 4617 & 450.5 & 90.24 & 204 & 25.5 \\
\hline 12 & 5 & 30.2 & 13.74 & 414.6 & 361.3 & 1.165 & 421.0 & 6.35 & 98.49 & & \\
\hline 12 & 60 & 30.3 & 197.6 & 5980 & 361.2 & 18.13 & 6550 & 566.8 & 91.35 & & \\
\hline 12 & 5 & 30.1 & 46.78 & 1407 & 401.1 & 3.590 & 1440 & 33.06 & 97.70 & & \\
\hline 12 & 60 & 30.1 & 224.4 & 6746 & 401.1 & 18.48 & 7411 & 665.0 & 91.03 & & \\
\hline
\end{tabular}

Table 5.5: Maximum efficiency and maximum power for each tap. Taps 2-8 with transformer $\mathrm{T}_{3}$, Tap 12 with transformer $\mathrm{T}_{4}$

\section{Measurement results with $V_{1}=50 \mathrm{~V}$}

In the last group of graphs, the voltage at the primary is set to $V_{1}=50 \mathrm{~V}$. In figures $5.18 \mathrm{a}$ and $5.18 \mathrm{~b}$, all measurement points from the tap with $n_{\mathrm{T}}=3$ to the tap with $n_{\mathrm{T}}=8$ are plotted. The modulation strategy is always phase shift modulation. For overlapping points, the points with the higher efficiency have been chosen. The effect of the taps is to produce a homogeneous region with high efficiency that tends to cover the entire voltage and power range. Those points with low values of voltage $V_{2}$ haves not been represented because not enough data was available. As mentioned before, here too trapezoidal and triangular modulation strategies both extend the soft-switching region.

Figure 5.18c shows another feature of a dual active bridge and the modification with a tap changer. The ratio between the RMS current in the transformer and the DC current in 


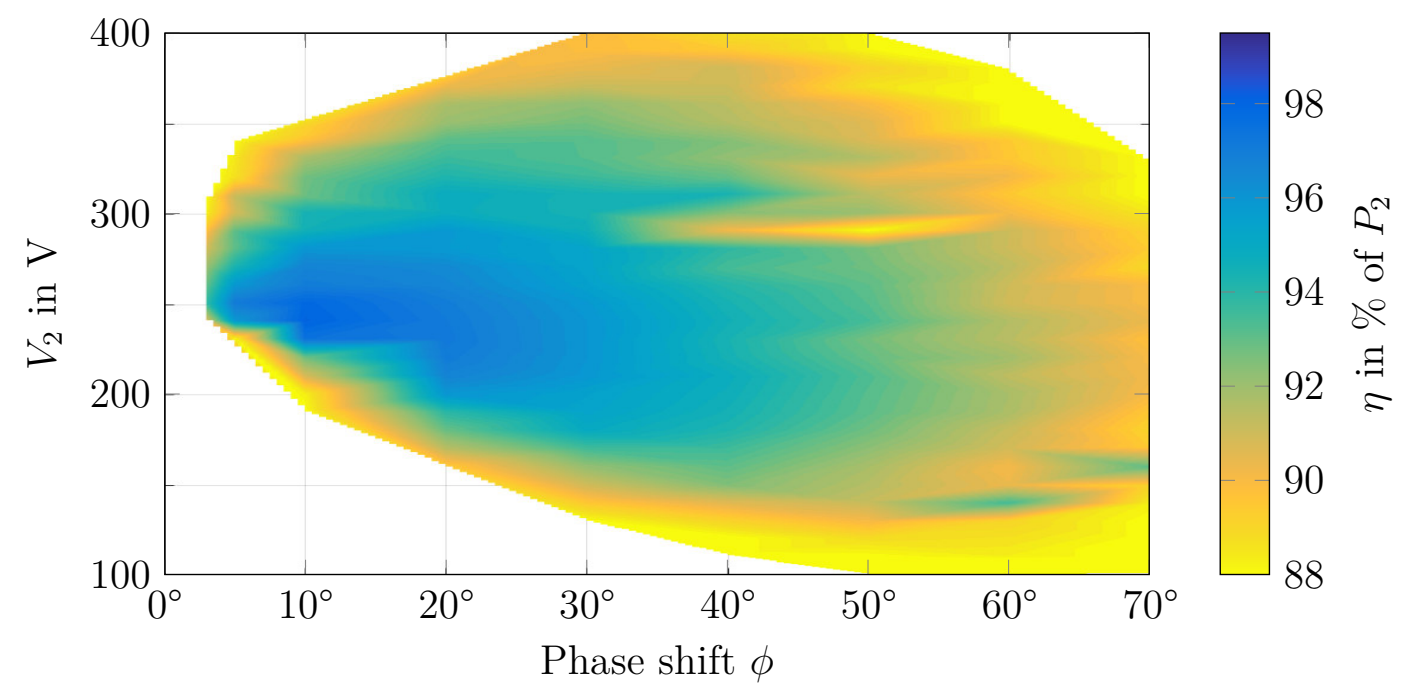

(a) Efficiency for the single Tap Tath $_{8}$ whase shift $\phi$

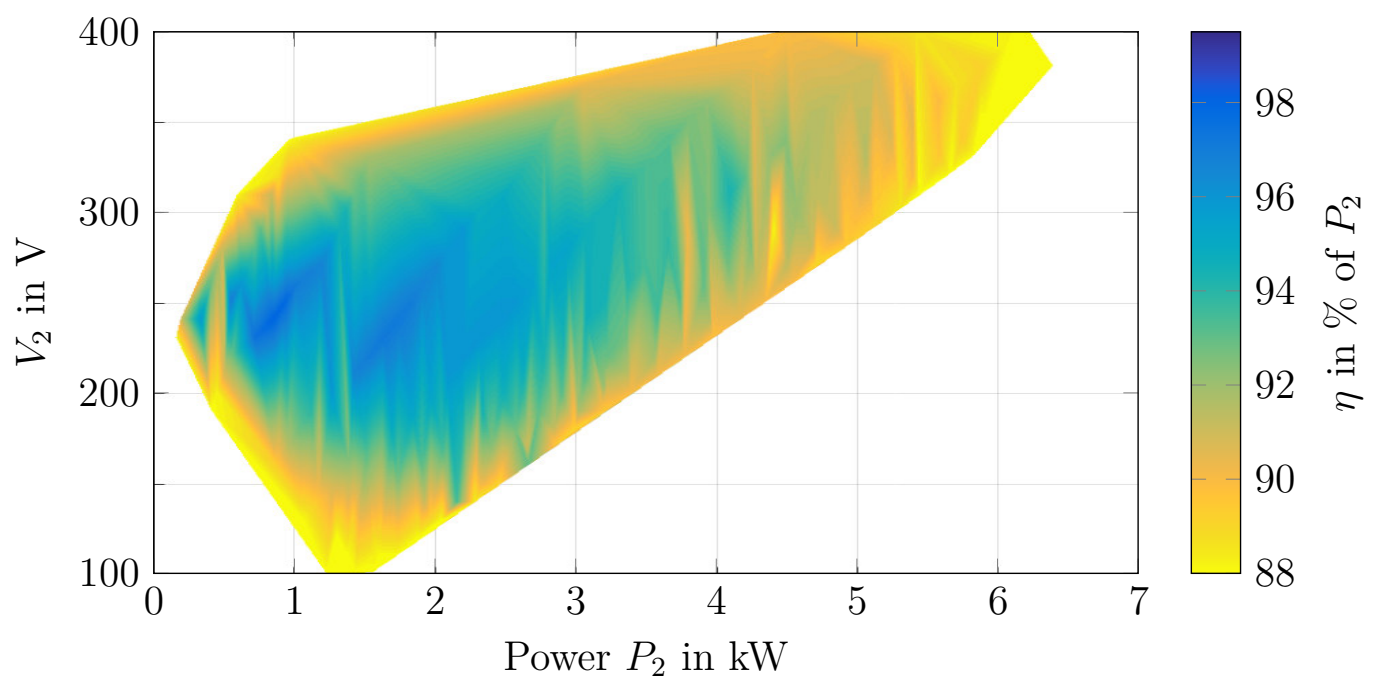

(b) Efficiency for the single $\operatorname{Tap}_{8}$ with power $P_{2}$

Figure 5.15: Efficiency with $V_{1}=30 \mathrm{~V}$ in phase shift modulation and Tap with $_{\mathrm{T}}=8$

the converter $I_{\mathrm{rms}, \mathrm{tr} 2} / I_{\mathrm{dc}, 2}$ grows by increasing the phase shift angle $\phi$ and the voltage ratio referred to primary side $d$. Without the tap changer, this ratio would reach 1.8 , whereas with the tap changer, the ratio remains below 1.2 for a large part of the points. This consistently the conduction losses in semiconductors and the transformer. It should be remembered that by increasing the RMS current by about $40 \%$, the conduction losses will double.

\section{Conclusion}

In conclusion, these figures show that the tap changer significantly increases the efficiency on the whole domain $V_{2}-\phi$ and even significantly reduces the current in the transformer, which in turn leads to generally reduced conduction losses and switching losses. The use of other modulations strategies could reduce these advantages when compared to the solution without a tap changer, but the reduction of losses continues unabated, as showed in the 


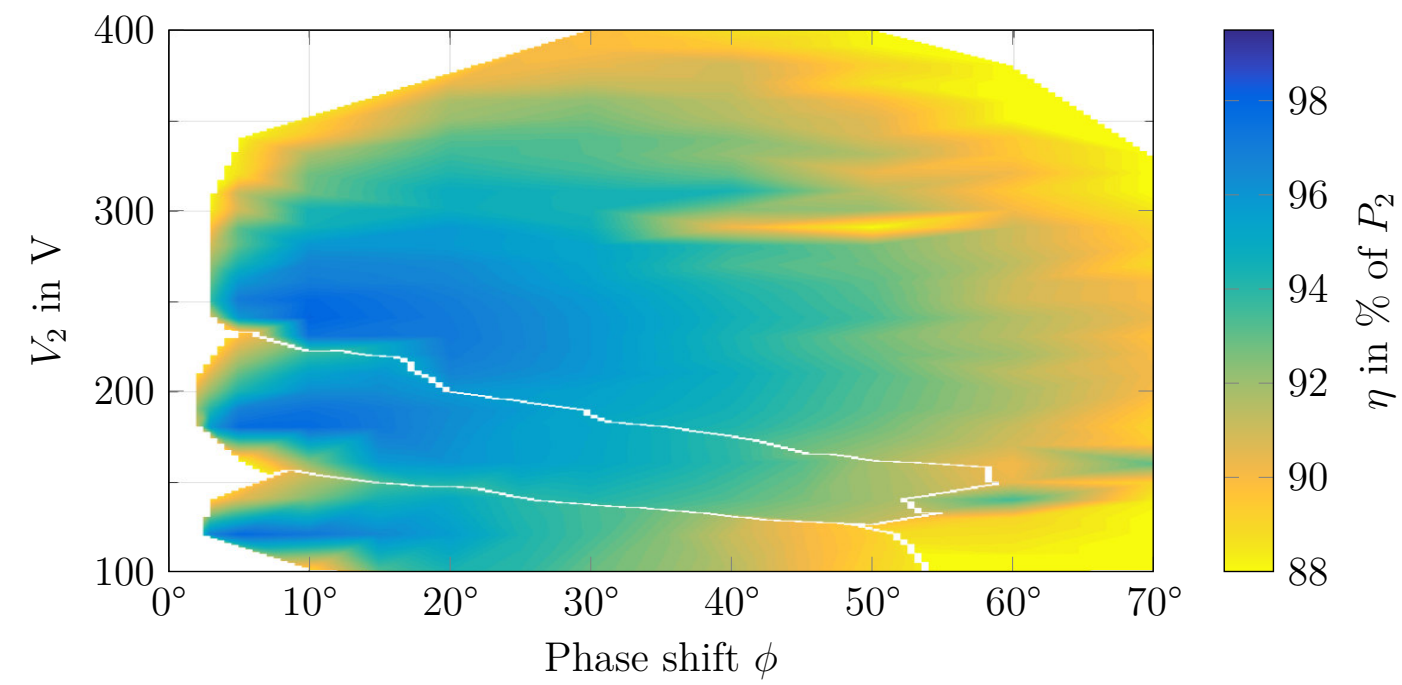

(a) Efficiency for taps $\mathrm{Tap}_{4}, \mathrm{Tap}_{6}$ and $\mathrm{Tap}_{8}$ on $\phi$

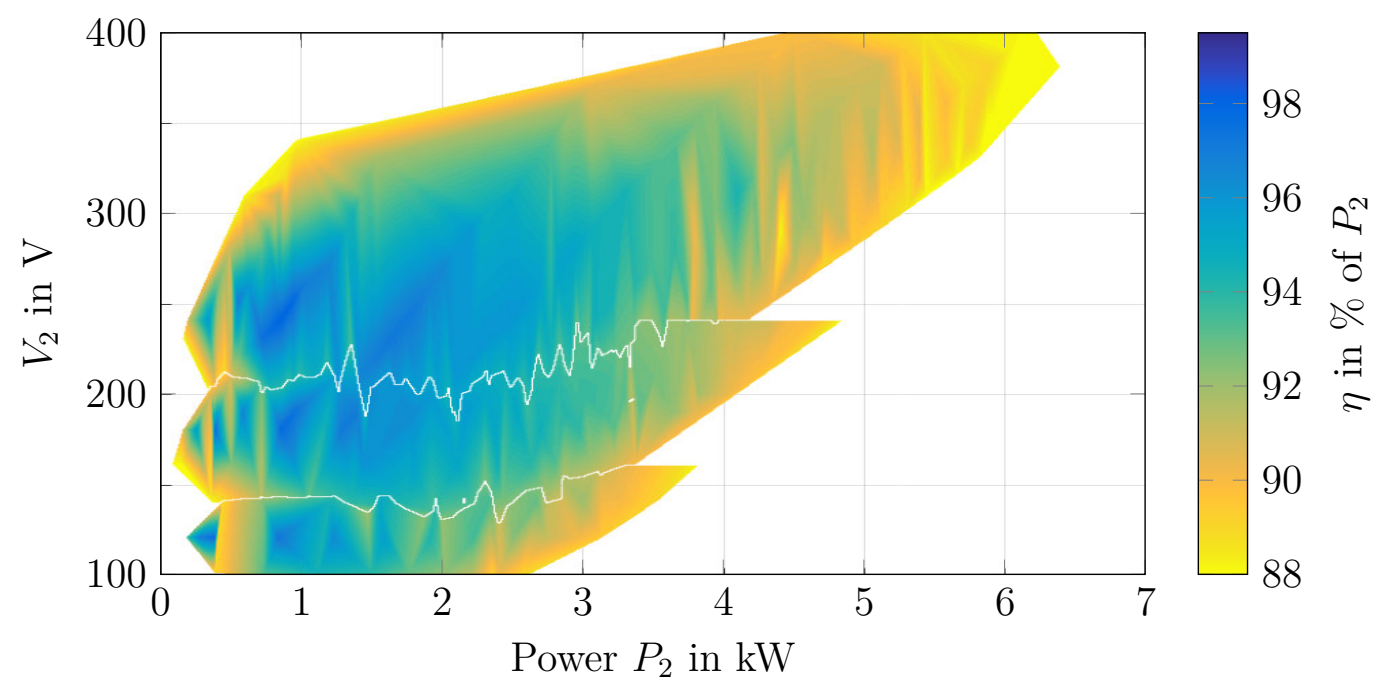

(b) Efficiency for taps $\mathrm{Tap}_{4}, \mathrm{Tap}_{6}$ and $\mathrm{Tap}_{8}$ on $P_{2}$

Figure 5.16: Efficiency in function of the power with $V_{1}=30 \mathrm{~V}$ in phase shift modulation

simulations. With the use of these further modulations strategies, the efficiency will be very high at all point. These worthwhile values will be slightly reduced by using a tap changer with MOSFTETs or IGBTs. In the case of relays, the difference will not be appreciable because the efficiency variation will be less than $0.1 \%$. 


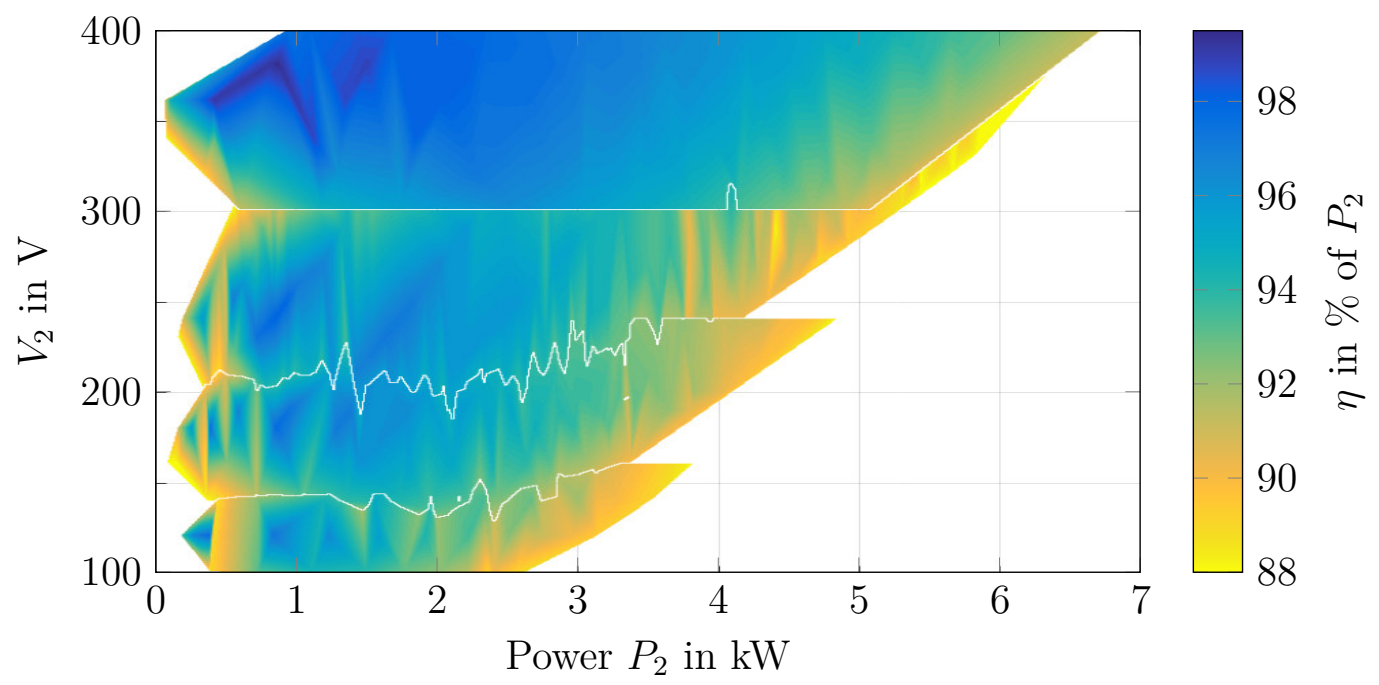

(a) Efficiency for taps $\mathrm{Tap}_{4}, \mathrm{Tap}_{6}, \mathrm{Tap}_{8}$ and $\mathrm{Tap}_{12}$ on $P_{2}$

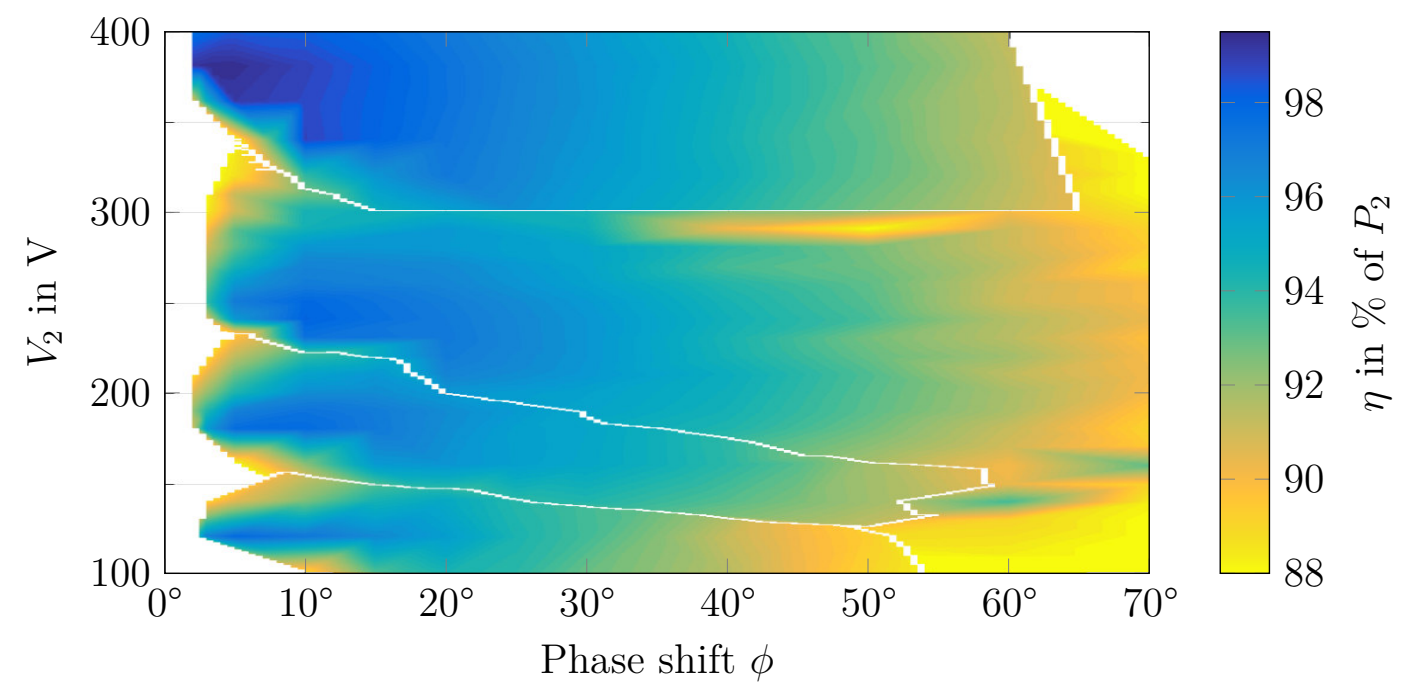

(b) Efficiency for taps $\operatorname{Tap}_{4}, \operatorname{Tap}_{6}, \operatorname{Tap}_{8}$ and $\operatorname{Tap}_{12}$ on $\phi$

Figure 5.17: Efficiency in function of the phase shift angle with $V_{1}=30 \mathrm{~V}$ in phase shift modulation 

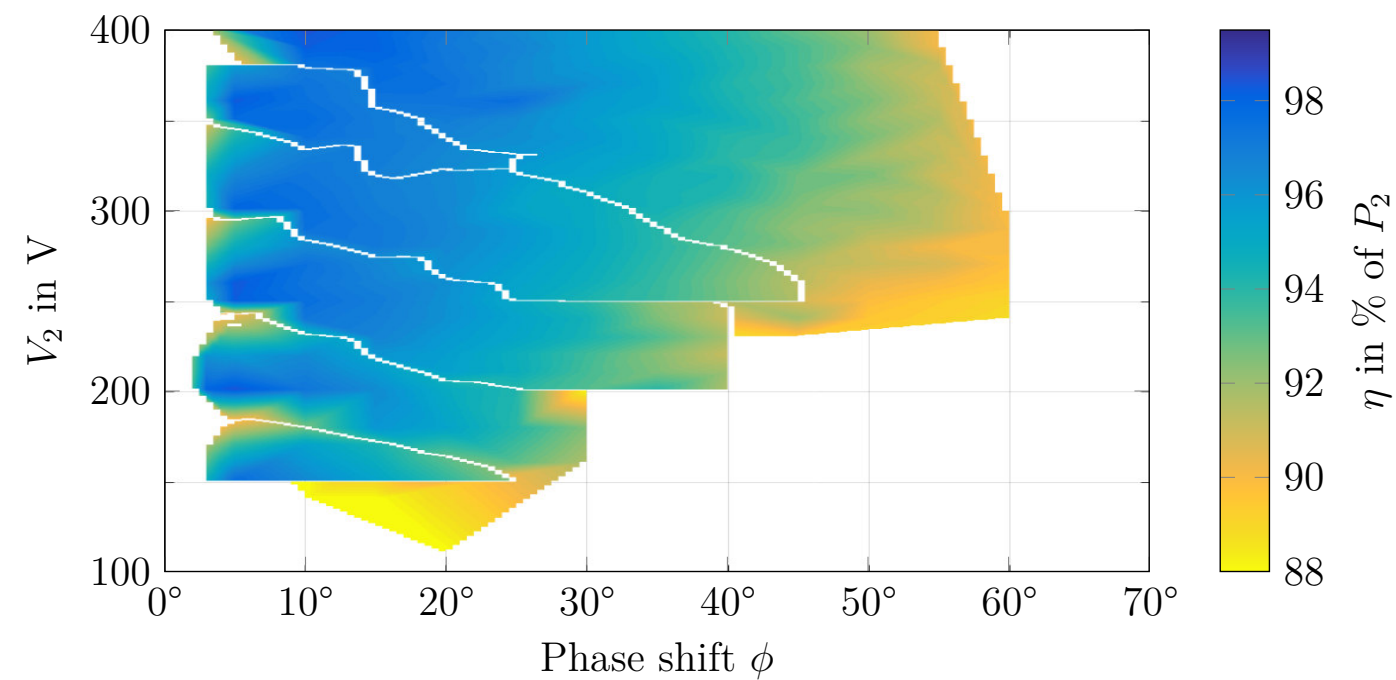

(a) Efficiency over the phase shift for all the taps combined
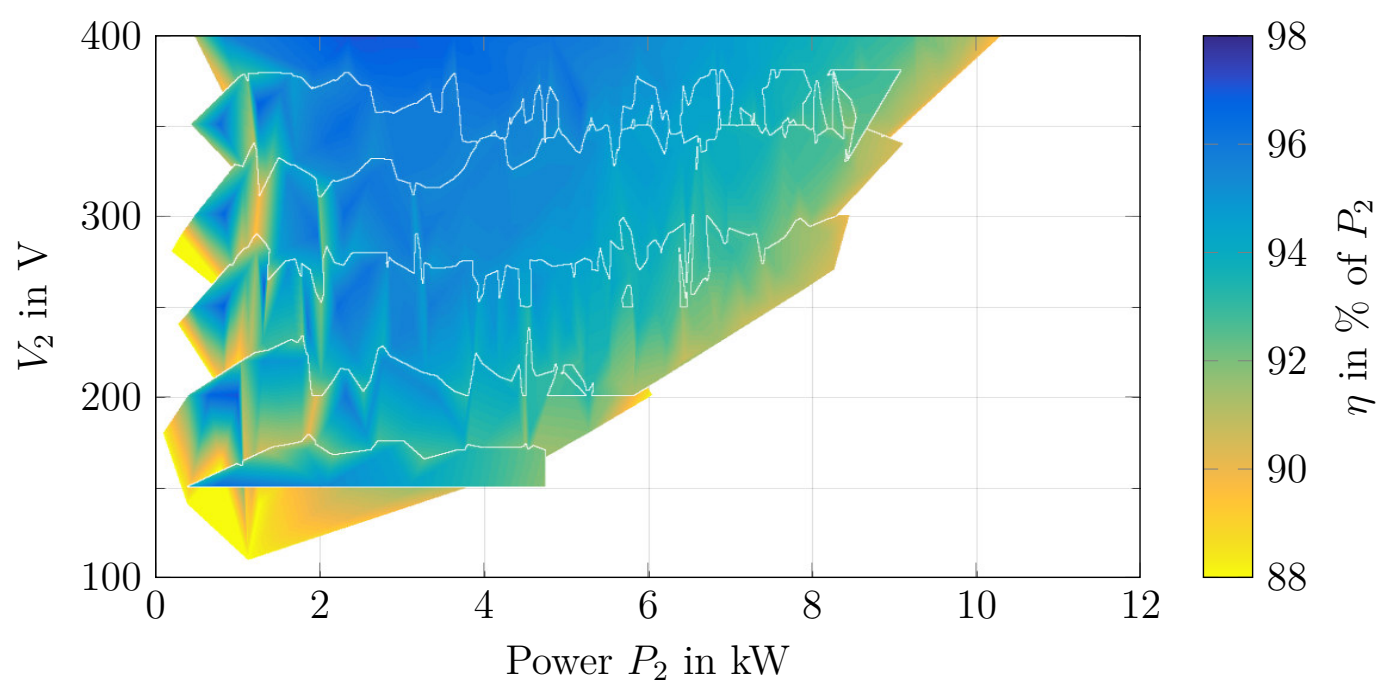

(b) Efficiency over the power for all taps combined

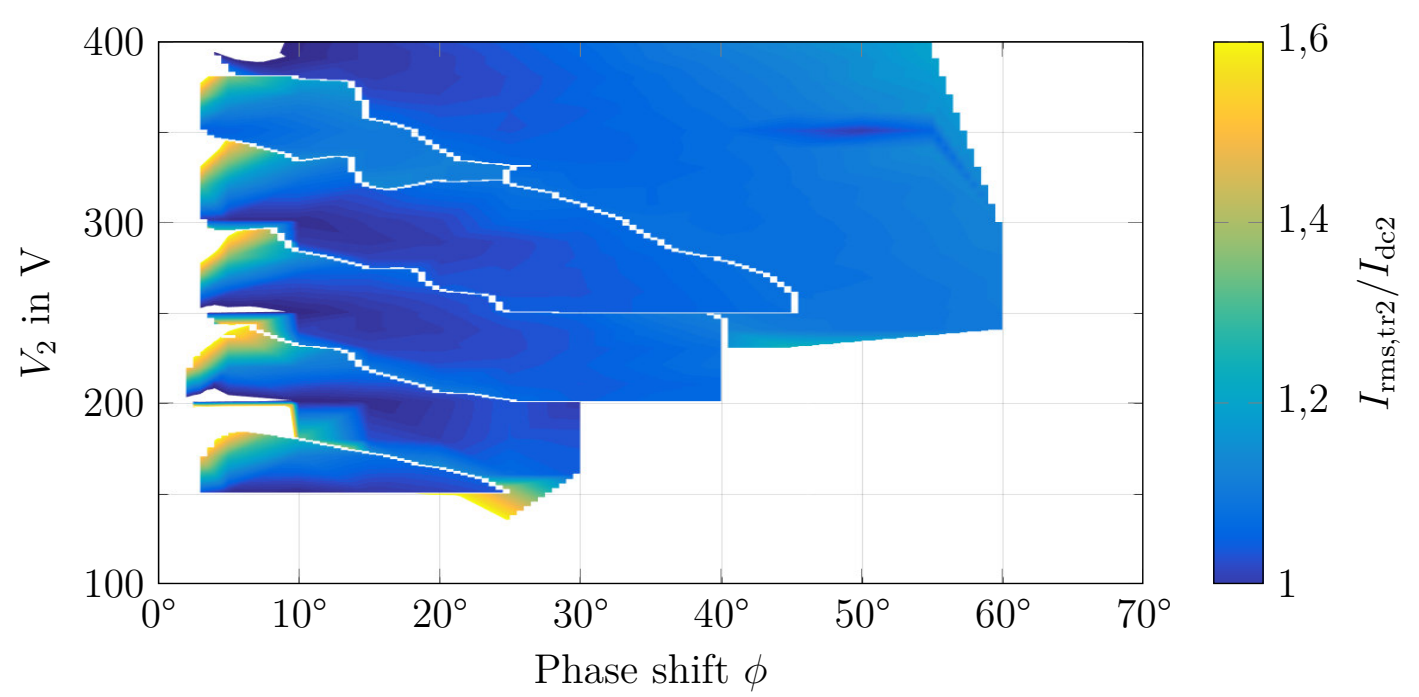

(c) Ratio between transformer current and DC-current

Figure 5.18: $V_{1}=50 \mathrm{~V}$ in phase shift modulation 


\section{Conclusion and Outlook}

\subsection{Conclusion}

In this work, the feasibility of a dual active bridge with tap changer has been verified. In the course of constructing this converter, a transformer with several windings both in the primary and secondary side was first developed. Here, the choice was made that the number of windings in the primary should equal those in the secondary. A transformer with $8+8$ windings and a transformer with $12+12$ windings have been simulated and realized. Following this, the electronic parts have been designed, including the H-bridges, a control board and drivers board. A variety of tap changers were built. At the end, the construction of a converter has been executed, with the converter then being put into operation, and tests have been carried out on the various types of tap changers to verify which can operate properly under the given conditions. Subsequently, a large spectrum of measurements was made by directly connecting the H-bridge to the transformer to evaluate the maximum possible efficiency with an ideal tap changer. The resulting converter has an efficiency between $90 \%$ and $98 \%$ over a wide range of powers and voltages. In the area where it operates in soft switching, it always has an efficiency of $90-91 \%$. Subsequently, the question was considered of how to increase the performance of the converter, with particular attention paid to the region with the highest power transfer, where the converter yields too much in efficiency and which cannot be explained by a normal operating mode. A more in-depth analysis has shown that the transformer contributes significantly to this drop in efficiency, and a new proposed version of the transformer should prevent the drop of efficiency.

\subsection{Outlook}

\section{Improved version of the transformer}

In 2.5, improved versions of the transformer are introduced, and these should have a better performance than the implemented transformers. Further efforts are needed to evaluate transformers with primary and secondary windings on two or more different columns, e.g. with primary windings on one column and secondary windings on another column. This typically leads to greater leakage inductance, which can however be limited through the use of windings with few turns and increased iron section. In addition to this, it is not necessary that the windings of the secondary side exhibit all identical leakage inductances since they are connected in series and can be conveniently assorted. This does not hold true, however, for the primary windings, which are in parallel. Here, it is preferable that the leakage inductance of the windings, and even the coupling factor with the secondary, are as similar as possible in order to obtain a uniform distribution of the current in the primary windings. This can make the transformer easier to manufacture, to cool and to obtain a modular construction. 


\section{Implementation of further modulation strategies for the DAB-TC}

In the first part of this text, in addition to phase shift modulation, two further modulation strategies, the trapezoidal mode and the triangular mode, were also considered. These two modulation strategies have been simulated, but they have not yet been implemented in the hardware. The set-up is ready for this implementation and it need only be reprogrammed.

\section{Implementation of a control unit for the DAB-TC}

This control unit must be able to set a voltage in the presence of a load at one terminal and a power supply at the other terminal and perform the switch continuously from one tap to the other. It must be able, even in the case of fast voltage variations at both terminals, to choose and change the tap changer rapidly and set the right phase shift angle and other parameters, in the case of other modulation strategies. The DAB-TC with a MOSFETs-based tap changer is able to change within a single modulation period from the tap with the lowest voltage to the tap with the highest voltage.

\section{Evaluation of the use of the DAB-TC in DC-DC converter with power factor corrector unit}

A DC-DC converter with high dynamic and wide voltage range can be useful implemented in many applications. Consider now DC-link of the high voltage side connected to a rectifier bridge, the DC-link is connected to the high voltage side of the DAB-TC, which low voltage side, is connected to battery packs and the DAB-TC works as battery charger. In this working condition, the DAB-TC can be operated as a power factor corrector (PFC).

\section{$1: n_{\mathrm{T}}$}
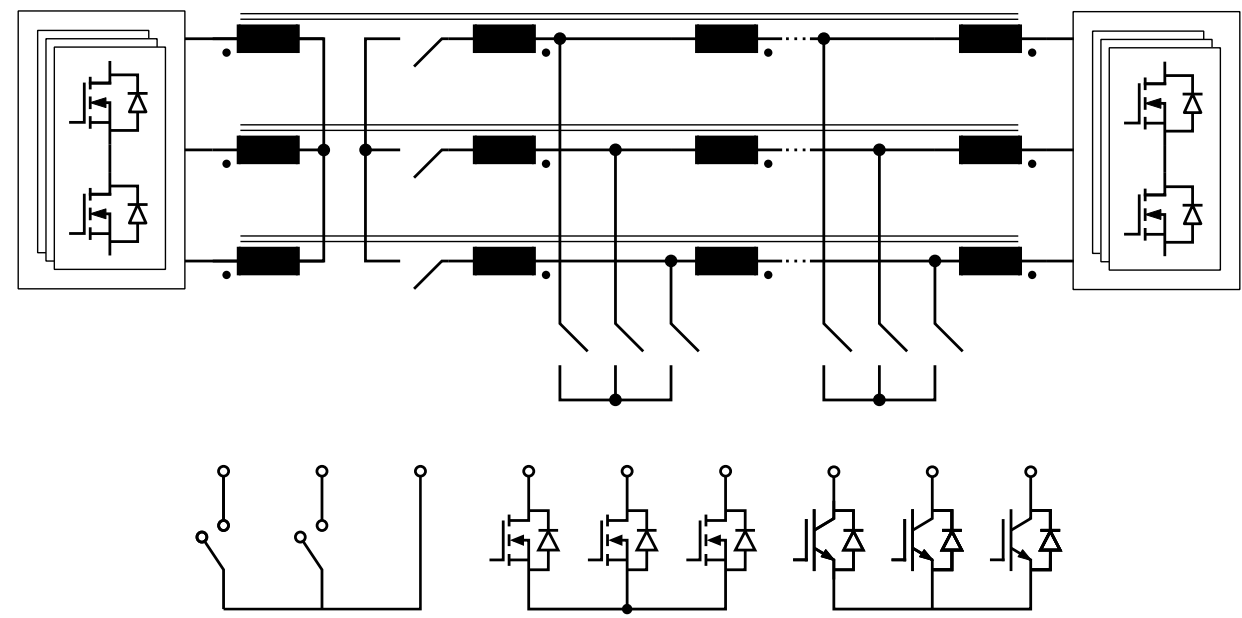

Figure 6.1: Three-phase dual active bridge with tap changer and tap switches implementation

\section{Three-phase dual active bridge with tap changer}

The three-phase version of the dual active bridge with tap changer (3ph-DAB-TC) is depicted in figure 6.1. The tap changer changes the transformer ratio $n_{\mathrm{T}}$ by changing the position of the star center of the transformer. 


\section{A Transformer with Multiple Windings in Parallel and in Series}

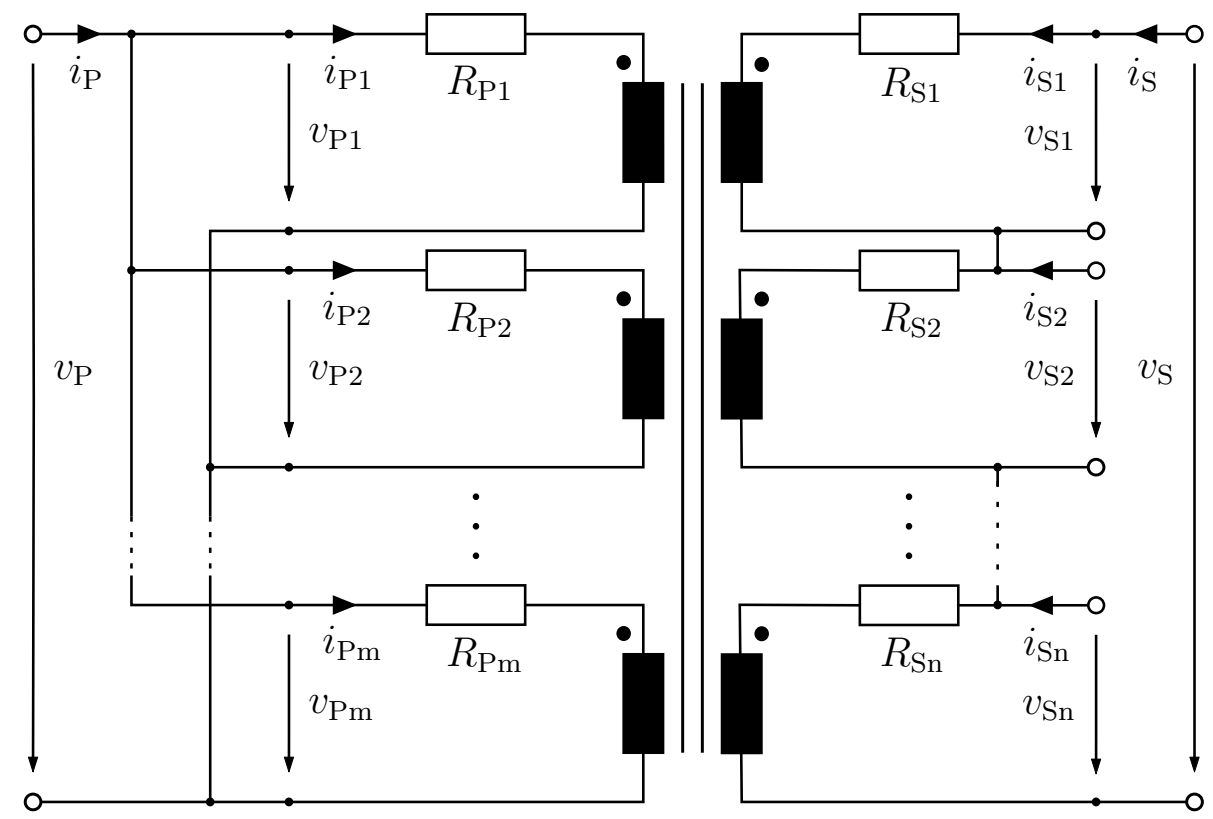

Figure A.1: Transformer with multiple windings in parallel at the primary side and in series at secondary side

For the transformer in figure A.1 the following equations can be written:

$$
\begin{gathered}
v_{\mathrm{P} 1}=L_{\mathrm{P} 1} \frac{\mathrm{d} i_{\mathrm{P} 1}}{\mathrm{~d} t}+\cdots+M_{\mathrm{P} 1, \mathrm{Pm}} \frac{\mathrm{d} i_{\mathrm{Pm}}}{\mathrm{d} t}+M_{\mathrm{P} 1, \mathrm{~S} 1} \frac{\mathrm{d} i_{\mathrm{S} 1}}{\mathrm{~d} t}+\cdots+M_{\mathrm{P} 1, \mathrm{Sn}} \frac{\mathrm{d} i_{\mathrm{Sn}}}{\mathrm{d} t}+R_{\mathrm{P} 1} i_{\mathrm{P} 1} \\
\quad \vdots \\
v_{\mathrm{Pm}}=M_{\mathrm{Pm}, \mathrm{P} 1} \frac{\mathrm{d} i_{\mathrm{P} 1}}{\mathrm{~d} t}+\cdots+L_{\mathrm{Pm}} \frac{\mathrm{d} i_{\mathrm{Pm}}}{\mathrm{d} t}+M_{\mathrm{Pm}, \mathrm{S} 1} \frac{\mathrm{d} i_{\mathrm{S} 1}}{\mathrm{~d} t}+\cdots+M_{\mathrm{Pm}, \mathrm{Sn}} \frac{\mathrm{d} i_{\mathrm{Sn}}}{\mathrm{d} t}+R_{\mathrm{Pm}} i_{\mathrm{Pm}} \\
v_{\mathrm{S} 1}=M_{\mathrm{S} 1, \mathrm{P} 1} \frac{\mathrm{d} i_{\mathrm{P} 1}}{\mathrm{~d} t}+\cdots+M_{\mathrm{S} 1, \mathrm{Pm}} \frac{\mathrm{d} i_{\mathrm{Pm}}}{\mathrm{d} t}+L_{\mathrm{S} 1} \frac{\mathrm{d} i_{\mathrm{S} 1}}{\mathrm{~d} t}+\cdots+M_{\mathrm{S} 1, \mathrm{Sn}} \frac{\mathrm{d} i_{\mathrm{Sn}}}{\mathrm{d} t}+R_{\mathrm{S} 1} i_{\mathrm{Pm}} \\
\quad \vdots \\
v_{\mathrm{Sn}}=M_{\mathrm{Sn}, \mathrm{P} 1} \frac{\mathrm{d} i_{\mathrm{P} 1}}{\mathrm{~d} t}+\cdots+M_{\mathrm{Sn}, \mathrm{Pm}} \frac{\mathrm{d} i_{\mathrm{Pm}}}{\mathrm{d} t}+M_{\mathrm{Sn}, \mathrm{S} 1} \frac{\mathrm{d} i_{\mathrm{S} 1}}{\mathrm{~d} t}+\cdots+L_{\mathrm{Sn}} \frac{\mathrm{d} i_{\mathrm{Sn}}}{\mathrm{d} t}+R_{\mathrm{Sn}} i_{\mathrm{Sn}}
\end{gathered}
$$

Now, to reduce the system of equations A.1-A.4 we are going to assume that transformer is made by $m+n$ windings, the windings are all equal and with the same inductance and coupling factor. In other words we will have only one inductance $L$ and one mutual 
inductance $M$ in the system of equations.

With this assumption the equations A.1-A.4 can be written in the following simplified form:

$$
\begin{gathered}
v_{\mathrm{P} 1}=L \frac{\mathrm{d} i_{\mathrm{P} 1}}{\mathrm{~d} t}+\cdots+M \frac{\mathrm{d} i_{\mathrm{Pm}}}{\mathrm{d} t}+M \frac{\mathrm{d} i_{\mathrm{S} 1}}{\mathrm{~d} t}+\cdots+M \frac{\mathrm{d} i_{\mathrm{Sn}}}{\mathrm{d} t}+R_{\mathrm{P} 1} i_{\mathrm{P} 1} \\
\vdots \\
v_{\mathrm{Pm}}=M \frac{\mathrm{d} i_{\mathrm{P} 1}}{\mathrm{~d} t}+\cdots+L \frac{\mathrm{d} i_{\mathrm{Pm}}}{\mathrm{d} t}+M \frac{\mathrm{d} i_{\mathrm{S} 1}}{\mathrm{~d} t}+\cdots+M \frac{\mathrm{d} i_{\mathrm{Sn}}}{\mathrm{d} t}+R_{\mathrm{Pm}} i_{\mathrm{Pm}} \\
v_{\mathrm{S} 1}=M \frac{\mathrm{d} i_{\mathrm{P} 1}}{\mathrm{~d} t}+\cdots+M \frac{\mathrm{d} i_{\mathrm{Pm}}}{\mathrm{d} t}+L \frac{\mathrm{d} i_{\mathrm{S} 1}}{\mathrm{~d} t}+\cdots+M \frac{\mathrm{d} i_{\mathrm{Sn}}}{\mathrm{d} t}+R_{\mathrm{S} 1} i_{\mathrm{Pm}} \\
\vdots \\
v_{\mathrm{Sn}}=M \frac{\mathrm{d} i_{\mathrm{P} 1}}{\mathrm{~d} t}+\cdots+M \frac{\mathrm{d} i_{\mathrm{Pm}}}{\mathrm{d} t}+M \frac{\mathrm{d} i_{\mathrm{S} 1}}{\mathrm{~d} t}+\cdots+L \frac{\mathrm{d} i_{\mathrm{Sn}}}{\mathrm{d} t}+R_{\mathrm{Sn}} i_{\mathrm{Sn}}
\end{gathered}
$$

For the input voltage we have $v_{\mathrm{P}}=v_{\mathrm{P} 1} \ldots v_{\mathrm{Pm}}$ and for the secondary side currents we have that $i_{\mathrm{S}}=i_{\mathrm{S} 1}=\ldots i_{\mathrm{Sn}}$ and $i_{\mathrm{Pj}}=\frac{i_{\mathrm{P}}}{m}$. This allows us to write the equations for each primary winding $j$ of the primary side:

$$
v_{\mathrm{P}}=v_{\mathrm{Pj}}=\frac{1}{m} L \frac{\mathrm{d} i_{\mathrm{P}}}{\mathrm{d} t}+\frac{m-1}{m} M \frac{\mathrm{d} i_{\mathrm{P}}}{\mathrm{d} t}+n M \frac{\mathrm{d} i_{\mathrm{S}}}{\mathrm{d} t}+\frac{1}{m} R_{\mathrm{P}} i_{\mathrm{P}}
$$

and for each secondary winding we have

$$
v_{\mathrm{Sk}}=L \frac{\mathrm{d} i_{\mathrm{S}}}{\mathrm{d} t}+(n-1) M \frac{\mathrm{d} i_{\mathrm{S}}}{\mathrm{d} t}+m M \frac{1}{m} \frac{\mathrm{d} i_{\mathrm{P}}}{\mathrm{d} t}+R_{\mathrm{Sk}} i_{\mathrm{Sk}}
$$

For the voltage $v_{\mathrm{S}}$ it gilts $v_{\mathrm{S}}=v_{\mathrm{S} 1}+\ldots v_{\mathrm{Sn}}$ and adding all the $v_{\mathrm{Sk}}$ with $R_{\mathrm{P}}=R_{\mathrm{P} 1}=\ldots=R_{\mathrm{Pm}}$, $R_{\mathrm{S}}=R_{\mathrm{S} 1}=\ldots=R_{\mathrm{Sn}}$, we optain:

$$
v_{\mathrm{S}}=n L \frac{\mathrm{d} i_{\mathrm{S}}}{\mathrm{d} t}+n(n-1) M \frac{\mathrm{d} i_{\mathrm{S}}}{\mathrm{d} t}+n M \frac{\mathrm{d} i_{\mathrm{P}}}{\mathrm{d} t}+n R_{\mathrm{S}} i_{\mathrm{S}}
$$

Finally, we have the equations of a new transformer

\section{Symmetric transformer}

$$
\begin{aligned}
& v_{\mathrm{P}}=L_{1} \frac{\mathrm{d} i_{\mathrm{P}}}{\mathrm{d} t}+M_{12} \frac{\mathrm{d} i_{\mathrm{S}}}{\mathrm{d} t}+\frac{R_{\mathrm{P}}}{m} \\
& v_{\mathrm{S}}=M_{21} \frac{\mathrm{d} i_{\mathrm{P}}}{\mathrm{d} t}+L_{2} \frac{\mathrm{d} i_{\mathrm{S}}}{\mathrm{d} t}+n R_{\mathrm{S}}
\end{aligned}
$$

where

$$
\begin{aligned}
L_{1} & =\left(\frac{1}{m} L+\frac{m-1}{m} M\right) \\
L_{2} & =n L+n(n-1) M \\
M_{12} & =M_{21}=n M
\end{aligned}
$$


$m$ is the number of windings connected in parallel at the primary side of the transformer and $n$ is the number of windings connected in series at the secondary side of the transformer.

\section{Leakage inductance of the symmetric transformer}

$$
\begin{aligned}
L_{\sigma 1} & =L_{1}-t M, \\
L_{\sigma 2} & =L_{2}-\frac{1}{t} M, \\
L_{\sigma} & =L_{\sigma 1}+t^{2} L_{\sigma 2}
\end{aligned}
$$

Replacing the A.13 in the A.14 we obtain for $L_{\sigma}$

$$
\begin{aligned}
L^{\prime}{ }_{\sigma} & =\left(\frac{1}{m}+\frac{1}{n}\right)(L-M) \\
L^{\prime \prime}{ }_{\sigma} & =n^{2}\left(\frac{1}{m}+\frac{1}{n}\right)(L-M)
\end{aligned}
$$

$L_{\sigma}^{\prime}$ is referred to the low voltage side and $L^{\prime \prime}{ }_{\sigma}$ is referred to the high voltage side. 


\section{B Measurement results}

Table B.1: Transformer $\mathrm{T}_{3}$, Tap 2, $V_{1}=50 \mathrm{~V}$

\begin{tabular}{ccccccccccc}
\hline$\phi^{\circ}$ & $\begin{array}{c}V_{1} \\
\text { in V }\end{array}$ & $\begin{array}{c}I_{1} \\
\text { in A }\end{array}$ & $\begin{array}{c}P_{1} \\
\text { in W }\end{array}$ & $\begin{array}{c}V_{2} \\
\text { in V }\end{array}$ & $\begin{array}{c}I_{2} \\
\text { in A }\end{array}$ & $\begin{array}{c}P_{2} \\
\text { in W }\end{array}$ & $\begin{array}{c}P_{\text {loss }} \\
\text { in W }\end{array}$ & $\begin{array}{c}\eta \\
\text { in \% }\end{array}$ & $\begin{array}{c}I_{\text {rms, } 1} \\
\text { in A }\end{array}$ & $\begin{array}{c}I_{\text {rms }, 2} \\
\text { in A }\end{array}$ \\
\hline 2 & 50.01 & 6.753 & 337.7 & 100.6 & 3.630 & 365.1 & 27.42 & 92.49 & 7.10 & 3.67 \\
3 & 50.05 & 9.901 & 495.6 & 100.5 & 5.158 & 518.6 & 23.05 & 95.56 & 10.3 & 5.15 \\
5 & 50.12 & 15.99 & 801.2 & 100.5 & 8.295 & 833.4 & 32.25 & 96.13 & 16.8 & 8.31 \\
10 & 50.29 & 35.47 & 1784 & 100.3 & 18.97 & 1903 & 119.3 & 93.73 & 39.6 & 19.3 \\
15 & 50.49 & 50.43 & 2546 & 100.1 & 27.59 & 2762 & 215.6 & 92.19 & 59.0 & 28.5 \\
20 & 50.29 & 63.73 & 3205 & 100.2 & 35.51 & 3559 & 353.8 & 90.06 & & \\
\hline 3 & 50.46 & 23.70 & 1196 & 111.3 & 11.74 & 1307 & 111.5 & 91.47 & 28.6 & 15.1 \\
5 & 50.56 & 31.15 & 1575 & 111.2 & 15.30 & 1701 & 126.7 & 92.55 & 34.8 & 17.8 \\
10 & 50.47 & 44.96 & 2269 & 111.2 & 22.06 & 2454 & 184.3 & 92.49 & 48.0 & 24.2 \\
15 & 50.65 & 60.58 & 3068 & 111.1 & 30.40 & 3377 & 308.7 & 90.86 & 65.2 & 32.5 \\
\hline 3 & 50.56 & 30.32 & 1533 & 121.1 & 14.67 & 1777 & 244.3 & 86.25 & 43.5 & 24.4 \\
5 & 50.68 & 38.24 & 1938 & 121.0 & 18.19 & 2202 & 264.0 & 88.01 & 48.2 & 26.1 \\
10 & 50.88 & 56.32 & 2866 & 120.9 & 26.30 & 3179 & 312.7 & 90.16 & 63.3 & 31.4 \\
10 & 50.82 & 56.66 & 2880 & 120.9 & 26.50 & 3203 & 322.9 & 89.92 & & \\
\hline
\end{tabular}


Table B.2: Transformer $\mathrm{T}_{3}$, Tap $3, V_{1}=50 \mathrm{~V}$

\begin{tabular}{ccccccccccc}
\hline$\phi^{\circ}$ & $\begin{array}{c}V_{1} \\
\text { in V }\end{array}$ & $\begin{array}{c}I_{1} \\
\text { in A }\end{array}$ & $\begin{array}{c}P_{1} \\
\text { in W }\end{array}$ & $\begin{array}{c}V_{2} \\
\text { in V }\end{array}$ & $\begin{array}{c}I_{2} \\
\text { in A }\end{array}$ & $\begin{array}{c}P_{2} \\
\text { in W }\end{array}$ & $\begin{array}{c}P_{\text {loss }} \\
\text { in W }\end{array}$ & $\begin{array}{c}\eta \\
\text { in \% }\end{array}$ & $\begin{array}{c}I_{\text {rms }, 1} \\
\text { in A }\end{array}$ & $\begin{array}{c}I_{\text {rms }, 2} \\
\text { in A }\end{array}$ \\
\hline 10 & 50.18 & 17.46 & 876.0 & 130.6 & 7.624 & 876.0 & 119.9 & 87.96 & & \\
15 & 50.14 & 37.34 & 1872 & 130.6 & 15.46 & 1872 & 147.1 & 92.72 & & \\
20 & 50.27 & 61.99 & 3117 & 130.5 & 25.80 & 3117 & 250.9 & 92.55 & & \\
25 & 50.37 & 76.11 & 3834 & 130.4 & 32.16 & 3834 & 359.2 & 91.43 & & \\
\hline 3 & 50.46 & 7.75 & 391.3 & 150.5 & 2.773 & 391.3 & 26.01 & 93.77 & 8.33 & 2.94 \\
5 & 50.56 & 14.73 & 744.7 & 150.5 & 5.133 & 744.7 & 28.08 & 96.37 & 15.6 & 5.18 \\
10 & 50.86 & 40.97 & 2084 & 150.4 & 14.54 & 2084 & 103.0 & 95.29 & 45.2 & 14.6 \\
15 & 50.79 & 60.79 & 3087 & 150.4 & 21.75 & 3087 & 185.2 & 94.34 & 68.5 & 22.3 \\
20 & 50.80 & 78.25 & 3975 & 150.4 & 28.40 & 3975 & 294.6 & 93.10 & 91.5 & 29.5 \\
25 & 50.81 & 93.50 & 4751 & 150.2 & 34.45 & 4751 & 424.2 & 91.80 & 113 & 36.6 \\
\hline 3 & 50.71 & 26.87 & 1363 & 170.7 & 8.756 & 1363 & 132.1 & 91.16 & 36.1 & 13.4 \\
5 & 50.74 & 36.28 & 1841 & 170.7 & 11.60 & 1841 & 139.8 & 92.94 & 43.6 & 15 \\
10 & 50.80 & 55.71 & 2830 & 170.5 & 17.58 & 2830 & 167.8 & 94.40 & 61 & 20 \\
15 & 50.77 & 74.70 & 3793 & 170.6 & 23.78 & 3793 & 263.3 & 93.51 & 80.1 & 26.2 \\
20 & 50.75 & 93.78 & 4760 & 170.5 & 30.34 & 4760 & 413.7 & 92.00 & 102 & 33.3 \\
\hline 5 & 50.94 & 45.01 & 2293 & 190.5 & 13.69 & 2293 & 315.3 & 87.91 & 69.7 & 23.7 \\
10 & 51.00 & 70.17 & 3579 & 190.4 & 20.97 & 3579 & 414.7 & 89.62 & 84.9 & 29 \\
15 & 51.01 & 91.18 & 4651 & 190.4 & 27.08 & 4651 & 503.4 & 90.23 & & \\
\hline
\end{tabular}


Table B.3: Transformer $\mathrm{T}_{3}$, Tap $4, V_{1}=50 \mathrm{~V}$

\begin{tabular}{|c|c|c|c|c|c|c|c|c|c|c|}
\hline$\phi^{\circ}$ & $\begin{array}{c}V_{1} \\
\text { in } \mathrm{V}\end{array}$ & $\begin{array}{c}I_{1} \\
\text { in } \mathrm{A}\end{array}$ & $\begin{array}{c}P_{1} \\
\text { in } \mathrm{W}\end{array}$ & $\begin{array}{c}V_{2} \\
\text { in } \mathrm{V}\end{array}$ & $\begin{array}{c}I_{2} \\
\text { in } \mathrm{A}\end{array}$ & $\begin{array}{l}P_{2} \\
\text { in } \mathrm{W}\end{array}$ & $\begin{array}{l}P_{\text {loss }} \\
\text { in W }\end{array}$ & $\begin{array}{c}\eta \\
\text { in } \%\end{array}$ & $\begin{array}{l}I_{\mathrm{rms}, 1} \\
\text { in A }\end{array}$ & $\begin{array}{c}I_{\mathrm{rms}, 2} \\
\text { in A }\end{array}$ \\
\hline 10 & 50.37 & 15.80 & 795.8 & 160.7 & 6.091 & 978.9 & 183.1 & 81.30 & 62.2 & 14.2 \\
\hline 15 & 50.41 & 35.31 & 1780 & 160.7 & 12.31 & 1978 & 198.1 & 89.99 & 75.9 & 17.6 \\
\hline 20 & 50.67 & 53.21 & 2696 & 160.5 & 18.28 & 2935 & 239.0 & 91.86 & 95.0 & 22.2 \\
\hline 25 & 50.64 & 74.68 & 3782 & 160.5 & 25.49 & 4093 & 310.9 & 92.40 & 121 & 28.7 \\
\hline 30 & 50.59 & 89.36 & 4520 & 160.5 & 30.88 & 4957 & 437.1 & 91.18 & 147 & 33.8 \\
\hline 5 & 50.17 & 1.844 & 92.50 & 180.1 & 1.048 & 188.7 & 96.21 & 49.02 & 28.7 & 6.55 \\
\hline 10 & 50.48 & 24.39 & 1231 & 180.0 & 7.436 & 1338 & 107.0 & 92.01 & 43.0 & 10.0 \\
\hline 15 & 50.86 & 50.57 & 2572 & 179.7 & 15.09 & 2712 & 139.8 & 94.84 & 71.1 & 16.9 \\
\hline 20 & 50.65 & 74.27 & 3762 & 179.9 & 22.18 & 3989 & 227.4 & 94.30 & 99.5 & 23.7 \\
\hline 25 & 50.60 & 90.14 & 4561 & 179.9 & 27.19 & 4892 & 331.1 & 93.23 & 122 & 29.0 \\
\hline 30 & 50.55 & 104.4 & 5279 & 179.9 & 31.94 & 5746 & 466.7 & 91.88 & 146 & 34.4 \\
\hline 2 & 50.03 & 7.982 & 399.4 & 201.1 & 2.144 & 431.2 & 31.88 & 92.61 & 8.39 & 2.1 \\
\hline 3 & 50.10 & 13.14 & 658.4 & 201.1 & 3.390 & 681.7 & 23.32 & 96.58 & 13.6 & 3.3 \\
\hline 5 & 50.20 & 20.13 & 1011 & 201.1 & 5.182 & 1042 & 31.39 & 96.99 & 20.9 & 5.1 \\
\hline 10 & 50.07 & 46.31 & 2319 & 201.1 & 12.01 & 2415 & 96.71 & 96.00 & 49.7 & 12.2 \\
\hline 15 & 50.23 & 67.98 & 3414 & 201.0 & 17.84 & 3587 & 172.1 & 95.20 & 75.7 & 18.5 \\
\hline 20 & 50.49 & 87.15 & 4400 & 200.9 & 23.31 & 4682 & 281.5 & 93.99 & 102 & 24.8 \\
\hline 25 & 50.40 & 104.8 & 5284 & 200.9 & 28.18 & 5662 & 378.2 & 93.32 & 124 & 30.2 \\
\hline 30 & 50.40 & 120.3 & 6063 & 200.9 & 34.92 & 7015 & 951.6 & 86.43 & 148 & 36.0 \\
\hline 2 & 50.39 & 20.82 & 1049 & 219.9 & 5.179 & 1139 & 89.81 & 92.12 & 31.9 & 8.8 \\
\hline 3 & 50.46 & 25.88 & 1306 & 219.9 & 6.256 & 1376 & 69.76 & 94.93 & 34.5 & 9.4 \\
\hline 5 & 50.60 & 35.39 & 1791 & 219.8 & 8.600 & 1891 & 99.80 & 94.72 & 41.1 & 10.5 \\
\hline 10 & 50.38 & 55.05 & 2774 & 219.9 & 13.25 & 2913 & 139.6 & 95.21 & 59.9 & 15.0 \\
\hline 15 & 50.46 & 77.38 & 3905 & 219.9 & 18.84 & 4142 & 237.4 & 94.27 & 83.7 & 21.0 \\
\hline 20 & 50.43 & 97.84 & 4934 & 219.9 & 24.14 & 5308 & 374.4 & 92.95 & 109 & 27.3 \\
\hline 25 & 50.46 & 115.7 & 5837 & 219.8 & 29.01 & 6377 & 540.5 & 91.52 & 132 & 33.1 \\
\hline 5 & 50.36 & 42.77 & 2154 & 240.4 & 9.913 & 2383 & 229.0 & 90.39 & 62.2 & 16.8 \\
\hline 10 & 50.10 & 69.18 & 3466 & 240.5 & 15.64 & 3760 & 293.7 & 92.19 & 82.7 & 21.5 \\
\hline 15 & 50.38 & 88.93 & 4480 & 240.4 & 19.99 & 4805 & 324.5 & 93.25 & 99.7 & 24.6 \\
\hline 20 & 50.69 & 110.2 & 5584 & 240.2 & 25.19 & 6051 & 466.7 & 92.29 & 121 & 29.9 \\
\hline 5 & 50.52 & 48.55 & 2453 & 259.1 & 11.03 & 2857 & 404.1 & 85.86 & 81.20 & 23.7 \\
\hline 10 & 50.86 & 77.62 & 3948 & 260.0 & 16.91 & 4398 & 450.0 & 89.77 & 101 & 26.2 \\
\hline 15 & 50.75 & 104.1 & 5281 & 260.0 & 22.50 & 5851 & 569.7 & 90.26 & 122 & 30.6 \\
\hline
\end{tabular}


Table B.4: Transformer $\mathrm{T}_{3}$, Tap $5, V_{1}=50 \mathrm{~V}$

\begin{tabular}{|c|c|c|c|c|c|c|c|c|c|c|}
\hline$\phi^{\circ}$ & $\begin{array}{c}V_{1} \\
\text { in } \mathrm{V}\end{array}$ & $\begin{array}{c}I_{1} \\
\text { in } \mathrm{A}\end{array}$ & $\begin{array}{c}P_{1} \\
\text { in } \mathrm{W}\end{array}$ & $\begin{array}{c}V_{2} \\
\text { in } \mathrm{V}\end{array}$ & $\begin{array}{c}I_{2} \\
\text { in } \mathrm{A}\end{array}$ & $\begin{array}{c}P_{2} \\
\text { in W }\end{array}$ & $\begin{array}{l}P_{\text {loss }} \\
\text { in } \mathrm{W}\end{array}$ & $\begin{array}{c}\eta \\
\text { in } \%\end{array}$ & $\begin{array}{c}I_{\mathrm{rms}, 1} \\
\text { in A }\end{array}$ & $\begin{array}{c}I_{\mathrm{rms}, 2} \\
\text { in A }\end{array}$ \\
\hline 10 & 50.02 & 16.79 & 839.8 & 200.8 & 5.05 & 1013 & 173.5 & & 61.9 & 10.8 \\
\hline 15 & & .48 & & 00.9 & & 2002 & & & & \\
\hline 20 & & .93 & & & & & & & & 7.1 \\
\hline 25 & .04 & 7.21 & 3864 & 200.8 & 0.64 & 4145 & & & 123 & 22.6 \\
\hline 30 & 0.13 & 8 & 4586 & 00.6 & 4.70 & 4956 & & & 4 & 26.5 \\
\hline 40 & .13 & 6.1 & 5822 & 00.6 & 1.83 & 6384 & & & 183 & 34.5 \\
\hline 10 & .07 & .78 & 990.6 & 10.7 & 538 & 1134 & 42.9 & & 52.7 & 9.32 \\
\hline 15 & & .51 & 2023 & .8 & & & & & 8.9 & 12.5 \\
\hline 20 & & & 33 & 210 & & & & & 97.1 & 18.3 \\
\hline 25 & & & & & & & & & & 22.7 \\
\hline 30 & & 19 & & 210 & & 59 & & & 146 & 26.6 \\
\hline 40 & & 23.5 & & & & & & & & 4.9 \\
\hline 10 & 1 & .07 & 130 & 230.2 & & 1405 & & & 8.5 & 7.16 \\
\hline 15 & & & & & & & & & & 3.8 \\
\hline 20 & 0 & .32 & 3866 & 230 . & .72 & & & & 97.9 & 18.5 \\
\hline 25 & & & 47 & & & & & & 120 & 22.9 \\
\hline 30 & .03 & 0.3 & & 230 & & 59 & & & 43 & 27.4 \\
\hline 40 & & 6.9 & 6841 & 230 & 54 & & & & 187 & 35.9 \\
\hline 5 & 9 & .76 & 839.3 & 250 & & & & & 17.40 & 3.41 \\
\hline 10 & & & & 250 & & 23 & & & 47.4 & 9.24 \\
\hline 15 & & & & & & & & & 3.2 & 4.3 \\
\hline 20 & ? & 6.81 & 4373 & 249.9 & & & & & 98.8 & 19.2 \\
\hline 25 & & & & & & & & & 12 & 24 \\
\hline 30 & 2 & 1.4 & & 249.9 & & & & & 146 & 28.4 \\
\hline 40 & & 149.5 & & 249 & 33.16 & 8286 & & & 197 & 38 \\
\hline 5 & 50.43 & 32.22 & 1625 & 270.4 & 622 & 1708 & 83.53 & & 36.4 & 7.46 \\
\hline 10 & & & & & & & & & & 10.7 \\
\hline 15 & & & 0 & 4 & & & & & 9.3 & 15.6 \\
\hline 20 & & & & & & & & & & 20.7 \\
\hline 25 & & & & 3 & & & & & & 5.6 \\
\hline 30 & & & & & & & & & & 30.4 \\
\hline 40 & & 164.1 & 8274 & 270.2 & 33.85 & 9147 & 873.3 & 90.45 & 201 & 39.3 \\
\hline 5 & & & & & & & & & 52.4 & 11.2 \\
\hline 10 & & & & & & & & & & 14.5 \\
\hline 15 & & & & & & & & & 91.6 & 17.9 \\
\hline 20 & & & & & & & & & 115 & 22.4 \\
\hline 25 & & & & & & & & & 138 & 27.1 \\
\hline 35 & & 162.3 & & 290.1 & 30.97 & 8986 & 791.7 & 91.19 & 186 & 36.4 \\
\hline 5 & & & & & & & & & & 13.2 \\
\hline 10 & & & & & & & & & 81.5 & 16.2 \\
\hline 15 & & & & & & & & & 101 & 19.8 \\
\hline 20 & & & & & & & & & 121 & 23.7 \\
\hline 25 & & & & & & & & & 144 & 28.1 \\
\hline 30 & 50.26 & 151.4 & 7607 & 300.8 & 27.51 & 8275 & 667.9 & 91.93 & 168 & 33.3 \\
\hline
\end{tabular}


Table B.5: Transformer $\mathrm{T}_{3}$, Tap $6, V_{1}=50 \mathrm{~V}$

\begin{tabular}{|c|c|c|c|c|c|c|c|c|c|c|}
\hline$\phi^{\circ}$ & $\begin{array}{c}V_{1} \\
\text { in } \mathrm{V}\end{array}$ & $\begin{array}{c}I_{1} \\
\text { in } \mathrm{A}\end{array}$ & $\begin{array}{c}P_{1} \\
\text { in } \mathrm{W}\end{array}$ & $\begin{array}{l}V_{2} \\
\text { in } \mathrm{V}\end{array}$ & $\begin{array}{c}I_{2} \\
\text { in } \mathrm{A}\end{array}$ & $\begin{array}{c}P_{2} \\
\text { in } \mathrm{W}\end{array}$ & $\begin{array}{l}P_{\text {loss }} \\
\text { in } \mathrm{W}\end{array}$ & $\begin{array}{c}\eta \\
\text { in } \%\end{array}$ & $\begin{array}{c}I_{\mathrm{rms}, 1} \\
\text { in A }\end{array}$ & $\begin{array}{c}I_{\mathrm{rms}, 2} \\
\text { in A }\end{array}$ \\
\hline 10 & 50.11 & 24.56 & 1231 & 261.6 & 5.21 & 1363 & 131.9 & 90.32 & 48.4 & 7.76 \\
\hline 15 & 50.23 & 47.00 & 2361 & 261.6 & 9.59 & 2509 & 148.5 & 94.08 & 69.7 & 11.1 \\
\hline 20 & 50.27 & 75.01 & 3770 & 261.6 & 15.13 & 3958 & 187.6 & 95.26 & 102.0 & 16.4 \\
\hline 25 & 50.06 & 93.16 & 4663 & 261.6 & 18.81 & 4922 & 258.8 & 94.74 & 125.0 & 20.1 \\
\hline 30 & 50.04 & 109.30 & 5469 & 261.6 & 22.23 & 5817 & 347.7 & 94.02 & 148.0 & 23.9 \\
\hline 35 & 50.25 & 123.48 & 6205 & 261.5 & 25.45 & 6657 & 452.5 & 93.20 & 172.0 & 27.7 \\
\hline 40 & 50.35 & 147.90 & 7447 & 261.5 & 30.94 & 8089 & 642.0 & 92.06 & 195.0 & 31.3 \\
\hline 5 & 47.79 & 10.13 & 484.3 & 281.0 & 1.86 & 523.2 & 38.90 & 92.57 & 12.5 & 1.99 \\
\hline 10 & 50.04 & 34.35 & 1719 & 280.8 & 6.39 & 1796 & 76.66 & 95.73 & 43.5 & 6.98 \\
\hline 15 & 50.17 & 62.73 & 3148 & 280.8 & 11.67 & 3276 & 128.5 & 96.08 & 75.1 & 12.2 \\
\hline 20 & 50.32 & 83.57 & 4205 & 280.7 & 15.66 & 4396 & 191.5 & 95.65 & 101 & 16.4 \\
\hline 30 & 50.01 & 119.3 & 5965 & 280.8 & 22.48 & 6312 & 346.9 & 94.50 & 148 & 24.2 \\
\hline 40 & 50.02 & 148.3 & 7417 & 280.8 & 28.46 & 7990 & 572.7 & 92.83 & 194 & 31.7 \\
\hline 45 & 50.20 & 160.4 & 8053 & 280.7 & 31.20 & 8757 & 704.2 & 91.96 & 216 & 35.4 \\
\hline 5 & 50.03 & 18.74 & 937.5 & 300.7 & 3.21 & 964.4 & 26.89 & 97.21 & & \\
\hline 10 & 50.46 & 46.94 & 2369 & 300.5 & 8.14 & 2448 & 78.92 & 96.78 & & \\
\hline 15 & 50.44 & 71.39 & 3601 & 300.5 & 12.46 & 3744 & 142.5 & 96.19 & & \\
\hline 20 & 50.42 & 93.48 & 4713 & 300.5 & 16.42 & 4935 & 222.3 & 95.50 & & \\
\hline 30 & 50.39 & 131.4 & 6620 & 300.5 & 23.44 & 7045 & 425.3 & 93.96 & & \\
\hline 40 & 50.39 & 162.7 & 8197 & 300.5 & 29.63 & 8904 & 707.8 & 92.05 & & \\
\hline 50 & 50.31 & 175.7 & 8837 & 300.5 & 32.35 & 9719 & 881.5 & 90.93 & & \\
\hline 5 & 50.20 & 32.08 & 1610 & 320.7 & 5.27 & 1690 & 79.88 & 95.27 & 35.8 & 6.26 \\
\hline 10 & 50.32 & 51.90 & 2612 & 320.7 & 8.48 & 2721 & 109.0 & 95.99 & 55 & 9.31 \\
\hline 15 & 50.39 & 76.06 & 3833 & 320.6 & 12.52 & 4012 & 178.9 & 95.54 & 81.2 & 13.4 \\
\hline 20 & 50.40 & 98.62 & 4971 & 320.6 & 16.28 & 5218 & 247.4 & 95.26 & 108 & 17.9 \\
\hline 30 & 50.46 & 137.9 & 6958 & 320.5 & 23.13 & 7412 & 453.7 & 93.88 & 158 & 25.8 \\
\hline 40 & 50.39 & 169.7 & 8552 & 320.5 & 29.26 & 9379 & 827.4 & 91.18 & 206 & 33.6 \\
\hline 5 & 50.50 & 36.49 & 1843 & 340.3 & 5.79 & 1971 & 128.6 & 93.47 & 47.3 & 8.58 \\
\hline 10 & 50.66 & 61.20 & 3100 & 340.3 & 9.57 & 3256 & 155.5 & 95.23 & 68.2 & 11.7 \\
\hline 15 & 50.37 & 82.79 & 4170 & 340.4 & 12.82 & 4365 & 194.7 & 95.54 & 90 & 14.8 \\
\hline 20 & 50.45 & 106.3 & 5361 & 340.2 & 16.57 & 5639 & 278.2 & 95.07 & 115 & 18.7 \\
\hline 25 & 50.42 & 127.2 & 6413 & 340.3 & 19.98 & 6798 & 385.9 & 94.32 & 139 & 22.8 \\
\hline 30 & 50.36 & 147.5 & 7428 & 340.1 & 23.33 & 7935 & 506.6 & 93.62 & 165 & 26.8 \\
\hline 35 & 50.34 & 166.0 & 8357 & 340.2 & 26.53 & 9023 & 666.5 & 92.61 & 190 & 30.9 \\
\hline 40 & 50.32 & 181.1 & 9115 & 340.2 & 29.63 & 10081 & 965.2 & 90.42 & 215 & 35.2 \\
\hline 5 & 50.53 & 38.33 & 1936 & 350.2 & 5.99 & 2096 & 159.9 & 92.37 & 54.4 & 9.88 \\
\hline 10 & 50.63 & 66.08 & 3346 & 350.2 & 10.11 & 3539 & 193.6 & 94.53 & 76.5 & 12.7 \\
\hline 15 & 50.53 & 86.29 & 4360 & 350.1 & 13.11 & 4589 & 228.8 & 95.01 & 95.5 & 15.5 \\
\hline 20 & 50.40 & 109.9 & 5540 & 350.2 & 16.71 & 5852 & 311.4 & 94.68 & 120 & 19.5 \\
\hline 25 & 50.38 & 131.5 & 6623 & 350.2 & 20.12 & 7045 & 422.6 & 94.00 & 144 & 23.5 \\
\hline 30 & 50.36 & 151.8 & 7646 & 350.2 & 23.46 & 8216 & 570.2 & 93.06 & 169 & 27.5 \\
\hline 35 & 50.34 & 169.9 & 8551 & 350.1 & 26.69 & 9345 & 794.4 & 91.50 & 193 & 31.5 \\
\hline
\end{tabular}


Table B.6: Transformer $\mathrm{T}_{3}$, Tap 7, $V_{1}=50 \mathrm{~V}$

\begin{tabular}{|c|c|c|c|c|c|c|c|c|c|c|}
\hline$\phi^{\circ}$ & $\begin{array}{c}V_{1} \\
\text { in } \mathrm{V}\end{array}$ & $\begin{array}{c}I_{1} \\
\text { in } \mathrm{A}\end{array}$ & $\begin{array}{c}P_{1} \\
\text { in } \mathrm{W}\end{array}$ & $\begin{array}{l}V_{2} \\
\text { in } \mathrm{V}\end{array}$ & $\begin{array}{c}I_{2} \\
\text { in } \mathrm{A}\end{array}$ & $\begin{array}{c}P_{2} \\
\text { in } W\end{array}$ & $\begin{array}{l}P_{\text {loss }} \\
\text { in W }\end{array}$ & $\begin{array}{c}\eta \\
\text { in } \%\end{array}$ & $\begin{array}{l}I_{\mathrm{rms}, 1} \\
\text { in A }\end{array}$ & $\begin{array}{c}I_{\mathrm{rms}, 2} \\
\text { in A }\end{array}$ \\
\hline 10 & 50.32 & 25.23 & 1269 & 311.0 & 4.550 & 1415 & 145.6 & 89.71 & 47.3 & 6.83 \\
\hline 15 & 50.69 & 51.00 & 2585 & 310.9 & 8.769 & 2726 & 141.6 & 94.81 & 73.0 & 10.7 \\
\hline 20 & 50.39 & 78.44 & 3953 & 310.9 & 13.38 & 4159 & 206.2 & 95.04 & 105 & 15.5 \\
\hline 25 & 50.41 & 96.12 & 4846 & 310.8 & 16.53 & 5139 & 293.5 & 94.29 & 131 & 18.9 \\
\hline 30 & 50.42 & 112.1 & 5652 & 310.9 & 19.49 & 6059 & 406.8 & 93.29 & 157 & 22.7 \\
\hline 35 & 50.40 & 126.5 & 6375 & 310.9 & 22.21 & 6905 & 529.5 & 92.33 & 183 & 26.5 \\
\hline 40 & 50.39 & 139.7 & 7038 & 310.9 & 24.75 & 7694 & 655.3 & 91.48 & 207 & 30.1 \\
\hline 10 & 50.54 & 27.25 & 1377 & 321.0 & 4.699 & 1508 & 131.0 & 91.31 & 42.9 & 6.31 \\
\hline 15 & 50.74 & 58.78 & 2983 & 321.0 & 9.713 & 3118 & 135.1 & 95.67 & 76.0 & 11.3 \\
\hline 20 & 50.44 & 82.33 & 4152 & 321.1 & 13.59 & 4362 & 209.3 & 95.20 & 104 & 15.5 \\
\hline 25 & 50.46 & 100.4 & 5065 & 320.9 & 16.70 & 5358 & 293.7 & 94.52 & 130 & 19 \\
\hline 30 & 50.45 & 117.1 & 5908 & 321.7 & 19.66 & 6325 & 417.1 & 93.41 & 156 & 22.8 \\
\hline 35 & 50.47 & 134.2 & 6772 & 320.8 & 22.61 & 7254 & 481.2 & 93.37 & 176 & 26.3 \\
\hline 40 & 50.43 & 145.8 & 7353 & 320.8 & 24.99 & 8017 & 664.0 & 91.72 & 206 & 30.3 \\
\hline 45 & 50.37 & 157.5 & 7935 & 320.8 & 27.30 & 8759 & 824.0 & 90.59 & 232 & 34.2 \\
\hline 10 & 50.57 & 41.13 & 2080 & 340.7 & 6.346 & 2162 & 82.36 & 96.19 & 46.9 & 7.11 \\
\hline 15 & 50.66 & 67.31 & 3410 & 340.6 & 10.45 & 3559 & 149.1 & 95.81 & 77.7 & 11.8 \\
\hline 20 & 50.80 & 89.28 & 4535 & 340.5 & 13.95 & 4751 & 215.9 & 95.46 & 105 & 15.8 \\
\hline 25 & 50.52 & 108.1 & 5459 & 340.6 & 16.97 & 5779 & 319.9 & 94.46 & 131 & 19.9 \\
\hline 30 & 50.55 & 127.4 & 6442 & 340.6 & 20.06 & 6833 & 390.6 & 94.28 & 157 & 23.4 \\
\hline 35 & 50.54 & 142.9 & 7222 & 340.5 & 22.78 & 7759 & 537.4 & 93.07 & 181 & 27 \\
\hline 40 & 50.54 & 159.2 & 8043 & 340.5 & 25.44 & 8661 & 618.1 & 92.86 & 203 & 30.4 \\
\hline 45 & 50.40 & 167.6 & 8445 & 340.6 & 27.44 & 9346 & 900.3 & 90.37 & 236 & 35.3 \\
\hline 5 & 50.15 & 15.69 & 786.6 & 350.7 & 2.328 & 816.2 & 29.64 & 96.37 & 16.3 & 2.51 \\
\hline 10 & 50.27 & 46.07 & 2316 & 350.7 & 6.850 & 2402 & 86.42 & 96.40 & 49.7 & 7.56 \\
\hline 15 & 50.62 & 70.41 & 3564 & 350.6 & 10.61 & 3721 & 156.6 & 95.79 & 78.6 & 12 \\
\hline 20 & 50.54 & 92.67 & 4683 & 350.4 & 14.03 & 4916 & 233.0 & 95.26 & 106 & 15.7 \\
\hline 30 & 50.57 & 131.7 & 6660 & 350.4 & 20.17 & 7068 & 407.6 & 94.23 & 156 & 23.4 \\
\hline 40 & 50.52 & 162.8 & 8225 & 350.4 & 25.47 & 8923 & 698.1 & 92.18 & 212 & 31.8 \\
\hline 5 & 50.31 & 24.82 & 1249 & 361.0 & 3.571 & 1289 & 40.65 & 96.85 & 25.9 & 4.08 \\
\hline 10 & 50.48 & 48.89 & 2468 & 361.0 & 7.110 & 2567 & 98.57 & 96.16 & 51.4 & 8 \\
\hline 15 & 50.54 & 73.51 & 3715 & 361.0 & 10.76 & 3885 & 169.7 & 95.63 & 79.8 & 12.4 \\
\hline 20 & 50.40 & 96.59 & 4868 & 360.9 & 14.13 & 5099 & 231.5 & 95.46 & 107 & 16.4 \\
\hline 25 & 50.40 & 117.0 & 5896 & 360.9 & 17.23 & 6219 & 322.5 & 94.81 & 132 & 20.3 \\
\hline 30 & 50.42 & 136.3 & 6874 & 360.9 & 20.19 & 7284 & 409.9 & 94.37 & 158 & 23.7 \\
\hline 40 & 50.41 & 170.0 & 8570 & 360.8 & 25.65 & 9257 & 686.6 & 92.58 & 210 & 31.4 \\
\hline 5 & 50.55 & 33.23 & 1680 & 380.9 & 4.660 & 1775 & 95.34 & 94.63 & 38.5 & 6.44 \\
\hline 10 & 50.63 & 54.19 & 2744 & 381.0 & 7.517 & 2864 & 120.4 & 95.80 & 58.2 & 9.23 \\
\hline 15 & 50.74 & 79.10 & 4013 & 381.0 & 11.05 & 4210 & 196.6 & 95.33 & 84.7 & 13.4 \\
\hline 20 & 50.83 & 102.3 & 5201 & 380.9 & 14.42 & 5493 & 292.4 & 94.68 & 113 & 17.4 \\
\hline 30 & 50.48 & 143.0 & 7217 & 380.9 & 20.43 & 7782 & 564.5 & 92.75 & & \\
\hline 40 & 50.43 & 180.1 & 9080 & 380.8 & 25.72 & 9793 & 713.4 & 92.72 & 220 & 33.6 \\
\hline
\end{tabular}


Table B.7: Transformer $\mathrm{T}_{3}$, Tap 8, $V_{1}=50 \mathrm{~V}$

\begin{tabular}{|c|c|c|c|c|c|c|c|c|c|c|}
\hline$\phi^{\circ}$ & $\begin{array}{c}V_{1} \\
\text { in } \mathrm{V}\end{array}$ & $\begin{array}{c}I_{1} \\
\text { in } \mathrm{A}\end{array}$ & $\begin{array}{c}P_{1} \\
\text { in } \mathrm{W}\end{array}$ & $\begin{array}{l}V_{2} \\
\text { in } \mathrm{V}\end{array}$ & $\begin{array}{c}I_{2} \\
\text { in } \mathrm{A}\end{array}$ & $\begin{array}{c}P_{2} \\
\text { in } \mathrm{W}\end{array}$ & $\begin{array}{l}P_{\text {loss }} \\
\text { in W }\end{array}$ & $\begin{array}{c}\eta \\
\text { in } \%\end{array}$ & $\begin{array}{c}I_{\mathrm{rms}, 1} \\
\text { in A }\end{array}$ & $\begin{array}{c}I_{\mathrm{rms}, 2} \\
\text { in A }\end{array}$ \\
\hline 20 & 50.24 & 50.42 & 2533 & 280.9 & 10.08 & 2832 & 298.8 & 89.45 & 115 & 14.2 \\
\hline 30 & 50.69 & 80.93 & 4102 & 280.7 & 15.92 & 4469 & 366.8 & 91.79 & 154 & 18.6 \\
\hline 35 & 50.70 & 98.98 & 5018 & 280.7 & 19.28 & 5413 & 394.3 & 92.72 & 176 & 21.7 \\
\hline 40 & 50.72 & 111.75 & 5668 & 280.7 & 21.84 & 6130 & 461.9 & 92.46 & 194 & 24.3 \\
\hline 50 & 50.69 & 130.5 & 6614 & 280.7 & 25.99 & 7296 & 681.5 & 90.66 & 237 & 29.0 \\
\hline 60 & 50.72 & 144.9 & 7349 & 280.7 & 29.14 & 8179 & 830.9 & 89.84 & 261 & 33.2 \\
\hline 20 & 50.03 & 56.32 & 2818 & 300.6 & 10.21 & 3071 & 253.4 & 91.75 & 106 & 13.1 \\
\hline 30 & 50.59 & 93.43 & 4727 & 300.5 & 16.86 & 5067 & 340.6 & 93.28 & 154 & 18.8 \\
\hline 40 & 50.68 & 121.5 & 6158 & 300.4 & 22.11 & 6642 & 483.6 & 92.72 & 197 & 24.3 \\
\hline 50 & 50.54 & 141.5 & 7153 & 300.5 & 25.95 & 7797 & 644.0 & 91.74 & 232 & 29.0 \\
\hline 55 & 50.50 & 149.8 & 7566 & 300.5 & 27.70 & 8322 & 755.7 & 90.92 & 251 & 31.4 \\
\hline 20 & 50.08 & 61.99 & 3104 & 320.1 & 10.42 & 3334 & 230.0 & 93.10 & 100 & 12.2 \\
\hline 25 & 50.42 & 84.52 & 4262 & 320.0 & 14.08 & 4504 & 242.6 & 94.61 & 128 & 15.7 \\
\hline 30 & 50.41 & 103.1 & 5198 & 320.0 & 17.22 & 5511 & 312.8 & 94.32 & 151 & 18.8 \\
\hline 40 & 50.66 & 130.5 & 6611 & 319.9 & 22.11 & 7075 & 463.3 & 93.45 & 194 & 24.3 \\
\hline 50 & 50.61 & 151.9 & 7688 & 319.9 & 26.11 & 8353 & 664.7 & 92.04 & 234 & 29.3 \\
\hline 55 & 50.62 & 160.6 & 8128 & 319.9 & 28.03 & 8967 & 838.9 & 90.64 & 255 & 31.8 \\
\hline 20 & 50.05 & 74.67 & 3737 & 340.8 & 11.49 & 3914 & 177.2 & 95.47 & 103 & 12.6 \\
\hline 30 & 50.59 & 111.4 & 5637 & 340.6 & 17.47 & 5950 & 313.0 & 94.74 & 151 & 18.8 \\
\hline 40 & 50.35 & 140.8 & 7089 & 340.6 & 22.32 & 7604 & 515.1 & 93.23 & 198 & 24.6 \\
\hline 50 & 50.25 & 163.3 & 8208 & 340.7 & 26.19 & 8920 & 711.9 & 92.02 & 238 & 29.8 \\
\hline 55 & 50.20 & 172.5 & 8657 & 340.6 & 28.00 & 9539 & 882.0 & 90.75 & 263 & 32.7 \\
\hline 20 & 50.13 & 82.83 & 4152 & 361.1 & 11.97 & 4323 & 171.2 & 96.04 & 102 & 12.7 \\
\hline 25 & 50.42 & 102.8 & 5181 & 361.1 & 14.92 & 5385 & 203.9 & 96.21 & 127 & 15.9 \\
\hline 30 & 50.68 & 119.5 & 6059 & 361.0 & 17.72 & 6398 & 339.2 & 94.70 & 153 & 19.0 \\
\hline 40 & 50.53 & 150.3 & 7595 & 361.0 & 22.50 & 8124 & 529.2 & 93.49 & 200 & 24.9 \\
\hline 50 & 50.57 & 173.9 & 8792 & 361.0 & 26.47 & 9556 & 763.8 & 92.01 & 243 & 30.5 \\
\hline 55 & 50.59 & 183.7 & 9293 & 361.0 & 28.36 & 10238 & 944.1 & 90.78 & 269 & 33.5 \\
\hline 20 & 50.23 & 89.13 & 4477 & 380.1 & 12.28 & 4666 & 188.4 & 95.96 & 103 & 12.8 \\
\hline 30 & 50.52 & 127.2 & 6427 & 380.0 & 17.85 & 6781 & 354.1 & 94.78 & 154 & 19.2 \\
\hline 40 & 50.58 & 159.1 & 8047 & 380.0 & 22.65 & 8604 & 557.4 & 93.52 & 203 & 25.4 \\
\hline 50 & 50.51 & 183.7 & 9278 & 379.9 & 26.72 & 10151 & 873.8 & 91.39 & 251 & 31.4 \\
\hline 55 & 50.17 & 193.8 & 9724 & 380.9 & 28.10 & 10702 & 977.9 & 90.86 & 267 & 33.6 \\
\hline 5 & 50.14 & 16.57 & 830.6 & 401.2 & 2.15 & 861.1 & 30.54 & 96.45 & 16.8 & 2.12 \\
\hline 10 & 50.09 & 46.86 & 2347 & 401.2 & 6.02 & 2417 & 69.65 & 97.12 & 48.7 & 6.11 \\
\hline 15 & 50.30 & 72.13 & 3629 & 401.2 & 9.37 & 3757 & 128.6 & 96.58 & 76.9 & 9.69 \\
\hline 20 & 50.27 & 95.21 & 4786 & 401.2 & 12.41 & 4980 & 194.3 & 96.10 & 105 & 13.1 \\
\hline 30 & 50.22 & 135.0 & 6779 & 401.1 & 17.81 & 7145 & 365.5 & 94.88 & 156 & 19.6 \\
\hline 40 & 50.17 & 168.2 & 8440 & 401.1 & 22.62 & 9073 & 633.8 & 93.01 & 207 & 25.9 \\
\hline 50 & 50.08 & 194.1 & 9718 & 401.1 & 26.56 & 10654 & 935.4 & 91.22 & 249 & 31.4 \\
\hline 55 & 49.97 & 203.9 & 10188 & 401.1 & 28.11 & 11275 & 1087 & 90.36 & 271 & 34.0 \\
\hline
\end{tabular}


Table B.8: Transformer $\mathrm{T}_{3}$, Tap $4, V_{1}=30 \mathrm{~V}$

\begin{tabular}{|c|c|c|c|c|c|c|c|c|c|c|}
\hline$\phi^{\circ}$ & $\begin{array}{c}V_{1} \\
\text { in } \mathrm{V}\end{array}$ & $\begin{array}{c}I_{1} \\
\text { in } \mathrm{A}\end{array}$ & $\begin{array}{c}P_{1} \\
\text { in } \mathrm{W}\end{array}$ & $\begin{array}{l}V_{2} \\
\text { in } \mathrm{V}\end{array}$ & $\begin{array}{c}I_{2} \\
\text { in } \mathrm{A}\end{array}$ & $\begin{array}{c}P_{2} \\
\text { in } \mathrm{W}\end{array}$ & $\begin{array}{l}P_{\text {loss }} \\
\text { in } \mathrm{W}\end{array}$ & $\begin{array}{c}\eta \\
\text { in } \%\end{array}$ & $\begin{array}{c}I_{\mathrm{rms}, 1} \\
\text { in A }\end{array}$ & $\begin{array}{l}I_{\mathrm{rms}, 2} \\
\text { in A }\end{array}$ \\
\hline 10 & 0.05 & 12.86 & 386.3 & 100.9 & 4.31 & 434.4 & 48.08 & 88.93 & 31.1 & 7.38 \\
\hline 15 & 0.22 & 24.47 & 739.5 & 100.8 & 7.89 & 794.9 & 55.39 & .03 & 41 & 10.0 \\
\hline 20 & 0.40 & 36.88 & 1121 & 100.7 & 11.85 & 1193 & 71.40 & & 55.6 & 13.5 \\
\hline 25 & 0.31 & 49.42 & 1498 & 100.7 & 15.88 & 1600 & 101.3 & 93.67 & 71.5 & 17.3 \\
\hline 30 & 30.45 & 58.24 & 1773 & 100.7 & 19.01 & 1913 & 140.3 & 2.67 & 4.0 & 20.5 \\
\hline 35 & 0.56 & 65.95 & 2015 & 100.6 & 21.76 & 2189 & 173.4 & 92.08 & 97.4 & 23.6 \\
\hline 40 & 30.34 & 73.17 & 2220 & 100.7 & 24.14 & 2431 & 210.1 & 1.36 & 108 & 86.1 \\
\hline 45 & 30.43 & 79.10 & 2407 & 100.6 & 26.52 & 2669 & 262.4 & 90.17 & 122 & 29.5 \\
\hline 50 & 30.51 & 84.10 & 2566 & 100.6 & 28.64 & 2880 & 314.2 & 89.09 & 131 & 32.1 \\
\hline 55 & 30.46 & 77.72 & 2367 & 90.0 & 30.00 & 2698 & 331.4 & 87.72 & 138 & 33.8 \\
\hline 2 & 29.87 & 5.96 & 177.9 & 120.8 & 1.59 & 191.5 & 13.56 & 92.92 & 6.2 & 1.60 \\
\hline 3 & .92 & 14 & 273.3 & .8 & 2.35 & 83.9 & & & & 2.33 \\
\hline 5 & 29.97 & 12.99 & 389.2 & 120.8 & 3.31 & 400.1 & 10.90 & 97.27 & 13.4 & 3.32 \\
\hline 10 & .24 & 27.56 & 833.2 & & 7.1 & & & & 9.3 & 7.24 \\
\hline 15 & 30.21 & 40.55 & 1225 & 120.7 & 10.57 & 1276 & 51.21 & 95.99 & 44.3 & 10.9 \\
\hline 20 & .11 & 2.82 & 1591 & 120.8 & 13.8 & 1670 & & .25 & 59 & 14.6 \\
\hline 25 & 30.27 & 63.34 & 1917 & 120.7 & 16.90 & 2040 & 123.0 & 93.97 & 73.2 & 18.1 \\
\hline 30 & .41 & 3.26 & 2228 & 120.6 & 19.81 & 2389 & & 93.25 & 89 & 21.7 \\
\hline 35 & 39 & .43 & 2505 & 120.6 & 22.51 & 2715 & 210.3 & & 10 & 24.9 \\
\hline 40 & 30.27 & 90.52 & 2740 & 120.7 & 24.95 & 3010 & 270.0 & 91.03 & 116 & 28.5 \\
\hline 45 & 30.37 & .65 & 2965 & 6 & 27.29 & 3291 & 326.3 & & 9 & 31.7 \\
\hline 50 & 30.45 & 3.51 & 3152 & 120.6 & 29.28 & 3530 & 377.8 & 89.30 & 140 & 34.4 \\
\hline 3 & 30.18 & 14.68 & 43.1 & 140.8 & 3.54 & 498.8 & 55.72 & 88.83 & 28. & 7.70 \\
\hline 5 & 30.23 & 17.71 & 535.5 & 140.8 & 4.21 & 592.7 & 57.18 & & 29.4 & 7.97 \\
\hline 10 & 0.32 & 4.23 & 734.8 & 140.8 & 5.66 & 796.2 & & 92.29 & 33 & 8.73 \\
\hline 15 & 30.35 & 39.94 & 1212 & 140.8 & 9.16 & 1289 & 76.53 & 94.06 & 45.5 & 11.4 \\
\hline 20 & 30.52 & & & 140.7 & 11.70 & & 88.04 & & 55 & 13.8 \\
\hline 25 & 30.24 & 64.66 & 1955 & 140.8 & 14.81 & 2085 & 130.4 & 93.75 & 70.7 & 17.4 \\
\hline 30 & 30.34 & & 2340 & 140 & 17.84 & 2511 & & & & 21.2 \\
\hline 35 & 30.40 & & 2681 & 140.7 & 20.55 & 2891 & 21 & 92.72 & 99 & 24.2 \\
\hline 40 & 30.56 & & 3014 & & 23.34 & & & & 113 & 27.8 \\
\hline 45 & 30.41 & & 3276 & 140.7 & 25.87 & 3639 & & 90.00 & 127 & 31.7 \\
\hline 50 & 30.54 & 115.96 & 3541 & 140.6 & 28.29 & 3978 & 437.3 & 89.01 & 141 & 35.1 \\
\hline 10 & 30.38 & 48.13 & 1462 & 160.7 & 10.07 & 1619 & 156.5 & 90.33 & 65.2 & 17.7 \\
\hline 15 & 30.63 & 64.51 & 1976 & 160.6 & 13.41 & 2153 & 177.5 & 91.76 & 77.6 & 19.3 \\
\hline 20 & 30.41 & 9.34 & 2413 & 160.7 & 16.38 & 2632 & 219.1 & 91.68 & 90.7 & 22.4 \\
\hline 25 & 30.57 & & 750 & & 18.73 & 3009 & 259.8 & & 100 & 25.1 \\
\hline 30 & 30.43 & 102.92 & 132 & 160.7 & 21.44 & 3445 & 313.1 & 90.91 & 115 & 28.2 \\
\hline 35 & 30.62 & & 3502 & & 24.31 & 3905 & 402.4 & & 129 & 32.3 \\
\hline 40 & 30.76 & 124.48 & 3830 & 160.5 & 27.07 & 4346 & 516.5 & 88.12 & 143 & 35.6 \\
\hline
\end{tabular}


Table B.9: Transformer $\mathrm{T}_{3}$, Tap $6, V_{1}=30 \mathrm{~V}$

\begin{tabular}{|c|c|c|c|c|c|c|c|c|c|c|}
\hline$\phi^{\circ}$ & $\begin{array}{c}V_{1} \\
\text { in } \mathrm{V}\end{array}$ & $\begin{array}{c}I_{1} \\
\text { in } \mathrm{A}\end{array}$ & $\begin{array}{c}P_{1} \\
\text { in } W\end{array}$ & $\begin{array}{l}V_{2} \\
\text { in } \mathrm{V}\end{array}$ & $\begin{array}{c}I_{2} \\
\text { in } \mathrm{A}\end{array}$ & $\begin{array}{c}P_{2} \\
\text { in } \mathrm{W}\end{array}$ & $\begin{array}{l}P_{\text {loss }} \\
\text { in W }\end{array}$ & $\begin{array}{c}\eta \\
\text { in } \%\end{array}$ & $\begin{array}{l}I_{\mathrm{rms}, 1} \\
\text { in } \mathrm{A}\end{array}$ & $\begin{array}{c}I_{\mathrm{rms}, 2} \\
\text { in A }\end{array}$ \\
\hline 10 & .12 & 12.18 & 366.8 & 140.0 & 3.09 & 432 & 65.07 & & 42.5 & 602 \\
\hline 20 & .32 & 67 & 051 & & & & & & & \\
\hline 30 & .52 & 7.45 & 753 & & 3.36 & & & & & 14.8 \\
\hline 40 & .46 & 3.34 & 2234 & & 7.19 & 2403 & & & & 18.8 \\
\hline 50 & 0.51 & 6.74 & 2311 & & 20.10 & 2536 & & & & 22.4 \\
\hline 60 & 0.44 & 94.41 & 2874 & 139.8 & 22.75 & 3180 & 306.0 & & & 26.4 \\
\hline 5 & 0.16 & .78 & 84.0 & 61.0 & 0.77 & 125 & 40.65 & 728 & & 3.22 \\
\hline 10 & & 78 & .6 & & 3.44 & 55 & & & & 4.62 \\
\hline 20 & & & & & & & & & & 0.0 \\
\hline 30 & .67 & .72 & 110 & & 13.83 & 2220 & 5.7 & & 90.9 & 14.8 \\
\hline 40 & & & & & 7.54 & 28 & & & & 19.4 \\
\hline 50 & .60 & .89 & 60 & & 20.73 & 3330 & & & 140 & 23.8 \\
\hline 60 & .75 & 109.9 & 3380 & & 23.38 & 3760 & & 89.92 & 173 & 28.2 \\
\hline 3 & 9.70 & & 0.1 & & 1.51 & 273 & & 5.28 & 9.47 & 1.5 \\
\hline 5 & & & & & 2. & 40 & & & & 2.2 \\
\hline 10 & & & & & & & & & & 4.9 \\
\hline 20 & .06 & & & & 9.7 & 1760 & & & 2.2 & 10.3 \\
\hline 30 & & & & & & & & & & 5.2 \\
\hline 40 & .44 & & & & 2 & 31 & & & 12 & 20.2 \\
\hline 50 & .37 & & & & 21.90 & 3710 & & & 149 & 24.5 \\
\hline 3 & .91 & & 7.5 & & 2.49 & 49 & & & 23. & 4.27 \\
\hline 5 & & & & & & & & & & .89 \\
\hline 10 & & & & & 5.76 & & & & 0.1 & 6.69 \\
\hline 20 & & & & & 10.09 & & & & & 11.5 \\
\hline 30 & & & & & & & & & & 6.7 \\
\hline 40 & & & & & & & & & & 21.4 \\
\hline 50 & & & & & & & & & & 26.0 \\
\hline 55 & 30.16 & 134.0 & 041 & 200.0 & 22.40 & 4479 & 438.3 & & 174 & 28.6 \\
\hline 5 & & 26. & .9 & & & & & & 42.4 & 7.7 \\
\hline 10 & & & & 221.4 & 6.46 & & 89.26 & & 55 & 9.28 \\
\hline 15 & & & & & & & & & & 1.3 \\
\hline 20 & & & & & 17 & 2319 & & & 80.7 & 13.3 \\
\hline 30 & & & & & & & & & & 19.1 \\
\hline 40 & & & & & & & & & & 23.1 \\
\hline 50 & & & & & & & & & 169.4 & 27.5 \\
\hline 55 & & & 4449 & 221.3 & 22.41 & 4958 & 508.6 & 89.74 & 184 & 30.4 \\
\hline 15 & & & & & & & & & 83.4 & 13.8 \\
\hline 10 & & & & & & & & & 72 & 12.0 \\
\hline 20 & & & & & & & & & 96 & 16.3 \\
\hline 30 & & & 3326 & & & 3601 & & 92.37 & 123 & 20.6 \\
\hline 40 & & & & & & 4510 & & & 100 & 25.5 \\
\hline 50 & 30.40 & 154.7 & 4711 & 240.5 & 21.92 & 5271 & 559.9 & 89.38 & 183 & 30.8 \\
\hline
\end{tabular}


Table B.10: Transformer $\mathrm{T}_{3}$, Tap 8, $V_{1}=30 \mathrm{~V}$

\begin{tabular}{|c|c|c|c|c|c|c|c|c|c|c|}
\hline$\phi^{\circ}$ & $\begin{array}{c}V_{1} \\
\text { in } \mathrm{V}\end{array}$ & $\begin{array}{c}I_{1} \\
\text { in } \mathrm{A}\end{array}$ & $\begin{array}{c}P_{1} \\
\text { in } \mathrm{W}\end{array}$ & $\begin{array}{c}V_{2} \\
\text { in } \mathrm{V}\end{array}$ & $\begin{array}{c}I_{2} \\
\text { in } \mathrm{A}\end{array}$ & $\begin{array}{c}P_{2} \\
\text { in } \mathrm{W}\end{array}$ & $\begin{array}{l}P_{\text {loss }} \\
\text { in W }\end{array}$ & $\begin{array}{c}\eta \\
\text { in } \%\end{array}$ & $\begin{array}{c}I_{\mathrm{rms}, 1} \\
\text { in A }\end{array}$ & $\begin{array}{l}I_{\mathrm{rms}, 2} \\
\text { in A }\end{array}$ \\
\hline 20 & 29.94 & 34.89 & 1045 & 180.3 & 6.25 & 1127 & 82.59 & 92.67 & 63.5 & 7.85 \\
\hline 30 & 30.19 & 56.30 & 1699 & 180.2 & 9.97 & 1797 & 97.26 & 94.59 & 89.9 & 11.1 \\
\hline 40 & 29.98 & 73.39 & 2200 & 180.2 & 13.00 & 2343 & 143.1 & 93.89 & 114 & 14.2 \\
\hline 50 & 30.21 & 85.38 & 2580 & 180.2 & 15.47 & 2787 & 207.3 & 92.56 & & \\
\hline 60 & 29.90 & 95.43 & 2854 & 180.6 & 17.36 & 3135 & 281.1 & 91.03 & & \\
\hline 10 & 30.06 & 15.23 & 457.6 & 200.3 & 2.59 & 518.5 & 60.86 & 88.26 & 34.9 & 4.33 \\
\hline 20 & 30.04 & 42.29 & 1270 & 200.2 & 6.64 & 1330 & 59.32 & 95.54 & & \\
\hline 30 & 30.10 & 65.53 & 1972 & 200.3 & 10.36 & 2075 & 102.4 & 95.07 & 90.2 & 11.10 \\
\hline 40 & 30.05 & 82.82 & 2488 & 200.2 & 13.18 & 2638 & 150.0 & 94.31 & 116 & 14.4 \\
\hline 50 & 30.27 & 95.97 & 2905 & 200.2 & 15.62 & 3126 & 220.5 & 92.95 & 141 & 17.7 \\
\hline 60 & 29.97 & 107.0 & 3207 & 200.2 & 17.49 & 3501 & 293.8 & 91.61 & & \\
\hline 70 & 29.98 & 113.18 & 3394 & 200.1 & 18.85 & 3772 & 378.4 & 89.97 & 187 & 23.4 \\
\hline 10 & 30.11 & 18.63 & 561.0 & 220.3 & 2.75 & 606.4 & 45.40 & 92.51 & 25.9 & 3.18 \\
\hline 20 & 30.16 & 51.03 & 1539 & 220.2 & 7.24 & 1595 & 55.65 & 96.51 & 61.3 & 7.54 \\
\hline 30 & 30.09 & 73.35 & 2207 & 220.2 & 10.49 & 2309 & 102.3 & 95.57 & 90.5 & 11.2 \\
\hline 40 & 30.12 & 92.13 & 2775 & 220.2 & 13.39 & 2948 & 173.3 & 94.12 & 120 & 14.9 \\
\hline 50 & 30.35 & 106.3 & 3225 & 220.2 & 15.80 & 3478 & 252.9 & 92.73 & 147 & 18.3 \\
\hline 60 & 30.04 & 118.7 & 3566 & 220.2 & 17.65 & 3886 & 320.6 & 91.75 & 169 & 21.1 \\
\hline 70 & 30.08 & 125.5 & 3774 & 220.1 & 19.05 & 4194 & 419.5 & 90.00 & 195 & 24.4 \\
\hline 5 & 30.05 & 11.39 & 342.4 & 240.8 & 1.49 & 358.5 & 16.19 & 95.48 & 11.5 & 1.46 \\
\hline 10 & 30.12 & 28.39 & 855.1 & 240.7 & 3.64 & 877 & 22.03 & 97.49 & 29.6 & 3.69 \\
\hline 20 & 30.39 & 57.48 & 1747 & 240.7 & 7.51 & 1808 & 61.24 & 96.61 & 63.0 & 7.9 \\
\hline 30 & 30.21 & 81.65 & 2467 & 240.7 & 10.72 & 2581 & 114.5 & 95.56 & 94.3 & 11.7 \\
\hline 40 & 30.17 & 102.0 & 3077 & 240.7 & 13.57 & 3266 & 188.5 & 94.23 & 124 & 15.5 \\
\hline 50 & 30.43 & 117.8 & 3583 & 240.6 & 15.98 & 3845 & 261.9 & 93.19 & 152 & 19.1 \\
\hline 60 & 30.48 & 129.9 & 3960 & 240.6 & 18.00 & 4331 & 370.9 & 91.44 & 180 & 22.6 \\
\hline 70 & 30.09 & 138.4 & 4166 & 240.6 & 19.19 & 4617 & 450.5 & 90.24 & 204 & 25.5 \\
\hline 5 & 30.29 & 20.69 & 626.6 & 260.5 & 2.52 & 656.3 & 29.65 & 95.48 & 23.7 & 3.05 \\
\hline 10 & 30.15 & 33.92 & 1023 & 260.4 & 4.07 & 1060 & 37.14 & 96.50 & 36.0 & 4.62 \\
\hline 20 & 30.15 & 63.60 & 1918 & 260.4 & 7.66 & 1994 & 76.78 & 96.15 & 67.3 & 8.45 \\
\hline 30 & 30.27 & 89.33 & 2704 & 260.4 & 10.92 & 2843 & 139.3 & 95.10 & 99.6 & 12.5 \\
\hline 40 & 30.24 & 111.4 & 3368 & 260.4 & 13.79 & 3591 & 223.0 & 93.79 & 131 & 16.5 \\
\hline 50 & 30.49 & 128.4 & 3915 & 260.4 & 16.20 & 4217 & 302.6 & 92.83 & 160 & 20.2 \\
\hline 60 & 30.53 & 140.4 & 4284 & 260.3 & 18.10 & 4713 & 428.5 & 90.91 & 189 & 23.8 \\
\hline 70 & 30.18 & 150.4 & 4538 & 260.3 & 19.38 & 5045 & 507.3 & 89.94 & 212 & 26.5 \\
\hline 5 & 30.41 & 25.10 & 763.2 & 289.9 & 2.83 & 821.8 & 58.62 & 92.87 & 40.4 & 5.21 \\
\hline 10 & 30.14 & 41.77 & 1259 & 280.9 & 4.69 & 1318 & 58.70 & 95.55 & 48.8 & 6.20 \\
\hline 20 & 30.24 & 69.74 & 2109 & 280.8 & 7.87 & 2211 & 101.7 & 95.40 & 74.7 & 9.56 \\
\hline 30 & 30.32 & 97.15 & 2946 & 280.9 & 11.05 & 3104 & 158.0 & 94.91 & 106 & 13.2 \\
\hline 40 & 30.29 & 120.8 & 3659 & 280.7 & 13.93 & 3910 & 251.7 & 93.56 & 137 & 17.4 \\
\hline 50 & 30.55 & 139.1 & 4249 & 280.8 & 16.37 & 4597 & 348.4 & 92.42 & 167 & 21.2 \\
\hline 60 & 30.60 & 153.2 & 4688 & 280.8 & 18.37 & 5157 & 469.2 & 90.90 & 196 & 24.7 \\
\hline
\end{tabular}


Table B.11: Transformer $\mathrm{T}_{4}$, Tap 12, $V_{1}=30 \mathrm{~V}$

\begin{tabular}{|c|c|c|c|c|c|c|c|c|}
\hline$\phi$ & $V_{1}$ in $\mathrm{V}$ & $I_{1}$ in $\mathrm{A}$ & $P_{1}$ in $\mathrm{W}$ & $V_{2}$ in $\mathrm{V}$ & $I_{2}$ in $\mathrm{A}$ & $P_{2}$ in $\mathrm{W}$ & $P_{\text {loss }}$ in $\mathrm{W}$ & $\eta$ in $\%$ \\
\hline 10 & 30.3 & 19.71 & 596.4 & 300.7 & 2.178 & 655.1 & 58.70 & 91.04 \\
\hline 20 & 30.8 & 56.88 & 1751 & 300.6 & 6.127 & 1842 & 90.74 & 95.07 \\
\hline 25 & 30.1 & 84.75 & 2555 & 300.7 & 8.868 & 2666 & 111.4 & 95.82 \\
\hline 30 & 30.3 & 100.1 & 3037 & 300.7 & 10.61 & 3190 & 153.7 & 95.18 \\
\hline 40 & 30.1 & 126.4 & 3807 & 300.7 & 13.47 & 4052 & 244.8 & 93.96 \\
\hline 50 & 30.4 & 146.7 & 4452 & 300.7 & 16.00 & 4814 & 361.8 & 92.48 \\
\hline 60 & 30.2 & 161.8 & 4886 & 300.7 & 17.83 & 5360 & 474.6 & 91.15 \\
\hline 10 & 30.3 & 22.33 & 676.4 & 320.2 & 2.258 & 723.1 & 46.65 & 93.55 \\
\hline 20 & 30.5 & 74.45 & 2270 & 320.2 & 7.336 & 2350 & 78.93 & 96.64 \\
\hline 25 & 30.4 & 91.96 & 2800 & 320.1 & 9.100 & 2910 & 114.1 & 96.08 \\
\hline 30 & 30.6 & 108.1 & 3300 & 320.1 & 10.82 & 3460 & 159.4 & 95.40 \\
\hline 40 & 30.3 & 135.7 & 4110 & 320.2 & 13.61 & 4360 & 246.8 & 94.34 \\
\hline 50 & 30.3 & 157.6 & 4780 & 320.1 & 16.07 & 5150 & 368.6 & 92.84 \\
\hline 60 & 30.3 & 173.7 & 5260 & 320.1 & 17.99 & 5760 & 500.2 & 91.32 \\
\hline 10 & 29.6 & 38.05 & 1130 & 340.0 & 3.37 & 1150 & 21.01 & 98.17 \\
\hline 20 & 30.3 & 81.60 & 2470 & 339.9 & 7.50 & 2550 & 81.26 & 96.81 \\
\hline 25 & 30.4 & 99.28 & 3020 & 339.9 & 9.24 & 3140 & 120.8 & 96.15 \\
\hline 30 & 30.1 & 116.1 & 3490 & 339.9 & 10.74 & 3650 & 161.7 & 95.57 \\
\hline 40 & 30.5 & 144.8 & 4410 & 339.9 & 13.77 & 4680 & 272.4 & 94.18 \\
\hline 50 & 30.4 & 167.7 & 5090 & 339.9 & 16.13 & 5480 & 388.9 & 92.91 \\
\hline 60 & 30.5 & 184.9 & 5630 & 339.9 & 18.17 & 6180 & 544.5 & 91.18 \\
\hline 3 & 30.0 & 3.649 & 109.6 & 361.3 & 0.321 & 116.2 & 6.60 & 94.32 \\
\hline 5 & 30.2 & 13.74 & 414.6 & 361.3 & 1.165 & 421.0 & 6.35 & 98.49 \\
\hline 10 & 30.6 & 44.02 & 1350 & 361.3 & 3.800 & 1370 & 26.12 & 98.10 \\
\hline 15 & 30.3 & 67.54 & 2050 & 361.3 & 5.809 & 2100 & 51.81 & 97.53 \\
\hline 20 & 30.4 & 88.34 & 2680 & 361.3 & 7.663 & 2770 & 84.23 & 96.96 \\
\hline 25 & 30.6 & 106.7 & 3270 & 361.2 & 9.403 & 3400 & 127.8 & 96.24 \\
\hline 30 & 30.3 & 124.6 & 3780 & 361.2 & 10.94 & 3950 & 170.4 & 95.69 \\
\hline 40 & 30.1 & 155.2 & 4680 & 361.3 & 13.74 & 4960 & 283.6 & 94.29 \\
\hline 50 & 30.2 & 179.5 & 5430 & 361.2 & 16.20 & 5850 & 424.8 & 92.74 \\
\hline 60 & 30.3 & 197.6 & 5980 & 361.2 & 18.13 & 6550 & 566.8 & 91.35 \\
\hline 5 & 30.0 & 28.83 & 865.8 & 381.0 & 2.301 & 876.6 & 10.78 & 98.77 \\
\hline 10 & 30.3 & 49.96 & 1514 & 381.0 & 4.047 & 1542 & 27.36 & 98.23 \\
\hline 15 & 30.2 & 73.53 & 2221 & 381.0 & 5.972 & 2275 & 54.45 & 97.61 \\
\hline 20 & 29.7 & 95.91 & 2853 & 381.1 & 7.724 & 2943 & 90.08 & 96.94 \\
\hline 30 & 30.0 & 134.1 & 4018 & 381.0 & 11.02 & 4201 & 182.7 & 95.65 \\
\hline 40 & 30.1 & 166.7 & 5011 & 381.0 & 13.93 & 5308 & 297.6 & 94.39 \\
\hline 50 & 30.0 & 192.2 & 5759 & 381.0 & 16.27 & 6198 & 439.0 & 92.92 \\
\hline 60 & 29.9 & 212.0 & 6330 & 381.0 & 18.21 & 6937 & 606.6 & 91.26 \\
\hline 5 & 30.1 & 46.78 & 1407 & 401.1 & 3.590 & 1440 & 33.06 & 97.70 \\
\hline 10 & 29.8 & 56.46 & 1682 & 401.2 & 4.294 & 1723 & 40.93 & 97.62 \\
\hline 15 & 29.9 & 79.19 & 2368 & 401.2 & 6.069 & 2435 & 67.13 & 97.24 \\
\hline 20 & 30.1 & 102.1 & 3069 & 401.1 & 7.912 & 3174 & 104.8 & 96.70 \\
\hline 30 & 29.6 & 142.4 & 4208 & 401.2 & 10.98 & 4406 & 198.0 & 95.51 \\
\hline 40 & 29.7 & 176.2 & 5237 & 401.1 & 13.86 & 5560 & 322.5 & 94.20 \\
\hline 50 & 29.8 & 203.1 & 6044 & 401.1 & 16.23 & 6511 & 467.2 & 92.82 \\
\hline 60 & 30.1 & 224.4 & 6746 & 401.1 & 18.48 & 7411 & 665.0 & 91.03 \\
\hline
\end{tabular}




\section{List of Figures}

1.1 Drive train topology . . . . . . . . . . . . . . . . . . . 1

1.2 Voltages, torque and power in the drive train topology with DC-DC converter 2

2.1 Ideal transformer . . . . . . . . . . . . . . . . . . . . . . . . . . . . . . .

2.2 Cross section of a transformer . . . . . . . . . . . . . . . . 6

2.3 Coupling T-model for the transformer . . . . . . . . . . . . . 7

2.4 Transformer T-model referred to the primary . . . . . . . . . . . 7

2.5 Transformer with multiple windings in parallel at the primary side and in series at secondary side . . . . . . . . . . . . . . . 8

2.6 Core dimension . . . . . . . . . . . . . . . . . . . . . . . . . . . . . . . . . . . . 11

2.7 Transformer winding configurations . . . . . . . . . . . . . . . 13

2.81 - Magnetic simulations for transformers with EE70 core, $i_{\mathrm{pk}, \mathrm{w}}=30 \mathrm{~A}$ with windings as reported in figure $2.7 \ldots \ldots . \ldots . . \ldots . . \ldots 16$

2.92 - Magnetic simulations for transformers with EE70 core, $i_{\mathrm{pk}, \mathrm{w}}=30 \mathrm{~A}$ with windings as reported in figure $2.7 \ldots \ldots . \ldots . \ldots . \ldots 17$

2.103 - Magnetic simulations for transformers with EE70 core, $i_{\mathrm{pk}, \mathrm{w}}=30 \mathrm{~A}$ with

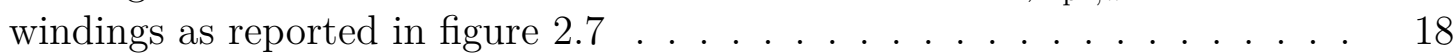

2.11 Schematic for the transformers $T_{1}, T_{2}$ and $T_{3}$ with eight primary and eight secondary windings . . . . . . . . . . . . . . . . . . 19

2.12 Picture of transformer $\mathrm{T}_{1}$ and windings configuration . . . . . . . . . . . 20

2.13 Leakage inductance between the transformer and the low voltage H-bridges 20

2.14 Measured and simulated current distribution in the transformer with the effect of the external connectors . . . . . . . . . . . . . . . 21

2.15 Comparison between transformer $T_{1}$ and the improved version $T_{5} \ldots \ldots 22$

2.16 Comparison between transformer $T_{3}$ and the improved version $T_{6} \ldots \ldots$

2.17 Primary side referred leakage inductances for the manufactured transformers 24

3.1 Dual active bridge . . . . . . . . . . . . . . . . . . . . 27

3.2 Simplified L-model of the DAB f . . . . . . . . . . . . . . . 28

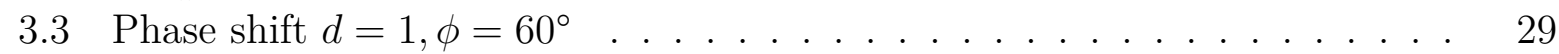

3.4 Phase shift $\phi=45^{\circ}, d>1 \ldots \ldots \ldots \ldots$

3.5 Soft turn-on switching in phase shift modulation . . . . . . . . . . . . . 30

3.6 Hard turn-on switching in phase shift modulation . . . . . . . . . . . . . 31

3.7 Power limits for the modulation strategies . . . . . . . . . . . . . . . . . . . 32

3.8 Trapezoidal current modulation . . . . . . . . . . . . . . . . 34

3.9 Triangular current modulation . . . . . . . . . . . . . . . . . . . . 36

4.1 Dual active bridge with tap changer . . . . . . . . . . . . . . . . . . . . . . . . 39

4.2 Tap changer structure with different devices . . . . . . . . . . . . . . . 40

4.3 Zero voltage switching limits for phase shift modulation . . . . . . . . . . . 40 
4.4 Power limit for the modulation strategies at different taps . . . . . . . . . 42

4.5 SMC-losses with $V_{1}=45 \mathrm{~V}$ with phase shift modulation . . . . . . . . . . . 44

4.6 SMC-losses with phase shift modulation with $V_{1}=30 \mathrm{~V}$ and with $V_{1}=60 \mathrm{~V} \quad 45$

4.7 SMC-losses with $V_{1}=45 \mathrm{~V}$ with PS, TRI and TRAP modulation strategies combined . . . . . . . . . . . . . . . . 46

4.8 SMC-losses with PS, TRI and TRAP modulation strategies combined and

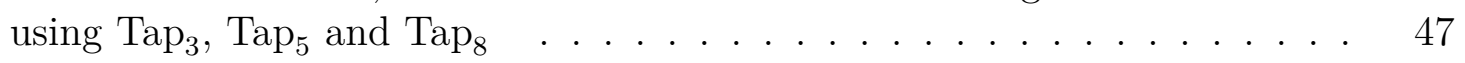

4.9 Transformer RMS primary current with $V_{1}=45 \mathrm{~V}$ and PS modulation . . . 49

4.10 Transformer RMS primary current with $V_{1}=45 \mathrm{~V}$ and PS, TRI and TRAP modulation strategies combined . . . . . . . . . . . . . . 50

5.1 Two DABs with tap changer in back-to-back configuration . . . . . . . 51

5.2 Low voltage H-bridge . . . . . . . . . . . . . . . . . . 52

5.3 High voltage H-bridge . . . . . . . . . . . . . . . . . . . . . . 53

5.4 Control board . . . . . . . . . . . . . . . . . . . . . . . . . . . . . . . . 54

5.5 Test circuit for the tap changer . . . . . . . . . . . . . . . . . . 55

5.6 Tap changer with relays . . . . . . . . . . . . . . . . . 55

5.7 Brush based tap changers . . . . . . . . . . . . . . . . . 57

5.8 Thyristor based tap changers . . . . . . . . . . . . . . . . . 58

5.9 Four channel tap changer set-up for MOSFETs and IGBTs . . . . . . . . . 59

5.10 Tap changer with MOSFETs . . . . . . . . . . . . . . . . . 59

5.11 Commutation of the tap changer with MOSFETs . . . . . . . . . . 60

5.12 Tap changer with IGBTs . . . . . . . . . . . . . . . . 60

5.13 Conduction Losses . . . . . . . . . . . . . . . . . . . . . 61

5.14 Back-to-back configuration in the measurement set-up . . . . . . . . . . . 62

5.15 Efficiency with $V_{1}=30 \mathrm{~V}$ in phase shift modulation and $\operatorname{Tap}_{8}$ with $n_{\mathrm{T}}=8 \quad 65$

5.16 Efficiency in function of the power with $V_{1}=30 \mathrm{~V}$ in phase shift modulation 66

5.17 Efficiency in function of the phase shift angle with $V_{1}=30 \mathrm{~V}$ in phase shift modulation ........................ 67

$5.18 V_{1}=50 \mathrm{~V}$ in phase shift modulation . . . . . . . . . . . 68

6.1 Three-phase dual active bridge with tap changer and tap switches implementation . . . . . . . . . . . . . . . . . . . 70

A.1 Transformer with multiple windings in parallel at the primary side and in series at secondary side . . . . . . . . . . . . . . . . . 71 


\section{List of Tables}

2.1 Transformer specifications . . . . . . . . . . . . . . . . . . . 10

2.2 Used core for the transformers . . . . . . . . . . . . . . . . . . . . . . . . . . . . . . . . . . . .

2.3 List of the transformers . . . . . . . . . . . . . . . . . 12

3.1 Switch state in the phase shift mode . . . . . . . . . . . . . . 31

3.2 Switch state in trapezoidal mode . . . . . . . . . . . . . . . . . . . 34

3.3 Switch turn-on angle for trapezoidal modulation . . . . . . . . . . . . . . . . . . 35

3.4 Switch state in triangular mode . . . . . . . . . . . . . . . 36

5.1 Prototype specifications . . . . . . . . . . . . . . . 52

5.2 Specifications of the device in the low voltage H-bridge . . . . . . . . . . 52

5.3 MOSFETs for the high voltage H-bridge . . . . . . . . . . . . . 53

5.4 Specifications of the device used in the tap changer . . . . . . . . . . . . 59

5.5 Maximum efficiency and maximum power for each tap. Taps 2-8 with transformer $\mathrm{T}_{3}$, Tap 12 with transformer $\mathrm{T}_{4} \ldots \ldots \ldots$. . . . . . 64

B.1 Transformer $\mathrm{T}_{3}$, Tap $2, V_{1}=50 \mathrm{~V} \ldots \ldots \ldots \ldots$

B.2 Transformer $\mathrm{T}_{3}$, Tap $3, V_{1}=50 \mathrm{~V} \ldots \ldots \ldots \ldots$

B.3 Transformer $\mathrm{T}_{3}$, Tap $4, V_{1}=50 \mathrm{~V} \ldots \ldots \ldots \ldots$. . . . . . . . . . . . . . . . .

B.4 Transformer $\mathrm{T}_{3}$, Tap $5, V_{1}=50 \mathrm{~V} \ldots \ldots \ldots \ldots$

B.5 Transformer $\mathrm{T}_{3}$, Tap $6, V_{1}=50 \mathrm{~V} \ldots \ldots \ldots \ldots \ldots \ldots$

B.6 Transformer $\mathrm{T}_{3}$, Tap $7, V_{1}=50 \mathrm{~V} \ldots \ldots \ldots \ldots \ldots$

B.7 Transformer $\mathrm{T}_{3}$, Tap $8, V_{1}=50 \mathrm{~V} \ldots \ldots \ldots \ldots$. . . . . . . . . . . . . . . . 81

B.8 Transformer $\mathrm{T}_{3}$, Tap $4, V_{1}=30 \mathrm{~V} \ldots \ldots \ldots \ldots$

B.9 Transformer $\mathrm{T}_{3}$, Tap $6, V_{1}=30 \mathrm{~V} \ldots \ldots \ldots \ldots$

B.10 Transformer $\mathrm{T}_{3}$, Tap $8, V_{1}=30 \mathrm{~V} \ldots \ldots \ldots \ldots$

B.11 Transformer $\mathrm{T}_{4}$, Tap $12, V_{1}=30 \mathrm{~V} \ldots \ldots \ldots \ldots$ 


\section{Bibliography}

[1] Alex Van den Bossche, V. C. V. Inductors and Transformers for Power Electronics. CRC Press, 2005.

[2] Atmel. Datasheet AT32UC3A, High Performance, Low Power 32-Bit Atmel AVR Microcontroller AT32UC3A1256-U. 32058K-AVR32-01/12. Jan. 2012.

[3] Baliga, B. J. Fundamentals of Power Semiconductor Devices. Ed. by Springer. Springer, 2008.

[4] CREE. Datasheet C3M0065090D, Silicon Carbide Power MOSFET. May 2015.

[5] De Doncker, R. et al. "A three-phase soft-switched high-power-density DC-DC converter for high-power applications". In: Industry Applications, IEEE Transactions on 27.1 (Jan. 1991), pp. 63-73. ISSN: 0093-9994. DOI: 10.1109/28.67533.

[6] Doncker, R. W. D. et al. "A three-phase soft-switched high power density DC-DC converter for high power applications". In: Conference Record of the 1988 IEEE Industry Applications Society Annual Meeting. Oct. 1988, 796-805 vol.1. DOI: 10 . 1109/IAS. 1988. 25153.

[7] FERROXCUBE. Data Handbook 2013, Soft Ferrites and Accessories. Sept. 2013.

[8] Hoek, H. v. et al. "Comparison of a single-phase and a three-phase dual active bridge with low-voltage, high-current output". In: 2012 International Conference on Renewable Energy Research and Applications (ICRERA). Nov. 2012, pp. 1-6. DOI: 10.1109/ICRERA. 2012.6477466.

[9] Hoek, H. v. et al. "Enhanced Modulation Strategy for a Three-Phase Dual Active Bridge-Boosting Efficiency of an Electric Vehicle Converter". In: IEEE Transactions on Power Electronics 28.12 (Dec. 2013), pp. 5499-5507. ISSN: 0885-8993. DOI: 10. 1109/TPEL. 2013. 2251905.

[10] Hoek, H. v. et al. "Power electronic architectures for electric vehicles". In: 2010 Emobility - Electrical Power Train. Nov. 2010, pp. 1-6. DOI: 10.1109/EMOBILITY. 2010.5668048.

[11] Infineon Technologies AG. Application Note AN 2013-04, Mastering the Art of Quickness. v1.0. Apr. 2013.

[12] Infineon Technologies AG. Datasheet IPW65R045Cr7, 650V CoolMOS Cr Power Transistor. v2.1. Apr. 2013.

[13] International Rectifier. Datasheet IRF7769L2PbF, DirectFET Power MOSFET. May 2014.

[14] IXYS. Datasheet IXFX120N65X2, X2-Class HiPerFET Power MOSFET. 2015. 
[15] Kheraluwala, M. N. et al. "Performance characterization of a high-power dual active bridge DC-to-DC converter". In: IEEE Transactions on Industry Applications 28.6 (Nov. 1992), pp. 1294-1301. ISSN: 0093-9994. DOI: 10.1109/28.175280.

[16] Krismer, F. and Kolar, J. "Efficiency-Optimized High-Current Dual Active Bridge Converter for Automotive Applications". In: Industrial Electronics, IEEE Transactions on 59.7 (July 2012), pp. 2745-2760. ISSN: 0278-0046. DOI: 10 . 1109 / TIE . 2011. 2112312.

[17] Krismer, F. "Modeling and Optimization of Bidirectional Dual Active Bridge DCDC Converter Topologies". PhD thesis. ETH ZURICH, 2010.

[18] Krismer, F. et al. "A comparative evaluation of isolated bi-directional DC-DC converters with wide input and output voltage range". In: Fourtieth IAS Annual Meeting. Conference Record of the 2005 Industry Applications Conference, 2005. Vol. 1. Oct. 2005, 599-606 Vol. 1. DOI: 10.1109/IAS.2005.1518368.

[19] Krismer, F. et al. "Performance Optimization of a High Current Dual Active Bridge with a Wide Operating Voltage Range". In: Power Electronics Specialists Conference, 2006. PESC '06. 37th IEEE. June 2006, pp. 1-7. DOI: 10.1109/PESC . 2006.1712096.

[20] Küpfmüller, K et Kohn, G. Theoretische Elektrotechnik und Elektronik. Ed. by SpringerVerlag. 14. Auflage. Springer-Verlag, 1993.

[21] LEM. Current Transducer IT 205-S ULTRASTAB, I $\mathrm{PN}=200$ A. v1. Apr. 2015.

[22] Li, J. et al. "Improved calculation of core loss with nonsinusoidal waveforms". In: Conference Record of the 2001 IEEE Industry Applications Conference. 36th IAS Annual Meeting (Cat. No.01CH37248). Vol. 4. Sept. 2001, 2203-2210 vol.4. Dor: 10.1109/IAS.2001.955931.

[23] Lutz, J. Halbleiter-Leistungsbauelemente Physik, Eigenschaften, Zuverlässigkeit. Ed. by Springer-Verlag. Springer-Verlag, 2006.

[24] Lutz, J. et al. Semiconductor Power Devices Physics, Characteristics, Reliability. Springer-Verlag, 2011.

[25] Meeker, D. FEMM 4.2 Magnetics, Electrostatics, Heat Flow, and Current Flow. 2016. URL: http://www.femm.info.

[26] Ralev, I. et al. "Wide speed range six-step mode operation of IPMSM drives with adjustable dc-link voltage". In: 2014 17th International Conference on Electrical Machines and Systems (ICEMS). Oct. 2014, pp. 2987-2993. DOI: 10.1109/ICEMS . 2014.7014008.

[27] Riedel, J. et al. "Active Suppression of Selected DC Bus Harmonics for Dual Active Bridge DC-DC Converters". In: IEEE Transactions on Power Electronics 32.11 (Nov. 2017), pp. 8857-8867. ISSN: 0885-8993. DOI: 10.1109/TPEL. 2016. 2647078.

[28] Rik W. A. A. De Doncker, Robert D. King. "Technique for decoupling the energy storage system voltage from the DC link voltage in AC electric drive systems". U.S. pat. 5373195. 1994. 
[29] Rodrguez, A. et al. "Different Purpose Design Strategies and Techniques to Improve the Performance of a Dual Active Bridge With Phase-Shift Control". In: IEEE Transactions on Power Electronics 30.2 (Feb. 2015), pp. 790-804. ISSN: 0885-8993. DOI: 10.1109/TPEL. 2014.2309853.

[30] Rothgang, S. et al. "Diversion of Aging of Battery Cells in Automotive Systems". In: 2014 IEEE Vehicle Power and Propulsion Conference (VPPC). Oct. 2014, pp. 1-6. DOI: $10.1109 /$ VPPC. 2014.7007050.

[31] Schibli, N. "Symmetrical Multilevel Converters with two Quadrant DC-DC Feeding". $\mathrm{PhD}$ thesis. Lausanne, EPFL, 2000.

[32] Schoenen, T. et al. "Advantages of a variable DC-link voltage by using a DC-DC converter in hybrid-electric vehicles". In: 2010 IEEE Vehicle Power and Propulsion Conference. Sept. 2010, pp. 1-5. DOI: 10.1109/VPPC.2010.5729003.

[33] Schoenen, T. et al. "Maximum DC-link voltage utilization for optimal operation of IPMSM". In: 2009 IEEE International Electric Machines and Drives Conference. May 2009, pp. 1547-1550. DOI: 10.1109/IEMDC.2009.5075409.

[34] Shiva, S. M. et al. "Tap changing transformer based dual active bridge bi-directional DC-DC converter". In: 2015 9th International Conference on Power Electronics and ECCE Asia (ICPE-ECCE Asia). June 2015, pp. 2025-2030. DOI: 10.1109/ICPE. 2015.7168056.

[35] Steigerwald, R. L. et al. "A comparison of high power DC-to-DC soft-switched converter topologies". In: Proceedings of 1994 IEEE Industry Applications Society Annual Meeting. Oct. 1994, 1090-1096 vol.2. DOI: 10.1109/IAS.1994.377564.

[36] Stieneker Marco, De Doncker Rik W. A. A. "DC-to-DC Converter Comprising a Transformer". German pat. DE102014214542 (A1). 2016.

[37] STMicroelectronics. Datasheet TM8050H-8W, 80 A high temperature Thyristor (SCR). Rev. 1. May 2016.

[38] Taraborrelli, S. et al. "Bidirectional dual active bridge converter using a tap changer for extended voltage ranges". In: 2016 18th European Conference on Power Electronics and Applications (EPE'16 ECCE Europe). Sept. 2016, pp. 1-10. DOI: 10.1109/EPE. 2016.7695668.

[39] TDK. Datasheet, Nn-Zn Ferrite mMaterial Characteristics. Dec. 2014.

[40] TDK. Datasheet, SIFERRIT material N9\%. Sept. 2006.

[41] Tenner, S. et al. "Loss minimization of electric drive systems using a DC/DC converter and an optimized battery voltage in automotive applications". In: 2011 IEEE Vehicle Power and Propulsion Conference. Sept. 2011, pp. 1-7. DOI: 10.1109/VPPC. 2011. 6043024.

[42] Venkatachalam, K. et al. "Accurate prediction of ferrite core loss with nonsinusoidal waveforms using only Steinmetz parameters". In: 2002 IEEE Workshop on Computers in Power Electronics, 2002. Proceedings. June 2002, pp. 36-41. DOI: 10.1109/CIPE. 2002.1196712.

[43] Xilinx Inc. Product Specification UG385, Spartan-6 FPGA. v2.3. May 2014. 
[44] Zach, F. Leistungselektronik. Springer-Verlag, 1979. 


\author{
ABISEA Band 1 \\ Eßer, A. \\ Berührungslose, kombinierte \\ Energie- und Informations- \\ übertragung für bewegliche \\ Systeme \\ 1. Auflage 1992, 130 Seiten \\ ISBN 3-86073-046-0
}

\section{ABISEA Band 2 \\ Vogel, $U$. \\ Entwurf und Beurteilung von Verfahren zur Hochausnutzung des Rad-Schiene- \\ Kraftschlusses durch \\ Triebfahrzeuge \\ 1. Auflage 1992, 130 Seiten \\ ISBN 3-86073-060-6}

\section{ABISEA Band 3 \\ Redehorn, Th. \\ Stromeinprägendes \\ Antriebssystem mit \\ fremderregter Synchron- \\ maschine \\ 1. Auflage 1992, 130 Seiten \\ ISBN 3-86073-061-4}

\section{ABISEA Band 4 \\ Ackva, A.}

Spannungseinprägendes

Antriebssystem mit

Synchron-maschine und direkter Stromregelung 1. Auflage 1992, 135 Seiten ISBN 3-86073-062-2

\section{ABISEA Band 5 \\ Mertens, A.}

Analyse des

Oberschwingungsverhaltens von taktsynchronen Delta Modulationsverfahren zur Steuerung von Pulsstromrichtern bei hoher Taktzahl

1. Auflage 1992, 170 Seiten ISBN 3-86073-069-X

\section{ABISEA Band 6 \\ Geuer, W.}

Untersuchungen über das

Alterungsverhalten von

Bleiakkumulatoren

1. Auflage 1993, 100 Seiten

ISBN 3-86073-097-5

\author{
ABISEA Band 7 \\ Langheim, J. \\ Einzelradantrieb für \\ Elektrostraßenfahrzeuge \\ 1. Auflage 1993, 215 Seiten \\ ISBN 3-86073-123-8 \\ (vergriffen)
}

\section{ABISEA Band 8 \\ Fetz, J.}

Fehlertolerante Regelung eines Asynchron-Doppelantriebes für ein Elektrospeicherfahrzeug 1. Auflage 1993, 136 Seiten ISBN 3-86073-124-6 (vergriffen)

\section{ABISEA Band 9}

\section{Schülting, L.}

Optimierte Auslegung

induktiver Bauelemente für den

Mittelfrequenzbereich

1. Auflage 1993, 136 Seiten

ISBN 3-86073-174-2

(vergriffen)

ABISEA Band 10

Skudelny, H.-Ch.

Stromrichtertechnik

4. Auflage 1997, 259 Seiten

ISBN 3-86073-189-0

\section{ABISEA Band 11}

Skudelny, Ch.

Elektrische Antriebe

3. Auflage 1997, 124 Seiten

ISBN 3-86073-231-5

\section{ABISEA Band 12 \\ Schöpe, $F$.}

Batterie-Management für

Nickel-Cadmium

Akkumulatoren

1. Auflage 1994, 156 Seiten

ISBN 3-86073-232-3

(vergriffen)

\section{ABISEA Band 13 \\ v. d. Weem, J.}

Schmalbandige aktive Filter für

Schienentriebfahrzeuge am

Gleichspannungs-fahrdraht

1. Auflage 1995, 125 Seiten

ISBN 3-86073-233-1

\section{ABISEA Band 14 \\ Backhaus, $\mathrm{K}$.}

Spannungseinprägendes

Direktantriebssystem mit schnelllaufender geschalteter

Reluktanzmaschine

1. Auflage 1995, 156 Seiten

ISBN 3-86073-234-X

(vergriffen)

\section{ABISEA Band 15 \\ Reinold, $\mathbf{H}$.}

Optimierung dreiphasiger

Pulsdauermodulations-

verfahren

1. Auflage 1996, 116 Seiten

ISBN 3-86073-235-8

\section{ABISEA Band 16 \\ Köpken, H.-G.}

Regelverfahren für

Parallelschwingkreis-

umrichter

1. Auflage 1996, 125 Seiten

ISBN 3-86073-236-6

\section{ABISEA Band 17 \\ Mauracher, $\mathbf{P}$. \\ Modellbildung und \\ Verbundoptimierung bei \\ Elektrostraßenfahrzeugen \\ 1. Auflage 1996, 192 Seiten \\ ISBN 3-86073-237-4}

\section{ABISEA Band 18 \\ Protiwa, F.-F.}

Vergleich dreiphasiger

Resonanz-Wechselrichter in

Simulation und Messung

1. Auflage 1997, 178 Seiten

ISBN 3-86073-238-2

\section{ABISEA Band 19 \\ Brockmeyer, $\mathbf{A}$.}

Dimensionierungswerkzeug für magnetische Bau-

elemente in Stromrichter-

anwendungen

1. Auflage 1997, 182 Seiten

ISBN 3-86073-239-0
ABISEA Band 20
Apeldoorn, 0.
Simulationsgestützte Bewer- tung von Steuerverfahren für netzgeführte Stromrichter mit verringerter Netzrück-wirkung 1. Auflage 1997, 132 Seiten ISBN 3-86073-680-9 


\author{
ABISEA Band 21 \\ Lohner, A. \\ Batteriemanagement für \\ verschlossene Blei-Batterien \\ am Beispiel von Unter- \\ brechungsfreien \\ Stromversorgungen \\ 1. Auflage 1998, 144 Seiten \\ ISBN 3-86073-681-7
}

\section{ABISEA Band 22}

Reinert, J.

Optimierung der Betriebseigenschaften von Antrieben mit geschalteter Reluktanzmaschine

1. Auflage 1998, 168 Seiten ISBN 3-86073-682-5

\author{
ABISEA Band 23 \\ Nagel, A. \\ Leitungsgebundene \\ Störungen in der \\ Leistungselektronik: \\ Entstehung, Ausbreitung \\ und Filterung \\ 1. Auflage 1999, 160 Seiten \\ ISBN 3-86073-683-3
}

\section{ABISEA Band 24 \\ Menne, $M$.}

Drehschwingungen im Antriebsstrang von Elektro-

straßenfahrzeugen -

Analyse und aktive

Dämpfung

1. Auflage 2001, 192 Seiten

ISBN 3-86073-684-1

\author{
ABISEA Band 25 \\ von Bloh, J. \\ Multilevel-Umrichter zum \\ Einsatz in Mittelspannungs- \\ Gleichspannungs- \\ Übertragungen \\ 1. Auflage 2001, 152 Seiten \\ ISBN 3-86073-685-X
}

\author{
ABISEA Band 26 \\ Karden, E. \\ Using low-frequency \\ impedance spectroscopy for \\ characterization, monitoring, \\ and modeling of industrial \\ batteries \\ 1. Auflage 2002, 154 Seiten \\ ISBN 3-8265-9766-4
}

\author{
ABISEA Band 27 \\ Karipidis, C.-U. \\ A Versatile DSP/ FPGA \\ Structure optimized for \\ Rapid Prototyping and \\ Digital Real-Time Simulation \\ of Power Electronic and \\ Electrical Drive Systems \\ 1. Auflage 2001, 164 Seiten \\ ISBN 3-8265-9738-9
}

\section{ABISEA Band 28 \\ Kahlen, $\mathrm{K}$.}

Regelungsstrategien für permanentmagnetische Direkt-

antriebe mit mehreren

Freiheitsgraden

1. Auflage 2003, 158 Seiten

ISBN 3-8322-1222-1

\section{ABISEA Band 29 \\ Inderka, R. \\ Direkte Drehmoment- \\ regelung Geschalteter \\ Reluktanzantriebe \\ 1. Auflage 2003, 190 Seiten \\ ISBN 3-8322-1175-6}

\section{ABISEA Band 30 \\ Schröder, S.}

Circuit-Simulation Models of High-Power Devices Based on Semiconductor Physics

1. Auflage 2003, 124 Seiten ISBN 3-8322-1250-7

\section{ABISEA Band 31}

Buller, S.

Impedance-Based Simulation Models for Energy

Storage Devices in

Advanced Automotive

Power Systems

1. Auflage 2003, 136 Seiten

ISBN 3-8322-1225-6

\section{ABISEA Band 32}

\section{Schönknecht, A.}

Topologien und Regelungsstrategien für das induktive

Erwärmen mit hohen

Frequenz-Leistungs-

produkten

1. Auflage 2004, 170 Seiten

ISBN 3-8322-2408-4

\section{ABISEA Band 33 \\ Tolle, $\mathrm{T}$.}

Konvertertopologien für ein aufwandsarmes, zweistufiges Schaltnetzteil zum Laden von Batterien aus dem Netz

1. Auflage 2004, 150 Seiten ISBN 3-8322-2676-1

\section{ABISEA Band 34 \\ Götting, G.}

Dynamische Antriebsregelung von Elektrostraßenfahrzeugen unter Berücksichtigung eines schwingungsfähigen Antriebsstrangs 1. Auflage 2004, 166 Seiten ISBN 3-8322-2804-7

\section{ABISEA Band 35 \\ Dieckerhoff, $\mathbf{S}$.}

Transformatorlose Stromrichterschaltungen für Bahnfahrzeuge am 16 2/3Hz Netz 1. Auflage 2004, 158 Seiten ISBN 3-8322-3094-7

\section{ABISEA Band 36}

$\mathrm{Hu}, \mathrm{J}$.

Bewertung von DC-DC-

Topologien und Optimierung eines DC-DC-Leistungsmoduls für das $42-\mathrm{V}-\mathrm{Kfz}$ Bordnetz

1. Auflage 2004, 156 Seiten ISBN 3-8322-3201-X

\section{ABISEA Band 37 \\ Detjen, D.-0. \\ Characterization and Modeling of Si-Si Bonded Hydrophobie Interfaces for Novel High-Power BIMOS Devices \\ 1. Auflage 2004, 146 Seiten ISBN 3-8322-2963-9}

\section{ABISEA Band 38 \\ Walter, J.}

Simulationsbasierte Zuverlässigkeitsanalyse in der modernen Leistungselektronik 1. Auflage 2004, 134 Seiten ISBN 3-8322-3481-0 


\author{
ABISEA Band 39 \\ Schwarzer, U. \\ IGBT versus GCT in der \\ Mittelspannungsanwendung \\ - ein experimenteller und \\ simulativer Vergleich \\ 1. Auflage 2005, 184 Seiten \\ ISBN 3-8322-4489-1
}

\section{ABISEA Band 40 \\ Bartram, $M$.}

IGBT-Umrichtersysteme für Windkraftanlagen: Analyse der Zyklenbelastung, Modellbildung, Optimierung und Lebensdauervorhersage 1. Auflage 2006, 195 Seiten ISBN 3-8322-5039-5

\section{ABISEA Band 41 \\ Ponnaluri, S. \\ Generalized Design, Analysis and Control of Grid side converters with integrated UPS or Islanding functionality \\ 1. Auflage 2006, 163 Seiten \\ ISBN 3-8322-5281-9}

\section{ABISEA Band 42 \\ Jacobs, J. \\ Multi-Phase Series \\ Resonant DC-to-DC \\ Converters \\ 1. Auflage 2006, 185 Seiten \\ ISBN 3-8322-5532-X}

\section{ABISEA Band 43 \\ Linzen, D.}

Impedance-Based Loss

Calculation and Thermal

Modeling of Electrochemical

Energy Storage Devices for

Design Considerations of

Automotive Power Systems

1. Auflage 2006, 150 Seiten

ISBN 3-8322-5706-3

\section{ABISEA Band 44}

Fiedler, J.

Design of Low-Noise

Switched Reluctance Drives

1. Auflage 2007, 183 Seiten

ISBN 978-3-8322-5864-I

\begin{abstract}
ABISEA Band 45
Fuengwarodsakul, $\mathbf{N}$.

Predictive PWM-based

Direct Instantaneous Torque

Control for Switched

Reluctance Machines

1. Auflage 2007, 150 Seiten

ISBN 978-3-8322-6210-5
\end{abstract}

\section{ABISEA Band 46}

Meyer, C.

Key Components for Future

Offshore DC Grids

1. Auflage 2007, 196 Seiten

ISBN 978-3-8322-6571-7

\section{ABISEA Band 47}

Fujii, K.

Characterization and

Optimization of Soft-

Switched Multi-Level

Converters for STATCOMs

1. Auflage 2008, 206 Seiten

ISBN 978-3-8322-6981-4

\section{ABISEA Band 48 \\ Carstensen, C.}

Eddy Currents in Windings

of Switched Reluctance

Machines

1. Auflage 2008, 190 Seiten

ISBN 978-3-8322-7118-3

\section{ABISEA Band 49 \\ Bohlen, 0 .}

Impedance-based battery monitoring

1. Auflage 2008, 200 Seiten

ISBN 978-3-8322-7606-5

\section{ABISEA Band 50}

Thele, $M$.

A contribution to the modelling of the charge acceptance of lead-acid batteries - using frequency and time domain based concepts

1. Auflage 2008, 168 Seiten ISBN 978-3-8322-7659-1

\author{
ABISEA Band 51 \\ König, A. \\ High Temperature DC-to-DC \\ Converters for Downhole \\ Applications \\ 1. Auflage 2009, 160 Seiten \\ ISBN 978-3-8322-8489-3
}

\author{
ABISEA Band 52 \\ Dick, C. P. \\ Multi-Resonant Converters \\ as Photovoltaic Module- \\ Integrated Maximum Power \\ Point Tracker \\ 1. Auflage 2010, 192 Seiten \\ ISBN 978-3-8322-9199-0
}

\section{ABISEA Band 53}

\section{Kowal, J.}

Spatially-resolved impedance of nonlinear inhomogeneous devices using the example of leadacid batteries -

1. Auflage 2010, 214 Seiten ISBN 978-3-8322-9483-0

\section{ABISEA Band 54 \\ Roscher, M.}

Zustandserkennung von

LiFeP04-Batterien für

Hybrid- und

Elektrofahrzeuge

1. Auflage 2011, 194 Seiten

ISBN 978-3-8322-9738-I

\section{ABISEA Band 55 \\ Hirschmann, D. \\ Highly Dynamic \\ Piezoelectric Positioning \\ 1. Auflage 2011, 156 Seiten \\ ISBN 978-3-8322-9746-6}

\section{ABISEA Band 56 \\ Rigbers, $\mathrm{K}$.}

Highly Efficient Inverter

Architectures for Three-

Phase Grid Connection

of Photovoltaic Generators

1. Auflage 2011, 254 Seiten

ISBN 978-3-8322-9816-9

\section{ABISEA Band 57 \\ Kasper, $\mathrm{K}$. \\ Analysis and Control of the \\ Acoustic Behavior of \\ Switched Reluctance Drives \\ 1. Auflage 2011, 214 Seiten \\ ISBN 978-3-8322-9869-2}

\author{
ABISEA Band 58 \\ Köllensperger, $P$. \\ The Internally Commutated \\ Thyristor - Concept, Design \\ and Application \\ 1. Auflage $201 \mathrm{~J}, 212$ Seiten \\ ISBN 978-3-8322-9909-5
}




\author{
ABISEA Band 59 \\ Schoenen, T. \\ Einsatz eines DC/DC-Wand- \\ lers zur Spannungs- \\ anpassung zwischen Antrieb \\ und Energiespeicher in \\ Elektro-und Hybrid- \\ fahrzeugen \\ 1. Auflage 2011, 138 Seiten \\ ISBN 978-3-8440-0622-3
}

\section{ABISEA Band 60 Hennen, M. \\ Switched Reluctance Direct Drive with Integrated Distributed Inverter 1. Auflage 2012, 150 Seiten ISBN 978-3-8440-0731-2}

\author{
ABISEA Band 61 \\ van Treek, D. \\ Position Sensorless Torque \\ Control of Switched \\ Reluctance Machines \\ 1. Auflage 2012, 144 Seiten \\ ISBN 978-3-8440-IO 14-5
}

\section{ABISEA Band 62 Bragard, $M$. \\ Tue Integrated Emitter Turn- Off Thyristor. An Innovative MOS-Gated High-Power Device \\ 1. Auflage 2012, 172 Seiten ISBN 978-3-8440-1152-4}

\section{ABISEA Band 63}

Gerschler, J. B.

Ortsaufgelöste Modellbildung von Lithium-lonenSystemen unter spezieller Berücksichtigung der Batteriealterung 1. Auflage 2012, 350 Seiten ISBN 978-3-8440-1307-8

\author{
ABISEA Band 64 \\ Neuhaus, $C$. \\ Schaltstrategien für \\ Geschaltete Reluktanz- \\ antriebe mit kleinem \\ Zwischenkreis \\ 1. Auflage 2012, 144 Seiten \\ ISBN 978-3-8440-1487-7
}

\author{
ABISEA Band 65 \\ Butschen, $T$. \\ Dual-ICT- A Clever Way to \\ Unite Conduction and \\ Switching Optimized \\ Properties in a Single Wafer \\ 1. Auflage 2012, 178 Seiten \\ ISBN 978-3-8440-1771-7
}

\section{ABISEA Band 66}

Plum, T.

Design and Realization of

High-Power MOS Turn-Off

Thyristors

1. Auflage 2013, 130 Seiten ISBN 978-3-8440-1884-4

\section{ABISEA Band 67 \\ Kiel, $M$.}

Impedanzspektroskopie an

Batterien unter besonderer

Berücksichtigung von

Batteriesensoren für den

Feldeinsatz

1. Auflage 2013, 232 Seiten

ISBN 978-3-8440-1973-5

\section{ABISEA Band 68 \\ Brauer, $\mathbf{H}$. \\ Schnelldrehender}

Geschalteter Reluktanz-

antrieb mit extremem

Längendurchmesser-

verhältnis

1. Auflage 2013, 202 Seiten ISBN 978-3-8440-2345-9

\section{ABISEA Band 69 \\ Thomas, $S$.}

A Medium-Voltage Multi-

Level DC/DC Converter with

High Voltage Transformation

Ratio

1. Auflage 2014, 236 Seiten ISBN 978-3-8440-2605-4

\section{ABISEA Band 70 \\ Richter, S.}

Digitale Regelung von PWM

Wechselrichtern mit niedrigen Trägerfrequenzen 1. Auflage 2014, 134 Seiten ISBN 978-3-8440-2641-2

\author{
ABISEA Band 71 \\ Bösing, $M$. \\ Acoustic Modeling of \\ Electrical Drives - Noise and \\ Vibration Synthesis based \\ on Force Response \\ Superposition \\ 1. Auflage 2014, 208 Seiten \\ ISBN 978-3-8440-2752-5
}

\section{ABISEA Band 72 \\ Waag, W.}

Adaptive algorithms for monitoring of lithium-ion batteries in electric vehicles 1. Auflage 2014, 242 Seiten ISBN 978-3-8440-2976-5

\section{ABISEA Band 73 \\ Sanders, $T$.}

Spatially Resolved Electrical

In-Situ Measurement

Techniques for Fuel Cells

1. Auflage 2014, 138 Seiten

ISBN 978-3-8440-3121-8

\section{ABISEA Band 74 \\ Baumhöfer, T.}

Statistische Betrachtung experimenteller Alterungsuntersuchungen an LithiumIonen Batterien

1. Auflage 2015, 174 Seiten ISBN 978-3-8440-3423-3

\section{ABISEA Band 75 \\ Andre, D. \\ Systematic Characterization of Ageing Factors for High- \\ Energy Lithium-lon Cells and Approaches for Lifetime Modelling Regarding an Optimized Operating Strategy in Automotive Applications \\ 1. Auflage 2015, 210 Seiten ISBN 978-3-8440-3587-2}

\author{
ABISEA Band 76 \\ Merei, G. \\ Optimization of off-grid \\ hybrid PV-wind-diesel power \\ supplies with multi- \\ technology battery systems \\ taking into account battery \\ aging \\ 1. Auflage 2015, 194 Seiten \\ ISBN 978-3-8440-4148-4
}




\author{
ABISEA Band 77 \\ Schulte, D. \\ Modellierung und experi- \\ mentelle Validierung der \\ Alterung von Blei-Säure \\ Batterien durch inhomogene \\ Stromverteilung und \\ Säureschichtung \\ 1. Auflage 2016, 168 Seiten \\ ISBN 978-3-8440-4216-0
}

\section{ABISEA Band 78 \\ Schenk, M.}

Simulative Untersuchung der Wicklungsverluste in Geschalteten Reluktanzmaschinen 1. Auflage 2016, 142 Seiten ISBN 978-3-8440-4282-5

\section{ABISEA Band 79 \\ Wang, $Y$. \\ Development of Dynamic Models with Spatial Resolution for Electro- chemical Energy Converters as Basis for Control and Management Strategies 1. Auflage 2016, 198 Seiten} ISBN 978-3-8440-4303-7

\section{ABISEA Band 80 \\ Ecker, M. \\ Lithium Plating in Lithium- \\ Ion Batteries: An \\ Experimental and Simulation Approach \\ 1. Auflage 2016, 170 Seiten ISBN 978-3-8440-4525-3}

\section{ABISEA Band 81}

Zhou, W.

Modellbasierte Auslegungsmethode von Temperierungssystemen für Hochvolt-Batterien in Personenkraftfahrzeugen 1. Auflage 2016, 192 Seiten ISBN 978-3-8440-4589-5

\footnotetext{
ABISEA Band 82 Lunz, B.

Deutschlands Stromversorgung im Jahr 2050 Ein szenariobasiertes Verfahren zur vergleichenden Bewertung von Systemvarianten und Flexibilitätsoptionen 1. Auflage 2016, 196 Seiten ISBN 978-3-8440-4627-4
}

\author{
ABISEA Band 83 \\ Hofmann, A. \\ Direct Instantaneous Force \\ Control Key to Low-Noise \\ Switched Reluctance \\ Traction Drives \\ 1. Auflage 2016, 244 Seiten \\ ISBN 978-3-8440-4715-8
}

ABISEA Band 84

Budde-Meiwes, $\mathrm{H}$.

Dynamic Charge

Acceptance of Lead-Acid

Batteries for Micro-Hybrid

Automotive Applications

1. Auflage 2016, 168 Seiten

ISBN 978-3-8440-4733-2

\section{ABISEA Band 85 \\ Engel, S. P.}

Thyristor-Based High-Power

On-Load Tap Changers

Control under Harsh Load

Conditions

1. Auflage 2016, 170 Seiten

ISBN 978-3-8440-4986-2

\section{ABISEA Band 86 \\ VanHoek, $\mathbf{H}$. \\ Design and Operation \\ Considerations of Three- \\ Phase Dual Active Bridge \\ Converters for Low-Power \\ Applications with Wide \\ Voltage Ranges \\ 1. Auflage 2017, 242 Seiten \\ ISBN 978-3-8440-5011-0}

\section{ABISEA Band 87 \\ Diekhans, $T$.}

Wireless Charging of

Electric Vehicles - a Pareto-

Based Comparison of Power

Electronic Topologies

1. Auflage 2017, 156 Seiten

ISBN 978-3-8440-5048-6

\section{ABISEA Band 88 \\ Lehner, $\mathbf{S}$.}

Reliability Assessment of

Lithium-Ion Battery Systems

with Special Emphasis on

Cell Performance

Distribution

1. Auflage 2017, 202 Seiten ISBN 978-3-8440-5090-5

\section{ABISEA Band 89 \\ Käbitz, S.}

Untersuchung der Alterung von Lithium-Ionen-Batterien mittels Elektroanalytik und elektrochemischer Impedanzspektroskopie 1. Auflage 2016, 258 Seiten DOI: 10.18154/RWTH-201612094

\section{ABISEA Band 90 \\ Witzenhausen, $\mathrm{H}$. \\ Elektrische \\ Batteriespeichermodelle: \\ Modellbildung, \\ Parameteridentifikation und \\ Modellreduktion \\ 1. Auflage 2017, 286 Seiten \\ DOI: 10.18154/RWTH-2017- 03437}

\section{ABISEA Band 91 \\ Münnix, J.}

Einfluss von Stromstärke und Zyklentiefe auf graphitische Anoden 1. Auflage 2017, 178 Seiten DOI: 10.18154/RWTH-201701915

\section{ABISEA Band 92 \\ Pilatowicz, G. \\ Failure Detection and \\ Battery Management \\ Systems of Lead-Acid \\ Batteries for Micro- \\ Hybrid Vehicles \\ 1. Auflage 2017, 212 Seiten DOI: 10.18154/RWTH-2017- 09156}

\section{ABISEA Band 93 \\ Drillkens, J.}

Aging in Electrochemical

Double Layer Capacitors:

An Experimental and

Modeling Approach

1. Aufl. 2017, 179 Seiten

DOI: 10.18154/RWTH-2018223434

\author{
ABISEA Band 94 \\ Magnor, D. \\ Globale Optimierung netz- \\ gekoppelter PV-Batterie- \\ systeme unter besonderer \\ Berücksichtigung der \\ Batteriealterung \\ 1. Auflage 2017, 210 Seiten \\ DOI: 10.18154/RWTH-2017- \\ 06592
}




\author{
ABISEA Band 95 \\ Iliksu, M. \\ Elucidation and Comparison \\ of the Effects of Lithium \\ Salts on Discharge \\ Chemistry of Nonaqueous \\ $\mathrm{Li}-\mathrm{O}_{2}$ Batteries \\ 1. Aufl. 2018, 160 Seiten \\ DOI: 10.18154/RWTH-2018- \\ 223782
}

\author{
ABISEA Band 96 \\ Schmalstieg, J. \\ Physikalisch- \\ elektrochemische \\ Simulation von Lithium- \\ Ionen-Batterien: \\ Implementierung, \\ Parametrierung und \\ Anwendung \\ 1. Aufl. 2017, 176 Seiten \\ DOI: 10.18154/RWTH-2017- \\ 04693
}

\section{ABISEA Band 97 \\ Soltau, N. \\ High-Power Medium- \\ Voltage DC-DC Converters: \\ Design, Control and \\ Demonstration \\ 1. Aufl. 2017, 176 Seiten \\ DOI: 10.18154/RWTH-2017- 04084}

\section{ABISEA Band 98 \\ Stieneker, $M$.}

Analysis of Medium-Voltage

Direct-Current Collector

Grids in Offshore Wind

Parks

1. Aufl. 2017, 144 Seiten

DOI: 10.18154/RWTH-2017-

04667

\section{ABISEA Band 99 \\ Masomtob, $M$.}

A New Conceptual Design

of Battery Cell with an

Internal Cooling Channel

1. Aufl. 2017, 167 Seiten

DOI: 10.18154/RWTH-2018-

223281

\section{ABISEA Band 100 \\ Marongiu, A.}

Performance and Aging

Diagnostic on Lithium Iron

Phosphate Batteries for

Electric Vehicles and

Vehicle-to-Grid Strategies

1. Aufl. 2017, 222 Seiten
DOI: 10.18154/RWTH-2017-

09944

\author{
ABISEA Band 101 \\ Gitis, A. \\ Flaw detection in the coating \\ process of lithium-ion \\ battery electrodes with \\ acoustic guided waves \\ 1. Aufl. 2017, 132 Seiten \\ DOI: 10.18154/RWTH-2017- \\ 099519
}

\author{
ABISEA Band 102 \\ Neeb, C. \\ Packaging Technologies for \\ Power Electronics in \\ Automotive Applications \\ 1. Aufl. 2017, 132 Seiten \\ DOI: 10.18154/RWTH-2018- \\ 224569
}

\section{ABISEA Band 103}

\section{Adler, F. S.}

A Digital Hardware Platform for Distributed Real-Time

Simulation of Power

Electronic Systems

1. Aufl. 2017, 156 Seiten

DOI: 10.18154/RWTH-201710761

\author{
ABISEA Band 104 \\ Becker, J. \\ Flexible Dimensionierung \\ und Optimierung hybrider \\ Lithium- \\ Ionenbatteriespeichersyste \\ me mit verschiedenen \\ Auslegungszielen \\ 1. Aufl., 2017, 157 Seiten \\ DOI: 10.18154/RWTH-2017- \\ 09278
}

\author{
ABISEA Band 105 \\ Warnecke, A. \\ Degradation Mechanisms in \\ NMC Based Lithium-Ion \\ Batteries \\ 1. Aufl. 2017, 158 Seiten \\ DOI: 10.18154/RWTH-2017- \\ 09646
}



In electric vehicles today, typical power train architecture calls for a traction machine and battery pack, with an inverter between them. The inverter adjusts the state-of-charge-dependent voltage of the batteries to the speed-dependent voltage of the electric machine. To decouple the inverter and battery voltages, a DC-DC converter between the inverter and the battery pack is added, which, particularly at low speed, can enhance the overall efficiency and reduce its size. The nominal voltages of the batteries currently used in electric vehicles are in the order of hundreds of volts. The use of a DC-DC converter can be used to lower the voltage of the battery packs below the $60 \mathrm{~V}$ safety threshold.

In this thesis, DC-DC converters with a low voltage port for the battery storage systems and a high voltage port for the electric machines are designed and implemented. These DC-DC converters base on the dual active bridge DC-DC converter, which has inherent galvanic isolation combined with the capability of high voltage transformation and bidirectional power flow. To obtain a wide voltage operation range at the high voltage port, the use of a transformer with a tap changer is investigated.

In the final setup, a dual active bridge converter with tap changer for a rated power of $10 \mathrm{~kW}$ is constructed. The low-voltage port reaches from $30 \mathrm{~V}$ to $60 \mathrm{~V}$, and the high-voltage port spans a range from $100 \mathrm{~V}$ to $400 \mathrm{~V}$. The converter exhibits efficiency above $90 \%$ over the whole voltage and power range. The maximum efficiency is up to $98 \%$. The thesis concludes with an overview and design considerations of a three-phase dual active bridge with tap changer. 